\title{
DETECÇÃO DA PLUMA DE CONTAMINAÇÃO DE HIDROCARBONETOS EM SUBSUPERFÍCIE PELO MÉTODO DE RADAR DE PENETRAÇÃO
}

\author{
JAMILE DEHAINI
}

Orientador: Prof. Dr. Fabio Taioli

TESE DE DOUTORAMENTO

COMISSÃO JULGADORA

Nome

Presidente: Prof. Dr. Fabio Taioli

Examinadores: Dr. Everton de Oliveira

Prof. Dr. João Carlos Dourado

Prof ${ }^{\text {a. }} \mathrm{Dr}^{\text {a. }}$ Liliana Alcazar Diogo

Prof. Dr. William A. Sauck

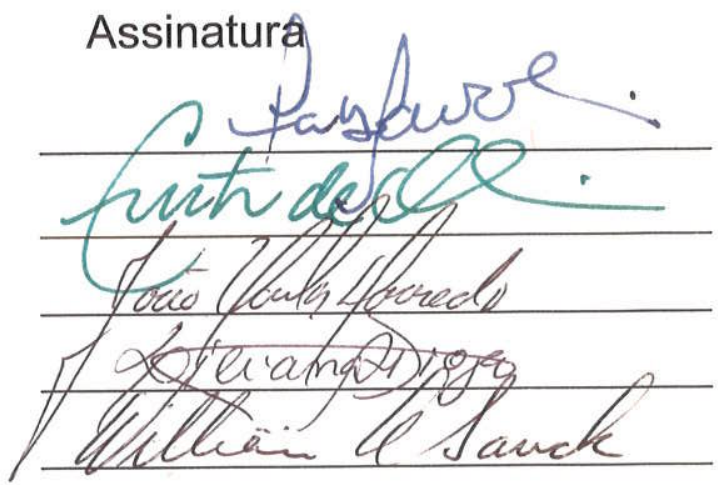

SÃO PAULO

2001 
INSTITUTO DE GEOCIENNCIAS

UNIVERSIDADE DE SÃO PAULO

Detecção da pluma de contaminação de hidrocarbonetos em subsuperfície pelo método de radar de penetração

Jamile Dehaini

Orientador: Prof. Dr. Fábio Taioli

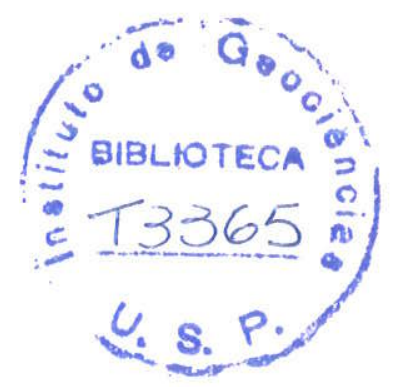

TESE DE DOUTORAMENTO

Programa de Pós-Graduação em Recursos Minerais e Hidrogeologia

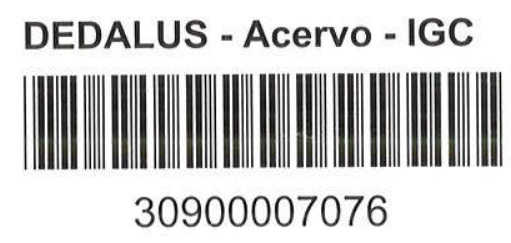

São Paulo

2001 


\section{Agradecimentos}

Agradeço ao saudoso Zé Milton (Prof. Dr. José Milton Benetti Mendes) pela proposta de pesquisa e contribuições para realização da tese. Agradeço pelo sentimento de angústia de querer dar mais contribuições na pesquisa e estar impossibilitado fisicamente. Agradeço por poder imaginar o sorriso em seu rosto pela satisfação de eu ter conseguido finalizar o nosso trabalho após enfrentar tantas dificuldades. (in memoriam)

Ao meu orientador Prof. Fábio Taioli pela orientação de fato, presteza e profissionalismo nas decisões que foram tomadas. Agradeço pelo crédito dado à pesquisa e ao contrário do que alguém possa vir a pensar, as contribuições vieram desde o início da pesquisa e não somente no final, quando o Prof. José Milton ficou impossibilitado.

Agradeço meu companheiro Gilberto que sempre me incentivou e apoiou ajudando a atravessar os momentos difíceis que passamos juntos. Agradeço por ter exercido o papel de mãe em muitos momentos além o de pai com a nossa Sofia. Agradeço pela segurança que sempre me transmitiu.

A Wagner França Aquino pessoa fundamental para realização desta tese, a qual merece muitos créditos pelos resultados alcançados, pois sempre esteve disposto a discutir e sugerir grandes idéias.

A Georadar-Levantamentos Geofísicos nas pessoas de Odilon M. Ferreira Filho e Otávio C. B. Gandolfo pelo acesso ao GPR para levantamento de dados, além de transporte e mão de obra auxiliar e pelo apoio incondicional.

À Hidroplan, principalmente na pessoa do Prof. Dr. Everton de Oliveira, à contribuição no exame de qualificação e que sempre motivado pelo espírito científico proporcionou uma nova área de pesquisa e forneceu vários dados que possuía.

À Prof. Dra. Liliana Alcazar Diogo pela contribuição no exame de qualificação e na parte de processamento dos dados.

Ao Dr. Rodrigo César Cunha Araújo, pelo "pontapé" inicial no Auto Posto "Fernão".

Ao Programa de Pós-Graduação do IGc-USP pela execução das sondagens a trado para averiguação da interpretação dos dados de GPR como também todo apoio material e estrutura do instituto para viabilizar a pesquisa.

À CETESB pelo apoio material através da utilização do GPR, medidor de interface água/hidrocarboneto.

Ao Silvio e Paulinho, que suaram a camisa para executar as sondagens a trado, a base de martelo, talhadeira e ponteira.

Aos colegas e amigos do IGc-USP que de uma forma ou de outra incentivaram e contribuiram com o trabalho.

Ao pessoal do IGc-USP que proporcionou durante esses anos um convívio pessoal gratificante.

Ao CNPq, pelo apoio financeiro com a concessão da bolsa de estudo. 


\section{ÍNDICE}

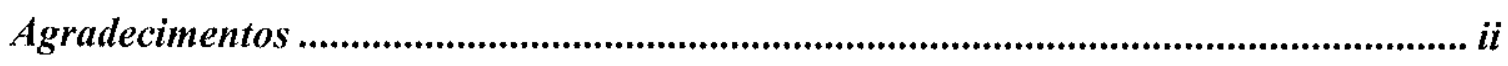

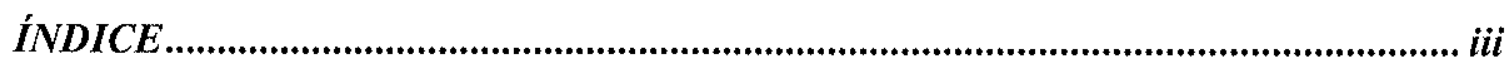

LISTA DE SÍMBOLOS, UNIDADES, ABREVIATURAS, SIGLAS

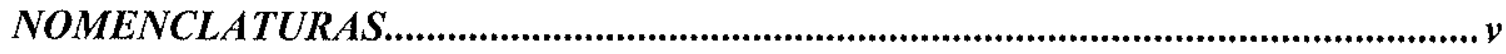

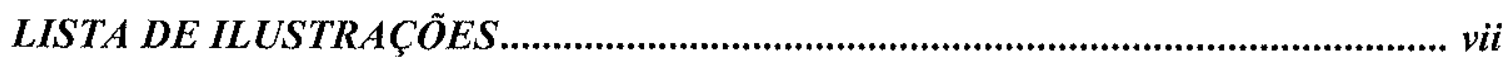

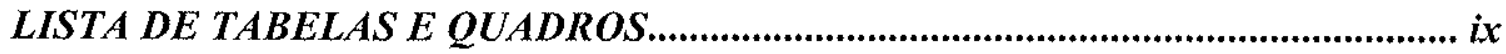

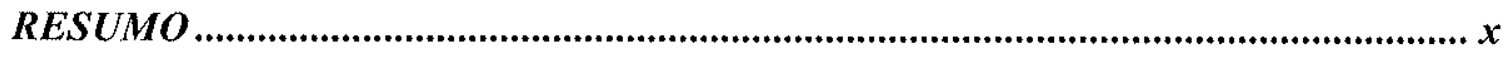

ABSTRACT

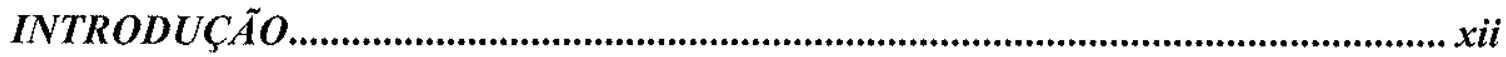

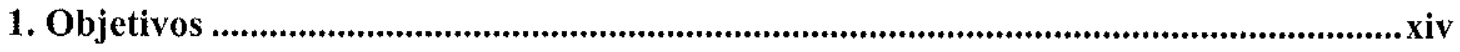

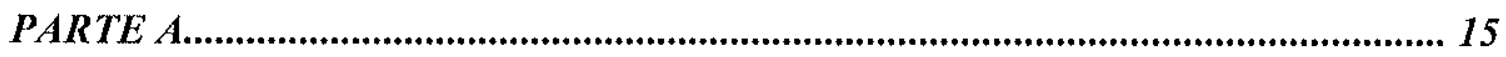

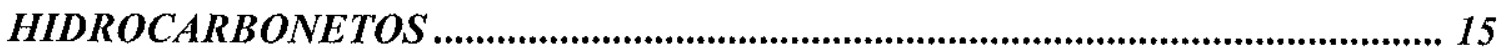

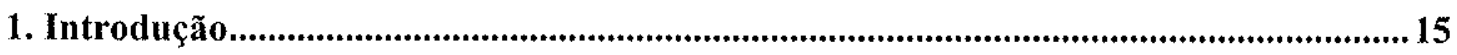

2. Fluxo dos contaminantes orgânicos em subsuperfície ....................................................16

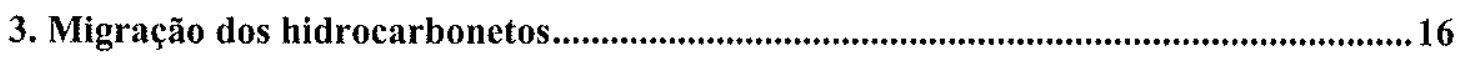

4. Processos de transporte e transformação dos compostos orgânicos................................19

5. Espessura verdadeira versus espessura aparente da lâmina de LNAPL .........................20

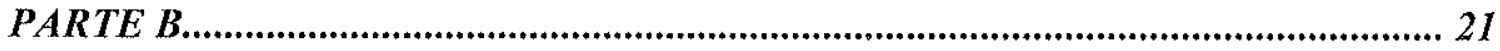

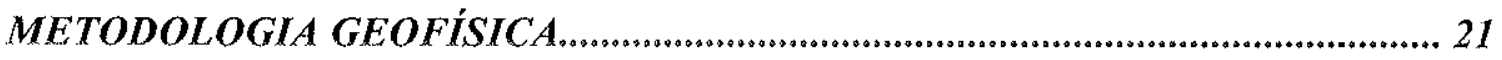

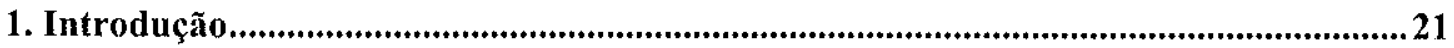

2. Propriedades eletromagnéticas das rochas e o GPR .................................................22

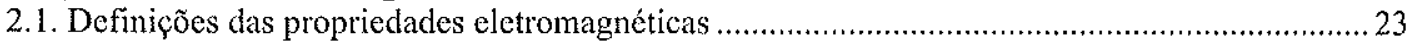

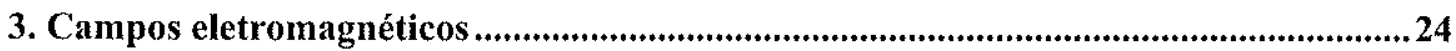

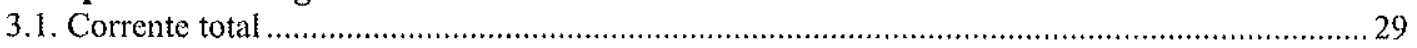

4. Parâmetros de propagação de ondas de rádio e propriedades eletromagnéticas.........31

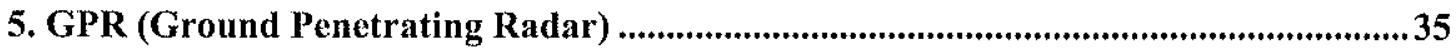

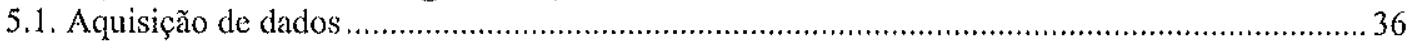

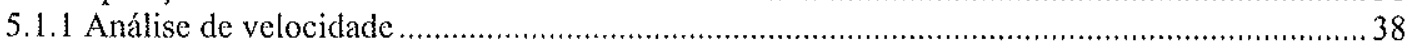

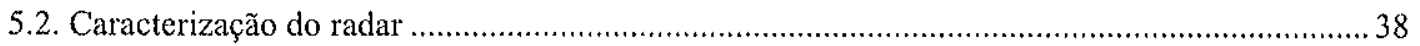

5.2.1 Penetração em profundidade do sinal do radar ................................................................. 39

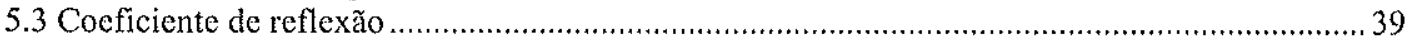

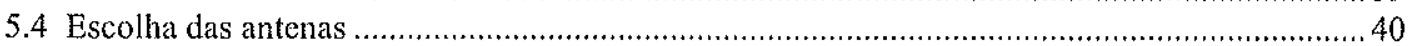

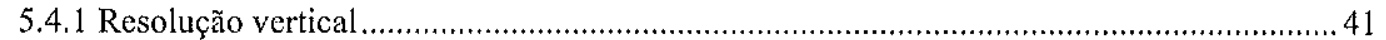

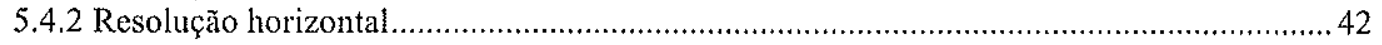

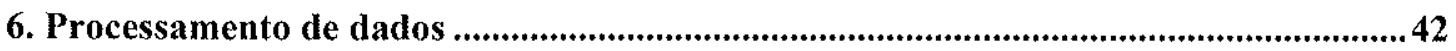

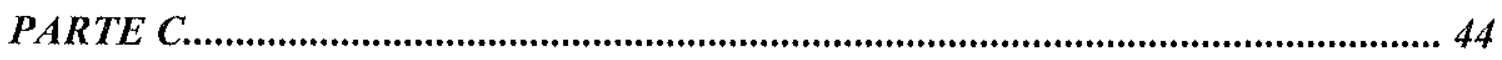

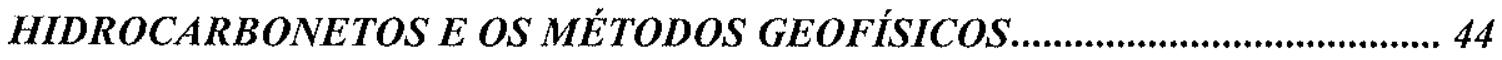

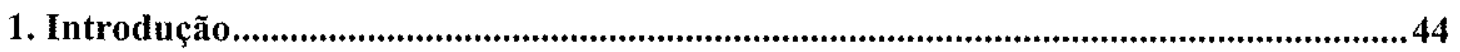

2. Resposta eletromagnética dos contaminantes orgânicos em subsuperfície....................44 
3. Métodos geofísicos e a detecção de contaminantes orgânicos ..........................................45

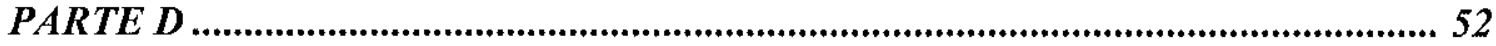

METODOLOGIA E LEVANTAMENTO DE DADOS........................................... 52

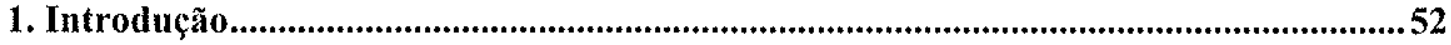

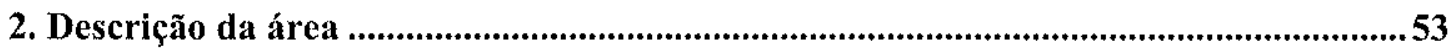

2.1 Histórico da contaminação na área de estudo ....................................................................5

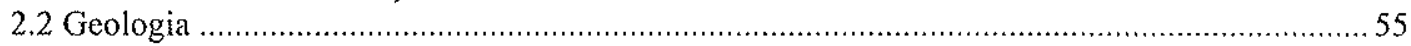

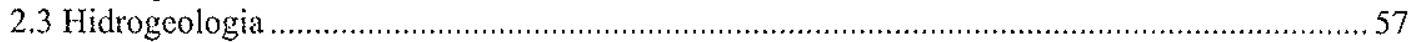

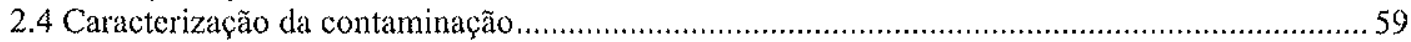

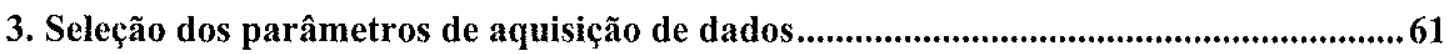

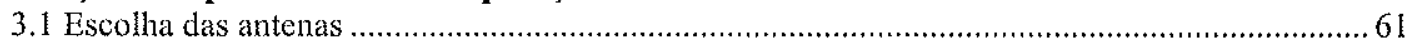

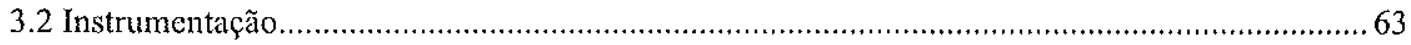

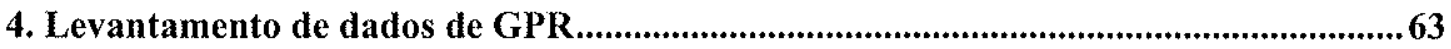

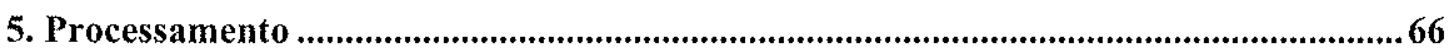

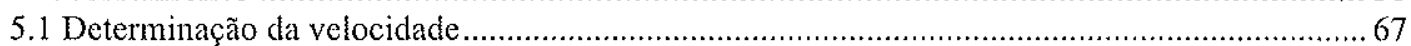

5.1.1 Processamento utilizado nas seções das sondagens CMP ..............................................6

5.2 Processamento utilizado nas seções tempo-distância dos perfis de caminhamento ......................69

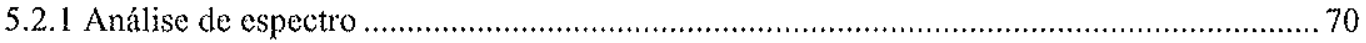

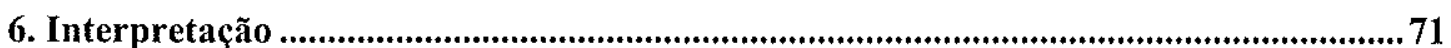

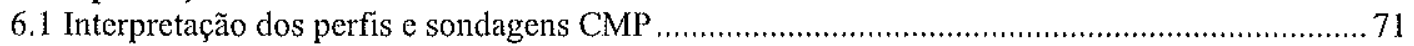

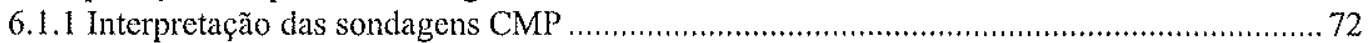

6.1.2 Interpretação das seções tempo-distância dos caminhamentos de reffexão ........................ 74

6.1.2.1 Interpretação dos perfis levantados com a antena blindada de $250 \mathrm{MHz} \ldots \ldots \ldots \ldots . . .74$

6.1.2.2 Interpretação dos perfis levantados com a antena de 100MHz ......................... 76

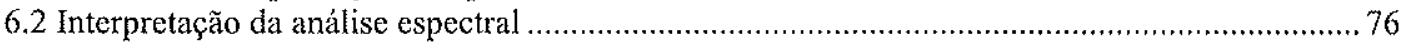

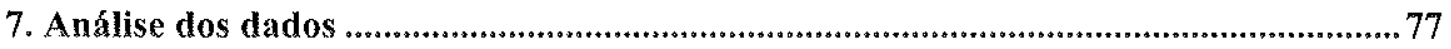

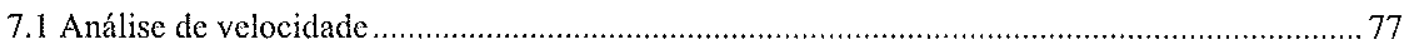

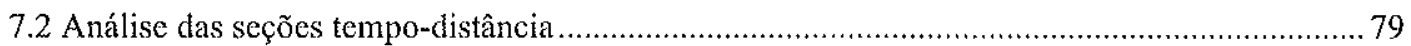

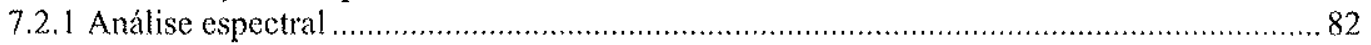

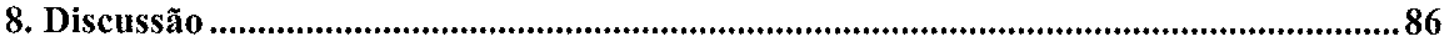

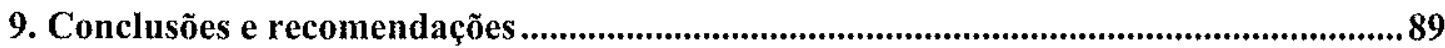

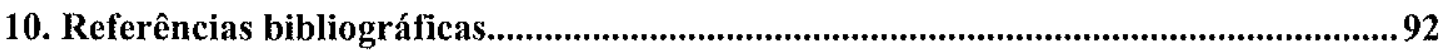

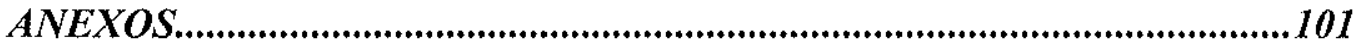




\title{
LISTA DE SÍMBOLOS, UNIDADES, ABREVIATURAS, SIGLAS e NOMENCLATURAS
}

\author{
SímBOLOS \\ $\rho$ \\ $\sigma$ \\ $\mathrm{K}$ \\ $E$ \\ $B$ \\ H \\ J \\ D \\ t \\ q \\ $\varepsilon$ \\ $\varepsilon_{0}$ \\ $\mu$ \\ $\mu_{0}$ \\ $\mathrm{k}$ \\ $\omega$ \\ $\lambda$ \\ $J_{\mathrm{c}}$ \\ $J_{d}$ \\ $\mathrm{ft}_{\mathrm{t}}$ \\ $\omega_{t}$ \\ $\tan \delta$ \\ $\mathrm{Q}$ \\ $\mathrm{K}^{*}$ \\ $\mathrm{K}^{\prime}$ \\ $\mathrm{K}^{\prime \prime}$ \\ $\mathrm{K}^{\prime \prime \prime}$ \\ $\mathrm{V}$ \\ C \\ z \\ $\operatorname{tr}$ \\ $\alpha$ \\ Tx \\ $\mathrm{Rx}$ \\ d \\ $v_{n}$ \\ $\theta_{\mathrm{c}}$ \\ $\mathrm{nx}$ \\ $\mathrm{R}$ \\ $K_{n}$ \\ $\mathrm{Or}_{\mathrm{r}}$ \\ $\mathrm{O}_{\mathrm{t}}$ \\ Z \\ $t_{0}$ \\ RA \\ $\mathrm{A}_{\mathrm{st}}$ \\ $A_{s p}$ \\ resistividade elétrica \\ condutividade elétrica \\ constante dielétrica ou permissividade dielétrica relativa \\ intensidade do campo elétrico \\ intensidade do campo magnético \\ indução magnética \\ densidade de corrente \\ deslocamento ou indução elétrica \\ tempo \\ densidade de carga livre \\ permissividade dielétrica do meio \\ permissividade dielétrica do vácuo \\ permeabilidade magnética do meio \\ permeabilidade magnética do vácuo \\ número de onda \\ freqüência angular \\ freqüência de excitação \\ comprimento de onda \\ corrente de condução \\ corrente de deslocamento \\ freqüência de transição \\ freqüência angular de transição \\ tangente de perda \\ eficiência da propagação da onda \\ constante dielétrica complexa \\ parte real da constante dielétrica \\ dispersão do sinal \\ parte imaginária ou de perda elétrica da constante dielétrica \\ velocidade com que o sinal do radar atravessa o meio \\ velocidade de propagação das ondas eletromagnéticas no vácuo \\ profundidade do refletor \\ tempo de trajetória de ida e volta do sinal \\ atenuação \\ antena transmissora \\ antena receptora \\ espessura da camada \\ velocidade com que o sinal atravessa a camada " $n "(n=1,2,3, \ldots)$ \\ ângulo crítico \\ distância entre a antena transmissora e receptora \\ coeficiente de reflexão \\ constante dielétrica da camada " $n "(n=1,2,3, \ldots)$ \\ onda refletida \\ onda transmitida \\ impedância elétrica \\ tempo de trajetória da onda com separação de antenas zero \\ razão de amplitude parcial em relação a amplitude total da seção \\ amplitude de toda seção em tempo e distância \\ amplitude parcial da seção do trecho contaminado em tempo a \\ cada $1 / 10$ de traços
}




\section{UNIDADES}

$\mathrm{MHz}$

$S$

$\mathrm{m}$

$\mathrm{GHz}$

$\mathrm{dB}$

\section{ABREVIATURAS}

GPR

BTX

BTEX

NAPL

LNAPL

ddp

WARR

CMP

CDP

TDR

SB

SEV

PCE

VLF

DNAPL

EM

RDEM

RAMAC

RADPRO

DC-Filter

AGC

Filter

DECON

SURFER

\section{SIGLAS}

EM-31

EM-34

CETESB

IBGE

GUIASP

LIG

HIDROPLAN megahertz $\left(10^{6}\right.$ hertz)

siemens

metro

gigahertz $\left(10^{9}\right.$ hertz)

decibel

ground penetrating radar

benzeno, tolueno e xileno

benzeno, tolueno, etilbenzeno e xileno

nonaqueous phase liquids

light nonaqueous phase liquids

diferença de potencial

wide angle reflection and refraction

commom mid-point

commom depth point

time domain reflectometry

screening body

sondagem elétrica vertical

tetracloroetileno

very low frequency

dense nonaqueous phase liquids

método eletromagnético

radiowave diffraction eletromagnetics

programa de aquisição de dados do radar

programa de processamento de dados do radar

programa para filtrar ruído DC dos dados do radar (RADPRO)

automatic gain control (RADPRO)

programa para filtrar no domínio da freqüência os dados do radar (RADPRO)

programa de deconvolução preditiva (RADPRO)

programa para produzir mapas de isolinhas dentre outras coisas

instrumento eletromagnético de baixa freqüência

instrumento eletromagnético de baixa freqüência

Companhia de Tecnologia e Saneamento Ambiental

Instituto Brasileiro de Geografia e Estatística

"site" na internet (www.guiasp.com.br)

Laboratório de Informática Geológica do Instituto de Geociências da USP

Hidrogeologia e Planejamento Ambiental S/C Ltda

\section{NOMENCLATURAS}

$P-n$

$P-n X$

$P M-n$

PMAdc-n

PR-n

$\mathrm{F}-\mathrm{n}$ perfil " $n$ " de radar $(n=1,2,3, \ldots .14)$

repetição do perfil " $n$ " de radar com parâmetros e/ou data diferentes $(X=A, B, C$ e $D)$

poço " $n$ " de monitoramento $(n=1,2,3,4,5,6$ e 7$)$

poço " $n$ " adicional $(n=1,2$ e 3$)$

poço " $n$ " de recuperação $(n=1,2,3,4$ e 5$)$

sondagem " $n$ " a trado manual executado pela aluna $(n=1,4,6$ e 7) 


\section{LISTA DE ILUSTRAÇÕES}

FIGURAS

Figura A.1 Distribuição em subsuperficie de um vazamento de LNAPL (modificada de Fetter, 1993)

Figura A.2 Processo inicial de contaminação de águas subterrâneas por constituintes de gasolina a partir da gasolina residual na zona vadosa (modificada de Fetter, 1993)

Figura B.1 GPR esquemático mostrando sistema de operação básica e componentes (Davis \& Annan, 1989)

Figura B.2 Gráfico simplificado da variação de corrente de condução $(J C)$, de deslocamento $(J d)$ e total $(J)$ em relação à freqüência (Annan, 1992)

Figura B.3 Curvas representativas da relação entre velocidade e freqüencia a diferentes condutividades (Davis \& Annan, 1989)

Figura B.4 Curvas representativas da relação entre atenuação e freqüência a diferentes condutividades de materiais com constante dielétrica 4 (Davis \& Annan, 1989)

Figura B.5 Profundidade em metros para uma atenuação de $100 \mathrm{~dB}$ da onda eletromagnética em função da condutividade (Annan, 1992)

Figura B.6 Registro do radar obtido em uma situação idealizada (Davis \& Annan, 1989)

Figura B.7 Modelo simplificado de camadas geológicas para representar os caminhos de propagação de ondas (Annan, 1992)

Figura B.8 Arranjo das antenas no caminhamento de reflexão com disposiçäo perpendicular em relação à linha do levantamento (Modificada de Annan, 1992)

Figura B.9 - Arranjo das antenas no levantamento CMP (Modificada de Annan, 1992)

Figura D.1 Localização da área de estudo no Estado de São Paulo (fonte: IBGE, 1999)

Figura D.2 Mapa de localização da área de estudo na cidade de São Paulo (fonte:Guiasp, 2001)

Figura D.3 Esboço da área de estudo com a localização dos poços de monitoramento e sondagens a trado

Figura D.4 Mapa geológico da área de estudo (modificado de LIG, 1999) 56

Figura D.5 Mapa hidrogeológico da área de estudo (modificado de LIG, 1999)

Figura D.6 Mapa de isocondutividade da água representativo da área de estudo

Figura D.7 Esboço da área de estudo com a localização dos perfis e sondagens CMP do GPR

Figura D.8 Representação da sondagem CMP para o cálculo da velocidade 
Figura D.9 Gráfico representativo do comportamento da velocidade e constante dielétrica calculados nos perfis

Figura D.10 Esboço da área de estudo com delineação da pluma de contaminação de acordo com interpretação visual dos dados de GPR

Figura D.11 Mapa de isolinha para representar a distribuição dos valores de RA

Figura $D .12$ Mapa de isolinha para representar a distribuição dos valores de $A_{s p}$

\section{FOTOS}

Foto 1 Fase I do levantamento dos dados com a antena blindada de $250 \mathrm{MHz}$ ao longo do perfil $P-1$

Foto 2 Levantamento dos dados coma a antena blindada de $250 \mathrm{MHz}$ ao longo do perfil P-1 simultaneamente a medida de nivel d'água e espessura de lâmina de fase livre

Foto 3 Execução da sondagem CMP-1 com a antena de $200 \mathrm{MHz}$

Foto 4 Execução da sondagem CMP-2 com a antena de $200 \mathrm{MHz}$

Foto 5 Fase /l do levantamento dos dados com a antena blindada de $250 \mathrm{MHz}$ ao longo do perfil P-10

Foto 6 Fase II do levantamento dos dados com a antena blindada de $250 \mathrm{MHz}$ ao longo do perfil $P-11$

Foto 7 (a) Constatação da existência de lâmina de fase livre no PMAdc-3

(b)medida de condutividade elétrica zero da água amostrada do PMAdc-3

Foto 8 (a) Medida de nivel d'água com o medidor de interface na sondagem a trado F-1 e (b) verificação de não ocorrência de lâmina de fase livre com amostrador transparente na sondagem a trado F-1

Foto 9 (a) Execução da sondagem a trado $F-4$ e (b) Constatação da existência de lâmina de fase livre na sondagem a trado F-4

Foto D.10 Medida de condutividade elétrica zero da água amostrada da sondagem a trado $F-4$

Foto 11 (a) Execução da sondagem a trado $F-6$ (b) execução da sondagem a trado F-7

Foto 12 (a) Constatação da existência de lâmina de fase livre no PMAdc-1 com amostrador transparente e (b) amostra de água do PMAdc-1 para medida de condutividade elétrica

Foto 13 Medida de condutividade elétrica em amostra de água do PMAdc-1 


\section{LISTA DE TABELAS E QUADROS}

TABELAS

Tabela B.1 Constante dielétrica $(K)$, condutividade elétrica $(\sigma)$, velocidade $(v)$ e atenuação $(\alpha)$ tipica de alguns materiais. (Davis \& Annan, 1989 e RAMAC, 1997).

Tabela D.1 Valores de profundidade do nivel d'água dos poços de monitoramento, de remediação e de sondagens a trado da área de estudo.

Tabela D.2 Valores de espessura da fase livre do produto nos poços de monitoramento, de remediação e de sondagens a trado da área de estudo.

Tabela D.3 Relação dos valores calculados de profundidade (z), velocidade (v) e constante dielétrica $(K)$.

Tabela D.4 Relação dos dados e valores calculados de velocidade (v) e constante dielétrica $(K)$.

Tabela D.5 Trechos em tempo e distância da zona de sombra nos perfis

Quadro C.1 Permissividades relativas para alguns hidrocarbonetos comuns (von Hippel, $1961^{1}$ apud: Daniels et al., 1995).

Quadro D.1 Extensão do levantamento de dados de GPR.

\footnotetext{
I von Hippel (1961) Dieletric materials and applications. MIT Press, Cambridge, MA. 438p.
} 


\section{RESUMO}

A pesquisa estabelece critérios para a aplicabilidade do método geofísico GPR (Ground Penetrating Radar), conhecido também por Radar de Penetração, em áreas sujeitas à fonte de contaminação em subsuperfície por substâncias orgânicas, em particular, por hidrocarbonetos, produzida por vazamento em postos de serviços. A solução deste problema pelos métodos diretos é muito complexa, principalmente pelo fato de contaminantes orgânicos moverem-se em subsuperfície de maneira dispersa e descontínua. Em contrapartida, devem ser imediatamente detectados e mapeados pois podem apresentar riscos de incêndio e explosões. Esta tese avalia a aplicabilidade do método GPR no estudo de vazamento de combustíveis em posto de serviço na cidade de São Paulo. As condições propostas podem ser consideradas como as piores possiveis do ponto de vista do método, aliando as limitações inerentes do GPR com as condições geológicas, de ocupação e presença de ruídos em ambiente altamente urbanizado. A metodologia proposta constitui-se de levantamento de campo com o GPR, execução de processamento dos dados, interpretação dos radargramas processados e sondagens a trado em locais sem contaminação e suspeitos de contaminação de acordo com a interpretação para confirmação da mesma. Um critério numérico é estabelecido para a apresentação dos resultados na forma de mapa de isolinhas para delinear a pluma de contaminação. As seções de GPR obtidas do local de estudo foram processadas e apresentaram anomalias na forma de ausência de reflexão de sinal denominadas por "zonas de sombra" ou "apagão". A ausência de reflexão provavelmente ocorreu devido ao fato do contaminante em subsuperfície expulsar parte da água contida no meio e, portanto, provocar um processo de "homogeneização" do ponto de vista eletromagnético. Outra observação que reforça a idéia da homogeneização causada pela diminuição da constante dielétrica é feita através do cálculo de velocidade que apresentou valores maiores nas áreas contaminadas e valores menores em locais sem indícios de contaminação. Apesar das condições de campo, o método possibilitou a delineação da pluma de contaminação além da extensão detectada por métodos diretos, o que mostra ser aplicável e eficiente para detecção de contaminação por vazamento de tanque subterrâneo de armazenamento de gasolina em postos de serviços. Concluiuse que a utilização de antenas blindadas do GPR na cidade de São Paulo viabiliza a delineação da pluma de contaminação por vazamento de gasolina proveniente de tanque subterrâneo de armazenamento em posto de serviço. 


\begin{abstract}
The present research establishes criterion for the applicability of the GPR (Ground Penetrating Radar) method in areas with organic contamination caused by leakage in gas stations. The solution of this problem by means of direct methods is very complex due to the discontinuous and disperse movement of the contaminant in subsurface. Otherwise, these problems must be detected rapidly due to the inherent fire and explosion risks. This thesis evaluates the applicability of the GPR method to study leakage from a gas station in São Paulo city. The conditions of this proposal may be considered as being the worst to apply the GPR method, considering the intrinsic limitations of the method, the geological conditions, the degree of occupation and the noise inherent to a highly urbanized environment. The proposed methodology is based on the field data acquisition, data processing, interpretation of the radargrams, and execution of boreholes in contaminated and non-contaminated areas as suggested by the interpretation. A numerical criterion was established to allow the representation of the conclusions in an isovalues map to allow the identification of the contamination extent. The GPR sections were processed and presented anomalies consisting of lack of reflection that were called as "shadow zones". That lack of reflection is probably due to the fact that the contaminant purges part of the water present in the medium, provoking a "homogenization" from the electromagnetic point of view. Another observation that reinforces this idea, caused by the decreasing of the dielectric constant, is the presence of larger velocity values in the contaminated areas and lower values in the non-contaminated ones. Despite the difficult field conditions, the method allowed to detect the contamination plume farther from the extension initially defined by direct methods, and showed that it is applicable and efficient to detect contamination due to leakage from underground gasoline vessels in gas stations. In addition, it was noted that the analysis was possible due to the use of shielded antennas, that allows to work in noisy environments.
\end{abstract}




\section{INTRODUÇÃO}

Atualmente os vazamentos de tanques de postos de serviços, refinarias e oleodutos constituem-se fontes de poluição das camadas em subsuperfície (não saturadas e saturadas) que causam grande interesse e preocupação entre pesquisadores, ambientalistas e a comunidade em gerai.

Após um vazamento deste gênero, existem riscos de incêndio e explosão como também as substâncias contaminantes podem provocar danos gravíssimos à saúde humana. O simples ato de beber água contaminada por compostos orgânicos pode causar câncer em humanos e animais, e propiciar outros problemas como danos no fígado, prejuizo da função cardio-vascular, depressão do sistema nervoso, desordem intelectual, e vários outros tipos de lesões (Domenico \& Schwartz, 1990).

Estudos hidrogeológicos têm mostrado que os mecanismos de dispersão e migração dos hidrocarbonetos são complexos, o que torna difícil estimar adequadamente a quantidade ou continuidade destes produtos em subsuperfície, utilizando apenas poços de monitoramento (Freeze \& Cherry, 1979; Mackay et al., 1985; Cherry, 1987; Domenico \& Schwartz, 1990). Baseados nesta questão, pesquisadores têm se esforçado em desenvolver técnicas práticas de detecção destes contaminantes no sentido de melhorar a estimativa de problemas de contaminação por hidrocarbonetos (Daniels et al.,1995).

Dentre os métodos de pesquisa utilizados para caracterização do meio físico com problemas de contaminação subterrânea estão os geofísicos. A eficácia desses métodos em problemas ambientais, no entanto, depende de alguns parâmetros como por exemplo: o grau de contaminação, profundidade do produto contaminante, características geológicas da área de estudo, tipo de contaminante e, conseqüentemente, da escolha criteriosa da técnica geofísica a ser empregada em cada situação (Matias et al., 1994; Nobes, 1996).

Em especial os métodos geoelétricos, têm contribuído de maneira eficaz na solução de problemas ambientais (Cartwright \& McComas, 1968; Kelly, 1976; Urish, 1983; Greenhouse \& Harris, 1983; Davis \& Annan, 1989; Ward (ed.), 1990; Börner et al., 1993; Zhdanov \& Keller, 1994; Nobes, 1996). No entanto, em estudo de casos de contaminação por substâncias orgânicas, consideradas de baixa ou nenhuma 
detectabilidade pelos métodos usuais, tem-se buscado um aprimoramento metodológico ou novas tecnologias.

Os hidrocarbonetos no meio físico natural podem proporcionar contrastes dos parâmetros eletromagnéticos sob a aplicação de um campo eletromagnético de alta freqüência. A variação destes parâmetros faz do GPR uma importante ferramenta para mapear os hidrocarbonetos. Este método basicamente utiliza a transmissão de sinais de altas frequências $(10$ a $1000 \mathrm{MHz})$ que são refletidos de volta para superfície quando encontram uma variação no tipo litológico em subsuperfície, pois a constante dielétrica (=permissividade dielétrica) muda a partir desta interface. A permissividade dielétrica relativa dos hidrocarbonetos (2 a 30) comparada com a da água (80) valores válidos nestas substâncias quando submetidos a um campo eletromagnético em um intervalo de altas freqüências - possibilita sua diferenciação. Por outro lado, a condutividade elétrica destas substâncias é muito baixa ( 0 a $0,02 \mathrm{~S} / \mathrm{m}$ ), o que nessas freqüências proporciona uma boa penetração do sinal em subsuperfície.

Atualmente, casos de estudo de contaminação de águas subterrâneas por hidrocarbonetos têm sido realizados com sucesso por meio deste método (Benson, 1995; Daniels et al., 1995, Benson et al., 1997; Bermejo et al., 1997; Nash et al., 1997; Nguyen et al., 1997; Sauck et al., 1998). No entanto, é extremamente polêmica qual seria a causa do efeito visual produzido pelos contaminantes nas seções de dados analisadas do GPR. Essa discussão é apresentada no artigo de Sauck et al. (1998), os quais mostram que o conhecimento sobre o comportamento eletromagnético destes contaminantes no meio em subsuperfície é ainda muito incipiente e deve ser mais pesquisado.

Geralmente, os casos estudados na literatura são provenientes de experimentos controlados, nos quais se conhece o sinal antes e depois da contaminação, ou condições quase ideais para aplicação do método do ponto de vista litológico (geralmente constituição arenosa para proporcionar boa penetração do sinal), lâmina de hidrocarbonetos relativamente espessa e locais com baixíssimo nivel de ruído externo.

A realidade na maioria dos casos é muito diferente das condições idealizadas que geralmente se apresentam nas pesquisas. A cidade de São Paulo é uma das cidades mais urbanizadas do mundo como também muito populosa e com postos de serviços espalhados generalizadamente. Por outro lado, do ponto de vista geológico em geral tem predominância argilosa nos seus primeiros metros de subsuperfície. 
Vivemos em um país que diferentemente dos países que já aplicaram o método, tem mão de obra muito barata e portanto facilita a construção de muitos poços de monitoramento. Estes fatores tornam a utilização do GPR para detecção de contaminação por vazamento de combustivel de postos de serviços em São Paulo uma metodologia economicamente questionável pois a presença da argila limita a investigação a profundidades muito rasas, os postos de serviços em geral estão situados em locais onde existem muitos ruidos e quando o indício de vazamento é notado, a lâmina de fase livre se apresenta bem espessa e fácil de ser bombeada. Por outro lado, muitas vezes se nota o vazamento através de uma explosão ou iminente risco de incêndio o que torna a detecção da pluma um caso de emergência nem sempre possível de resolver com a execução de poços aleatoriamente distribuídos. Após o bombeamento e extração da fase livre, permanecem a fase vapor e residual no meio, as quais são fontes permanentes de contaminação das águas subterrâneas e dificeis de serem mapeadas unicamente através de sondagens e poços de monitoramento.

\section{Objetivos}

Diante dos problemas apresentados foram definidos os objetivos da tese da seguinte maneira:

1. avaliar a aplicabilidade do radar de penetração para detectar contaminação em subsuperfície, proveniente de vazamento de tanque subterrâneo de armazenamento de gasolina, em uma condição desfavorável do ponto de vista prático. Os principais aspectos desta condição seriam litologia argilosa, destituída de fase livre do produto no poço (fase de pós-bombeamento) e local com ruídos externos;

2. avaliar quais as ferramentas de processamento são mais adequadas para se obter uma interpretação objetiva;

3. definir recomendações e parâmetros técnicos que indiquem a possibilidade de utilização do método para este fim em outros estudos de caso. 


\section{PARTE A \\ HIDROCARBONETOS}

\section{Introdução}

Os mais simples compostos orgânicos dentro da química orgânica são os hidrocarbonetos, os quais consistem somente de carbono e hidrogênio.

A fonte primária de aproximadamente quase todos os derivados de petróleo é o óleo cru. O óleo cru consiste de uma mistura de hidrocarbonetos de peso molecular variável e, na média, contém aproximadamente $84.5 \%$ de carbono, $13 \%$ de hidrogênio, $1.5 \%$ de enxofre, $0.5 \%$ de nitrogênio e $0.5 \%$ de oxigênio. Existem mais de 600 compostos de hidrocarbonetos identificados no petróleo (Fetter, 1993).

O processamento inicial de beneficiamento do óleo envolve sua separação, por destilação em uma série de frações caracterizadas por intervalos de temperatura e pressão. Além da destilação, numerosos processos de refinaria são utilizados para otimizar a produção de certos produtos e conseguir produtos característicos desejados. A gasolina é produto de uma combinação de numerosos fluxos de refinamento e vários aditivos são utilizados para encontrar o critério de melhor desempenho motor.

Indiferente aos modos de produção ou produtores, a maioria dos produtos são materiais complexos com uma larga gama de propriedades físicas e químicas. Gasolina (alvo de nossa pesquisa), óleo diesel, e produtos relacionados podem conter de centenas até milhares de constituintes individuais.

Outra significante característica destes produtos é que sua composição é variável, de acordo com as quantidades relativas dos vários tipos de hidrocarbonetos contidos nos mesmos. A composição relativa do produto deve mudar drasticamente depois de liberado para - ambiente. Os principais processos responsáveis por essa mudança são volatilização, dissolução e degradação química e biológica. Cada processo influencia em maior ou menor grau alguns constituintes químicos ou grupo de constituintes, e as taxas de transformação são função das condições ambientais. 
Alguns hidrocarbonetos ocorrem com muito mais freqüência do que outros nas águas subterrâneas após um vazamento de gasolina. Dentro deste grupo estão presentes o benzeno, tolueno, etilbenzeno, para-xileno, meta-xileno e orto-xileno e são chamados de compostos BTX ou BTEX, os quais constituem um pacote de contaminantes freqüentemente investigados quando um vazamento de gasolina ocorre (Domenico \& Schwartz, 1990).

\section{Fluxo dos contaminantes orgânicos em subsuperfície}

O movimento de líquidos que não são misciveis com a água através da zona vadosa como também na camada saturada é uma importante faceta do estudo de contaminação hidrogeológica. Na função de contaminantes esses líquidos são denominados por líquidos de fase não aquosa ou, freqüentemente, por NAPLs ("nonaqueous phase liquids"). Os hidrocarbonetos, alvo de nosso estudo, são menos densos do que a água e, portanto, denominados por LNAPL" ("light nonaqueous phase liquids").

Mackay et al. (1985) preferem denominar liquidos orgânicos menos densos do que a água como "floaters" (sobrenadantes), os quais se espalham sobre o nivel. Se o contaminante é levemente solúvel em água, uma pluma desenvolve-se por dissolução do líquido contaminante retido nos poros do aqüífero.

\section{Migração dos hidrocarbonetos}

Estudos hidrogeológicos têm mostrado que hidrocarbonetos não se dispersam completamente no solo de maneira uniforme e homogênea, mas movem-se através da zona não saturada na forma de acumulações discretas de contaminantes (Fetter, 1993). As características de migração dessas acumulações são dependentes das propriedades quimicas e físicas do meio e do fluido percolante.

Devido a mudanças na permeabilidade na zona não saturada podem ocorrer concentrações de LNAPLs acima do nivel freático, como por exemplo, empoçamento destes sobre lentes de argila.

Na zona vadosa pode ocorrer o fluxo de três fases com ar, água e um NAPL, onde este último pode particionar no ar em forma de fase vapor. LNAPLs sobre o nivel d'água não

\footnotetext{
* Essa denominação é um tanto quanto questionável, já que estes contaminantes em subsuperfície, em parte, podem se dissolver na água. Mas, será terminologia utilizada neste documento, já que, por enquanto, é a aceita na literatura.
} 
permanecem necessariamente em um local, mas eles podem migrar, ocorrendo parcialmente como fase dissolvida, e podendo temporariamente, ficar submersos abaixo do nível d'água durante periodos de grande precipitação. Na fase não aquosa podem existir múltiplos compostos, cada um com diferentes densidades, viscosidades, e tensões interfaciais, propriedades estas que determinam o fluxo do líquido. Em adição, podem ocorrer dispersão, difusão, adsorção e degradação química e biológica dos compostos. Esses processos possuem desafios extremamente complexos do ponto de vista hidrogeológico proporcionando o desenvolvimento de muitos modelos matemáticos que procuram simular o comportamento do fluxo desses líquidos (Fetter, 1993).

Quando os LNAPLs são derramados na superfície, eles migram verticalmente pela zona vadosa sob a influência das forças gravitacional e capilar. Alguma expansão horizontal também ocorrerá por causa das forças capilares.

Geralmente a zona vadosa é constituída por água e ar e então o LNAPL será a fase não molhante após o derramamento. Caso uma quantidade suficiente de LNAPL tenha sido derramado, de maneira que ocorra a saturação do LNAPL residual (a parte que fica retida por força capilar nos poros), então o LNAPL continua migrando até alcançar o topo da zona capilar (parte da franja capilar).

No movimento descendente, o LNAPL pode deslocar a água e ar retidos na zona vadosa e quando alcança a zona capilar inicia-se um processo de acumulação. Neste caso, o LNAPL estará sob tensão, e conforme o contaminante acumula-se acima da zona capilar, um "nivel d'óleo" desenvolve-se. Conforme o LNAPL continua a se acumular a zona capilar tornase menos espessa e móvel. Eventualmente, a zona capilar pode desaparecer completamente e o nivel d'óleo repousará diretamente sobre o nivel d'água. No centro de uma fina zona de LNAPL móvel, o nível d'água pode ser rebaixado pelo peso do LNAPL.

O LNAPL móvel pode migrar na zona vadosa seguindo o declive do nível d'água. $A$ Figura A.1 mostra como ocorre a migração do hidrocarboneto a partir de um vazamento. Podese notar que parte do hidrocarboneto derramado fica retido na zona vadosa e é denominado por fase residual do hidrocarboneto. Em adição, alguns dos constituintes químicos do LNAPL podem dissolver-se nas águas subterrâneas (fase dissolvida) e mover-se por dispersão com as águas subterrâneas. Por exemplo, gasolina liberará significativas quantidades de benzeno, tolueno, etilbenzeno, e xileno (BTEX) como frações solúveis. 


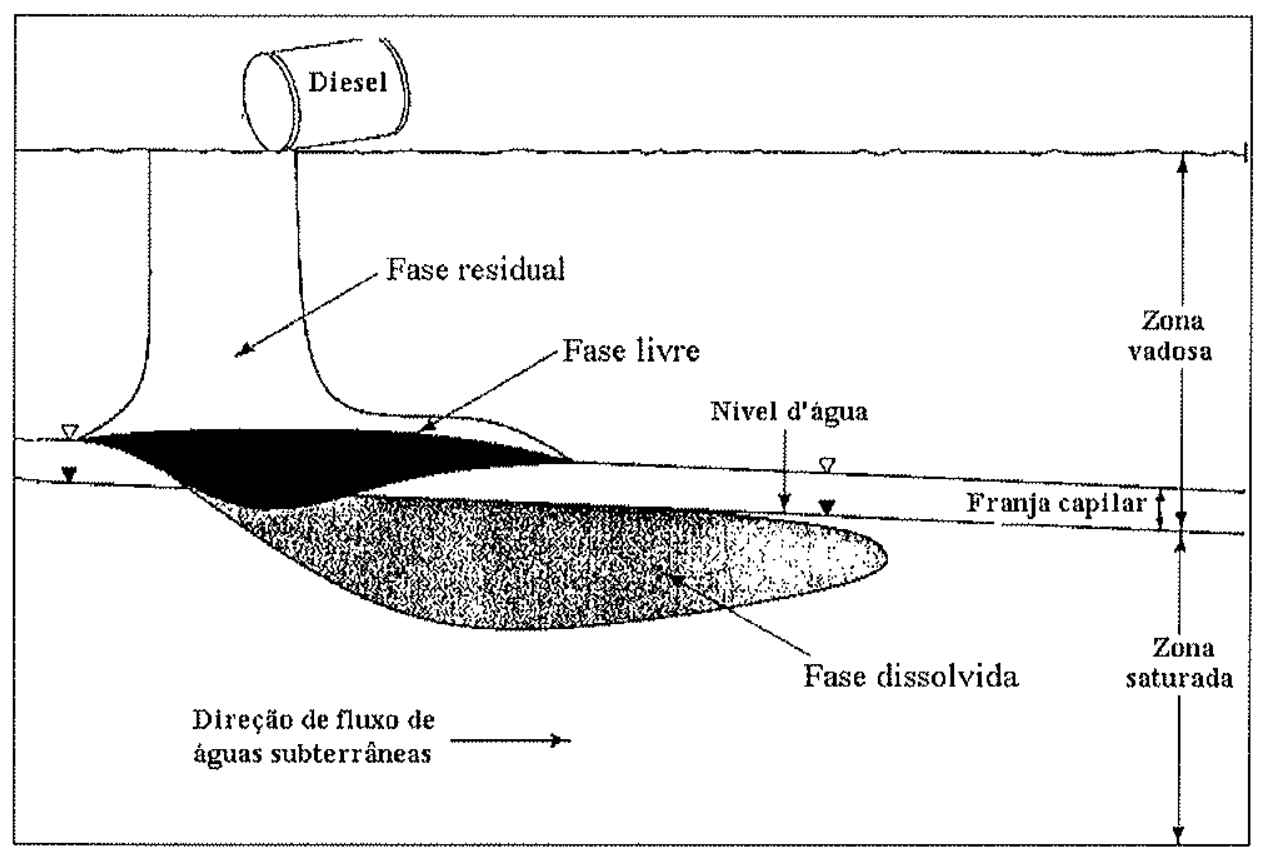

Figura A.1 - Distribuição em subsuperfície de um vazamento de LNAPL (modificada de Fetter, 1993).

A fase residual atua como uma fonte intermitente de contaminação podendo particionar tanto em fase vapor como em uma fase solúvel na água subterrânea. O grau de particionamento dependerá da volatibilidade do material e de sua solubilidade em água.

A fase residual retida nos poros também produz contaminantes dissolvidos na zona saturada, por lixiviação durante as épocas de chuvas e mudanças sazonais no nivel d'água. Com o hidrocarboneto preso dentro da zona saturada, ocorre um aumento relativo de hidrocarbonetos de fase dissolvida e, conseqüentemente, acréscimo de niveis de contaminantes nas águas subterrâneas. Ainda pode ocorrer tanto na zona saturada como na vadosa uma quarta fase denominada por fase adsorvida a qual se dá devido à adsorção do hidrocarboneto pela matéria orgânica.

Modelos físicos que descrevem o transporte aquoso e da fase vapor de hidrocarbonetos residuais na zona vadosa permitem concluir que ocorre um particionamento seletivo do benzeno, tolueno, etilbenzeno e xileno na fase capilar aquosa, possibilitando que esses componentes funcionem como indicadores de um vazamento de gasolina (Figura A.2). 


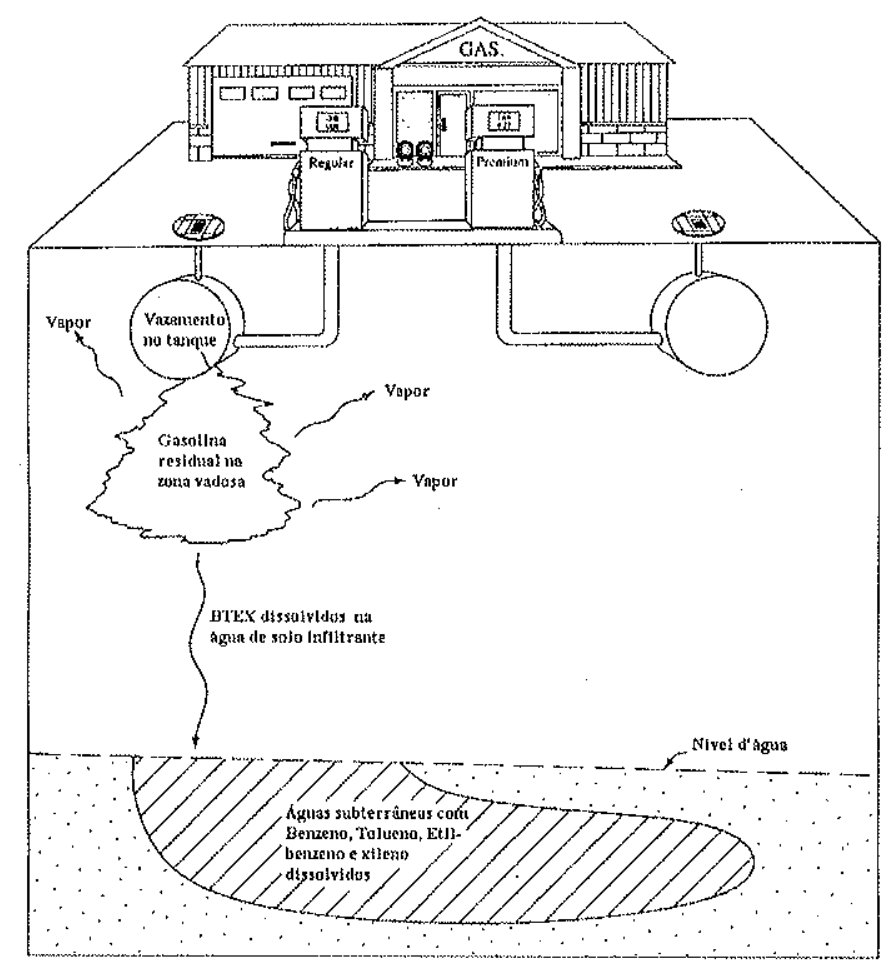

Figura A.2 - Processo inicial de contaminação de águas subterrâneas por constituintes de gasolina a partir da gasolina residual na zona vadosa (modificada de Fetter, 1993)

\section{Processos de transporte e transformação dos compostos orgânicos}

O transporte da fase dissolvida do LNAPL depende da velocidade das águas subterrâneas e taxas de migração. Os processos físicos que afetam o destino de hidrocarbonetos dissolvidos em subsuperfície são principalmente advecção, dispersão, difusão, volatilização e sorção.

A transformação de contaminantes dissolvidos é afetada pelos processos químicos da ionização, solubilidade e hidrólise, oxidação/redução e complexação, como também por processos biológicos de bioacumulação e biodegradação. É interessante notar que o processo da biodegradação do ponto de vista geofísico, transforma a pluma de contaminante de hidrocarbonetos, que possui características elétricas resistivas, para uma pluma de características elétricas condutivas (Sauck et al., 1998; Werkema et al., 2000).

A migração de uma fase líquida orgânica imiscivel é governada predominantemente por sua densidade, viscosidade, solubilidade e propriedades molhantes da superfície. 
O bombeamento não removerá todo contaminante e o produto "trapeado" irá continuar a descarregar componentes solúveis em água. Portanto, medidas preventivas como contenção de transbordamentos e detecção precoce de vazamentos são o melhor caminho para minimização dos problemas advindos.

\section{Espessura verdadeira versus espessura aparente da lâmina de LNAPL}

A observação de fase livre de hidrocarboneto no poço é a melhor evidência que o produto está presente em subsuperfície. No entanto, a medida da espessura da lâmina no poço é apenas uma indicação da ordem de magnitude da espessura real de LNAPL na formação e pode expressar de 2 a 10 vezes mais do que realmente está presente (Bedient et al., 1994). Por isso essa medida é denominada espessura aparente da lâmina. Isto pode ser explicado por dois fatores: a) dentro do poço as forças capilares existentes no meio poroso não atuam; b) devido à diferença de densidade dos líquidos, onde o de menor densidade tem que ocupar um espaço maior dentro do tubo para alcançar o equilibrio hidrostático. Por outro lado, o nível d'água medido no poço também é aparente, pois é parcialmente rebaixado pelo produto situado acima (Bedient et al., 1994). 


\section{PARTE B \\ METODOLOGIA GEOFÍSICA}

\section{Introdução}

Geofísica aplicada é a ciência que estuda o comportamento dos materiais do subsolo a partir de medidas indiretas de suas propriedades físicas para determinar as condições em subsuperfície, geralmente com um objetivo econômico (mineração, hidrogeologia, engenharia, ambiental, etc...). Conforme as características de cada caso se utiliza a integração de pelo menos dois métodos para medir as grandezas físicas que melhor expressam as condições dos materiais a serem estudados.

O método geofísico classificado como geoelétrico estuda basicamente os contrastes das propriedades eletromagnéticas do meio em subsuperficie (Zhdanov \& Keller, 1994). Tais métodos são muito versáteis e admitem uma variedade muito grande na técnica de aplicação: o campo eletromagnético utilizado pode ser natural ou artificial, o contato com o solo pode ser galvânico ou indutivo, a corrente utilizada pode ser contínua ou alternada e os procedimentos de medida também podem ser de vários tipos.

Em geral, os métodos geoelétricos são divididos em duas categorias: o da eletrorresistividade e o eletromagnético. No primeiro a variação do campo elétrico em relação ao tempo é nula (corrente contínua) enquanto no segundo o campo elétrico varia com o tempo (corrente alternada). No entanto, deve-se ter claro que os dois são regidos pelas mesmas equações de Maxwell que fundamentam o eletromagnetismo, o que torna a classificação acima irrelevante para alguns autores. Zhdanov \& Keller (1994), preferem considerar todos como eletromagnéticos com a sub-classificação de estáticos (não se considera campo elétrico e magnético simultaneamente), quasi-estáticos (considera-se a interação de campos elétricos e magnéticos mas não se consideram as correntes de deslocamento) e irradiativos (baseados em medidas de freqüências tão altas a ponto das correntes de deslocamento serem dominantes) como no caso do GPR.

Normalmente, os aspectos básicos abordados sobre teoria eletromagnética na literatura geofísica, ou seja, em casos onde os campos interagem com a terra, se baseiam em campos em regime quasi-estacionário ou estacionário, onde as componentes do campo eletromagnético variam lentamente com o tempo ou não variam. Isso se dá porque as ondas 
eletromagnéticas sofrem forte atenuação ao penetrarem em subsuperfície, então se prioriza a utilização de métodos de baixas freqüências, os quais possibilitam que o sinal atinja maiores profundidades. Tratando-se do GPR a abordagem é diversa, pois neste caso o campo eletromagnético varia relativamente mais rápido no tempo, fazendo com que o fenômeno de transporte irradiativo se torne importante.

A utilização de pulsos eletromagnéticos no intervalo de freqüências do GPR $(10 \mathrm{MHz}$ a $1 \mathrm{GHz}$ ) o torna muito diferente dos métodos eletromagnéticos usuais como também a instrumentação utilizada, fatos que serão abordados adiante.

\section{Propriedades eletromagnéticas das rochas e o GPR}

O comportamento físico das rochas depende das propriedades e do modo de agregação de seus minerais, da forma, volume e conteúdo dos poros e/ou fraturas (geralmente água e/ou ar) e grau de alteração. As propriedades que interessam ao estudo de problemas práticos, são as das rochas e minerais tal como se encontram na natureza, com suas impurezas, fraturas, fissuras, diáclases, umidade, etc... (Orellana, 1982).

No estudo de águas subterrâneas, os métodos geoelétricos são comprovados como os mais eficientes e economicamente viáveis. Neste caso, as magnitudes eletromagnéticas que podem refletir os contrastes dos meios em subsuperfície são a resistividade elétrica (ou sua inversa, a condutividade elétrica), constante dielétrica e a permeabilidade magnética (Keller \& Frischknecht, 1966; Orellana, 1982; Telford et al., 1990).

As propriedades eletromagnéticas de materiais geológicos são controladas principalmente pelo conteúdo de água (Topp et al. 1980). As águas presentes na natureza, em geral, apresentam condutividade elétrica apreciável, pois sempre têm algum sal dissolvido. No caso das rochas, todas possuem poros e/ou fissuras em proporção maior ou menor, os quais podem estar ocupados total ou parcialmente por eletrólitos, resultando em conjunto um comportamento de condutor iônico, com resistividade muito variável (Orellana, 1982). A constante dielétrica da água é outra propriedade eletromagnética que pode proporcionar grandes contrastes em relação a outros materiais do meio (Topp et al., 1980).

As variações nas propriedades eletromagnéticas do solo estão geralmente associadas a essas diferenças, as quais, por sua vez, causam reflexões e atenuações do sinal transmitido a partir do GPR. O sinal refletido é detectado pelo receptor onde é amplificado, digitalizado e 
registrado em um meio magnético digital para processamento e exibição de dados, como mostra, de maneira esquemática, a Figura B.1 (Davis \& Annan, 1989).

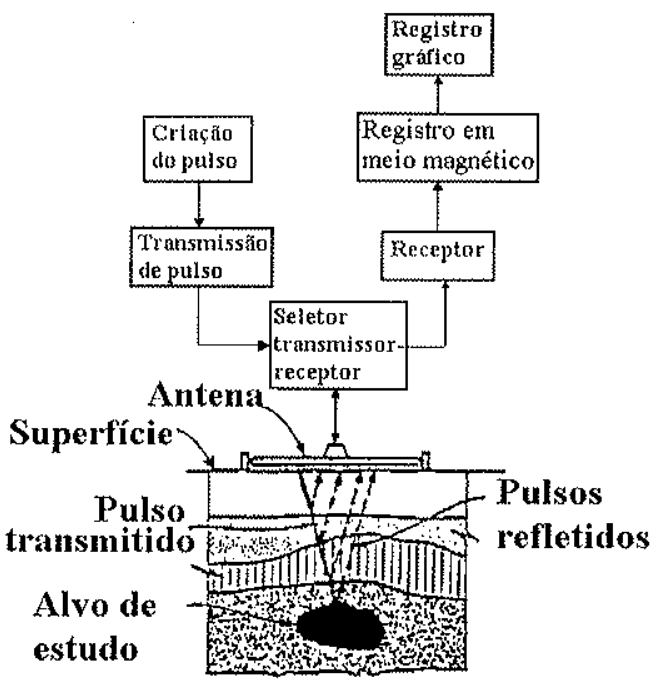

Figura B.1 - GPR esquemático mostrando sistema de operação básica e componentes (Davis \& Annan, 1989).

A seguir, serão abordados de forma generalizada informações sobre propriedades eletromagnéticas do mejo geológico e características de propagação de ondas eletromagnéticas nestes meios, nas quais se baseiam os principios do GPR. Em seguida, expõem-se as características intrínsecas do método utilizado em questão.

\subsection{Definições das propriedades eletromagnéticas}

O parâmetro mais explorado pelos métodos geoelétricos é a resistividade elétrica $(\rho)$ definida como a resistência que um material oferece ao fluxo de corrente elétrica quando submetido a uma diferença de potencial (d.d.p.), sendo que condutividade ( $\sigma$ ), é o seu inverso $(\sigma=1 / \rho)$. No caso do GPR esta propriedade exerce um papel importante no que diz respeito à atenuação do sinal em subsuperfície, pois a condutividade (ou resistividade) é um dos fatores controladores da penetração do sinal de altas freqüências. Meios muito condutores limitam a profundidade de investigação.

A constante dielétrica* ou permissividade dielétrica relativa $(K)$ é um fator de proporcionalidade específico para cada material e representa a quantidade de polarização

\footnotetext{
* Essa é a terminologia mais comumente utilizada na literatura, no entanto, Nobes (1996) questiona essa designação, pois na realidade a constante dielétrica do meio geológico em subsuperfíce não é constante, sendo que as
} 
elétrica causada neste material por ondas eletromagnéticas de altas freqüências, fenômeno no qual as cargas elétricas movem-se por uma pequena distância quando um campo elétrico é aplicado. A quantidade da polarização ocorrida é medida pelo deslocamento (quantidade e distância) das cargas elétricas quando da aplicação do campo elétrico (Keller \& Frischknecht, 1966; Keller, 1988; Telford et al., 1990).

A condução ocorre somente nos materiais que possuem cargas livres para se mover enquanto que a polarização ocorre em todos os materiais (von Hippel, 1954; Keller \& Frischknecht, 1966; Keller, 1988).

\section{Campos eletromagnéticos}

O GPR investiga a subsuperficie por uso de campos eletromagnéticos, os quais se propagam pelo solo. Campos eletromagnéticos consistem de campos elétricos (E) e magnéticos (B) acoplados variando no tempo. A maneira pela qual os campos eletromagnéticos interagem com materiais da terra controla o quanto estes vão se propagar e ser atenuados pelo meio (von Hippel, 1954; Keller \& Frischknecht, 1966; Keller, 1988; Telford et al., 1990; Zhdanov \& Keller, 1994).

A teoria eletromagnética estabelece basicamente que: 1) o fluxo de cargas elétricas é acompanhado de um campo magnético; 2) quando o campo magnético varia com o tempo, um campo elétrico é gerado e; 3) fluxo de cargas elétricas e fluxo magnético são conservativos. Estes fundamentos são expressos por quatro leis físicas conhecidas como equações de Maxwell (b1, b2, b3 e b4), as quais estabelecem o ponto de partida para entender como campos eletromagnéticos podem ser utilizados para estudar a estrutura da terra e determinar suas propriedades elétricas ou magnéticas (Zhdanov \& Keller, 1994):

$$
\begin{aligned}
& \nabla \times H=J+\frac{\partial D}{\partial t} \\
& \nabla \times E=-\frac{\partial B}{\partial t}
\end{aligned}
$$

propriedades dielétricas mudam conforme muda o conteúdo de água. Então o autor acredita ser correto a utilização do termo "coeficiente dielétrico" ou permissividade dielétrica. Concorda-se com a opinião do autor citado no caso em que as medidas de permissividade relativa sejam feitas in situ ou em amostras do material. No entanto, nesta pesquisa será utilizado o termo "constante dielétrica" pois os valores utilizados são de referências bibliográficas para se ter uma idéia aproximada do comportamento esperado de acordo com a litologia do local. 


$$
\begin{aligned}
& \nabla \cdot D=q \\
& \nabla \cdot B=0
\end{aligned}
$$

Onde $H$ é indução magnética, $J$ é a densidade de corrente de condução, $D$ é o deslocamento ou indução elétrica, $t$ é o tempo, $E$ é a intensidade do campo elétrico, $B$ é o campo magnético, $q$ expressa a densidade de carga livre (Orellana, 1974; Keller, 1988; Zhdanov \& Keller, 1994).

Ainda sobre as duas primeiras equações (b1 e b2) devemos dizer que: a equação (b1) representa o fato que campos magnéticos são causados por fluxo de corrente elétrica. A equação representa dois tipos de corrente, um, $J$, no qual portadores de carga fluem através de um meio sem qualquer impedimento, e o outro, $\partial D / \partial t$, o qual expressa a separação das cargas, de onde surge um "obstáculo" ao campo elétrico. O primeiro tipo de corrente é chamado ôhmico, ou galvânico ou de condução, enquanto o segundo tipo é conhecido pelo nome de corrente de deslocamento; a equação (b2) representa a lei física que rege os campos de indução magnética variáveis com o tempo os quais originam campos elétricos (Keller, 1988; Zhdanov \& Keller, 1994).

Essas duas equações caracterizam muito bem o comportamento eletromagnético para qualquer aplicação em exploração geofísica. Entretanto, da maneira que as equações estão expressas acima, não existe uma relação óbvia do comportamento eletromagnético com a estrutura da terra em subsuperfície ou de suas propriedades. Para essas dependências serem observadas, existem três relações conhecidas como equações constitutivas, as quais definem as três constantes características do meio (Orellana, 1974; Keller, 1988; e Zhdanov \& Keller, 1994).

$$
J=\sigma E \quad \text { (b5) } \quad D=\varepsilon E \quad \text { (b6) } \quad B=\mu H
$$

Para a maioria dos métodos geoelétricos, a mais importante é a que relaciona densidade de corrente $(J)$ com intensidade de campo elétrico (equação b5) por meio da condutividade elétrica $(\sigma)$, propriedade intrínseca do meio, cuja unidade no Sistema Internacional é siemens por metro $(\mathrm{S} / \mathrm{m})$. 
A segunda equação constitutiva (b6), relaciona intensidade de campo elétrico $(E)$ ao deslocamento $(D)$, que define outra propriedade do meio, conhecida como permissividade dielétrica $(\varepsilon)$ do meio, em $\mathrm{F} / \mathrm{m}$, e é sempre diferente de zero. Mesmo no vácuo, a permissividade $\left(\varepsilon_{0}\right)$ dá um valor finito de $8.85 \times 10^{-12} \mathrm{~F} / \mathrm{m}=8.85 \mathrm{pF} / \mathrm{m}$. Geralmente é mais conveniente lidar com um termo chamado permissividade relativa ou constante dielétrica, $K$, a qual fornece a razão da permissividade do material $(\varepsilon)$ em relação à permissividade do espaço livre $\left(\varepsilon_{0}\right)$ e define uma quantidade adimensional.

$$
K=\frac{\varepsilon}{\varepsilon_{0}}
$$

$\mathrm{Na}$ terceira equação constitutiva (b7) a permeabilidade magnética $(\mu)$ é um fator de proporcionalidade que relaciona intensidade de campo magnético $(B)$ com indução magnética (H) em um certo meio. A unidade de $H$ é tesla, também denominada ampére por metro, enquanto a de $B$ é weber $/ \mathrm{m}^{2}$, a qual representa o número de linhas de fluxo por metro quadrado. As propriedades magnéticas dos materiais geológicos, em geral, não sofrem mudanças significativas em relação às do vácuo $\left(\mu_{0}=4 \pi \times 10^{-7} \mathrm{H} / \mathrm{m}\right)$, exceto em casos raros, quando a rocha contém uma alta concentração de magnetita (Topp et al., 1980; Telford et al., 1990; Zhdanov \& Keller, 1994). Portanto, em geral se considera a permeabilidade magnética do vácuo para a maioria dos materiais geológicos.

As equações constitutivas foram consideradas separadamente, de maneira que cada propriedade da rocha afeta independentemente o campo eletromagnético. $\mathrm{Na}$ maioria das aplicações, as propriedades físicas definidas pelas três primeiras equações constitutivas combinam-se com a freqüência da onda eletromagnética para formar uma característica do meio denominada "número de onda" $(k)$, o qual determina o comportamento do campo eletromagnético. A expressão para o número de onda pode ser desenvolvida por substituição das três equações constitutivas (b5, b6 e b7) nas duas equações maxwellianas ( $\mathbf{b} 1$ e b2), sendo as últimas expressas em função da intensidade do campo magnético e elétrico (Keller, 1988 e Zhdanov \& Keller, 1994):

e

$$
\nabla \times H=\sigma E+\frac{\partial}{\partial t}(\delta E)
$$

$$
\nabla \times E=-\frac{\partial}{\partial t}(\mu H)
$$


Em um passo separado, e somente com a finalidade de demonstração, as derivadas em relação ao tempo nas equações (b8) e (b9) podem ser substituídas com a notação operacional (Keller, 1988):

$$
\frac{\partial}{\partial t}=\mathrm{i} \omega
$$

onde $\omega=2 \pi f=$ freqüência angular, em radianos por segundo e $f=$ freqüência de excitação e $i=(-1)^{1 / 2}$. Sabe-se que, uma onda que varia com o tempo senoidalmente pode ser representada pela seguinte expressão (Alonso e Finn, 1972):

$$
e^{i \omega t}=\cos \omega t+i \operatorname{sen} \omega t
$$

A derivada em relação ao tempo é

$$
\frac{d e^{i e x}}{d t}=i \omega e^{i w t}
$$

justificando a notação operacional.

O procedimento só é aceitável se a permissividade dielétrica e a permeabilidade magnética puderem ser consideradas independentes do tempo. Então, está excluído o caso das rochas ferromagnéticas, as quais possuem permeabilidade magnética muito diferente do vácuo. Portanto, pela utilização do operador, as equações (b8) e (b9) ficam da seguinte forma (Keller, 1988):

$$
\begin{gathered}
\nabla \times H=(\sigma+i \omega \varepsilon) E \\
\nabla \times E=-i \mu \omega H \Rightarrow H=-\frac{\nabla \times E}{i \mu \omega}
\end{gathered}
$$

E os dois campos $E$ e $H$ podem ser separados por uma simples operação algébrica, a partir da substituição de (b11) por (b10) (Keller, 1988): 


$$
\begin{aligned}
& \nabla \times\left(\frac{\nabla \times E}{-i \mu \omega}\right)=(\sigma+i \omega \varepsilon) E \\
& \nabla^{2} \times E=-i \mu \omega(\sigma+i \omega \varepsilon) E \\
& {\left[\nabla^{2}-i \mu \omega(\sigma+i \omega \varepsilon)\right] E=0}
\end{aligned}
$$

A partir da equação (b12) pode-se observar que todas propriedades da rocha, assim como a freqüência estão dentro de um mesmo termo (segundo termo em relação a $E$ de b12), o qual caracteriza a interação do campo eletromagnético com o meio (Keller, 1988 e Zhdanov \& Keller, 1994):

$$
\begin{aligned}
k^{2} & =-i \mu \omega(\sigma+i \varepsilon \omega) \\
& =\mu \varepsilon \omega^{2}-i \mu \omega \sigma
\end{aligned}
$$

O primeiro termo da equação (b13) é denominado como termo de propagação representando a contribuição das correntes de deslocamento, controladas pela constante dielétrica. O segundo termo chama-se geralmente de componente de difusão, o qual representa a contribuição das correntes elétricas de condução, controladas pela condutividade. $\mathrm{Na}$ resposta total do campo eletromagnético de um material geológico em subsuperfície essas contribuições relativas também dependem da freqüência $(\omega)$.

A altas freqüências o segundo termo da equação (b13) é desprezível pois está relacionado com as correntes de condução e portanto o número de onda é dado por (Keller, 1988 e Zhdanov \& Keller, 1994):

$$
k^{2} \approx \varepsilon \mu \omega^{2}
$$

Neste regime, $k$ é real e a propagação do campo eletromagnético ocorre sem atenuação significativa. Aqui as correntes de deslocamento são mais importantes e se diz que o campo se propaga por irradiação. Sabendo-se que $\lambda=2 \pi k$, onde $\lambda$ é o comprimento de onda, substitui-se o termo $k$ pela equação (b14) e obtém-se,

$$
\lambda=\frac{2 \pi}{\omega(\mu \mathcal{E})^{\frac{1}{2}}}
$$


A partir da equação (b15) observa-se que nas altas freqüências o comprimento de onda depende da constante dielétrica e independe da condutividade.

No caso do GPR, utiliza-se propagação de campos para se medir o tempo necessário para o campo atravessar o meio desde uma antena transmissora, ser refletido a partir de um material em subsuperfície, devido à mudança de constante dielétrica e voltar para a antena receptora.

As equações (b8) e (b14) expressam o comportamento do fluxo de correntes em termos de propagação e atenuação de sinal, o que torna interessante entendê-lo do ponto de vista físico, como será exposto adiante.

\subsection{Corrente total}

No meio geológico, a corrente que flui em resposta à aplicação de um campo elétrico é devida a correntes de condução $\left(J_{C}\right)$ e de deslocamento $(J d)$. Dependendo da razão de mudança do campo elétrico, qualquer um dos dois tipos de corrente pode dominar na resposta. A corrente total consiste de dois termos como mostra a equação (b16), relacionada com a equação (b8), um dos quais depende do próprio campo elétrico e outro da razão de mudança do campo elétrico com o tempo. Freqüentemente é útil tratar com campos de excitação variando senoidalmente no tempo, onde observa-se que as correntes de deslocamento são proporcionais à freqüência angular. Matematicamente, as correntes de deslocamento estão defasadas de $90^{\circ}$ em relação às correntes de condução. Esta mudança de fase entre as correntes de condução $e$ as correntes de deslocamento reflete o fato que uma é um mecanismo de dissipação de energia e o outro é um mecanismo de armazenamento de energia.

$$
J=J_{c}+J_{D}=\sigma E+\varepsilon \frac{d E}{d t}
$$

Uma representação gráfica simplificada das correntes de deslocamento, de condução e da corrente total em relação à freqüência é apresentada na figura B.2. 


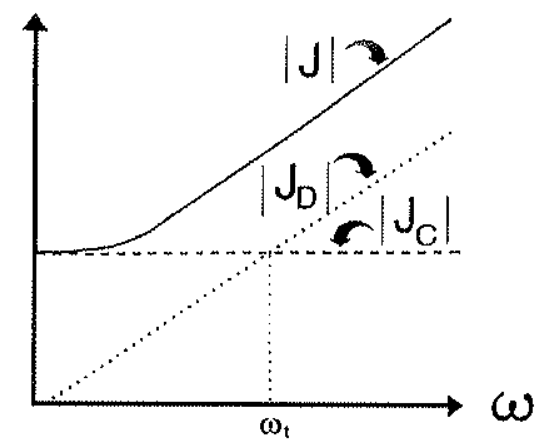

Figura B.2 - Gráfico simplificado da variação de corrente de condução (Jc), de deslocamento (Jd) e total (J) em relação à freqüência (Annan, 1992).

Em um meio geológico onde a condutividade e a permissividade dielétrica são constantes, existe um momento a partir do qual as correntes de deslocamento se tornam dominantes em relação às correntes de condução. Denomina-se freqüência de transição $\left(f_{\mathfrak{t}}\right)$ quando as correntes têm igual valor. A equação abaixo define matematicamente o conceito de freqüência de transição (Annan, 1992).

$$
\left|J_{c}\right|=\left|J_{D}\right| \Rightarrow|\sigma E|=\left|i \omega_{,} \varepsilon E\right| \Rightarrow \sigma=\omega_{1} \varepsilon \Rightarrow \omega_{1}=\frac{\sigma}{\varepsilon}
$$

Então, como $\omega=2 \pi f$, temos:

$$
f_{t}=\frac{\omega_{t}}{2 \pi}=\frac{\sigma}{2 \pi \varepsilon}
$$

Outro termo que deve ser considerado na discussão sobre propagação de ondas é o chamado tangente de perda, definido matematicamente na equação (b17). Fisicamente, a tangente de perda expressa a razão entre correntes de condução e correntes de deslocamento em um material e está relacionada com a dissipação (dependente da freqüência) da energia de onda eletromagnética causada por condução e relaxação dielétrica (Annan, 1992).

$$
\tan \delta=\frac{\left|J_{C}\right|}{\left|J_{D}\right|}=\frac{\sigma}{\omega \varepsilon}
$$

Parasnis (1997) prefere referir-se a este termo como $1 / Q$, onde $Q$ é um indicador de qualidade da eficiência da propagação da onda. Se $Q(=\omega \varepsilon / \sigma)>>1$, então a onda propagar-se-á eficientemente sem perda apreciável de energia a grandes distâncias. Se $Q<1$, a onda é 
atenuada em curta distância. A subsuperfície da terra não é homogênea, mas tem diferentes valores de $Q$ em diferentes estratos e essas considerações devem ser aplicadas a cada uma dessas partes (Parasnis, 1997). Deve-se salientar que as propriedades de condutividade elétrica e constante dielétrica não são independentes da freqüência de excitação, existindo sempre alguma variação. No entanto, em geral, estes valores são considerados constantes na faixa de freqüências do GPR.

\section{Parâmetros de propagação de ondas de rádio e propriedades eletromagnéticas}

A velocidade e a atenuação são os fatores que descrevem a propagação de ondas de rádio de alta freqüência no solo. Como já foi visto anteriormente, para descrever as propriedades eletromagnéticas de altas freqüências dos materiais utiliza-se a constante dielétrica, ou permissividade relativa.

Quando se considera simultaneamente propagação e atenuação de ondas, tem-se que citar a constante dielétrica complexa (ou permissividade dielétrica relativa complexa), a qual é dada pela soma das partes real e imaginária como (Davis \& Annan, 1989):

$$
K^{*}=K^{\prime}+i K^{\prime \prime \prime}
$$

onde $\mathrm{K}^{\prime}=$ parte real da constante dielétrica

K"'= parte imaginária ou parte de perda elétrica da constante dielétrica.

Sabendo-se que K"' representa as perdas de sinal durante a propagação, estas são constituidas por componentes dependentes da alta freqüência e da condutividade elétrica e podem ser expressas na forma de (Davis \& Annan, 1989):

$$
K^{*}=K^{\prime}+i\left[K^{\prime \prime}+\frac{\sigma}{\omega \varepsilon_{0}}\right]
$$

onde:

$\sigma$ = Condutividade de "freqüência zero"

$\omega$ = Freqüência angular

$K^{\prime \prime}$ = dispersão do sinal (dependência entre freqüência-material) associada com o fenômeno da resposta de relaxação das moléculas do material do meio atravessado. 
A Figura B.3 mostra a relação entre a velocidade e a freqüência para diferentes condutividades. Observa-se no gráfico que a velocidade do sinal permanece essencialmente constante e o sinal não é dispersado pela dependência freqüência-velocidade entre $10 \mathrm{e}$ $1000 \mathrm{MHz}$ para condutividades menores que $1000 \mathrm{mS} / \mathrm{m}$, motivo pelo qual os sistemas GPR operam nessa faixa de freqüências. A velocidade aumenta a freqüências maiores que $1000 \mathrm{MHz}$ devido à relaxação da molécula de água (Davis \& Annan, 1989).

Já a parte real da constante dielétrica $\left(K^{\prime}\right)$ está relacionada com a velocidade do sinal do radar (v) em materiais geológicos de baixa-perda (os quais são mais sensiveis ao radar e não ocorre muita dispersão do sinal) por (Davis \& Annan, 1989):

$$
\mathrm{v}=\frac{c}{\sqrt{K^{\prime}}}=\frac{3 \times 10^{8}}{\sqrt{K^{\prime}}}(\mathrm{m} / \mathrm{s})=\frac{0,3}{\sqrt{K^{\prime}}}(\mathrm{m} / \mathrm{ns})
$$

onde: $c=$ velocidade de propagação de ondas eletromagnéticas no vácuo.

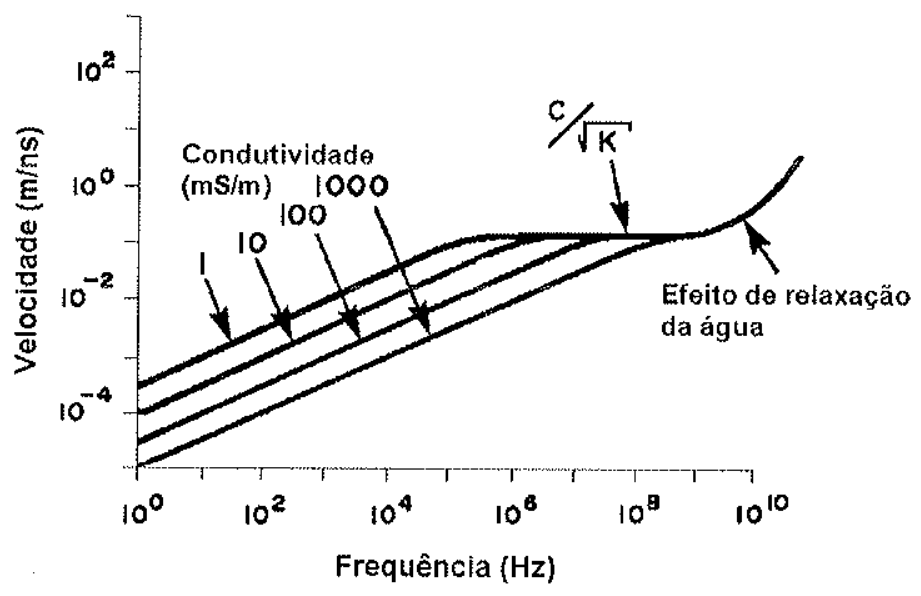

Figura B.3 - Curvas representativas da relação entre velocidade e freqüência a diferentes condutividades (Davis \& Annan, 1989).

A condutividade elétrica dos materiais do solo ou rocha provoca significantes perdas de propagação do sinal conforme seu valor aumenta devido à absorção de energia, o que limita a profundidade de penetração. A figura B.4 mostra a relação da atenuação do sinal com a freqüência para diferentes condutividades de materiais com constante dielétrica 4. A atenuação em meios com diferentes condutividades permanece aproximadamente constante na faixa de freqüências do radar. A atenuação aumenta rapidamente acima de $100 \mathrm{MHz}$ por causa da relaxação da água a qual ocorre a $10 \mathrm{GHz}$. O efeito de espalhamento ("scattering") de sinal por 
heterogeneidades escalarmente pequenas podem também aumentar a atenuação com o aumento da freqüência.

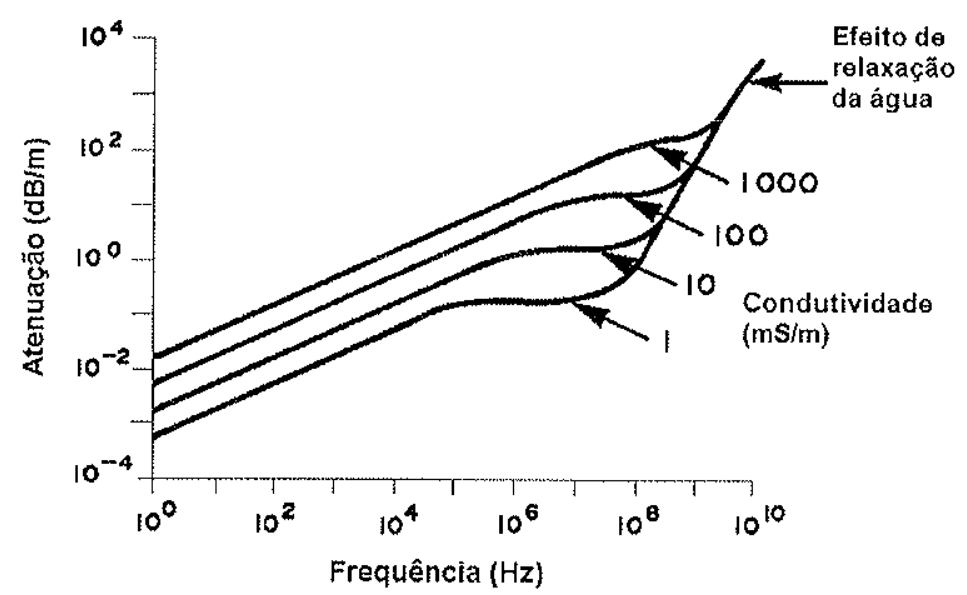

Figura B.4 - Curvas representativas da relação entre atenuação e freqüência a diferentes condutividades de materiais com constante dielétrica 4 (Davis \& Annan, 1989).

Portanto, as ondas são reduzidas em amplitude conforme se propagam pela Terra devido a três fatores: divergência geométrica, transmissão parcial e reflexão nas interfaces, e absorção de energia no meio de transmissão. A figura B.5 apresenta o efeito da atenuação através da medida da distância que uma onda consegue atravessar o meio antes da amplitude diminuir por $100 \mathrm{~dB}$ conforme variação de valores de condutividade elétrica. Neste gráfico observa-se que para uma condutividade de $200 \mathrm{mS} / \mathrm{m}$ a distância em que a onda pode ser detectada é menor do que $1 \mathrm{~m}$. Por outro lado, se a condutividade é da ordem de $1 \mathrm{mS} / \mathrm{m}$, a distância que a onda pode atravessar excede 100m. Essa forte dependência da condutividade elétrica é a razão pela qual o radar é efetivo em alguns lugares e em outros menos.

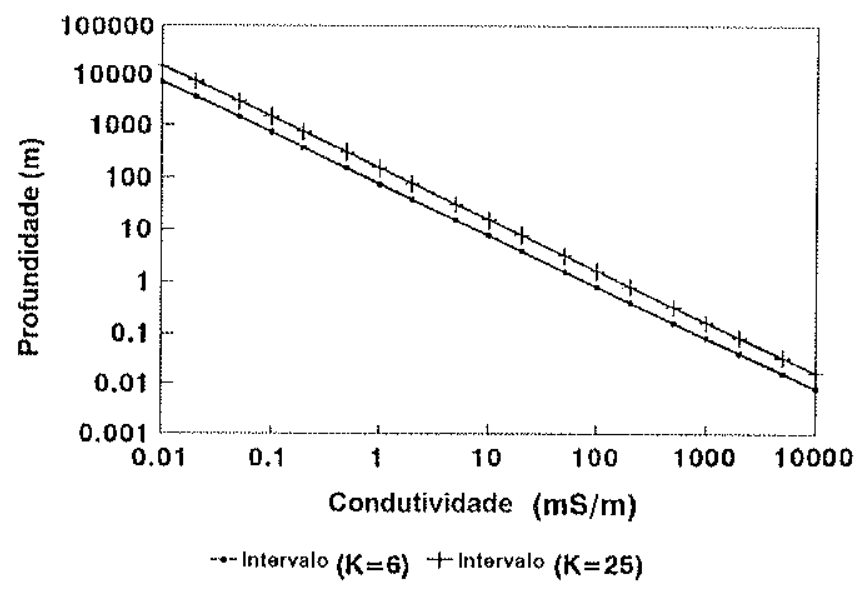

Figura B.5 - Profundidade em metros para uma atenuação de $100 \mathrm{~dB}$ da onda eletromagnética em função da condutividade (Annan, 1992). 
Os dados de GPR são apresentados em forma de perfil de profundidade bidimensional, no qual o eixo vertical é a medida do tempo de ida (a partir da antena transmissora) e volta do sinal (desde do refletor até a antena receptora), medida em nano-segundos, e no eixo horizontal tem-se a distância ao longo da linha medida em superfície (Figura B.6). Se a velocidade de propagação do pulso eletromagnético é conhecida, a profundidade do refletor pode ser dada por (Benson 1995):

$$
z \cong \frac{\mathrm{v} t_{r}}{2}
$$

onde $z$ é a profundidade do refletor, $t_{r}$ é aproximadamente o tempo da trajetória de ida e volta do sinal, e vé a velocidade com que o sinal atravessa o material em subsuperfície.

No caso de um meio uniforme de baixa perda com constante dielétrica relativa conhecida ou estimada, $K^{\prime}$, substitui-se v na equação (b18), então a profundidade do refletor é dada por (Benson 1995):

$$
z=\frac{c t_{r}}{2 \sqrt{K^{\prime}}}
$$
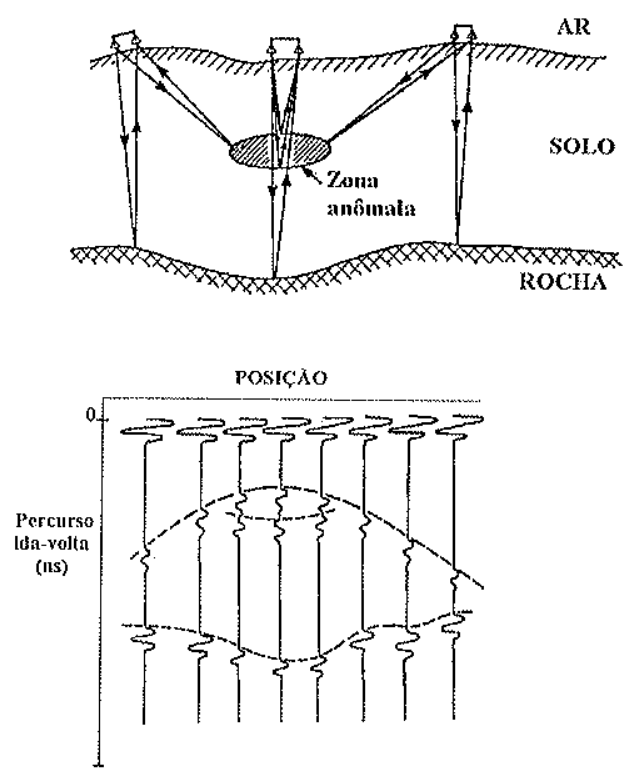

Figura B.6 - Registro do radar obtido em uma situação idealizada (Davis \& Annan, 1989). 
A Tabela B.1 apresenta, para materiais geológicos mais comuns, os valores de constante dielétrica, condutividade elétrica, velocidade e atenuação do sinal, todos observados a uma freqüência de $100 \mathrm{MHz}$.

Tabela B.1 - Constante dielétrica $(K)$, condutividade elétrica $(\sigma)$, velocidade $(v)$ e atenuação $(\alpha)$ típica de alguns materiais. (Davis \& Annan, 1989; RAMAC, 1997).

\begin{tabular}{|l|c|c|c|c|}
\hline Material & $\mathbf{K}$ & $\begin{array}{c}\sigma \\
(\mathrm{mS} / \mathrm{m})\end{array}$ & $\begin{array}{c}\mathbf{v} \\
(\mathrm{m} / \mathrm{ns})\end{array}$ & $\begin{array}{c}\alpha \\
(\mathrm{dB} / \mathrm{m})\end{array}$ \\
\hline Ar & 1 & 0 & 0,30 & 0 \\
\hline Água destilada & 80 & 0,01 & 0,033 & $2 \times 10^{-3}$ \\
\hline Água fresca & $80-81$ & 0,5 & 0,033 & 0,1 \\
\hline Água do mar & 80 & $3 \times 10^{4}$ & 0,01 & $10^{3}$ \\
\hline Areia seca & $3-5$ & 0,01 & 0,15 & 0,01 \\
\hline Areia saturada & $20-30$ & $0,1-1$ & 0,06 & $0,03-0,3$ \\
\hline Calcário & $4-8$ & $0,5-2$ & 0,12 & $0,4-1$ \\
& $(7-16)$ & & $\left(0.075-0.113^{*}\right)$ & \\
\hline Xisto & $5-15$ & $1-100$ & 0,09 & $1-100$ \\
\hline Silte & & & $\left(0.077-0.134^{\star}\right)$ & \\
\hline Argila & $5-30$ & $1-100$ & 0,07 & $1-100$ \\
\hline Concreto & $(9-23)$ & & $\left(0.063-0.100^{*}\right)$ & \\
\hline Granito & $5-40$ & $2-1000$ & 0,06 & $1-300$ \\
\hline Sal seco & $(4-16)$ & & $\left(0.074-0.150^{*}\right)$ & \\
\hline Gelo & $4-6$ & $0,01-1$ & 0,13 & $0,01-1$ \\
\hline & $(5-7)$ & & $\left(0.113-0.134^{*}\right)$ & $0,01-1$ \\
\hline
\end{tabular}

* valores para meio não saturado

valores entre parêntesis segundo Ramac (1997).

\section{GPR (Ground Penetrating Radar)}

A idéia de utilizar propagação de ondas eletromagnéticas de alta freqüência para estudar a subsuperfície vem desde o início do século com patentes criadas por alemães, mas sem obter sucesso até a invenção do radar (Parasnis, 1997). A origem da palavra radar é uma 
abreviação da denominação da tecnologia "Radio Detection and Ranging System" (Sistema de detecção e alcance por rádio), desenvolvida durante a $2^{\mathrm{a}}$ Guerra Mundial com objetivos bélicos. O conceito é simples: uma onda de rádio é transmitida e reflexões do campo eletromagnético a partir de objetos como aviões no ar ou embarcações no oceano são utilizadas para localizá-los. Após o final da guerra, com uma visão de sua capacidade próxima do "mágico", muitas tentativas foram feitas para utilizar o radar como um meio para explorar a subsuperficie da terra (Zhadanov \& Keller, 1994). Existem diferentes tipos de radar como de freqüência modulada, holográfico e radar de pulso, sendo que o GPR se enquadra neste último tipo. O início de seu desenvolvimento se deu por volta de 1956, mas o seu maior progresso foi a partir de 1970 graças aos avanços tecnológicos da informática e eletrônica (Parasnis, 1997).

O GPR possui a vantagem em relação a outros métodos eletromagnéticos por ser de alta freqüência e, portanto, proporcionar dados de alta resolução e por usufruir da tecnologia extremamente avançada de processamento de dados sísmicos para tratar seus próprios dados. Por outro lado, métodos geofísicos que trabalham nessa faixa de freqüências são extremamente limitados quanto à profundidade de investigação. Portanto, antes do início de um trabalho deve ser avaliado o custo/benefício do método para a situação a ser estudada.

\subsection{Aquisição de dados}

$\mathrm{Na}$ aquisição de dados com o GPR as ondas normalmente observadas são ondas de ar diretas, ondas do solo diretas e ondas refletidas e refratadas. Os conceitos básicos estão representados na figura B.7.
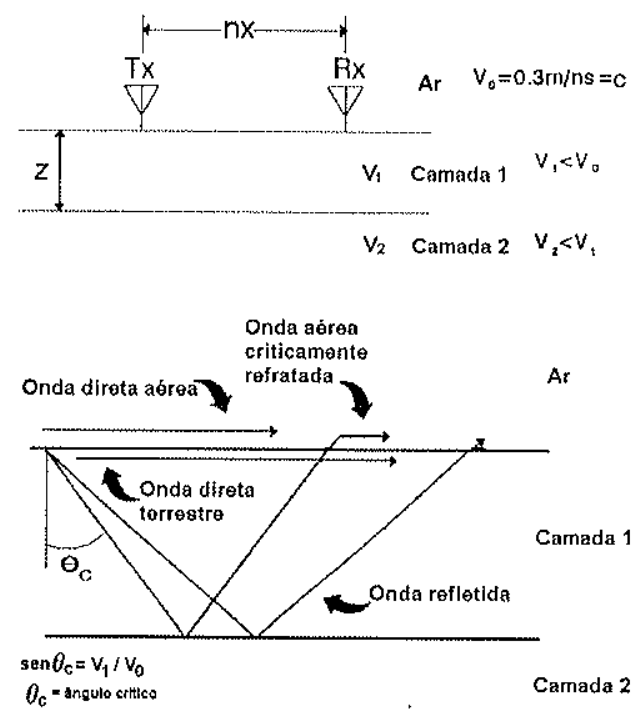

Figura B.7 - Modelo simplificado de camadas geológicas para representar os caminhos de propagação de ondas (Annan, 1992). 
As técnicas de campo variam, mas normalmente se utiliza o "caminhamento" de reflexão, onde a cada medida deslocam-se as antenas em conjunto, mantendo a mesma distância de separação entre elas (Figura B.8), para assim estudar as mudanças laterais.

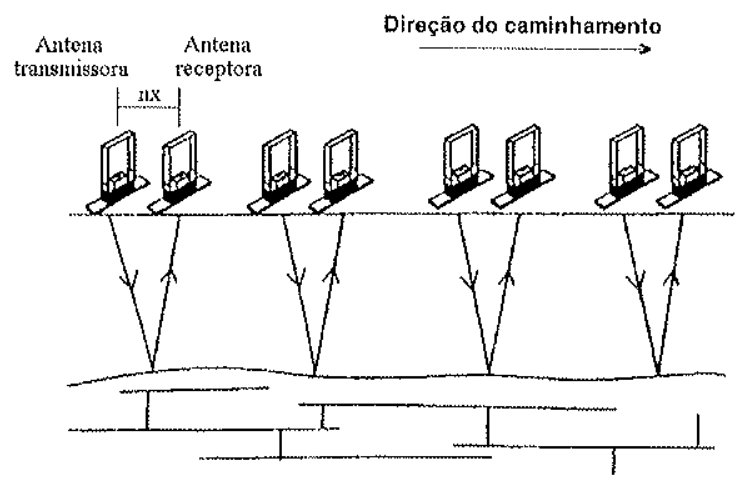

Figura B.8 - Arranjo das antenas no caminhamento de reflexão com disposição perpendicular em relação à linha do levantamento (modificada de Annan, 1992).

Outras técnicas de medidas são geralmente referidas (jargão da indústria sísmica) como sondagens WARR ("wide angle reflection and refraction") e CMP ("commom mid-point"), também conhecida como CDP ("commom depth point"), as quais são utilizadas para determinar a velocidade e atenuação do sinal (Annan, 1992). Na sondagem CMP (Figura B.9) cada sinal registrado é analisado na forma de variação do tempo percorrido com a separação das antenas, assim é possivel obter o valor de velocidade de sinal naquele ponto em subsuperfície. Em adição, pode-se utilizar a queda da amplitude com a distância para estimar a atenuação no meio.

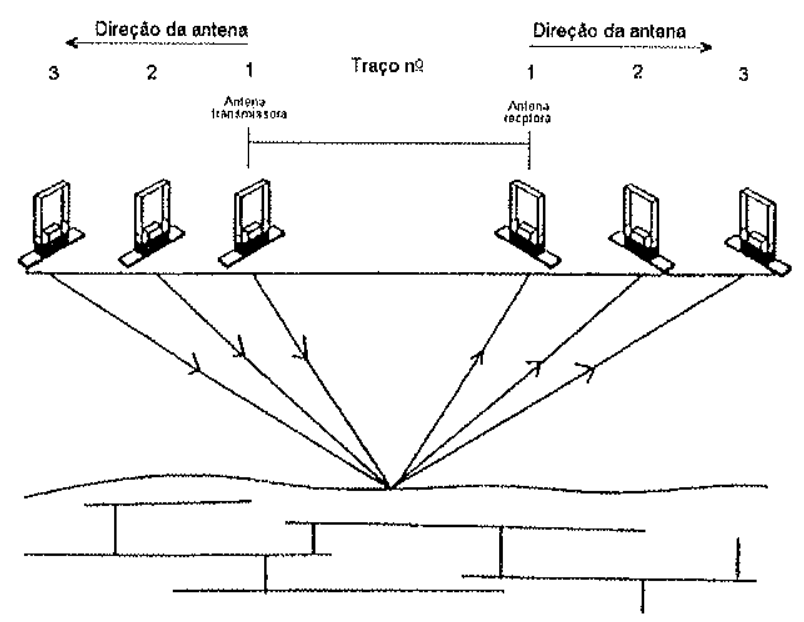

Figura B.9 - Arranjo das antenas no levantamento CMP (modificada de Annan, 1992). 
Neste procedimento seleciona-se um ponto sobre a superficie e acima do refletor de interesse, o qual foi identificado na seção de caminhamento de reflexão. Então as antenas são posicionadas em um ponto sobre o alvo com uma separação mínima. O espaçamento inicial geralmente é o intervalo de separação selecionado no caminhamento de reflexão ( $n x)$. A partir daí os dados adquiridos são relativos ao afastamento entre as antenas que aumentam de acordo com um múltiplo inteiro de $\mathrm{nx}$. A separação máxima em uma sondagem CMP é em geral de uma a duas vezes a profundidade do refletor. Se a atenuação em subsuperfície é alta, os sinais provavelmente desaparecerão antes da separação máxima ser alcançada. $O$ que difere a sondagem CMP da WARR é que na segunda uma das antenas fica fixa (geralmente a receptora) e a outra é distanciada a um intervalo fixo para cada medida. Neste caso vários pontos são amostrados em subsuperfície o que torna sua utilização vantajosa quando ocorre estratos inclinados em subsuperfície.

\subsubsection{Análise de velocidade}

A partir das medidas realizadas com o GPR são obtidos o tempo de percurso de ida e volta do sinal devido à reflexão sob o ponto medido e, portanto, para se estimar a profundidade atingida é necessário saber a velocidade de propagação do sinal no meio atravessado. Uma maneira é medir a velocidade do sinal do radar executando uma sondagem CMP (Figura B.9) ou WARR como visto no item anterior. Outra maneira é empírica, inferindo-se como velocidade do meio um valor baseado na experiência ou na literatura sobre aquele meio. Uma terceira alternativa seria medir a constante dielétrica no campo ou em laboratório por meio de instrumentos especiais, como por exemplo o TDR (Time Domain Reflectometry) e assim definir a velocidade.

Diferentemente da velocidade de propagação de ondas sísmicas (em geral aumenta com a profundidade devido ao aumento da densidade do meio), as velocidades das ondas eletromagnéticas do radar, em geral, diminuem com a profundidade, pois a permissividade dielétrica geralmente aumenta com a profundidade devido ao aumento de conteúdo de água (Fisher et al., 1992).

\subsection{Caracterização do radar}

As características fundamentais de um sistema de instrumentação geofísica em geral, que devem ser conhecidas para avaliação da aplicabilidade do método à pesquisa desejada, 
são o poder de penetração do sinal conforme as características litológicas do local e a resolução do sinal.

\subsubsection{Penetração em profundidade do sinal do radar}

Nos sistemas GPR a capacidade de penetração em um local específico depende da potência do equipamento, do espectro da freqüência das antenas, das características da antena, das propriedades eletromagnéticas dos materiais em subsuperfície (resistividade e permissividade). A atenuação, ou perda, do sinal são causadas por: conversão de energia radiada em energia calorífica devido às perdas por condução elétrica; perdas por relaxação dielétrica das moléculas de água; e/ou difusão química em minerais de argila. O efeito de espalhamento do sinal por heterogeneidades de pequena escala pode também aumentar a atenuação com o aumento da freqüência. Materiais com condutividade alta, como solos argilosos, podem reduzir rapidamente a profundidade de penetração.

Davis \& Annan (1989) sugerem uma equação para definir o desempenho do sistema em decibel a qual relaciona caracteristicas do sistema radar (eficiência e ganho das antenas, freqüência) com as condições em subsuperfície (distância em relação ao alvo, atenuação do meio, ganho de sinal que sofreu um espalhamento devido às características do alvo $e$ espalhamento do sinal por área de seção do alvo atravessado pelo sinal), para determinar o limite do sinal do radar. Os termos dependentes do projeto do instrumento podem ser medidos. Por outro lado as propriedades geométricas e eletromagnéticas da subsuperfície e do alvo são fatores incontroláveis e portanto a equação é de difícil aplicação.

\subsection{Coeficiente de reflexão}

Para quantificar as perdas devido à propagação esférica e espalhamento a partir de finas camadas ou objetos pontuais, consideremos a propagação da onda plana incidente verticalmente para baixo e sobre um limite plano. O coeficiente denominado de Fresnel pode ser calculado, o qual determina a amplitude do retorno do sinal.

A amplitude do sinal é reduzida nos refletores dependendo do contraste das propriedades eletromagnéticas e espessura da camada. O coeficiente de reflexão $(R)$ em um semi-espaço, para um sinal incidente normal sobre um limite entre materiais com constantes dielétricas $K_{1}$ e $K_{2}$ é: 


$$
R=\frac{\sqrt{K_{1}}-\sqrt{K_{2}}}{\sqrt{K_{1}}+\sqrt{K_{2}}}
$$

onde $K_{1}=$ constante dielétrica do meio 1

$\mathrm{K}_{2}=$ constante dielétrica do meio 2

Neste caso os dois meios são considerados não magnéticos e com condutividade elétrica nula. Uma onda refletida, $o_{r}$, retorna de volta e parte do sinal é transmitido para o meio 2 como onda transmitida, $o_{t}$.

Caso o meio seja condutor, Brewster \& Annan (1994) acreditam ser mais conveniente utilizar a seguinte expressão para calcular o coeficiente de reflexão para uma onda plana EM incidente normalmente:

$$
R=\frac{Z_{2}-Z_{1}}{Z_{2}+Z_{1}}
$$

onde $Z$ é a impedância elétrica do meio:

$$
Z=\left(\frac{i \omega \mu}{\sigma+i \omega \varepsilon}\right)^{\frac{1}{2}}
$$

A capacidade refletora é $|R|^{2}$. Quando a espessura de uma camada ou objeto diminui, a capacidade refletora diminui, dependendo da espessura da camada e comprimento de onda no meio. A rugosidade da interface entre dois materiais também afeta refletividade.

Muitas vezes uma forte reflexão é originada por uma camada extremamente fina $\left(K_{2}\right)$ que pode estar disposta entre duas camadas espessas $\left(K_{1}\right)$ mas de mesmas propriedades dielétricas. Neste caso, a amplitude da reflexão da camada fina é dependente da espessura da camada e também do coeficiente de reflexão de Fresnel para o meio (Annan, 1992).

\subsection{Escolha das antenas}

Geralmente, ao iniciar um levantamento deve-se ter uma idéia sobre a seção de profundidade/tempo necessária para se atingir o objetivo do estudo. A partir deste esboço se define a escolha da freqüência central da antena a ser utilizada. A seleção de uma freqüência ótima de operação deve manter um compromisso entre resolução espacial, profundidade de 
penetração e logística operacional do sistema no local de estudo (Annan, 1992). Sinais de alta freqüência produzem resolução maior, mas são limitados em profundidade de penetração.

A resolução è a capacidade do sistema de distinguir dois eventos próximos, expressa pela menor distância que eles podem chegar (Duarte, 1997). A resolução depende da largura de banda do pulso utilizado (Yilmaz, 1987; Nobes, 1996).

A escolha da freqüência depende do objetivo da aplicação, da profundidade de penetração necessária e das caracteristicas geológicas. Caso seja necessário se estudar um alvo a maior profundidade, uma menor resolução é aceitável e, caso uma resolução muito alta for necessária, então a profundidade atingida será, em geral, relativamente menor. A seguir discute-se com um pouco mais de detalhe essa questão.

\subsubsection{Resolução vertical}

A resolução vertical de um levantamento utilizando o GPR refere-se à separação mínima detectável em profundidade entre interfaces refletoras.

A resolução vertical que pode ser adquirida a partir de uma antena em particular é determinada pelo comprimento de onda do sinal de radar que penetra a terra. As camadas podem ser detectadas se elas estiverem separadas no mínimo por um quarto do comprimento de onda dominante. No entanto, na prática, camadas devem ter no mínimo um comprimento de onda de espessura para serem claramente determinadas no registro do GPR. Lembrando que antenas GPR são transmissoras de banda-larga, o comprimento de onda dominante, $\lambda$, pode ser calculado utilizando a seguinte fórmula simplificada (Lucius \& Powers, 1997):

$$
\lambda=\frac{\mathrm{v}}{f}=\frac{c}{\sqrt{K \cdot f}}
$$

onde $\quad \mathrm{v}=$ velocidade das ondas de radar no meio

$c=$ velocidade de ondas de radar no vácuo

$f=$ freqüência dominante das ondas no meio.

A hipótese simplificada considera que estão presentes no meio materiais não ferromagnéticos e que a condutividade do meio é baixa $(<5 \mathrm{mS} / \mathrm{m}$ a $100 \mathrm{MHz}$ e $<55 \mathrm{mS} / \mathrm{m}$ a $1000 \mathrm{MHz}$ ). Uma onda de radar pode ter o mesmo comprimento de onda na terra por várias combinações da freqüência e $K$. 


\subsubsection{Resolução horizontal}

A resolução horizontal que pode ser obtida das antenas de radar (ou seja, a separação lateral mínima de maneira que mais do que um objeto ou margem interfacial possa ser detectada) é uma função do padrão de radiação (e separação da antena), comprimento de onda, razão de amostragem horizontal (ou tamanho do passo), e profundidade do alvo. As antenas do GPR radiam energia em todas direções, mas sob condições favoráveis a maior parte da energia é dirigida para baixo em forma de um cone elíptico, freqüentemente chamado de cone de iluminação (Lucius \& Powers, 1997).

O ângulo crítico da interface ar-terra determina parcialmente o padrão de radiação da antena e o cone de iluminação. A resolução horizontal também é função da taxa de dados coletados, ou seja, depende se as antenas são rebocadas continuamente, ou do tamanho da medida, se as antenas estão colocadas a estações eqüidistantemente espaçadas. A razão de aquisição determinará a menor variação lateral nas propriedades do material que podem ser detectadas. Se o espaçamento aumenta acima de um certo limiar a resolução horizontal diminuirá. Entretanto, se o espaçamento entre as estações diminuir abaixo desse limiar, a resolução horizontal não diminuirá (Lucius \& Powers, 1997).

\section{Processamento de dados}

Apesar da tecnologia do GPR ter sido viabilizada recentemente (década de 70), o processamento de dados é um assunto tratado de maneira intensiva, já que o desenvolvimento de técnicas de processamento e os "softwares" da sísmica são aplicáveis no que se refere à parte cinemática de tratamento de dados neste caso. Como pode-se observar na literatura sobre GPR, toda a linguagem técnica como também técnicas de aquisição e processamento de dados foram herdados da literatura de sísmica.

Processamento de sinais é o conjunto de tratamento aplicados aos dados, para adequálos a um determinado propósito. Tanto no caso dos dados de reflexão sísmica como de GPR, o objetivo do processamento é produzir a imagem das camadas em subsuperfície, a partir do sinal transmitido, devolvido e registrado na superfície. (Duarte, 1997)

A possibilidade de se aplicar as mesmas técnicas de processamento de dados de reflexão sísmica em dados adquiridos por métodos eletromagnéticos são fundamentados em artigos da literatura científica como Szaraniec (1979), Ursin (1983) e Lee et al. (1987). Fisher et 
al. (1992)Fisher et al. (1994 e 1996) aplicam técnicas de processamento sísmico sobre dados de GPR e adquirem bons resultados.

Os registros de campo contêm (a) reflexões, (b) ruído coerente (c) ruído ambiente aleatório e, eventualmente, (d) ruído instrumental. Um importante aspecto do processamento de dados é discernir as reflexões genuínas (devido a interfaces litológicas) dos vários tipos de ruídos.

Segundo Yilmaz (1987), as estratégias e resultados de processamento de dados são fortemente afetados pelos parâmetros de aquisição de campo. Geralmente as condições de campo estão abaixo do ideal (condições de superfície de ordem ambiental ou demográfica, condições do tempo, cuidados tomados durante o registro e condições do equipamento influenciam a qualidade de dados). Para o autor, o papel do processamento então é eliminar o ruido e melhorar o sinal para aproveitá-lo o máximo permitido pela qualidade de aquisição dos dados. No entanto, o processamento não deve ser considerado como um passe de mágica, ou seja, caso durante o levantamento de campo o alvo de estudo não apresente sinais na seção, raramente este irá surgir devido ao processamento. Daniels et al. (1997) colocam muito bem essa questão ao escreverem que "processamento de dados de GPR tende a melhorar a aparência dos dados, mas raramente o processamento muda substancialmente a interpretação, sendo que, se o objeto de estudo não é detectado nos dados brutos de campo, então, geralmente, não serão detectáveis nos dados processados". O processamento é constituído por uma série de passos escolhidos cuidadosamente de maneira conveniente para cada caso. 


\section{PARTE C \\ HIDROCARBONETOS E OS MÉTODOS GEOFÍSICOS}

\section{Introdução}

Todos os fatores descritos na Parte $\mathrm{A}$ deste documento indicam a dificuldade de estimar adequadamente a quantidade e/ou continuidade dos hidrocarbonetos em subsuperfície utilizando poços de monitoramento. Obviamente, técnicas de detecção indireta contribuiriam para uma estimativa da contaminação do subsolo por hidrocarbonetos.

As principais propriedades físicas dos hidrocarbonetos que poderiam ser detectáveis a partir da superfície são os parâmetros eletromagnéticos de permissividade e condutividade. A permissividade relativa de produtos hidrocarbonetos varia entre 2 e 30 , aproximadamente, comparado a uma permissividade relativa para água de 80 . A condutividade varia desde próximo de zero até $20 \mathrm{mS} / \mathrm{m}$ entre freqüências de 100 e $1000 \mathrm{MHz}$. Estas propriedades fazem do GPR uma ferramenta adequada para detecção e mapeamento de contaminantes desta natureza em subsuperfície, devido à existência de contrastes de permissividade e à baixa condutividade que contribui para uma melhor penetração do sinal.

\section{Resposta eletromagnética dos contaminantes orgânicos em subsuperfície}

A permissividade relativa, ou constante dielétrica, de cada material ou substância em subsuperfície é o fator que proporciona os contrastes e torna possível a detecção de contaminantes orgânicos pelo método do GPR. Reflexões a partir de hidrocarbonetos nos interstícios do solo são uma função do contraste de permissividade entre o hidrocarboneto e o material "hospedeiro". Ná prática, um contraste detectável depende dos contrastes relativos entre as diferentes composições do solo e componentes líquidos presentes na interface. Medidas de laboratório de permissividades mais comuns são mostradas no Quadro C.1. Como pode ser observado no quadro, os valores para LNAPLs geralmente são baixos, os quais não devem proporcionar um contraste muito alto com a maioria das areias e pedregulhos secos, mas devem ter um bom contraste com solos argilosos, arenosos e com a água. Alguns trabalhos divulgados na literatura científica apresentam valores de constante dielétrica e outras características físicas referentes a algumas litologias e contaminantes orgânicos os quais são apresentados no Anexo 1. 
Quadro C.1 - Permissividades relativas para alguns hidrocarbonetos comuns (von Hippel, $1961^{2}$ apud: Daniels et al., 1995).

\begin{tabular}{c|ccccc} 
Líquidos orgânicos & \multicolumn{5}{|c}{ Freqüência (Hz) } \\
& $\times 10^{6}$ & $\times 10^{7}$ & $\times 10^{8}$ & $\mathbf{3 \times 1 0 ^ { 8 }}$ & $\mathbf{3 \times 1 0 ^ { 9 }}$ \\
\hline Álcool metil & 31 & 31 & 31 & 30.9 & 23.9 \\
Álcool etil & 24.5 & 24.1 & 23.7 & 22.3 & 6.5 \\
Tetracloreto carbono & 2.17 & 2.17 & 2.17 & 2.17 & 2.17 \\
Tetracloroetileno & 2.28 & 2.28 & - & - & 2.28 \\
Gasolina de avião (91 octanas) & - & - & - & 1.95 & 1.94 \\
Querosene & - & - & - & - & 2.09
\end{tabular}

O modelo intuitivo geoelétrico para plumas de contaminação por hidrocarbonetos trata a pluma como um corpo resistivo em subsuperfície, pois essas substâncias são apolares. No entanto, resultados de estudos de campo têm mostrado que o corpo da pluma pode desenvolver atributos condutivos através do tempo devido a processos de biodegradação (Sauck et al., 1998; Werkema et al., 2000).

\section{Métodos geofísicos e a detecção de contaminantes orgânicos}

Atualmente um dos principais desafios dos geofísicos em estudos sobre poluição em águas subterrâneas é detectar contrastes relacionados aos contaminantes orgânicos, dentro dos quais se incluem os derivados de petróleo. Hidrocarbonetos dissolvidos, provenientes do vazamento de tanques de combustivel enterrados, são relativamente móveis nas zonas saturadas e não saturadas, mas podem persistir nas águas subterrâneas durante décadas ou mais (Cherry, 1987; Cherry et al., 1990; Kueper et al., 1991).

Olhoeft (1985) foi idealizador do uso do método da polarização induzida espectral para monitoramento de contaminação por orgânicos. Os contrastes detectados nas medidas parecem ter origem em processos geoquímicos entre as argilas presentes e os contaminantes orgânicos. King \& Olhoeft (1989) divulgam novos resultados pelos quais demonstram que é possivel mapear a presença de tolueno quando em contato com argila pelo método da polarização induzida, devido ao processo de polimerização do tolueno com a montmorilonita. Os autores verificam que a medida de fase da resistividade complexa é um indicador muito

\footnotetext{
${ }^{2}$ von Hippel (1961) Dieletric materials and applications. MIT Press, Cambridge, MA. 438p.
} 
mais sensivel de contaminação por orgânicos do que a medida de magnitude da resistividade complexa.

Mazác et al. (1990) estudando a possibilidade de determinação da extensão de zonas contaminadas por derivados de óleo, desenvolveram um novo método geofísico designado por corpo blindado (SB - "screening body"). Esse método utiliza o efeito de blindagem elétrica do produto hidrocarboneto flutuando sobre o nível d'água e só é aplicável em casos sob certas condições específicas (a parte poluída apresenta uma resistividade alta em comparação com a resistividade da parte não poluída). O método utiliza as mesmas hipóteses da sondagem elétrica vertical mas aplica um arranjo de eletrodo diferente, onde um dos eletrodos de corrente é enterrado em um furo sob a camada de óleo e o outro é colocado na superfície a uma distância suficiente que se possa considerar no infinito e assim observam-se as variações de potencial elétrico. As possibilidades de detecção são verificadas por modelamento matemático e de laboratório. No estudo fez-se um levantamento de campo e uma comparação com o método da sondagem elétrica vertical (SEV). Os resultados de campo mostraram que o SB foi mais eficiente do que a SEV para indicar a zona contaminada. Os resultados geofísicos foram confirmados por sondagens de sondagem.

Vanhala et al. (1992), num estudo experimental utilizando o método da polarização induzida espectral, fizeram medidas em laboratório, sobre amostras de tilito $(2,5 \%$ de argila) contaminadas por tolueno, heptano e etileno glicol, e também não contaminadas, e observaram que os elementos químicos orgânicos apresentam um efeito distinto nas medidas de espectro de fase. No mesmo trabalho o pesquisador mostra, por meio de modelos teóricos, que o fenômeno medido em laboratório é detectável por investigações de campo utilizando freqüências maiores do que $50 \mathrm{~Hz}$.

Em outra publicação, Vanhala (1997) aplica o mesmo método, em campo e laboratório, para estudar os efeitos produzidos nas medidas de resistividade complexa devido à contaminação de óleo lubrificante e óleo queimado em tilitos e arenitos e a influência do tempo de contaminação nas medidas. No início das medidas de laboratório a amplitude e a fase diminuiram devido à contaminação de óleo. Depois, durante um período de maturação da contaminação, tanto as medidas de amplitude como as de fase aumentaram. As características observadas nas medidas de laboratório também foram observadas no campo em locais contaminados. Os testes de laboratório mostraram que a medida do espectro de fase em areias e tilitos limpos permaneceram estáveis com o tempo enquanto o espectro de fase de amostras 
contaminadas mudaram com o aumento de tempo de maturação. Essa última observação, juntamente com os resultados de campo, sugerem que diferenças entre o espectro de fase de solos limpos e poluídos e também mudanças que ocorrem no espectro de fase de solos contaminados com o tempo, podem ser indicativos de contaminação.

Pesquisadores de Waterloo (Ontario, Canadá) e do Colorado (EUA), realizaram experimentos em uma célula estanque em um aquífero arenoso com injeção controlada de percloroetileno (PCE), utilizando o GPR, TDR ("time domain reflectometry"), sonda de neutrons e eletrorresistividade (caminhamento e perfilagem). Os objetivos eram a detecção de contrastes nas medidas que indicassem a contaminação e monitoramento da contaminação ao longo do tempo. Os resultados obtidos com o objetivo de monitoramento da contaminação ao longo do tempo têm sido bem sucedidos, os quais indicaram contrastes nas medidas. No entanto, os resultados obtidos com o objetivo de detecção da contaminação ainda são muito incertos (Annan et al., 1991; Annan et al., 1992; Brewster et al., 1992a; Brewster et al., 1992b; Brewster et al., 1992c; Redman \& Annan, 1992; Schneider \& Greenhouse, 1992; Kueper et al., 1993; Greenhouse et al., 1993; Brewster \& Annan, 1994; Brewster et al. 1995).

Cruz-Sanjulián et al. (1992), em estudo hidrogeológico em área contaminada por hidrocarbonetos, sugerem uma correlação entre os valores medidos em uma zona de contaminação com altas concentrações de hidrocarbonetos precisamente sobre uma área com os menores valores de condutividade elétrica, a partir das medidas realizadas em amostras de águas coletadas de piezômetros instalados na área de estudo.

Börner et al. (1993) realizaram experiências em laboratório com amostras de arenito e argilito para detectar contaminantes orgânicos (hexano, diclorometano, benzeno e metanol) e inorgânicos (diferentes cloretos). O método geofísico utilizado é polarização induzida com freqüências entre $10^{-3}$ a $10^{5} \mathrm{~Hz}$, o qual demonstrou que as partes real e imaginária da condutividade elétrica complexa são influenciadas pela presença do contaminante e que os diferentes tipos de rocha condicionam diferentes resultados devido a processos de interação entre contaminante e rocha.

Frolhich et al. (1994), em um estudo de poluição das águas subterrâneas devido a um aterro sanitário e cunha salina, sugerem uma correlação entre os valores anômalos do fator de formação da rocha e a contaminação, a partir das medidas definidas em campo, pelo método da eletrorresistividade, e laboratório. Uma forte suspeita para explicar os valores anômalos 
seria devido a contaminantes orgânicos interagirem com bactérias formadoras de ferro. Para o autor, caso essa hipótese seja demonstrada, ela seria uma opção para detecção de poluentes orgânicos por métodos geoelétricos.

Benson (1995) apresenta dois estudos de casos bem sucedidos com a utilização do GPR para mapeamento da contaminação do solo e das águas subterrâneas por vazamento de tanque subterrâneo de gasolina em postos de serviço. $O$ autor interpreta qualitativamente uma forte reflexão nas seções de GPR como indício do contaminante e confirma essa suspeita pelos resultados de amostragens em poços de monitoramento, nos dois casos.

Daniels et al. (1995) aplicaram o método de GPR por meio de um experimento utilizando querosene como contaminante e uma situação real de vazamento de gasolina, para detecção de contaminação por hidrocarboneto em subsuperfície. Os autores comprovaram a qualidade e repetibilidade dos dados pela realização de um levantamento multitemporal (medidas realizadas em períodos diferentes) como também indicaram uma correlação entre a diminuição de amplitude do sinal com a presença de hidrocarbonetos.

Benson et al. 1997 demonstraram a possibilidade de utilização do VLF ("Very Low Frequency") para detecção de contaminação em subsuperfície por hidrocarbonetos. Os autores se baseiam no fato deste tipo de contaminação resultar em valores altos de resistividade elétrica em relação ao meio ou em valores baixos de resistividade, conseqüente da biodegradação do produto contaminante, o qual, neste caso, aumenta a quantidade de sólidos totais dissolvidos. Na pesquisa destes autores foram utilizados os métodos da eletrorresistividade e o VLF para delinear a pluma de contaminação produzida por um vazamento de tanque de armazenamento de gasolina. Foram realizadas 32 sondagens elétricas com arranjo Wenner em áreas contaminadas e não contaminadas e nove perfis de caminhamento com o VLF. A partir dos dados deste último, produziram-se gráficos de densidade de corrente relativa por posição de medida na superfície. Os autores mostram que existe uma boa correlação entre os levantamentos geofísicos e a contaminação por hidrocarboneto confirmada por poços de monitoramento. Ambos métodos identificaram a pluma contaminante por valores de alta resistividade, ainda que houvesse maior concentração de sólidos totais dissolvidos na água subterrânea contaminada quando comparada com a água subterrânea mais limpa. A resistividade produzida por hidrocarbonetos no solo (zona vadosa) e a parte flutuante sobre o nível d'água parece ser o fator dominante no local. Interpretações dos 
dados filtrados de VLF correlacionam-se bem com os dados interpretados de eletrorresistividade.

Nash et al. (1997) utilizaram os métodos de caminhamento elétrico (arranjo dipolodipolo), potencial espontâneo, e os métodos eletromagnéticos com os equipamentos EM-31, EM-34 (de baixa freqüência) e GPR (de alta freqüência) em uma antiga área destinada a exercícios bélicos com histórico de contaminação por hidrocarbonetos. Com exceção dos métodos de medida de condutividade (EM-31 e EM-34) devido às condições de campo, todos apresentaram uma forte resposta de caráter condutor relacionada ao longo período de existência da contaminação no meio. Neste caso ficou claramente demonstrado que a contaminação por hidrocarbonetos nem sempre gera uma anomalia de maior resistividade elétrica.

Bermejo et al. (1997) descobriram acidentalmente uma nova pluma de contaminação de caráter condutor, quando faziam caminhamentos com o GPR para estabelecer a variabilidade dos valores de "background" da área do estudo de Nash et al. (1997). O levantamento com o GPR foi suplementado por levantamento eletromagnético (EM-31) e um magnetométrico os quais detectaram objetos metálicos enterrados. Os dados foram confirmados por meio de uma amostragem de solo e água pela qual verificou-se presença de LNAPL residual e águas subterrâneas com valores de condutividade de 2.5 a 3.3 vezes acima do valor de "background". Sauck et al. (1998) apresentam uma discussão interessante, conduzindo uma investigação geofísica integrada, sobre a mudança de comportamento do hidrocarboneto a partir do momento do seu derramamento para o meio natural, de caráter resistivo para condutor devido à biodegradação ao longo do tempo. Werkema et al. (2000) executaram um levantamento de dados geoelétricos em conjunto com amostragens de solo utilizadas para contagem de bactérias em local contaminado por LNAPL. Nos pontos onde a contagem bacteriana foi alta, a resistividade elétrica aparente fol minima. Segundo os autores, os resultados indicaram que medidas de resistividade aparente podem proporcionar uma visualização de processos biogeoquímicos em locais impactados por contaminação de LNAPL.

Liu \& Quan (1997) introduzem um método denominado tomografia de atenuação do sinal ("attenuation tomography") com o objetivo de visualizar contaminantes orgânicos em subsuperfície como DNAPLs ("dense nonaqueous phase liquids"). O método é baseado na mudança da freqüência central, ou seja, baseia-se no fato de que como a atenuação das ondas eletromagnéticas aumenta com a freqüência, o centro do espectro do sinal experimenta uma 
queda durante a propagação, que é proporcional à distribuição de atenuação. Esta observação é aplicada aos dados de GPR de modo a reconstruir tomograficamente a distribuição de atenuação baseada nas mudanças de freqüências.

Nguyen et al. (1997) fazem parte de um programa patrocinado pela Shell Research do Reino Unido o qual tem como primeiro objetivo estabelecer a efetividade dos métodos geofísicos (GPR, EM, tomografia de resistividade $2 D$ ) em condições de campo para detecção de contaminação por hidrocarbonetos. Foram executados levantamentos de dados geofísicos em locais com diferentes características geológicas e culturais (postos de serviços, parte de uma planta química, partes de uma refinaria de petróleo e um terminal de distribuição de combustivel em desuso) os quais foram comparados com resultados de amostragem direta do solo. Um segundo objetivo, de longo prazo, seria relacionar as observações com propriedades eletromagnéticas em subsuperfície. Os autores concluem que ainda é necessário um maior entendimento sobre os processos físicos que originam as características observadas, mas que os resultados geofísicos e as análises de solo indicam que os métodos possuem potencial para serem utilizados dentro de custo efetivo.

Whiteley (1997) utiliza com sucesso um novo método denominado difração de ondas de rádio (RDEM - "radiowave diffraction electromagnetics") operando a freqüência de $1.6 \mathrm{MHz}$ combinado com imageamento tomográfico sísmico para detectar contaminação por hidrocarbonetos em região com alto nivel de vazios em subsuperfície.

Lien \& Enfield (1998) utilizaram o método de resistividade de compressão direta ("direct push resistivity") para delinear a distribuição de contaminação por hidrocarbonetos em uma unidade da Força Aérea Americana (Hill Air Force Base, Utah). Apesar das correlações estatísticas entre os resultados de resistividade e os analiticos referentes às análises de solo serem pobres, a produção de um mapa de distribuição de resistividade utilizando técnica de interpolação tridimensional proporcionou a delineação da distribuição de contaminação.

Daily et al. (1998) realizaram um experimento para mapear a pluma resultante de um derramamento de percloroetileno utilizando tomografia de impedância elétrica, o qual permitiu delinear o produto livre no meio estudado.

Newmark \& Daily (1998) realizaram um monitoramento utilizando sensores químicos de fibras óticas, sondas de nêutron e gama e tomografia de resistência elétrica, durante o 
bombeamento para retirada de uma pluma de produto livre de DNAPLs. Os autores observaram que durante o bombeamento os valores de resistividade elétrica diminuíram $e$ sugeriram que a causa está diretamente ligada à redução de DNAPLs.

Vickery \& Hobbs (1998) delinearam com sucesso a pluma de contaminante em subsuperficie com o método de condutividade do solo EM-31 com as medidas em quadratura, em uma antiga área de terminais de distribuição de petróleo. 


\section{PARTE D \\ METODOLOGIA E LEVANTAMENTO DE DADOS}

\section{Introdução}

A metodologia empregada para execução do estudo de caso pode ser dividida nas seguintes etapas:

1) foi realizado um levantamento de dados diretos disponiveis que caracterizam a área de estudo geologica e hidrogeologicamente e o histórico da contaminação;

2) conhecendo-se o mapa potenciométrico, profundidade do nível d'água subterrânea, as características litológicas e os pontos que apresentavam contaminação na área de estudo, definiu-se: a localização dos perfis de GPR com a intenção de mapear a pluma de contaminação; as freqüências das antenas do GPR que poderiam propiciar uma resolução razoável para detecção de contrastes como também pudessem atingir a profundidade de penetração até pelo menos o nível d'água;

3) foi executada uma linha com a intenção de definir os parâmetros de aquisição do radar (processo conhecido por análise de ruídos) para poder avaliar o melhor compromisso entre resolução e penetração do sinal. Postos de serviço são locais de intensos ruidos e, portanto, foi necessário o uso de antenas blindadas para a execução dos caminhamentos de reflexão. Neste caso haviam disponiveis somente antenas blindadas com 2 freqüências diferentes, de $250 \mathrm{MHz}$ e de $100 \mathrm{MHz}$. Portanto, não houve testes com outras freqüências;

4) com as linhas executadas, foi possivel fazer uma análise prévia dos dados, ainda no campo, e, assim, definir a localização das sondagens CMP com o objetivo de determinar a velocidade de propagação do sinal em um meio contaminado e em um meio não contaminado;

5) acabada a fase de campo, os dados foram submetidos a processamento com o intuito de melhorar a razão sinal/ruído. A partir daí os dados processados de todos perfis foram interpretados para definir a localização da pluma de contaminação;

6) com base na etapa precedente, as sondagens a trado manual foram locadas nos locais interpretados como contaminado e não contaminado para averiguação da interpretação dos perfis de radar.

A seguir, são apresentados os dados disponíveis da área de estudo, dados do levantamento geofísico (GPR) e seus processamentos, análises dos resultados, discussão, conclusões e recomendações. 
Os dados adquiridos diretamente (profundidade do nível d'água, espessura da "lâmina" de hidrocarboneto, litologia, hidrogeologia e características do solo) por meio de poços de monitoramento e de remediação do produto, foram levantados pela Hidroplan (1997), empresa responsável pela aquisição de dados na área para avaliação da situação de contaminação. Foram feitas consultas no processo sobre o caso, arquivado na Companhia de Tecnologia e Saneamento Ambiental CETESB (São Paulo, 1997), de onde foi possível obter informações sobre os poços em épocas diferentes devido às inspeções executadas pela CETESB. Os dados referentes às sondagens a trado manual (F-1, F-4, F-6 e F-7) foram levantados pela aluna para a tese para averiguação da interpretação das seções de radar.

\section{Descrição da área}

O estudo foi realizado em um posto de serviço, localizado no Bairro da Freguesia do Ó, no limite da região oeste/norte da cidade de São Paulo (Figura D.1). O posto de serviço é rodeado por residências e estabelecimentos comerciais. Localiza-se aproximadamente a 400 metros a montante do Rio Tietê apresentando uma sutil declividade em direção ao mesmo. $O$ esboço de localização da área encontra-se na Figura D.2.

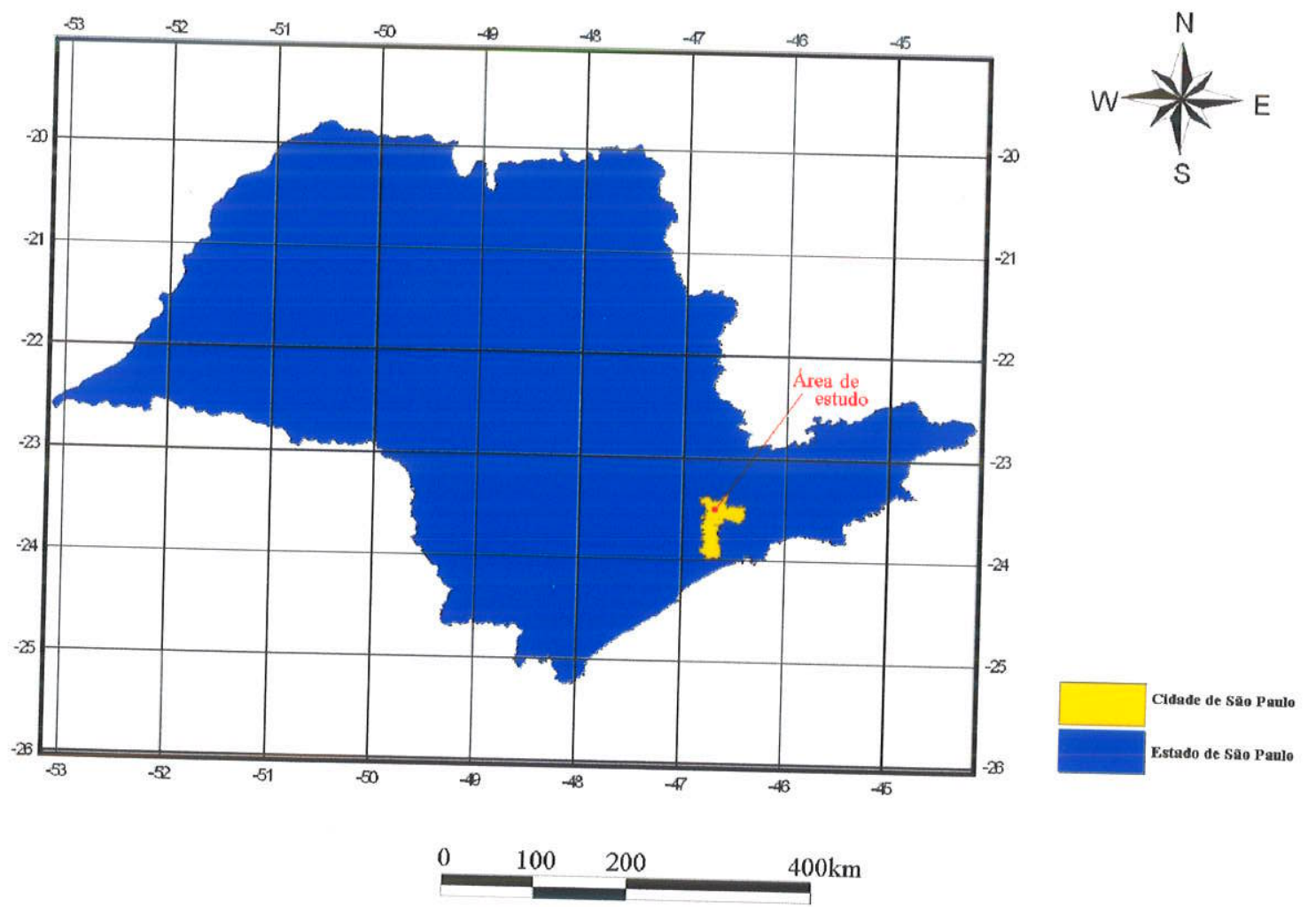

Figura D.1 - Localização da área de estudo no Estado de São Paulo (fonte: IBGE, 1999) 


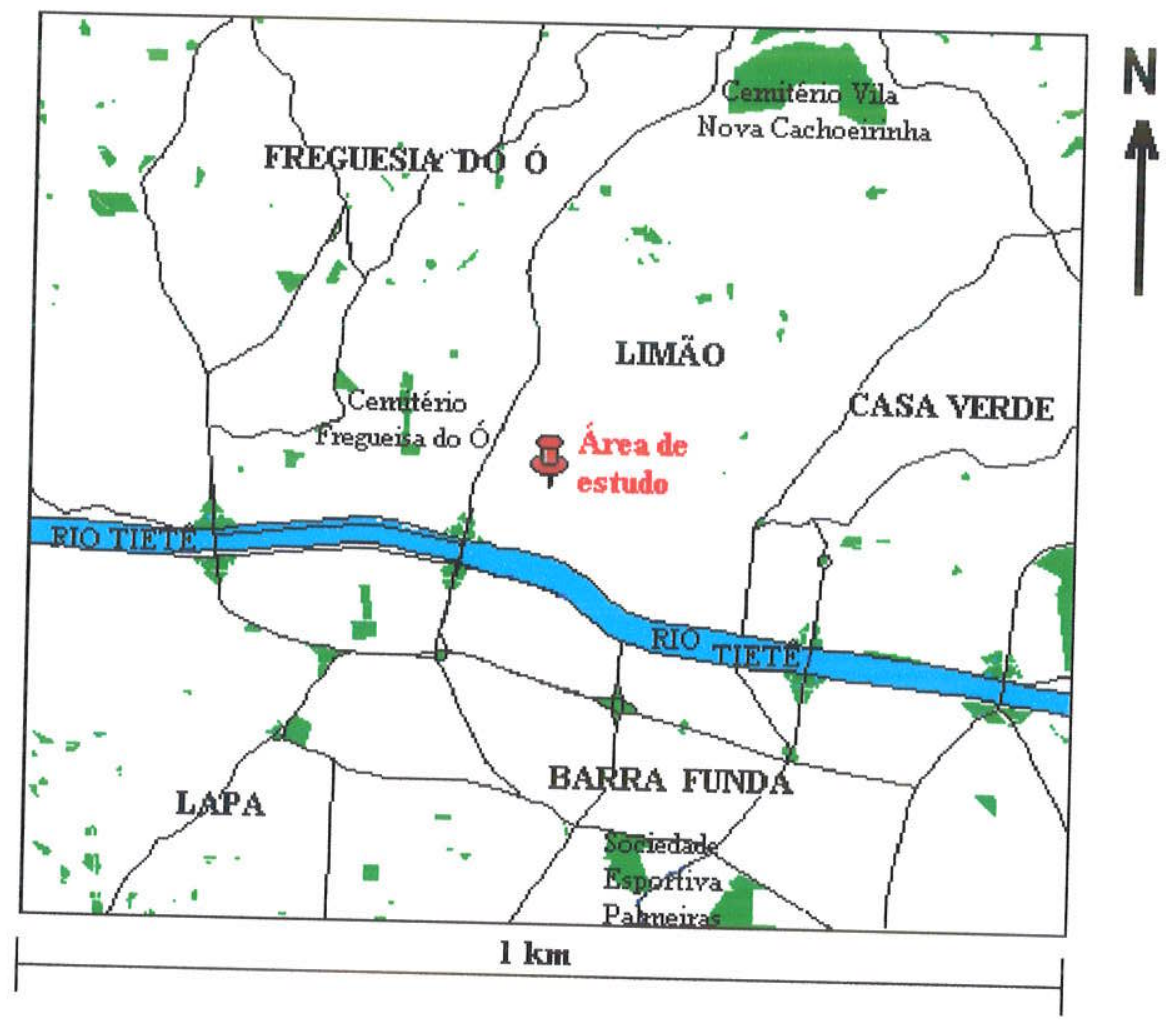

Figura D.2 - Mapa de localização da área de estudo na cidade de São Paulo (fonte:Guiasp,
2001)

Comercialmente a área é constituída de uma loja de acessórios de carros, escritório bombas e tanques de armazenamento de combustível para abastecimento de gasolina, álcool e diesel. Também executa-se troca de óleo e lavagens de veículos, realizadas em valas. $O$ esboço da área pode ser visto na Figura D.3.

\subsection{Histórico da contaminação na área de estudo}

Os indícios de contaminação surgiram em 1997 durante inspeção feita por funcionários da Telesp (a então companhia telefônica do Estado de São Paulo) em uma caixa subterrânea ao lado do Posto de Serviço. A presença de contaminação foi percebida pelo odor de produto na caixa subterrânea. O fato foi comunicado à CETESB, a qual enviou técnicos para o local que realizaram testes de explosividade e identificaram a existência de riscos.

$\mathrm{Na}$ época do levantamento de dados do radar o posto estava em atividades havia aproximadamente 30 anos, sendo que a idade dos tanques foi estimada em 11 anos, data em que houve uma reforma geral do posto e troca dos tanques de armazenamento. 


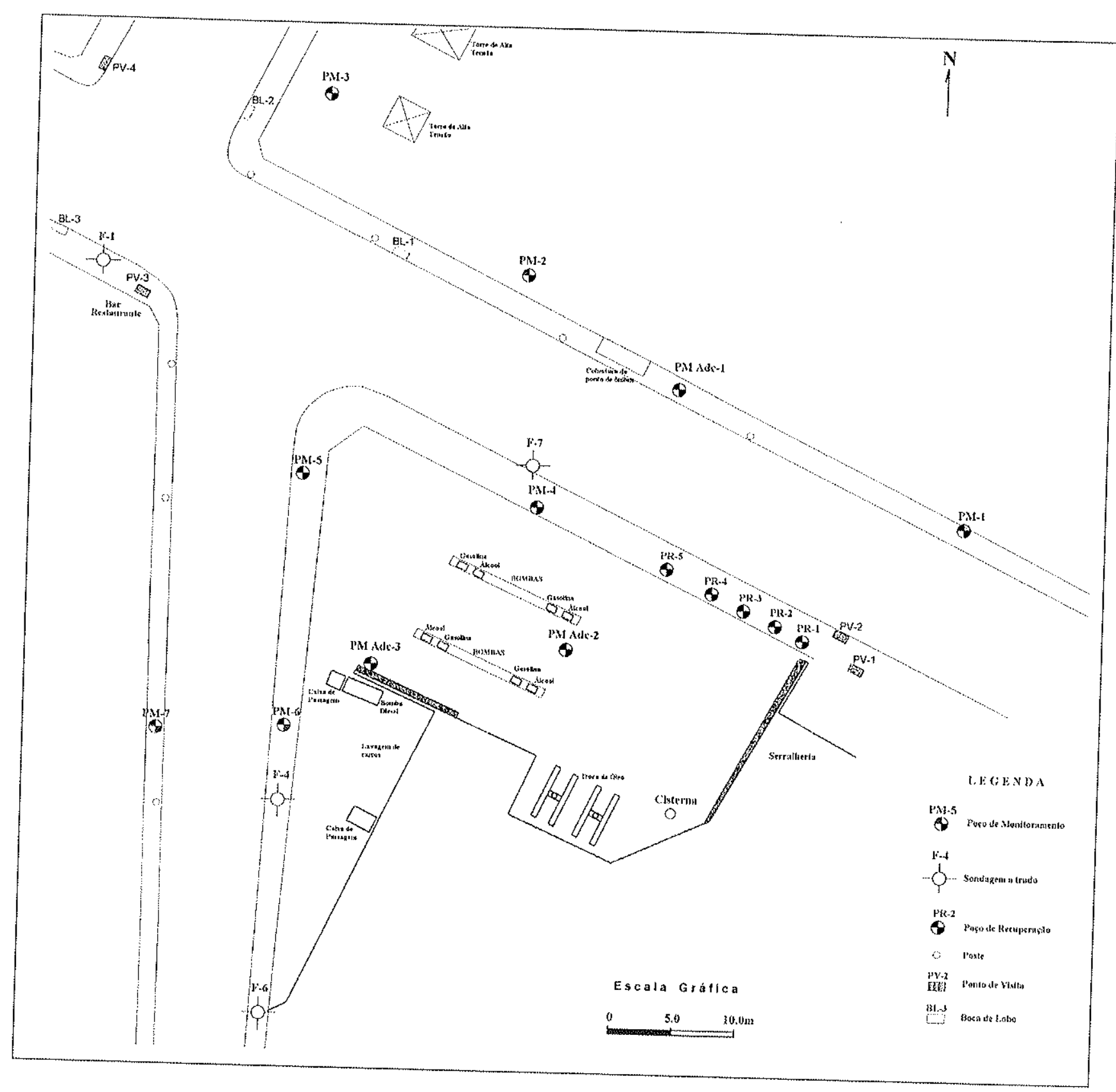

Figura D.3 - Esboço da área de estudo com a localização dos poços de monitoramento e
sondagens a trado

\subsection{Geologia}

Como pode ser observado no mapa geológico da região (Figura D.4) a área de estudo se situa sobre depósitos sedimentares aluviais associados ao Rio Tietê, de idade Quaternária (Qa), de predominância areno-argilosos. As unidades geológicas presentes na região e suas principais características litológicas são apresentadas e descritas na Fig. D.4. 


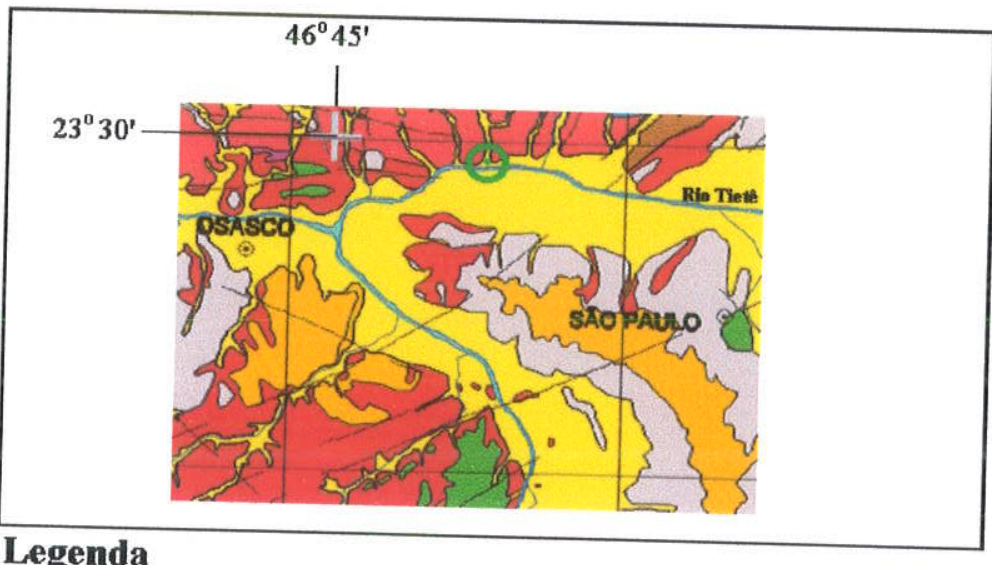

Legenda

\title{
Cenozóico: Quaternário
}

QA Depósitos sedimentares aluviais, predominantemente areno-argilosos

\author{
Cenozóico: Terciário \\ Formação São Paulo \\ DSP Depósito de sistema fluvial meandrante, compostos por cascalho,
areia e silte-argila \\ Formação Resende \\ ORL Depósitos de sistemas de leques aluviais a planície fluvial entrelaçada \\ Predominância de lamitos arenosos a argilosos \\ ORF Depósitos de sistemas de leques aluviais, com predominância de
lamitos seixosos.

\section{Proterozóico} \\ Per Filitos e xistos subordinados \\ PEX Micaxistos, com quartzitos e metassiltitos subordinados \\ PEG Rochas granitóides predominantemente maciças, de granulaçáo variada \\ PEGO Rochas granitóides predominantemente orientadas ou foliadas \\ PEA Anfibolitos \\ - Área de estudo
}

\section{E S C A L A}

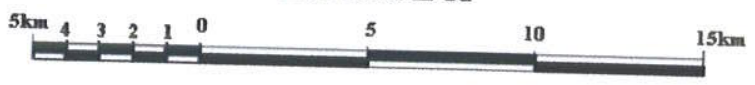

Figura D.4 - Mapa geológico da área de estudo (modificado de LIG, 1999)

Localmente, a descrição litológica foi feita a partir das 4 sondagens a trado manual ( $F-1$, F-4, F-6 e F-7) executadas para averiguação da interpretação dos perfis de GPR.

Basicamente, o posto situa-se sobre um aterro com material heterogêneo como pode ser observado na descrição apresentada no Anexo II, cuja espessura varia de 0.80 a 1.36 metros. A camada subjacente é caracterizada por uma argila plástica, com espessura variando de 1,1 a 2,2 metros, aproximadamente. 


\subsection{Hidrogeologia}

No contexto hidrogeológico regional a área de estudo apresenta características de dois domínios hidrogeológicos: rochas cristalinas e metamórficas de idade Pré-Cambriana, e rochas sedimentares de idades Tércio-Quaternárias da Bacia Sedimentar de São Paulo. O primeiro é denominado por Sistema Aquífero Cristalino e o segundo por Sistema Aquífero Sedimentar, sendo que na região da área de estudo ocorrem materiais geológicos representativos dos dois sistemas como pode ser visto no mapa e descrição apresentados na Fig. D.5.

Baseado nas informações obtidas a partir dos poços de monitoramento, poços de remediação e sondagens a trado (Figura D.3), concluiu-se que na área e na profundidade de interesse ocorre um único aqüífero de caráter livre, composto por sedimentos de predominância argilosa. A profundidade do nível d'água em março de 1997 variava de 1,38 a 2,25 metros (Hidroplan, 1997). Já em janeiro de 2001 a profundidade do nível d'água variou entre 0,66 a 2,07. A Tabela D.1 apresenta os valores de medida de profundidade de nivel d'água em épocas diferentes.

O baixo gradiente hidráulico apresentado faz com que o sentido do fluxo das águas subterrâneas se inverta facilmente, como pode ser observado nos mapas potenciométricos (Anexo III), referenciados nos valores das medidas de nível d'água estático, efetuadas nos poços de monitoramento e remediação (Hidroplan, 1997; São Paulo, 1997) e sondagens a trado. 


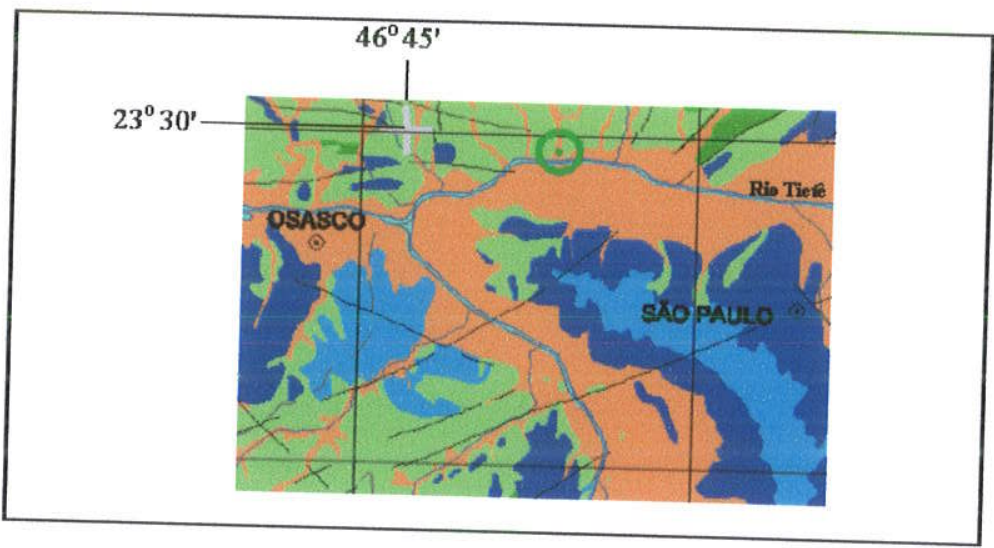

\section{Legenda}

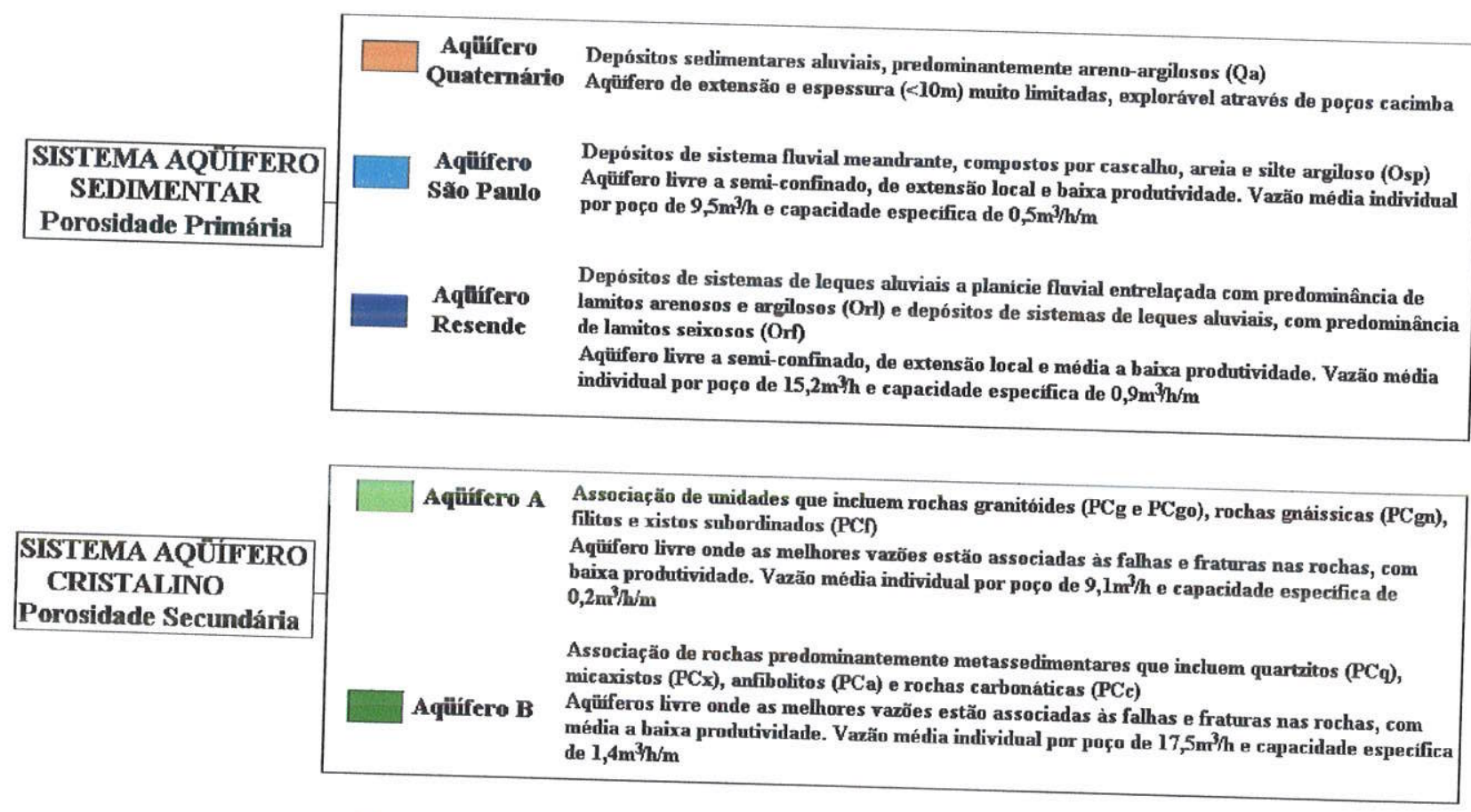

Área de estudo

E S C A LA

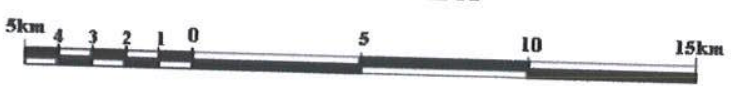

Figura D.5 - Mapa hidrogeológico da área de estudo (modificado de LIG, 1999) 
Tabela D.1 - Valores de profundidade do nível d'água dos poços de monitoramento, de remediação e de sondagens a trado da área de estudo.

\begin{tabular}{|c|c|c|c|c|c|}
\hline \multirow[t]{2}{*}{$\begin{array}{l}\text { Poços } \\
\left(n^{\circ}\right)\end{array}$} & \multicolumn{5}{|c|}{$\begin{array}{l}\text { Profundidade do nível d'água } \\
\qquad(\mathrm{m})\end{array}$} \\
\hline & $\begin{array}{l}27 / 03 / 1997 \\
\text { (Hidroplan) }\end{array}$ & $\begin{array}{l}20 / 10 / 1998 \\
\text { (CETESB) }\end{array}$ & $\begin{array}{l}12 / 11 / 1998 \\
\text { (CETESB) }\end{array}$ & $\begin{array}{l}\text { 05/07/2000 } \\
\text { (Hidroplan) }\end{array}$ & $19 / 01 / 2001$ \\
\hline $\mathrm{PM}-1$ & 2,00 & seco & seco & 3,56 & 2,24 \\
\hline $\mathrm{PM}-2$ & 2,25 & seco & 2,59 & 3,73 & - \\
\hline $\mathrm{PM}-3$ & 2,05 & - & seco & 3,39 & - \\
\hline PM-4 & 1,40 & 1,88 & 1,95 & Seco & 1,62 \\
\hline PM-5 & 1,50 & 1,63 & 1,72 & Seco & 1,38 \\
\hline PM-6 & 0,50 & 1,45 & 1,57 & 2,04 & 0,66 \\
\hline $\mathrm{PM}-7$ & 0,50 & - & seco & 1,96 & 1,09 \\
\hline Cisterna & 1,67 & - & - & - & - \\
\hline PM Adc-1 & - & seco & seco & 3,23 & 2,07 \\
\hline PM Adc-2 & - & 2,06 & seco & 2,54 & 1,90 \\
\hline PM Adc-3 & - & 2,08 & 1,97 & 2,48 & 1,92 \\
\hline PR-1 & 1,97 & 2,24 & 2,20 & - & 2,03 \\
\hline PR-2 & 1,95 & 2,17 & 2,16 & - & 2,00 \\
\hline PR-3 & 1,90 & 2,17 & 2,18 & - & 1,99 \\
\hline PR-4 & 1,65 & 2,18 & 2,18 & - & 1,87 \\
\hline PR-5 & 1,38 & 1,84 & - & - & 1,79 \\
\hline$F-1$ & - & - & - & 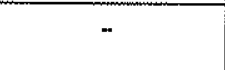 & 1,36 \\
\hline$F-4$ & - & - & - & - & 1,20 \\
\hline$F-6$ & - & - & - & - & 1,32 \\
\hline$F-7$ & $一$ & - & - & - & $1,50^{*}$ \\
\hline
\end{tabular}

${ }^{*}$ Dia 18/01/2001

\subsection{Caracterização da contaminação}

A caracterização da contaminação na área foi realizada primeiramente por meio de sondagens de reconhecimento com amostragem que serviram para caracterização geológica. Com os poços de monitoramento instalados, foi possivel acompanhar as variações do nível d'água e a evolução da pluma de contaminação. Os poços de remediação foram instalados de modo a efetuar o saneamento da área e a recuperação do produto em fase livre, por meio da 
sucção do combustível juntamente com a água contaminada e manta oleofillica (Hidroplan, 1997).

Hidroplan (1997) observou que: 1) nas leituras do nivel de fase livre em março de 1997, o poço de monitoramento PM-5, apresentou lâmina de gasolina na forma de fase livre, antes de iniciar o processo de bombeamento; 2) durante a perfuração dos poços era perceptível o odor de combustível na maior parte dos casos; 3) na mesma época foram feitas análises cromatográficas de $\mathrm{BTX}$, sendo que os resultados indicaram presença de fase livre nos PM-02, 04 e 05 e PR-02, 03 e 04.

No dia 20 de outubro de 1998 houve uma inspeção da CETESB (São Paulo, 1997), na qual fol observada fase livre nos PMAdc-3, PR-2, PR-5 e PM-5. Em outra inspeção da CETESB no dia 12 de novembro de 1998 (São Paulo, 1997) foi observada fase livre do produto nos PM4, PM-5 E PM-6 e nivel de explosividade de $100 \%$ na maioria dos poços (São Paulo, 1997). Durante o primeiro levantamento de dados com o GPR (5 de julho de 2000) o PMAdc-1 apresentou $18 \mathrm{~cm}$ de espessura de fase livre do produto. Nesta data também observou-se fase livre no PM-2, PM-3 e PMAdc-3 (Hidroplan, 1997). No dia 20 de julho de 2000 (Hidroplan, 1997) o PM-2, PM-3, PMAdc-1 e PMAdc-2 apresentaram espessura aparente da lâmina de fase livre. A Tabela D.2 apresenta um resumo das medidas realizadas nos dias citados.

Após o término do segundo levantamento geofísico (19 de janeiro de 2001) e juntamente com uma inspeção da CETESB, foram feitas medidas de nível d'água, espessura de lâmina de fase livre e condutividade elétrica das águas, além de observação a olho nu da aparência da água como também o odor de voláteis nos poços de monitoramento, remediação e nas sondagens feitas no dia anterior (Tabela D.2). Neste caso as medidas de espessura da lâmina foram feitas com um medidor de interface de hidrocarboneto/água e foi utilizado um amostrador transparente para observar o produto no caso deste não ser detectável pelo medidor de interface. Durante a amostragem das sondagens a trado manual realizadas em 18 de janeiro de 2001 foram observados odor de voláteis nas sondagens e nas amostras de solo dos F-4, F-6 e F-7.

Com base nas análises apresentadas pela Hidroplan (1997), foram feitos mapas de isoconcentração de Benzeno, Tolueno e Xileno (Anexo IV), para se ter uma idéia da pluma de contaminação na área de estudo. A Figura D.6 apresenta um mapa de isocondutividade de acordo com as medidas feitas no dia 19/01/2001, após a execução das sondagens a trado. 


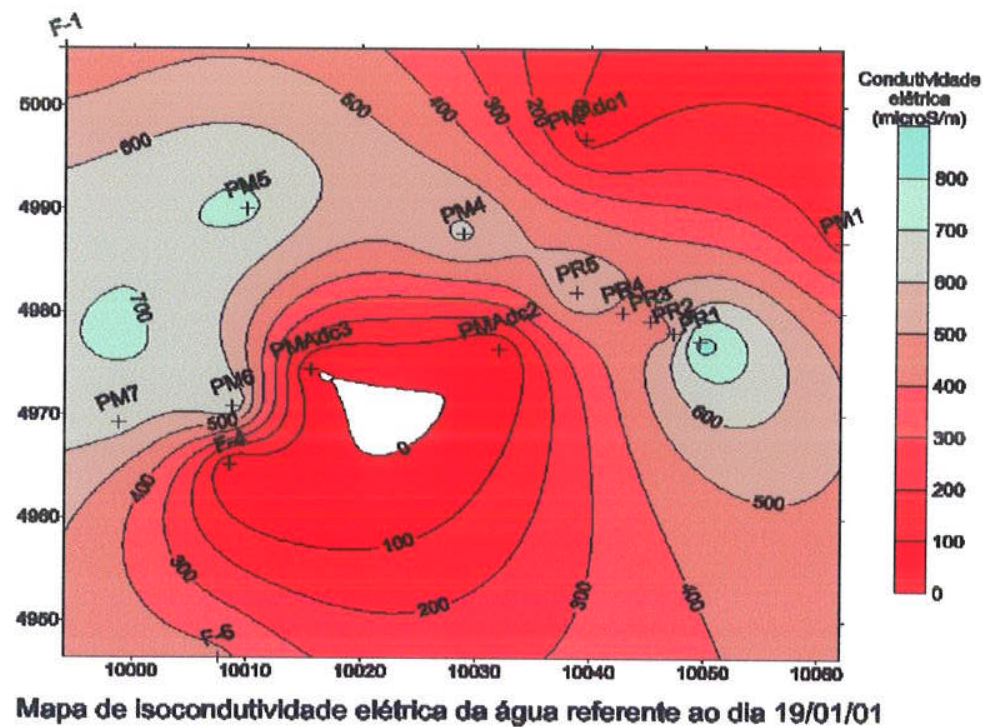

Figura D.6 - Mapa de isocondutividade da água representativo da área de estudo.

As medidas representadas no mapa da Figura D.6 podem ser observadas na Tabela D.2 e mostram que na maior parte dos casos, onde apresentou-se película ou lâmina do produto o valor de condutividade foi zero (F-4, PMAdc-2 e PMAdc-3) ou relativamente muito baixo como no PMAdc-1. No entanto, o PM-5 apresentou película mas o valor de condutividade elétrica medido na água foi significativamente maior $(725 \mu \mathrm{S} / \mathrm{m})$. Portanto, o valor de $0 \mu \mathrm{S} / \mathrm{m}$ não está relacionado com película ou lâmina do produto mas deve ser indício da fase dissolvida na água amostrada dos poços e da sondagem.

\section{Seleção dos parâmetros de aquisição de dados}

A qualidade dos dados do radar adquiridos em campo depende, como já foi citado, da escolha de vários parâmetros que é realizada na fase de pré-aquisição. O controle da qualidade de dados é feito durante sua coleta já que estes podem ser visualizados na tela do computador conforme são adquiridos.

\subsection{Escolha das antenas}

A área de estudo apresenta profundidade de nível d'água relativamente rasa (entre 1,5 e 3,5 metros no período clima de seco). O meio em subsuperfície, de acordo com descrição litológica dos poços de monitoramento, é argiloso e o local é altamente urbanizado o que causaria muitas interferências nos radargramas. Utilizou-se, portanto, duas antenas blindadas de freqüência central $250 \mathrm{MHz}$ e $100 \mathrm{MHz}$ para comparação entre elas, as quais possuem separação fixa entre a antena receptora e transmissora. Os dados foram avaliados qualitativamente, conforme eram adquiridos no campo, visualizando-os na unidade de 
aquisição de dados. Para execução da CMP foram utilizadas as antenas não blindadas, devido à necessidade de separação crescente durante a sondagem, de 100 e $200 \mathrm{MHz}$. A distância inicial entre as antenas nas sondagens CMP foi de $0,2 \mathrm{~m}$ e a abertura foi de $0,1 \mathrm{~m}$ para cada lado. Foi executada uma sondagem WARR como teste para verificar se esta proporcionava dados de melhor qualidade.

Tabela D.2 - Valores de espessura da fase livre do produto nos poços de monitoramento, de remediação e de sondagens a trado da área de estudo.

\begin{tabular}{|c|c|c|c|c|c|c|}
\hline \multirow[t]{2}{*}{$\begin{array}{c}\text { Poços } \\
\left(n^{\circ}\right)\end{array}$} & \multicolumn{5}{|c|}{$\begin{array}{l}\text { Espessura da fase livre do produto } \\
\qquad(\mathrm{cm})\end{array}$} & \multirow{2}{*}{\begin{tabular}{|c}
$\begin{array}{c}\text { Condutividade } \\
\text { elétrica da água } \\
\text { no dia } \\
(\mu \mathrm{S} / \mathrm{m})\end{array}$ \\
$19 / 1 / 2001$
\end{tabular}} \\
\hline & $\begin{array}{l}20 / 10 / 98 \\
\text { (CETESB) }\end{array}$ & $\begin{array}{c}12 / 11 / 98 \\
\text { (CETESB) }\end{array}$ & $\begin{array}{c}5 / 7 / 00 \\
\text { (Hidroplan) }\end{array}$ & $\begin{array}{c}20 / 7 / 00 \\
\text { (Hidroplan) }\end{array}$ & $19 / 1 / 01$ & \\
\hline $\mathrm{PM}-1$ & seco & seco & $n c$ & $n c$ & nc & 167 \\
\hline PM-2 & seco & $\mathrm{nc}$ & 2 & 14 & - & - \\
\hline PM-3 & - & seco & mancha & 3 & - & - \\
\hline $\mathrm{PM}-4$ & nc & 0,1 & seco & $\mathrm{nc}$ & $n c$ & 627 \\
\hline PM-5 & 0,7 & 0,3 & seco & $\mathrm{nc}$ & película & 725 \\
\hline PM-6 & nc & 0,2 & nc & $\mathrm{nc}$ & nc & 704 \\
\hline PM-7 & - & seco & nc & nc & $\mathrm{nc}$ & 643 \\
\hline PM Adc-1 & seco & seco & 18 & 4 & 0,3 & 69 \\
\hline PM Adc-2 & nc & seco & nc & 2 & 0,1 & 0 \\
\hline PM Adc-3 & 7 & nc & 0,5 & odor & $\begin{array}{c}4,3 \\
\text { (diesel) }\end{array}$ & 0 \\
\hline PR-1 & nc & $\mathrm{nc}$ & - & - & odor & 853 \\
\hline PR-2 & 1 & $n c$ & m & - & odor & 487 \\
\hline PR-3 & nc & $\mathrm{nc}$ & - & - & $\mathrm{nc}$ & 488 \\
\hline PR-4 & nc & $\mathrm{nc}$ & - & - & odor & 477 \\
\hline PR-5 & 0,3 & nc & - & - & odor & 601 \\
\hline$F-1$ & - & - & - & - & nc & 413 \\
\hline$F-4$ & - & - & - & - & 0,9 & 0 \\
\hline$F-6$ & - & - & - & - & $\mathrm{nc}$ & 426 \\
\hline
\end{tabular}

nc-não contém produto 


\subsection{Instrumentação}

O instrumento utilizado na pesquisa foi o RAMAC produzido pela MALÄ - GeoScience. Basicamente é constituído de uma unidade de controle RAMAC/GPR, antenas transmissoras e receptoras de várias freqüências, cabos de conexão de fibra óptica, baterias individuais de alimentação para as unidades eletrônicas, cabo paralelo de dados, um "notebook" para aquisição de dados e o software de aquisição de dados RAMAC2, versão 2.28 (1997). O software utilizado para processamento dos dados adquiridos pelo RAMAC/GPR foi o RADPRO (Radar Processing Software) versão 2.25 (1996).

\section{Levantamento de dados de GPR}

O levantamento de campo foi realizado em duas fases: uma primeira fase (05/07/2000) e outra posterior (15 a 19/01/2001). O objetivo da primeira fase foi adquirir dados com o GPR na área contaminada para constatação de contrastes nas medidas e assim processar o sinal e interpretar a anomalia evidentemente relacionada à contaminação (Fotos 1 a 4). A segunda fase foi realizada no sentido de adquirir dados de GPR relacionados à contaminação para delinear toda pluma (Fotos 5 e 6 ) e confirmar a interpretação por meio de sondagens a trado.

O arranjo das antenas para o levantamento de dados foi o afastamento comum ("common-offset") ao longo de caminhamentos com cobertura simples das reflexões ("singlefold reflection") ou para simplificar, caminhamento de reflexão (Ramac/GPR, 1997). Neste caso, o sistema (antena transmissora e receptora com separação fixa) é transportado ao longo da linha para mapear as reflexões a cada posição de medida (Fotos 1, 2, 5 e 6). As medidas são feitas automaticamente conforme o sistema é puxado e percorre a distância controlada pelo odômetro acoplado ao sistema. Neste modo o levantamento é mais rápido, portanto possibilita um empilhamento maior dos traços ("stacking") e conseqüentemente, uma intensificação de sinais mais fracos.

As localização dos perfis de caminhamento de reflexão e sondagens CMP estão representadas no esboço da área na Figura D.7. 


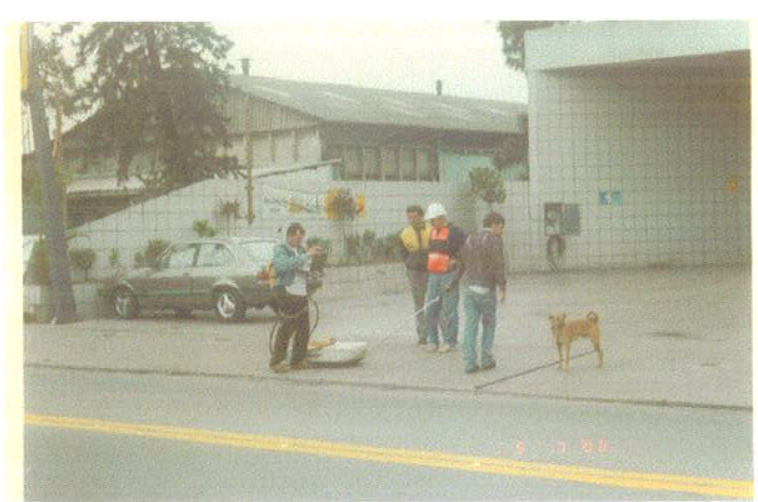

Foto 1- Fase I do levantamento dos dados com a antena blindada de $250 \mathrm{MHz}$ ao longo do perfil P-1

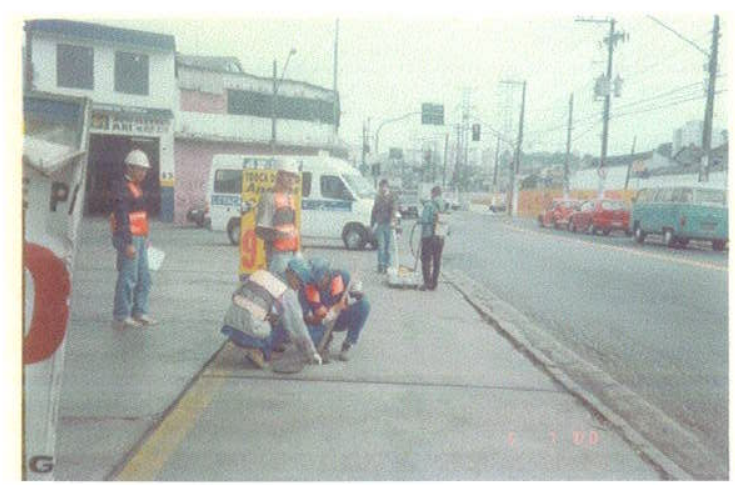

Foto 2 - Levantamento dos dados com a antena blindada de $250 \mathrm{MHz}$ ao longo do perfil P-1 simultaneamente a medida de nível d'água e espessura da lâmina de fase livre

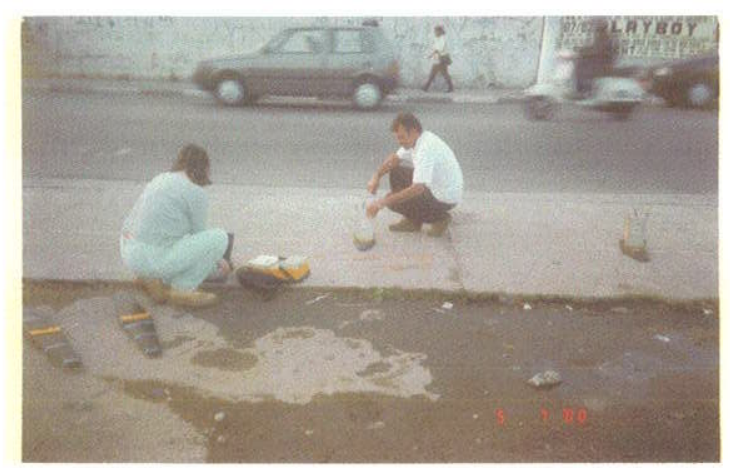

Foto 3 - Execução da sondagem CMP-1 com a antena de $200 \mathrm{MHz}$

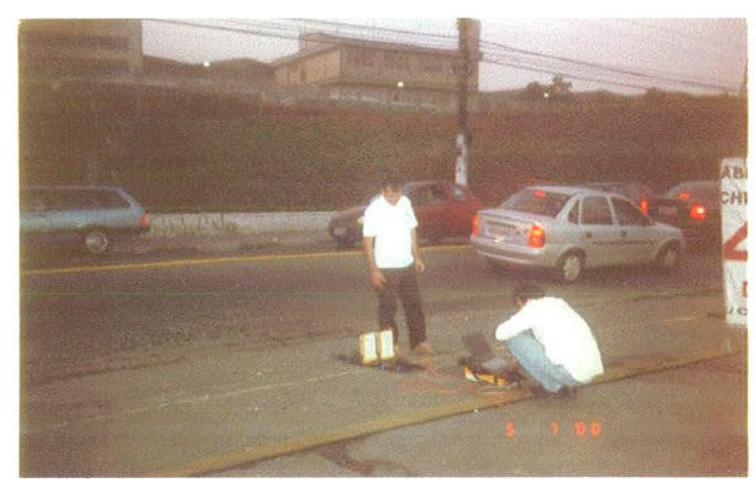

Foto 4 - Execução da sondagem CMP-2 com a antena de $200 \mathrm{MHz}$

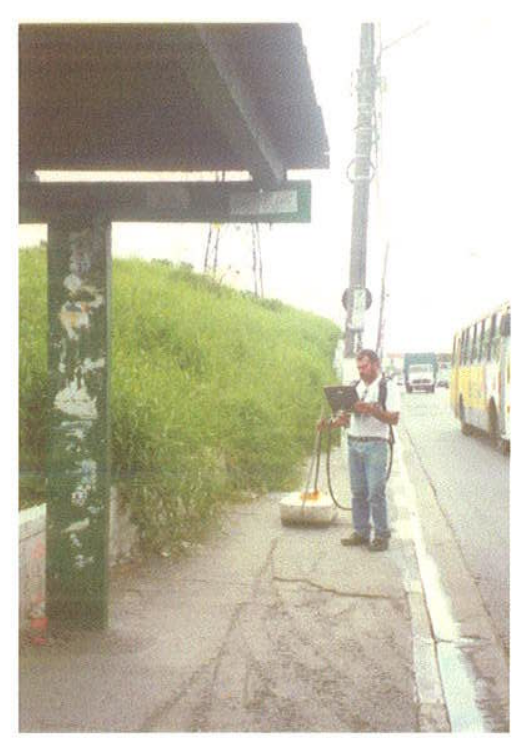

Foto 5 - Fase II do levantamento dos dados com a antena blindada de $250 \mathrm{MHz}$ ao longo do perfil P-10

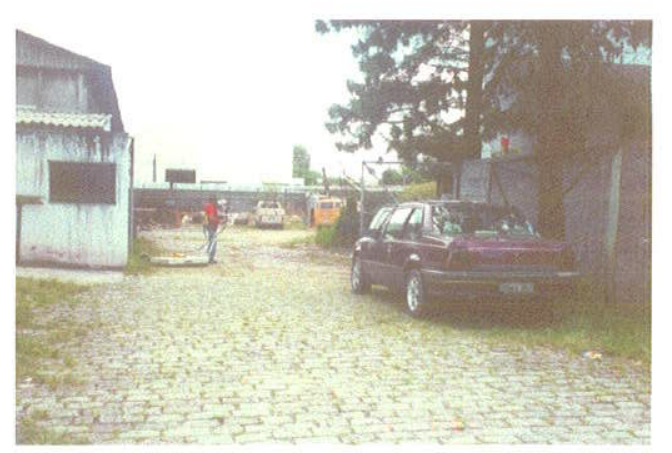

Foto 6 - Fase II do levantamento dos dados com a antena blindada de $250 \mathrm{MHz}$ ao longo do perfil P-11 


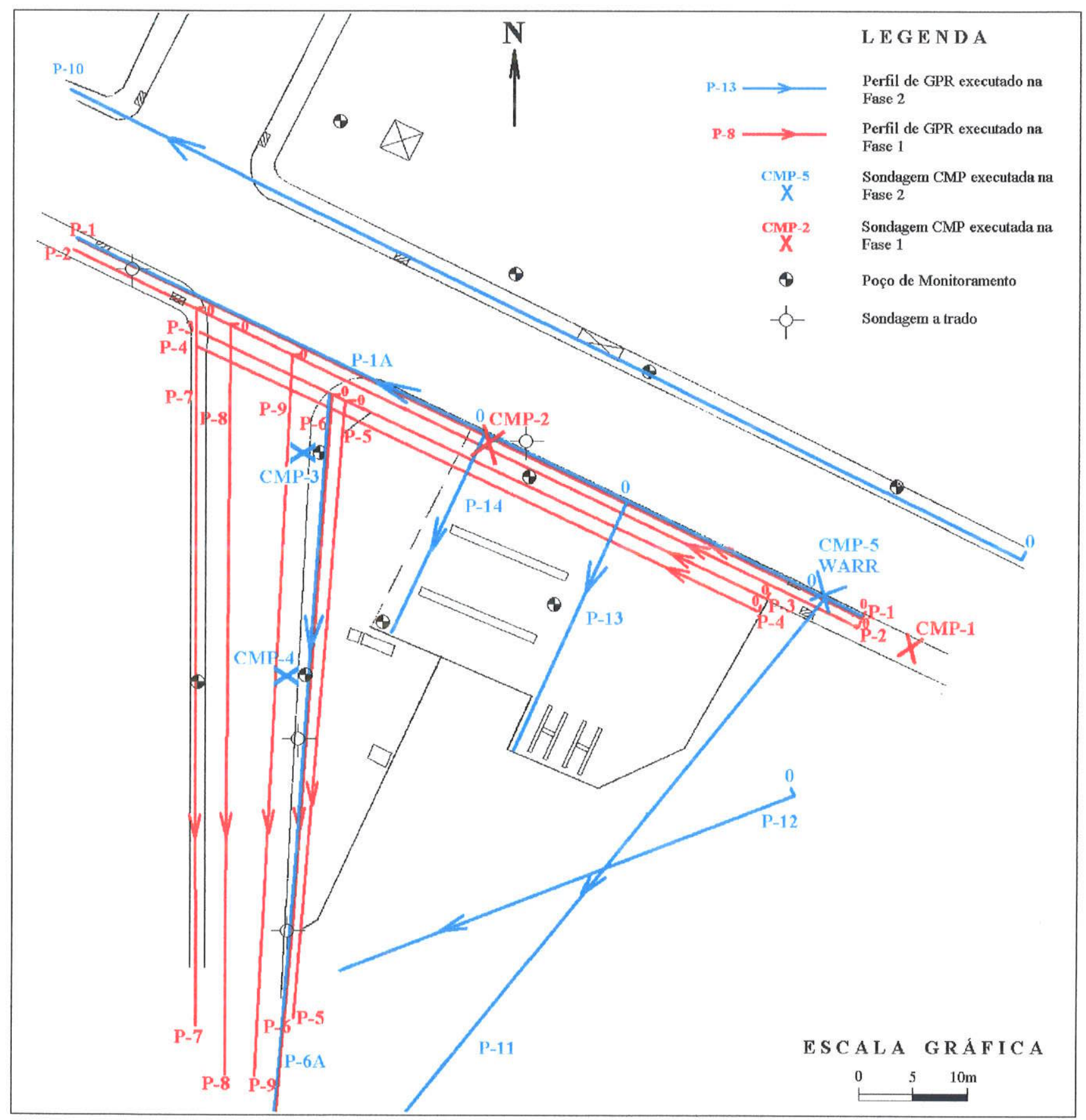

Figura D.7 - Esboço da área de estudo com a localização dos perfis e sondagens CMP do GPR 
Na primeira fase foram executadas 9 linhas (P-1 a P-9) totalizando em 585 metros com medidas a cada 0,1 metro e resultando 5830 traços, com a antena blindada de freqüência central 250MHz (Figura D.7). Foram realizadas duas sondagens CMP para análise de velocidade ao longo do perfil P-1, com afastamento inicial de $0,2 \mathrm{~m}$. A sondagem CMP-1 foi executada em área sem indício de contaminação (Foto 3) e a CMP-2 (Foto 4) sobre a parte relacionada à contaminação. Ambas sondagens foram feitas com as antenas de $200 \mathrm{MHz}$ (CMP-1_200 e CMP-2_200) e 100MHz (CMP-1_100 e CMP-2_100). O empilhamento ("stacking") foi de 128.

A segunda fase foi constituída da repetição de dois perfis da fase 1 ( $P-1$ e $P-6)$ e execução de cinco novos perfis: um a montante do posto $(P-10)$; dois no interior da serralheria vizinha ao posto (P-11 e P-12); dois perpendiculares ao perfil $\mathrm{P}-1$ no sentido do posto $(\mathrm{P}-13 \mathrm{e}$ P-14). Também foram realizadas três sondagens CMP (CMP-3, CMP-4 e CMP-5) e uma WARR, sendo esta última realizada no mesmo ponto da CMP-5 (Figura D.7). Neste caso o total de traços foi de 8690 em 934 metros de extensão. Nesta fase foram experimentados dois empilhamentos diferentes (128 e 256). O quadro D.1 apresenta um resumo do levantamento.

\section{Processamento}

O programa utilizado RADPRO, de acordo com suas características funcionais, é constituído basicamente de duas partes: processamento $e$ análise. No manual são apresentadas somente as diretrizes dos programas e propriedades de suas variáveis relevantes, sem descrição detalhada dos algoritmos utilizados.

Os dados levantados nos caminhamentos de reflexão e sondagens CMP e WARR foram processados pelo programa RADPRO. A seguir se descreve os passos que foram dados para se chegar à seção final dos caminhamentos de reflexão e sondagens CMP e WARR.

As seções de tempo por distância processadas, representativas dos perfis levantados com a antena blindada de $250 \mathrm{MHz}$ estão no Anexo $\mathrm{V}$ e com a antena blindada de $100 \mathrm{MHz}$ estão no Anexo VI. As seções referentes às sondagens CMP e WARR encontram-se no Anexo VII. 
Quadro D.1 - Extensão do levantamento de dados de GPR.

\begin{tabular}{|c|c|c|c|c|}
\hline \multirow[b]{2}{*}{ PERFIL } & \multicolumn{2}{|c|}{$\begin{array}{c}\text { FASEI } \\
\text { (antena blindada de } 250 \mathrm{MHz} \text { ) }\end{array}$} & \multicolumn{2}{|c|}{$\begin{array}{c}\text { FASE II } \\
\text { (antena blindada de } 250 \text { e } 100 \mathrm{MHz} \text { ) }\end{array}$} \\
\hline & $\begin{array}{l}\text { EXTENSÄO } \\
(m)\end{array}$ & $\begin{array}{c}\text { TRAÇOS } \\
\left(n^{2}\right)\end{array}$ & $\begin{array}{c}\text { EXTENSÁO } \\
(\mathrm{m})\end{array}$ & $\begin{array}{c}\text { TRAÇOS } \\
\left(n^{0}\right)\end{array}$ \\
\hline$P-1$ & 80,0 & 799 & $80,0^{*+}(P-1 A)$ & 799 \\
\hline$P-1 B$ & - & - & $80,0^{*^{++}}$ & 799 \\
\hline $\mathrm{P}-1 \mathrm{C}$ & - & - & $80,0^{* \star+}$ & 799 \\
\hline P-1D & - & - & $80,0^{* *++}$ & 799 \\
\hline $\mathrm{P}-2$ & 80,0 & 799 & - & - \\
\hline$P-3$ & 55,0 & 549 & - & - \\
\hline$P-4$ & 53,4 & 532 & - & $=$ \\
\hline P-5 & 56,6 & 564 & - & - \\
\hline P-6 & 57,8 & 576 & $57,8^{*++}(P-6 A)$ & 576 \\
\hline $\mathrm{P}-6 \mathrm{~B}$ & - & - & $57,8^{\star \star+}$ & 576 \\
\hline$P-7$ & 66,2 & 660 & - & - \\
\hline$P-8$ & 68,9 & 687 & - & $=$ \\
\hline P-9 & 66,7 & 665 & - & - \\
\hline $\mathrm{P}-10$ & - & - & $100,0^{\star++}$ & 997 \\
\hline P-10A & $\underline{-}$ & - & $100,0^{* *+}$ & 997 \\
\hline$P-11$ & - & $\underline{-}$ & $62^{\star++}$ & 613 \\
\hline $\mathrm{P}-11 \mathrm{~A}$ & $=$ & $\underline{-}$ & $62^{\star \star+}$ & 613 \\
\hline$P-12$ & $=$ & - & $43^{*++}$ & 423 \\
\hline$P-12 A$ & $=$ & - & $43^{* \star+}$ & 423 \\
\hline$P-13$ & $\overline{-}$ & $=$ & $24^{*++}$ & 229 \\
\hline$P-13 A$ & $=$ & $\overline{-}$ & $24^{\star \star *^{+}}$ & 229 \\
\hline$P-14$ & - & - & $20^{x+4}$ & 197 \\
\hline $\mathrm{P}-14 \mathrm{~A}$ & - & - & $20^{* *^{+}}$ & 197 \\
\hline Total Parcial & 584,6 & 5831 & 933,6 & 8690 \\
\hline TOTAL & \multicolumn{2}{|c|}{ Extensão $=1518,2 \mathrm{~m}$} & \multirow{2}{*}{\multicolumn{2}{|c|}{ Traços $=14521$}} \\
\hline \multicolumn{3}{|c|}{$\begin{array}{l}\text { "Linha executada com antena blindada de } 250 \mathrm{MHz} \\
* * \text { Linha executada com antena blindada de } 100 \mathrm{MHz}\end{array}$} & & \\
\hline${ }^{* *}$ Linha execute & com antena bli & de $100 \mathrm{MHz}$ & & \\
\hline \multirow{2}{*}{\multicolumn{5}{|c|}{$\begin{array}{l}{ }^{+} \text {Empilhamento }=128 \\
++ \\
+{ }^{++} \text {Empilhamento }=256\end{array}$}} \\
\hline Empilhament & & & & \\
\hline
\end{tabular}

\subsection{Determinação da velocidade}

Os tempos de chegada da reflexão na sondagem CMP possuem uma dependência hiperbólica (de primeira ordem) com a separação da antena. A análise do tempo em função da separação das antenas permite estimar a velocidade de propagação e a profundidade do alvo. Portanto, o cálculo da velocidade é feito com o objetivo de possibilitar a conversão das seções de tempo para profundidade. Neste caso, assume-se que o refletor é plano ao longo do perfil. O arranjo das antenas foi apresentado na Figura B.9 e a Figura D.8 representa o mesmo arranjo com o objetivo de calcular a profundidade do refletor. 


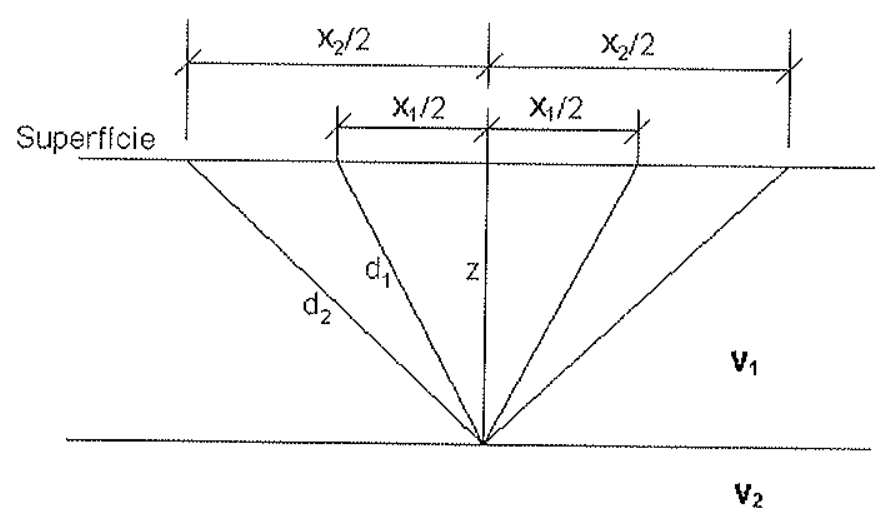

Figura D.8 - Representação da sondagem CMP para o cálculo da velocidade

Observando a figura D.8 e aplicando o teorema de Pitágoras pode-se chegar ao cálculo de $z$ (profundidade do refletor) pela seguinte expressão:

$$
z=\sqrt{\frac{x_{1}^{2} t_{2}^{2}-x_{2}^{2} t_{1}^{2}}{4\left(t_{1}^{2}-t_{2}^{2}\right)}}
$$

onde: $t_{1}$ e $t_{2}$ são, respectivamente, o tempo de percurso de $d_{1}$ e $d_{2}$.

Na seção da sondagem CMP obtida com o radar pode-se medir $x_{1}, x_{2}, t_{1}$ e $t_{2}$. Assim calcula-se a profundidade do primeiro refletor. Sabendo que $v=z /\left(t_{0} / 2\right)$, então definimos o valor da velocidade média $(v)$ onde $t_{0}$ se refere ao tempo de percurso do pulso quando a separação entre as antenas é zero" e pode ser medido na própria seção, sendo aproximadamente o tempo de chegada da hipérbole no primeiro traço. Com a velocidade definida pode-se então calcular a constante dielétrica do meio pelo qual o sinal se propagou pela equação (b.18) e, eventualmente, diferenciar o meio contaminado do meio não contaminado.

\subsubsection{Processamento utilizado nas seções das sondagens CMP}

As seções das sondagens CMP foram submetidas ao processamento no software RADPRO (1996) para melhorar a visualização dos sinais e eliminar ruídos, sendo assim possível a aquisição de dados de $t_{n}$ e $x_{n}$ com maior segurança. Os processamentos utilizados

\footnotetext{
* Na realidade, a sepação não é zero, mas considera-se o primeiro traço como se fosse referente à separação zero entre as antenas.
} 
foram "DC-Filter", "AGC" e "Filter". As seções das sondagens CMP processadas são apresentadas no Anexo VII.

O DC-Filter é utilizado para remover o ruido DC dos dados brutos, corrigir a posição do tempo zero e/ou apagar a primeira chegada de sinal a qual não está relacionada com algum evento de interesse.

Conforme os sinais de radar se propagam em subsuperficie são rapidamente atenuados. A grandes profundidades os sinais se tornam imperceptiveis ou praticamente somem. O AGC ("Automatic Gain Control") ou controle de ganho automático é um artifício matemático utilizado para compensar a rápida queda de amplitude no sinal de radar conforme atinge profundidades maiores. Neste caso, os ganhos são ajustados por estimativa de nível médio de sinal de todos os pontos da janela selecionada e então calcula-se o ganho que é inversamente proporcional ao nivel de sinal. Em áreas de sinais fracos o ganho é grande e em áreas de sinais altos o ganho é pequeno.

A técnica da filtragem ("Filter") é o ato de submeter um sinal a ação de um filtro*, pelo qual filtra-se a freqüência principal ao longo do eixo do tempo. Em muitos casos o sinal de radar a partir de pequenas feições tem diferentes freqüências em relação a estruturas escalarmente maiores de freqüências mais dominantes. Em adição é possível ter retorno de sinal a partir de feições no ar cuja freqüência, geralmente, será diferente da freqüência de sinais a partir de feições em subsuperfície. Pela filtragem pode-se separar a principal resposta ou remover sinais espúrios. O programa "Filter" pode executar três tipos de filtragem no domínio da freqüência que são corta altas, corta baixas e passa-banda.

\subsection{Processamento utilizado nas seções tempo-distância dos perfis de caminhamento}

Esta fase teve como diretrizes os seguintes passos:

a) eliminar ruídos coerentes e aleatórios detectados na análise espectral;

b) testar diferentes ganhos para compensar o espalhamento geométrico;

c) corrigir o tempo "zero" nas seções.

\footnotetext{
"Filtro (Duarte 1997) - designação genérica aplicável a qualquer agente capaz de alterar o espectro de amplitude ou fase dos dados. Os filtros são classificados em dois grandes grupos: lineares (convolutivos) e não lineares. Eles podem ser representados por dispositivos mecânicos, dispositivos elétricos ou algoritmos matemáticos.
} 
Primeiramente, executou-se uma análise espectral sobre os dados brutos, como análise preliminar do comportamento do sinal e para avaliar qual faixa de freqüencia seria representativa do sinal correspondente à resposta do meio, como também as frequências que corresponderiam a ruídos. Definida esta análise, processou-se as seções adquiridas com a antena blindada de $250 \mathrm{MHz}$ com "DC-Filter", "AGC" e "Filter". Já no caso das seções obtidas com a antena blindada de $100 \mathrm{MHz}$ foi aplicado o mesmo processamento acrescido do programa de deconvolução. A seqüência de passos e os parâmetros utilizados em cada programa são apresentados no Anexo VIII.

A deconvolução (programa "DECON" no Radpro, 1996) é aplicada com o objetivo de reduzir o efeito de reverberação ("ringing") e para aumentar a resolução espacial fazendo com que a "wavelet" seja afinada, ou seja, adquira uma forma compacta. Em adição, este programa pode eliminar múltiplas nos dados de reflexão.

Após os dados terem sido processados conforme os passos indicados anteriormente, partiu-se para uma nova análise espectral, desta vez com o intuito de avaliar a distribuição de energia em periodos e grupo de traços diferentes.

\subsubsection{Análise de espectro}

Este programa calcula e mostra o espectro de freqüência, utilizando dados da janela de tempo (ns) especificada pelo usuário, sobre o qual pode-se fazer uma análise da variação de amplitude do sinal em função da freqüência. O resultado calculado é a média do espectro dos traços de entrada ("input") especificados e suavização feita com a função janela de Hanning.

Os gráficos de análise espectral para trechos das seções de caminhamento com antena de $250 \mathrm{MHz}$ que apresentaram sinal relacionado com a contaminação e não apresentaram o mesmo estão no Anexo IX. A idéia de se fazer esta análise pós processamento tem o objetivo de se comparar como o sinal se comporta nos trechos representativos de contaminação (segundo a interpretação - item 6) em relação aos trechos que não apresentam sinal correspondente à contaminação. Para tanto, os traços foram separados em grupos relativos a trechos interpretados como locais contaminados e grupos de traços cuja interpretação não indicou contaminação. Esses grupos foram analisados em três períodos diferentes, de 0 a $30 \mathrm{~ns}$, de 30 a $60 \mathrm{~ns}$ e de 60 a 100ns, divididos desta maneira de acordo com observação do período onde se apresentou sinal relacionado à contaminação (principalmente entre 30 e 60ns) e período onde ela não ocorria ( 0 a 30ns e 60 a 100ns). 
O Anexo $X$ apresenta os gráficos relacionados à análise espectral de toda a seção em tempo e distância e os gráficos da análise espectral relacionados à porção da seção em tempo (30 a 60ns) que apresenta sinal relacionado à contaminação nas seções e para cada $1 / 10$ de traços, aproximadamente, da seção inteira. O intuito de produzir estes gráficos foi quantificar as amplitudes relacionadas à contaminação ou não contaminação em razão da amplitude total da seção e apresentar os valores em forma de mapas. Os mapas produzidos proporcionam uma interpretação quantificada da extensão da pluma de contaminação.

\section{Interpretação}

Parasnis (1997) comenta sobre essa atividade em uma frase curta mas bem colocada "enquanto a aquisição e processamento de dados podem ser referidos como uma questão de técnica, sua interpretação em termos de estrutura geológica é uma arte". Interpretação é uma atividade muito objetiva (no que depende da visualização de eventos na seção relacionados com o alvo de estudo) e ao mesmo tempo subjetiva (no que depende do indivíduo que está fazendo a interpretação).

Durante o processamento procurou-se identificar contrastes que poderiam ser indícios de contaminação. Neste caso a imagem típica que ocorreu foi a de ausência de sinal, na literatura em geral denominada por "zona de sombra" ou "apagão" (Nash et al., 1997; Bermejo et al., 1997; Aquino et al. 1998). Então a interpretação sobre os perfis feita a seguir se referirá a "zona de sombra" ou "apagão" quando se tratar de anomalia no sinal referente à contaminação.

A partir da seções do Anexo $V$ e gráficos de análise espectral (Anexo IX) foi feita uma interpretação de maneira visual e traçado um mapa delineando a pluma de contaminação de maneira qualitativa. Com os gráficos de análise espectral contidos no Anexo $X$ calculou-se a razão $(R A)$ da amplitude do trecho em tempo $\left(A_{s p}\right)$ onde visualizou-se "apagão" (30 a 60ns predominantemente) para cada $1 / 10$ dos traços em relação à amplitude de toda seção $\left(A_{s t}\right)$ em tempo e distância. Então delinearam-se dois mapas para representar a pluma de contaminação de maneira quantificada.

\subsection{Interpretação dos perfis e sondagens CMP}

A seguir são apresentadas as observações mais relevantes feitas sobre as seções tempo-distância e análise espectral produzidas. O objetivo dessas observações é contribuir 
com uma posterior análise dos dados que integre toda a interpretação às observações de campo relacionadas à contaminação.

Para facilitar a discussão, quando citada antena de $x \mathrm{MHz}$ (onde $x$ pode ser $250,200 \mathrm{ou}$ 100, no texto) utilizada, entenda-se por antena de freqüência central de $x \mathrm{MHz}$.

\subsubsection{Interpretação das sondagens CMP}

Como pode-se observar nas seções das sondagens CMP (Anexo VII) somente a CMP. 1, coincidentemente feita sobre local não contaminado, apresentou um refletor visível. Neste caso, ocorreu uma defasagem de tempo na seção correspondente à antena de $200 \mathrm{MHz}$ em relação à seção resultante feita com a antena de $100 \mathrm{MHz}$ na posição do refletor. A Tabela D.3 mostra como resultado dessa defasagem que o mesmo refletor ocorreu na seção a $1,1 \mathrm{~m}$ de profundidade quando medido com a antena de $200 \mathrm{MHz}$ e a $2,0 \mathrm{~m}$ com a antena de $100 \mathrm{MHz}$. Isso se dá devido à resolução vertical das antenas, sendo que a de $200 \mathrm{MHz}$ por possuir maior resolução provavelmente apresenta o resultado mais próximo da realidade.

A Tabela D.3 representa um resumo dos valores adquiridos nas seções de tempoxdistância das sondagens CMP, onde foi possivel identificar o refletor, e valores calculados de profundidade, velocidade e constante dielétrica.

Tabela D.3 - Relação dos valores calculados de profundidade ( $\mathrm{z}$ ), velocidade (v) e constante dielétrica $(\mathrm{K})$.

\begin{tabular}{|c|c|c|c|c|c|c|c|c|}
\hline CMP-1_200 & $\begin{array}{c}\mathbf{t}_{0} \\
\text { (ns) }\end{array}$ & $\begin{array}{c}\mathbf{t}_{1} \\
(n s)\end{array}$ & $\begin{array}{l}\mathbf{X}_{1} \\
(\mathrm{~m})\end{array}$ & $\begin{array}{c}t_{2} \\
\text { (ns) }\end{array}$ & $\begin{array}{c}\mathbf{X}_{2} \\
(\mathrm{~m})\end{array}$ & $\begin{array}{c}\mathbf{z} \\
(\mathrm{m})\end{array}$ & $\begin{array}{c}\mathrm{v} \\
(\mathrm{m} / \mathrm{ns})\end{array}$ & $\mathrm{K}$ \\
\hline Refletor & 27 & 28 & 0,8 & 34 & 1,8 & 1,1 & 0,08 & 14,06 \\
\hline \multicolumn{9}{|l|}{ CMP-1_100 } \\
\hline Refletor & 39 & 42 & 1,1 & 47 & 2,35 & 1,99 & 0,102 & 9,0 \\
\hline
\end{tabular}

Sobre a sondagem WARR pode-se dizer que da mesma maneira que ocorreu com a CMP-5, não foi possivel observar algum refletor, mas foi possivel identificar sinais correspondentes a camadas inclinadas no local.

Sendo assim, a velocidade determinada na sondagem CMP-1 não pôde ser aplicada para conversão de tempo em profundidade nas seções, pois provavelmente este valor 
corresponde à área não contaminada. Outra observação importante é que a velocidade definida neste caso e, consequentemente, a constante dielétrica deve ser considerada como característica de meio não contaminado no local.

O outro caminho para se determinar a velocidade do meio seria o inverso, ou seja, identificar o refletor correspondente ao topo da camada saturada na seção e assim converter o tempo para profundidade utilizando a profundidade do nível d'água conhecida em alguns pontos ao longo das seções.

As seções dos perfis de caminhamento de reflexão (Anexos $V$ e $V I$ ) apresentam um refletor no tempo de $25 \mathrm{~ns}$ a $30 \mathrm{~ns}$ na maioria dos perfis com exceção dos perfis P-7 e P-10 onde o refletor ocorre entre 44 e $47 \mathrm{~ns}$, aproximadamente. Assumindo-se esse refletor como topo da camada saturada e consultando a Tabela D.1 sobre o nivel d'água medido em alguns pontos ao longo dos perfis na data mais próxima ao levantamento (19/01/2001), então converte-se a seção de tempo para profundidade. A Tabela D.4 apresenta os dados utílizados para o cálculo da velocidade e constante dielétrica ao longo destes perfis.

Tabela D.4 - Relação dos dados e valores calculados de velocidade (v) e constante dielétrica (K).

\begin{tabular}{c|c|c|c|c}
\hline Perfil & $\begin{array}{c}\text { Tempo de registro do } \\
\text { refletor } \\
(\mathrm{ns})\end{array}$ & $\begin{array}{c}\text { Profundidade do } \\
\text { nível d'água } \\
(\mathrm{m})\end{array}$ & $\begin{array}{c}\text { Velocidade } \\
\text { calculada } \\
(\mathrm{m} / \mathrm{ns})\end{array}$ & $\begin{array}{c}\text { Constante } \\
\text { dielétrica }\end{array}$ \\
\hline $\mathrm{P}-1 \mathrm{~A}$ & 30 & $\begin{array}{c}1,77^{*} \\
\text { (PR1,PR2, PR3, PR4, } \\
\text { PR5, PM4 e F1) }\end{array}$ & 0,118 & 6,46 \\
\hline $\mathrm{P}-6 \mathrm{~A}$ & 25 & $\begin{array}{c}1,485^{*} \\
\text { (PM5, PM6 e F4) }\end{array}$ & 0,119 & 6,36 \\
\hline $\mathrm{P}-7^{* *}$ & 44 & $\begin{array}{c}1,96 \\
(\mathrm{PM})\end{array}$ & 0,089 & 11,36 \\
\hline $\mathrm{P}-10$ & 47 & $\begin{array}{c}2,155^{*} \\
\text { (PMAdc1 e PM1) }\end{array}$ & 0,092 & 10,60 \\
\hline $\mathrm{P}-13$ & 26 & $\begin{array}{c}1,90 \\
\text { (PMAdc2) }\end{array}$ & 0,146 & 4,22 \\
\hline $\mathrm{P}-14$ & 26 & $\begin{array}{c}1,92 \\
\text { (PMAdc3) }\end{array}$ & 0,148 & 4,10 \\
\hline
\end{tabular}

*valores calculados a partir da média de profundidade de nível d'água dos poços existentes ao longo do perfil (referenciados entre parêntesis)

** perfil executado em 05/07/2000 (periodo de clima seco) 
Com os resultados da Tabela D.4 observa-se que seria possivel converter somente algumas seções de tempo para profundidade, pois esses valores diferem entre si e assim não é possivel generalizar. Portanto, a discussão sobre as seções serão feitas em termos de tempo.

\subsubsection{Interpretação das seções tempo-distância dos caminhamentos de reflexão}

A interpretação apresentada aqui é baseada nas seções dos perfis de caminhamento de reflexão contidas nos Anexos $\mathrm{V}$ e VI (antena blindada de $250 \mathrm{MHz}$ e de $100 \mathrm{MHz}$, respectivamente). Deve-se ter em mente que nas seções, o eixo " $y$ " representa o tempo que o pulso levou para chegar no refletor a partir da antena transmissora e voltar para a antena receptora. Outra observação importante é que a primeira chegada está relacionada com a onda direta, a qual viaja pela superficie entre a antena transmissora e receptora, sendo o primeiro sinal que se apresenta ao longo da seção semelhante a um refletor, o qual não será levado em consideração na discussão.

A interpretação dos perfis será dividida em dois itens: o primeiro constituirá a interpretação dos perfis levantados com a antena blindada de $250 \mathrm{MHz}$ e o segundo com os perfis levantados com a antena blindada de $100 \mathrm{MHz}$.

\subsubsection{Interpretação dos perfis levantados com a antena blindada de $250 \mathrm{MHz}$ \\ Como pode ser observado nas figuras do Anexo $V$ as "zonas de sombra" foram assinaladas de maneira aproximada. Os perfis P-1, P-2, P-3, P-4, P-5, P-6, P-13 e P-14 apresentaram as denominadas "zonas de sombra", as quais são interpretadas no nosso estudo como indício de contaminação por gasolina. Os perfis P-1A, P-1B e P-6A também apresentaram "zona de sombra" o que era de se esperar já que trata-se da repetição dos perfjs P-1 e P-6, como já foi citado no item sobre levantamento de dados de GPR. Estas anomalias foram assinaladas nas figuras das seções.}

Esta ausência de sinal ocorreu de forma mais evidente nos perfis P-1, P-6, P-13 e P-14. As anomalias ocorreram principalmente entre 30 e $60 \mathrm{~ns}$.

O aspecto dos perfis P-7, P-8, P-9 será considerado como representativo do "background" na área de estudo, pois nestes casos não se apresenta "zona de sombra". 
Um outro grupo de perfis constituído por P-10, P-11 e P-12 apresenta esta anomalia de forma bem sutil em relação ao restante.

Outra observação interessante deve ser feita sobre os perfis P-3, P-4, P-13 e P-14, os quais mesmo sendo feitos dentro da área do Posto, cujo piso é construído com malha de ferro e concreto de $40 \mathrm{~cm}$ de espessura, foi possível visualizar a "zona de sombra".

A Tabela D.5 apresenta, aproximadamente, um resumo dos trechos (em tempo e distância) em que ocorreram "zona de sombra" de forma mais evidente nos perfis.

Conforme procura-se comparar as seções de perfis repetidos nas duas fases, observase que os perfis P-1 e P-1A são similares, no entanto o P-1B indica uma "zona de sombra" mais abrangente. $O$ mesmo pode ser observado entre o P-6 e o P-6A. Coincidentemente, os perfis $P-1, P-1 A$ e $P-6$ foram levantados com empilhamento 128 , como pode ser verificado na Tabela D.3, enquanto os perfis P-1B e P-6A com empilhamento 256, o que deve explicar a diferença na visualização da zona de sombra.

Tabela D.5 - Trechos em tempo e distância da zona de sombra nos perfis

\begin{tabular}{c|c|c}
\hline $\begin{array}{c}\text { Perfil } \\
\left(n^{\circ}\right)\end{array}$ & $\begin{array}{c}\text { Tempo } \\
(\mathrm{ns})\end{array}$ & $\begin{array}{c}\text { Distância } \\
(\mathrm{m})\end{array}$ \\
\hline P-1 & 30 a 65 & 9 a 55 \\
\hline P-1A & 30 a 65 & 9 a 55 \\
\hline P-1B & 30 a 80 & 5 a 60 \\
\hline P-2 & 30 a 60 & 10 a 52 \\
\hline P-3 & 30 a 60 & 5 a 45 \\
\hline P-4 & 30 a 50 & 0 a 45 \\
\hline P-5 & 30 a 55 & 0 a 45 \\
\hline P-6 & 30 a 60 & 0 a 45 \\
\hline P-6A & 30 a 70 & 0 a 55 \\
\hline P-13 & 30 a 60 & 0 a 24 \\
\hline P-14 & 25 a 60 & 0 a 20 \\
\hline
\end{tabular}




\subsubsection{Interpretação dos perfis levantados com a antena de $100 \mathrm{MHz}$}

A observação de "zonas de sombra" nas seções dos perfis executados com antena blindada de $100 \mathrm{MHz}$ (Anexo VI) já não é tão evidente como no caso anterior. Isto provavelmente se explica pela diminuição de resolução ao se utilizar esta antena. Mesmo assim é possivel observar esta anomalia de forma bem sutil nos perfis P-1C, P-1D, P-6B, P13A e P14-A.

O início no eixo do tempo das "zonas de sombra" nestas seções ocorre em 40ns, apresentando um atraso em média de $10 \mathrm{~ns}$ em relação ao tempo observado nas seções de $250 \mathrm{MHz}$. Isso se dá provavelmente devido à resolução menor da antena de $100 \mathrm{MHz}$ em
relação a outra antena.

No perfil P-1D executado com empilhamento 256, observa-se um "apagão" mais evidente do que no P-1C feito com empilhamento 128.

\subsection{Interpretação da análise espectral}

As análises de espectro feitas com intuito de verificar e comparar o comportamento do sinal relacionado à contaminação com sinal relacionado à não contaminação (após as seções terem sido processadas) foram executadas sobre os dados levantados com a antena blindada de $250 \mathrm{MHz}$, pois através destes dados foi possivel visualizar de forma significativa os contrastes, enquanto com os dados levantados com a antena de $100 \mathrm{MHz}$ isto não ocorreu.

Foram produzidos três grupos de gráficos para cada perfil que apresentou "zona de sombra" de forma mais evidente. Um grupo de gráficos representa a análise espectral feita para toda seção em três períodos de tempo diferentes (0-30, 30-60 e 60-100ns) subdivididos de acordo com a ocorrência da "zona de sombra", predominantemente entre 30 e $60 \mathrm{~ns}$. Um segundo grupo é constituído pela análise espectral feita sobre o trecho de traços que apresentou "zona de sombra" e para os mesmos periodos analisados no grupo anterior. Um terceiro grupo de gráficos representa a análise espectral feita em trecho desprovido de contaminação, ou seja, sem "zona de sombra".

De acordo com os gráficos apresentados no Anexo IX, a principal observação é que as análises feitas sobre a parte contaminada mostram que a freqüência de maior amplitude praticamente se mantém igual do ponto de vista energético nos dois últimos períodos analisados (30-60ns e 60-100ns). Como comparação, quando essa mesma análise é realizada 
sobre o grupo de traços correspondentes à área não contaminada (sem "zona de sombra") ocorre uma diminuição de amplitude relativamente grande no último período de tempo (60100ns), comportamento similar ao da seção inteira.

\section{Análise dos dados}

A seguir faz-se uma análise das interpretações consideradas mais relevantes do ponto de vista dos objetivos do estudo. Portanto, as seções produzidas a partir do levantamento com a antena blindada de $100 \mathrm{MHz}$ não será analisada aqui, pois os dados não proporcionaram subsídios da mesma forma que os dados da antena de $250 \mathrm{MHz}$ para estudar a contaminação no local.

\subsection{Análise de velocidade}

A ausência de refletores na maior parte das sondagens CMP, com exceção da CMP-1 feita sobre local não contaminado, pode ser considerada como um indício da contaminação em

Com os resultados da Tabela D.4, construiu-se um gráfico (Figura D.9) para representar e assim visualizar o comportamento da velocidade e constante dielétrica ao longo dos perfis que apresentaram contaminação e dos que não apresentaram.

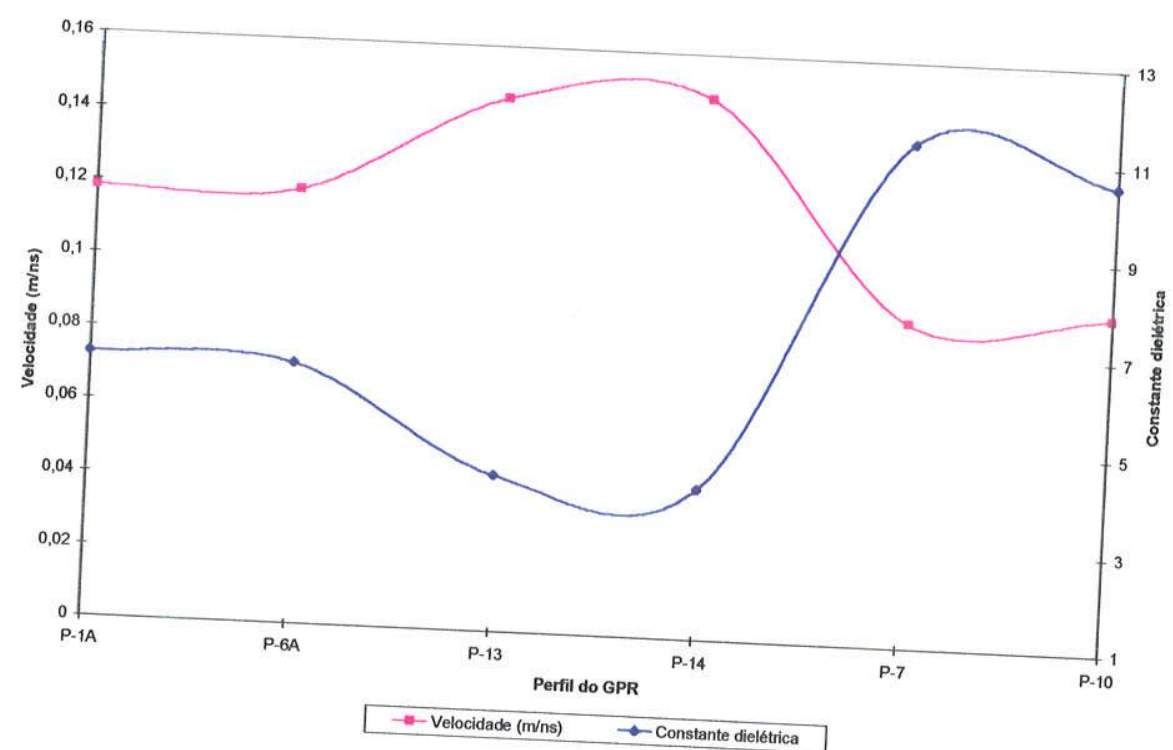

Figura D.9 - Gráfico representativo do comportamento da velocidade e constante dielétrica
calculados nos perfis 
Relembrando que a velocidade foi calculada de maneira aproximada por $v=c /(K)^{1 / 2} e$ considerando a constante dielétrica da gasolina aproximadamente $K=2$, a velocidade e constante dielétrica calculadas nos perfis $\mathrm{P}-1 \mathrm{~A}, \mathrm{P}-6 \mathrm{~A}, \mathrm{P}-13$ e $\mathrm{P}-14$ parecem estar relacionadas com a contaminação, constituída de fase livre, adsorvida e vapor, que preenchem os poros em subsuperfície e, ao mesmo tempo, expulsa parte da água contida nestes poros (Oliveira, 1997) o que diminuiria a constante dielétrica do meio e, conseqüentemente, causaria um aumento de velocidade da propagação do pulso por este meio. Observando as curvas da Figura D.9 notase que os perfis P-7 e P-10 apresentam velocidade relativamente menor e constante dielétrica maior, sendo que estes valores podem ser considerados de "background" para área de estudo. Outra observação interessante é que no perfil P-7, mesmo sendo executado em época de clima seco e, portanto, com menos água no meio em subsuperfície, possui $\mathrm{K}$ maior.

Os valores de constante dielétrica calculados para os perfis P-13 e P-14 são relativamente baixos e indicam que nestes locais provavelmente o nível de contaminação é maior. Esta observação está de acordo com a amostragem e medida de condutividade elétrica da água dos poços PMAdc-2 e 3, que apresentaram fase livre e condutividade zero (Foto 7 ).

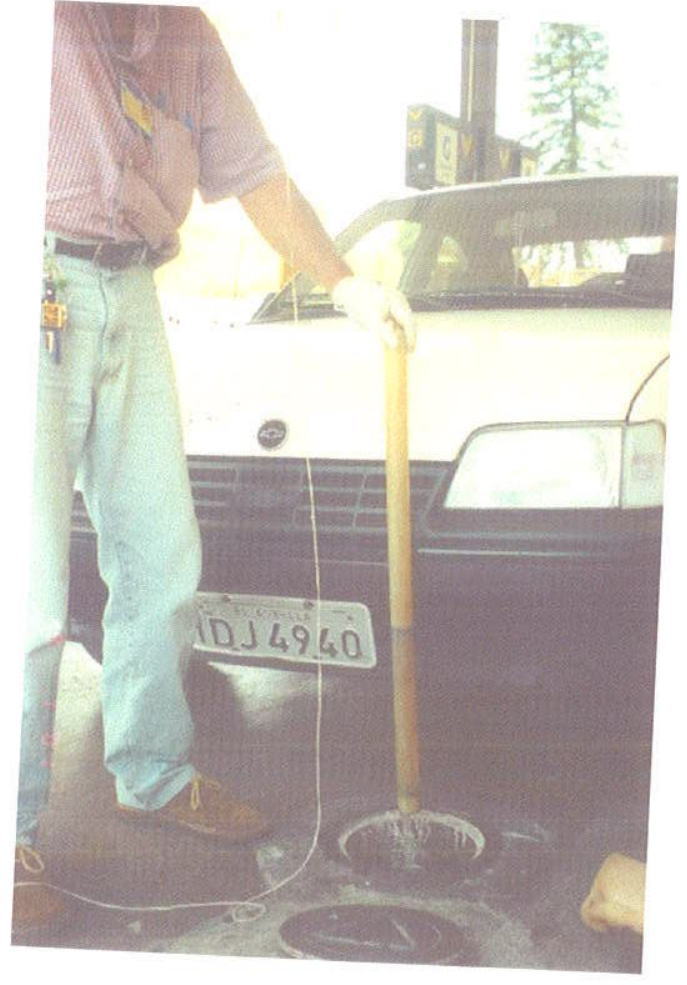

(a)

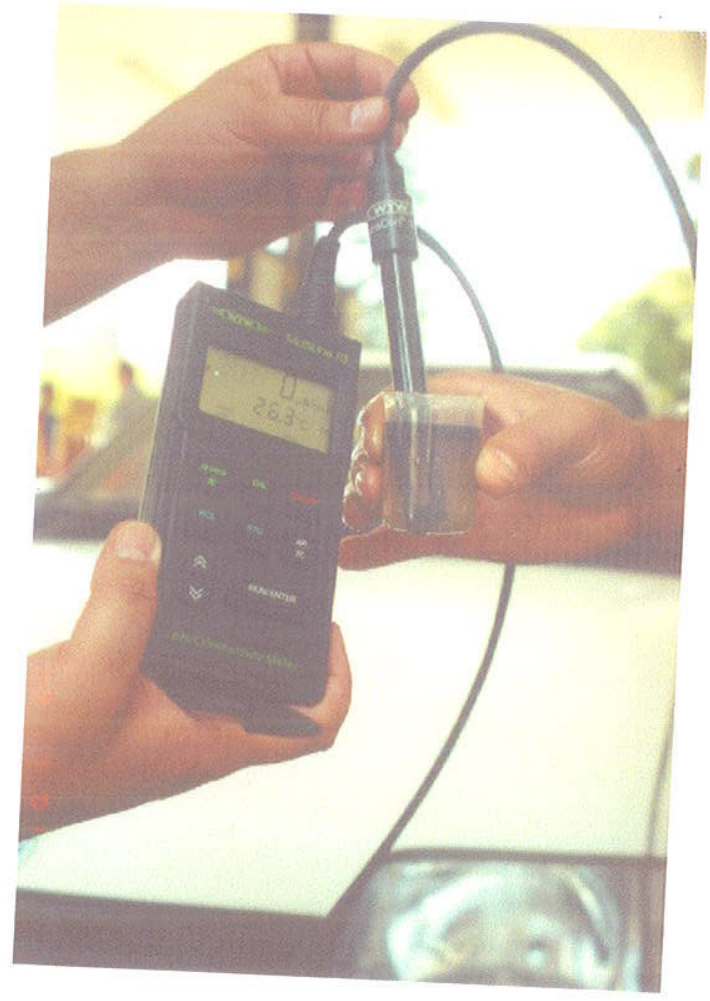

(b)

Foto 7 - (a) Constatacão da existenc 


\subsection{Análise das seções tempo-distância}

De acordo com a interpretação feita a partir das seções dos perfis levantados nas duas fases com a antena blindada de $250 \mathrm{MHz}$ foi possível delinear a pluma de contaminação na área de estudo como pode ser visto na Figura D.10. Com este esboço sugere-se que a pluma de contaminação é maior do que a indicada por métodos diretos, estendendo-se para parte sudoeste da área de estudo. Neste caso, consideram-se as duas fases do levantamento, já que o período entre elas foi relativamente pequeno (6 meses) e principalmente porque os perfis executados nas duas fases não mostraram mudanças significativas.

A partir da interpretação foram feitas sondagens a trado para confirmação da mesma. Então, foi possível verificar o acerto da interpretação pois a sondagem F-1 feita na parte interpretada como não contaminada do perfil P-1 (Foto 8) realmente não apresentou indícios de contaminação ao longo da mesma. Já as sondagens F-4, F-6 e F-7 (Fotos 9 a 11), locadas em trechos interpretados como contaminados apresentaram indícios de contaminação como pode ser verificado nas descrição das sondagens contida na Tabela A-III.2 no Anexo III. A constatação da contaminação nestas sondagens foi feita pelo odor nas amostras de solo. A sondagem F-4 também apresentou fase livre de gasolina (Foto 9b) e medida de condutividade elétrica zero (Foto 10), provavelmente devido à fase dissolvida do contaminante na água.

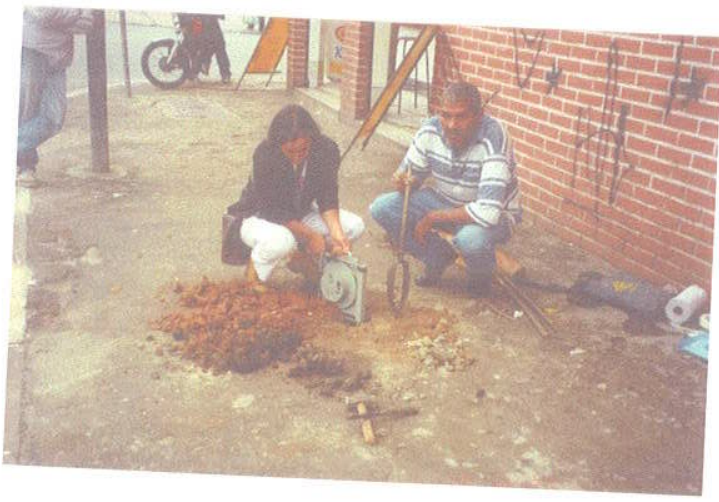

(a)

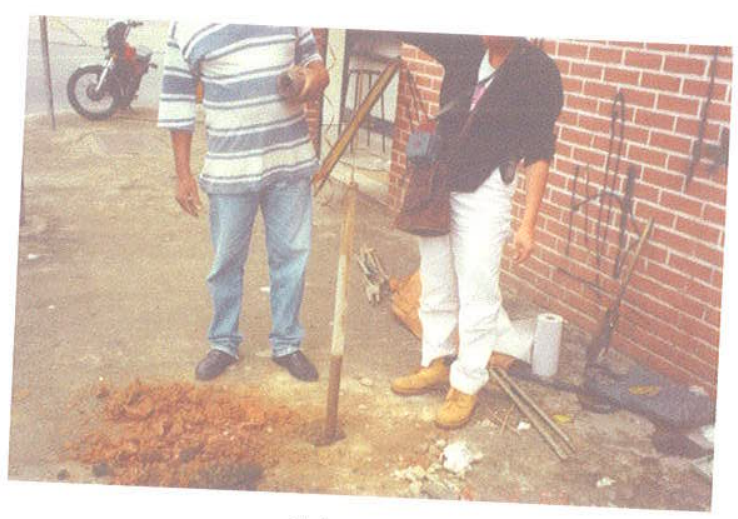

(b)

Foto 8 - (a) Medida do nível d'água com o medidor de interface na sonc verificação de ocorrência de lâmina com o medidor de interface na sondagem a trado F-1 e (b) trado F-1

Como citado no item anterior, a ocupação do contaminante no meio poroso em subsuperfície simultaneamente à "retirada" parcial da água desse meio (Oliveira, 1997) 
provavelmente causa uma "homogeneização" do ponto de vista eletromagnético, pois materiais geológicos desprovidos de água possuem constante dielétrica baixa, como pode ser visto na tabela B.1 e nos valores do Anexo I, ao mesmo tempo a constante dielétrica da gasolina é baixa. Desta forma, a homogeneização do meio é causada pela diminuição da constante dielétrica e faz com que a propagação do sinal não sofra reflexões, o que explicaria a ausência de sinal na parte contaminada das seções.

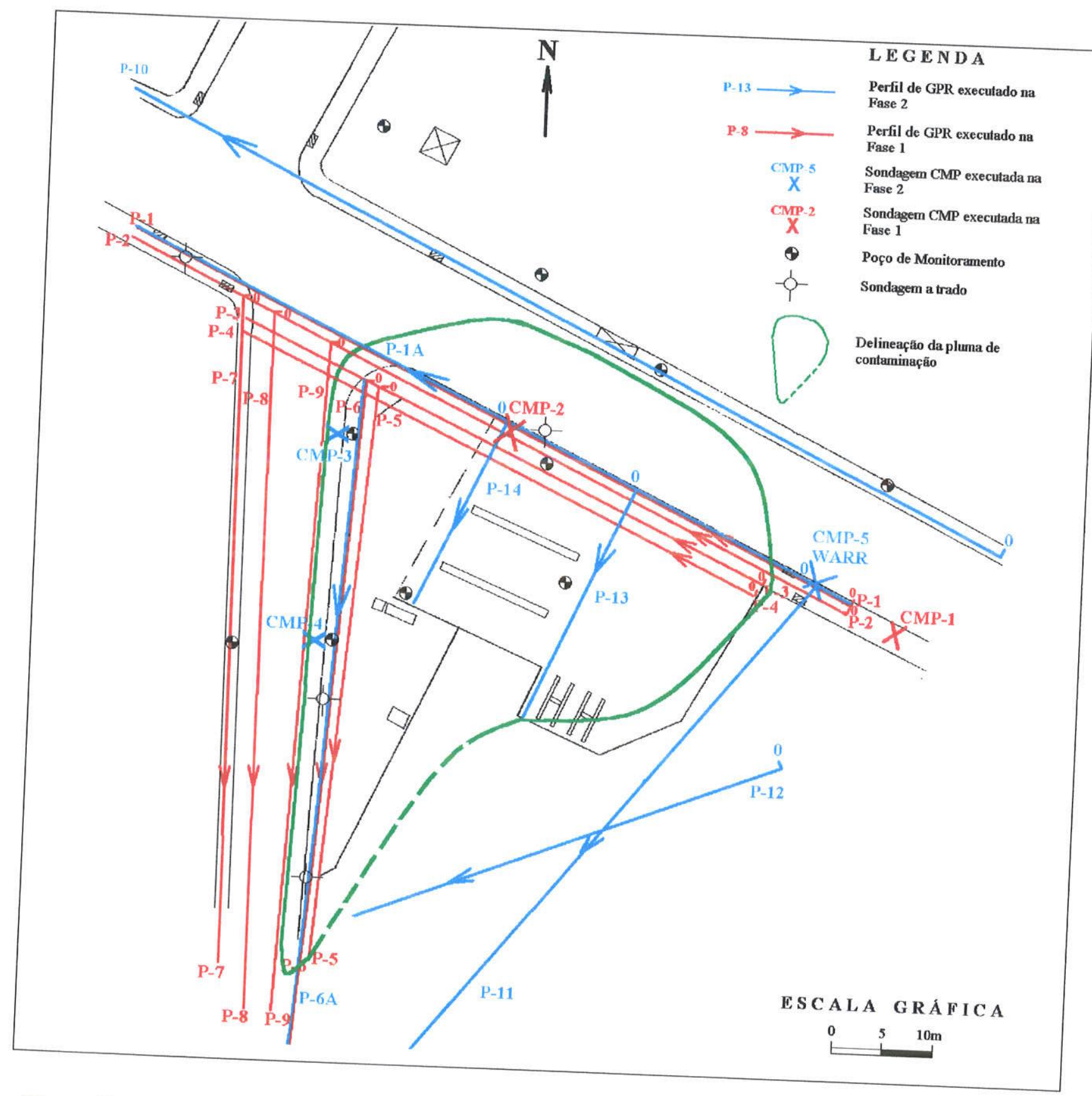
Figura D.10 - Esboço da área de estudo com delineação da pluma de contaminação de acordo
com interpretação visual dos dados de GPR 
Sobre a parte oeste da pluma, cujo desenho de uma linha retilínea não é comum nesse tipo de estudo, pode ser explicada pela existência de uma caixa subterrânea no local que provavelmente recebe o contaminante e limita a sua ocorrência em subsuperfície.

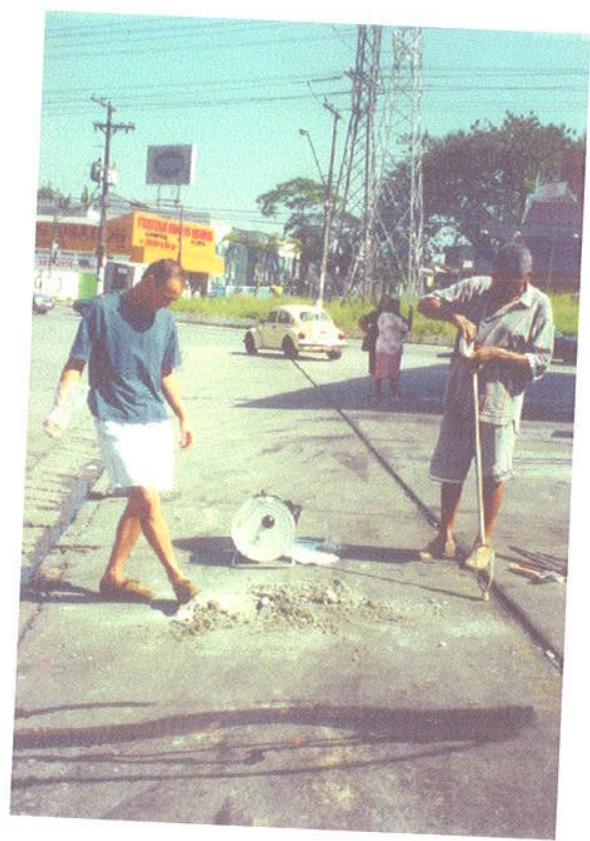

(a)

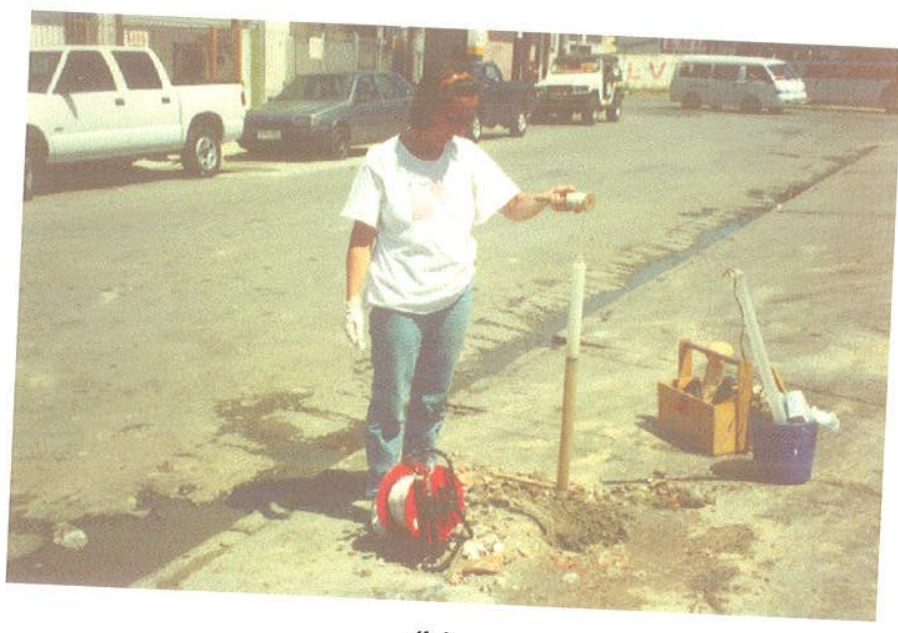

(b)

Foto 9 - (a) Execução da sondagem a trado F-4 e (b) constatação de existência de lâmina de fase livre com amostrador transparente na sondagem a trado F-4

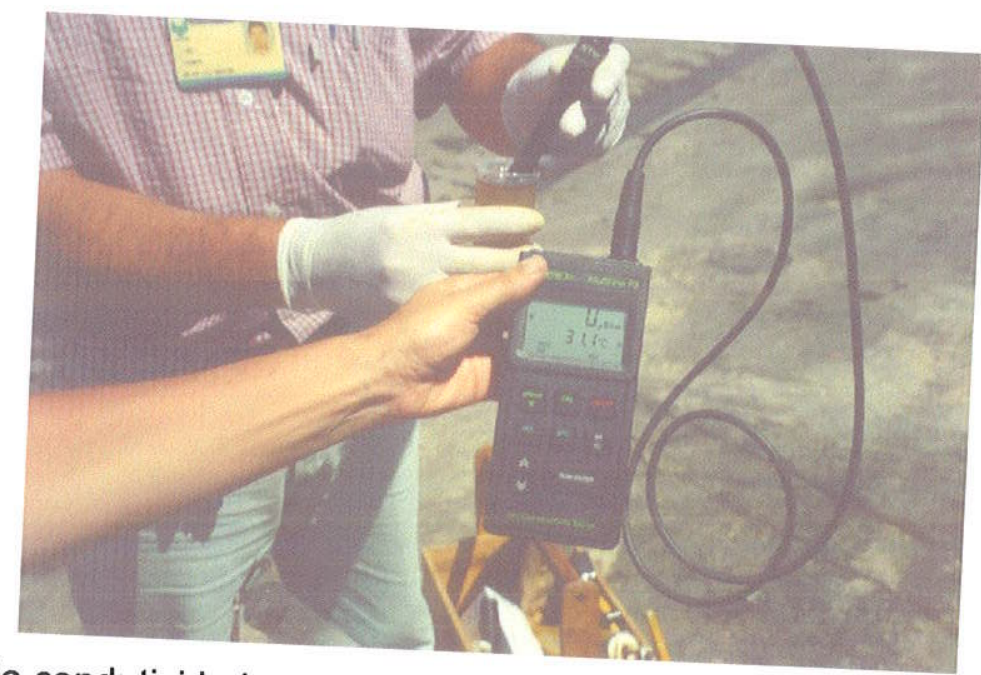

Foto 10 - Medida de condutividade elétrica zero da água amostrada da sondagem a trado F-4 


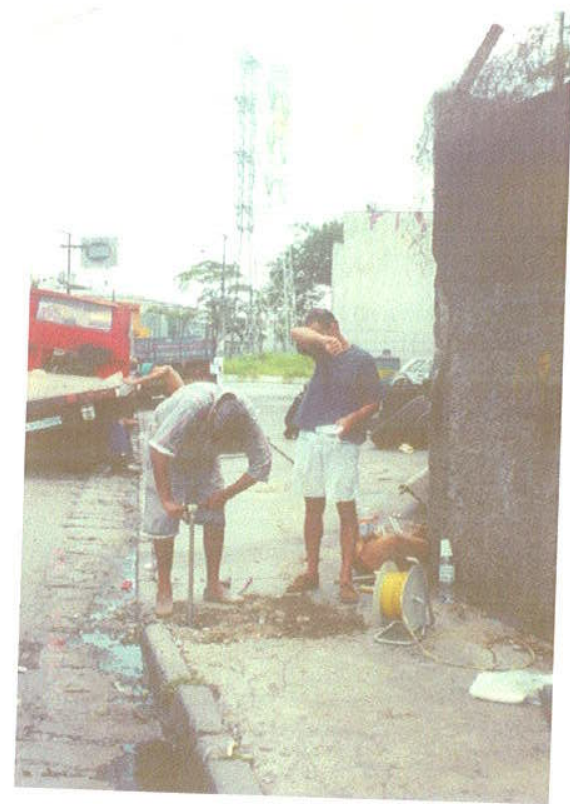

(a)

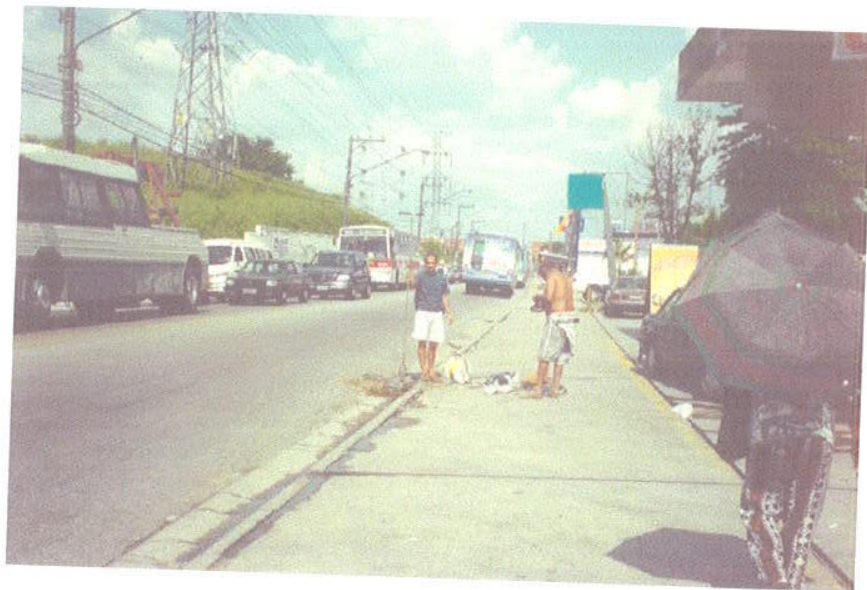

(b)

Foto 11 - (a) Execução da sondagem a trado F-6 e (b) Execução da sondagem a trado F-7

\subsubsection{Análise espectral}

A análise espectral apresentada através de gráficos contidos no Anexo IX feita de modo a comparar o comportamento do sinal em trechos que apresentaram "zona de sombra", tanto espacialmente como temporalmente, mostra que o conteúdo energético do sinal não sofre mudanças significativas como ocorre nos trechos que não apresentam "zona de sombra".

A manutenção de conteúdo energético até o final da seção em tempo na parte correspondente à contaminação provavelmente ocorre devido à homogeneização do meio com a presença de hidrocarbonetos e, consequentemente, o sinal se propaga sem reflexões. Neste caso não há perda de energia pois além do pulso não ser refletido de volta para a superfície o meio se torna mais resistivo eletricamente em função da presença do hidrocarboneto e retirada de parte da água, o que pode explicar as observações feitas na análise espectral.

A análise feita foi baseada na interpretação visual da contaminação nas seções e proporcionou bons resultados pois foi possível diferenciar na análise espectral os contrastes detectados qualitativamente. Outro procedimento de se fazer análise espectral de forma que fosse possível quantificar a contaminação proporcionou os mapas apresentados nas Figuras D.11 e D.12. 

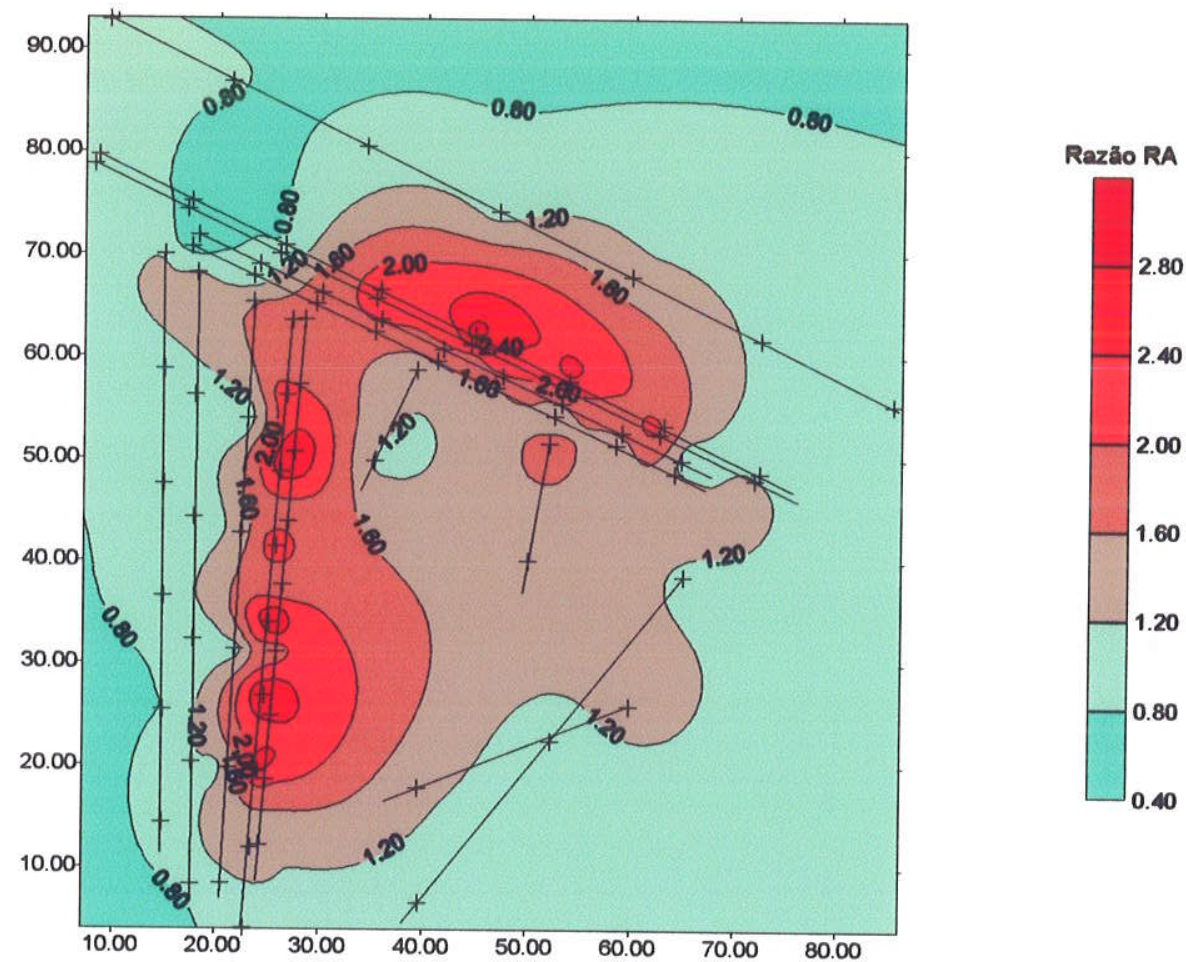

Figura D.11 - Mapa de isolinhas para representar a distribuiçăo de RA

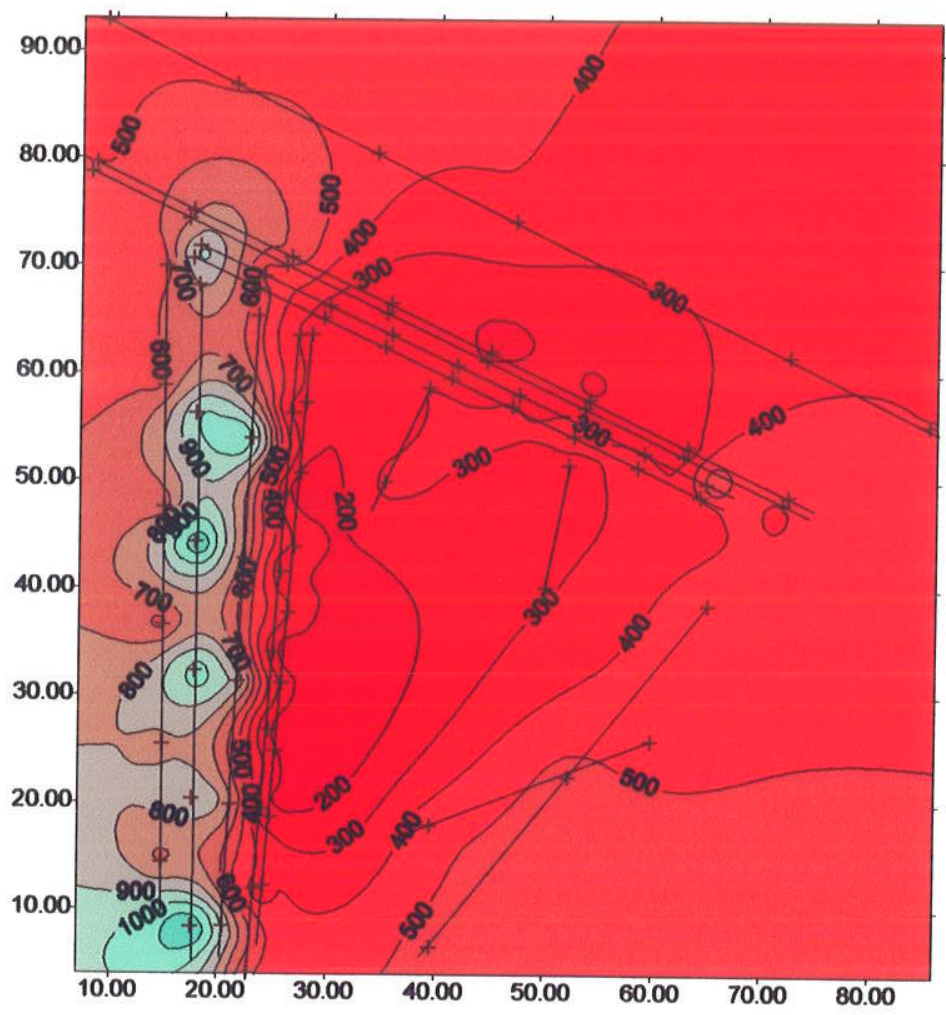

Valor de Asp

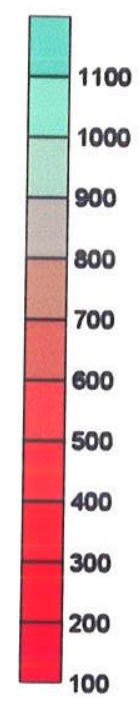

Figura D.12 - Mapa de isolinhas para representar a distribuição dos valores de Asp 
O mapa da Figura D.11 representa a distribuição de valores RA (=razão entre amplitudes) calculados e interpolados a partir da razão de amplitude da seção parcial $\left(A_{s p}\right)$ em relação à amplitude da seção total $\left(A_{s t}\right)$.

$$
R A=\frac{A_{s t}}{A_{s p}}
$$

A $A_{s p}$ foi medida a partir da análise espectral feita sobre o período de tempo que apresentou zona de sombra (30 a 60ns) e para cada 1/10 de traços, aproximadamente, da seção de cada perfil. A $A_{s t}$ corresponde à amplitude do espectro de toda seção (em tempo e distância). Os gráficos desta análise encontram-se no Anexo $X$. Os valores de $R A$ foram "plotados" no ponto médio do trecho correspondente a $1 / 10$ dos traços.

Os gráficos indicam que os valores $A_{s p}$ de trechos com zona de sombra são menores do que o valor de $A_{s t}$ do respectivo perfil. Portanto, valores de $R A$ maiores do que um $(R A>1)$ estão relacionados à zona de sombra, em geral. Outra observação é que conforme a zona de sombra é mais abrangente na seção o valor de $A_{s t}$ é menor se comparado aos das seções sem zona de sombra. Isto faz com que uma seção que apresenta zona de sombra em toda sua extensão (como os perfis $\mathrm{P}-13$ e P-14) apresentem um valor de $R A$ menor do que outra seção que apresente zona de sombra somente em um trecho. Então valores de $R A$ maiores não correspondem a uma extensão de contaminação maior. Mesmo assim estes valores "plotados" e interpolados proporcionaram a delineação da pluma de contaminação como pode ser visto na Figura D.11.

O mapa da Figura D.12 corresponde à distribuição de valores de $A_{s p}$. Neste caso os valores menores estão relacionados à zona de sombra. $O$ valor máximo de $A_{s p}$ usado como referência para limitar a pluma de contaminação é 400, o qual representa o menor valor de $A_{s t}$ dentre os perfis considerados de "background". No caso foi considerado o valor do perfil P-10. Portanto, pode-se considerar que a pluma está concentrada principalmente na região do mapa que indica valores iguais ou menores do que 400. Devido ao processo de interpolação, a pluma está extrapolada no canto superior direito do mapa da Figura D.12. Neste caso, a limitação da pluma de acordo com o mapa da Figura D.11 provavelmente se aproxima mais da pluma existente no local.

Comparando o esboço da pluma de contaminação da Figura D.10 feito de maneira subjetiva com as delineasses apresentadas nas Figuras D.11 e D.12, verifica-se que os três mapas são similares, mas no primeiro mapa a parte superior da pluma desenhada ficou restrita 
à avenida não chegando a atingir o trecho do perfil P-10, como ocorre nos outros dois mapas. Isto é mais um fator que valoriza o critério numérico estabelecido, já que segundo amostragem de água e medida de condutividade elétrica da água do PMAdc-1, ocorre fase livre e dissolvida no local (Foto 12 e 13).

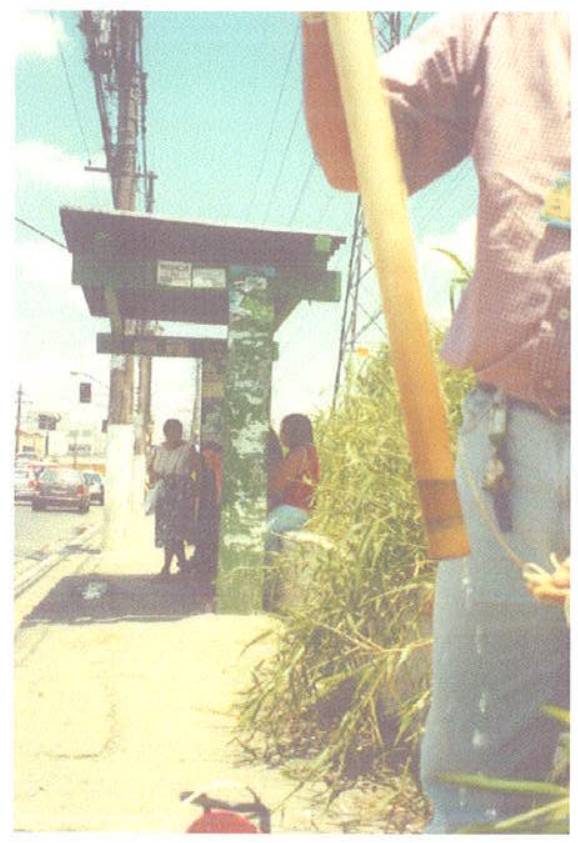

(a)

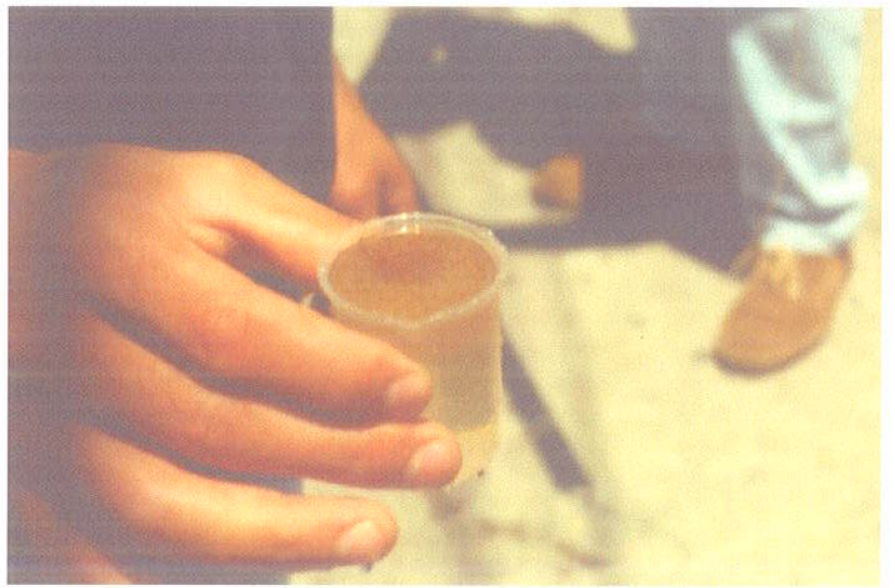

(b)

Foto 12 - (a) constatação de existência de lâmina de fase livre com amostrador transparente no PMAdc-1 e (b) amostra de água do PMAdc-1 para medida de condutividade elétrica

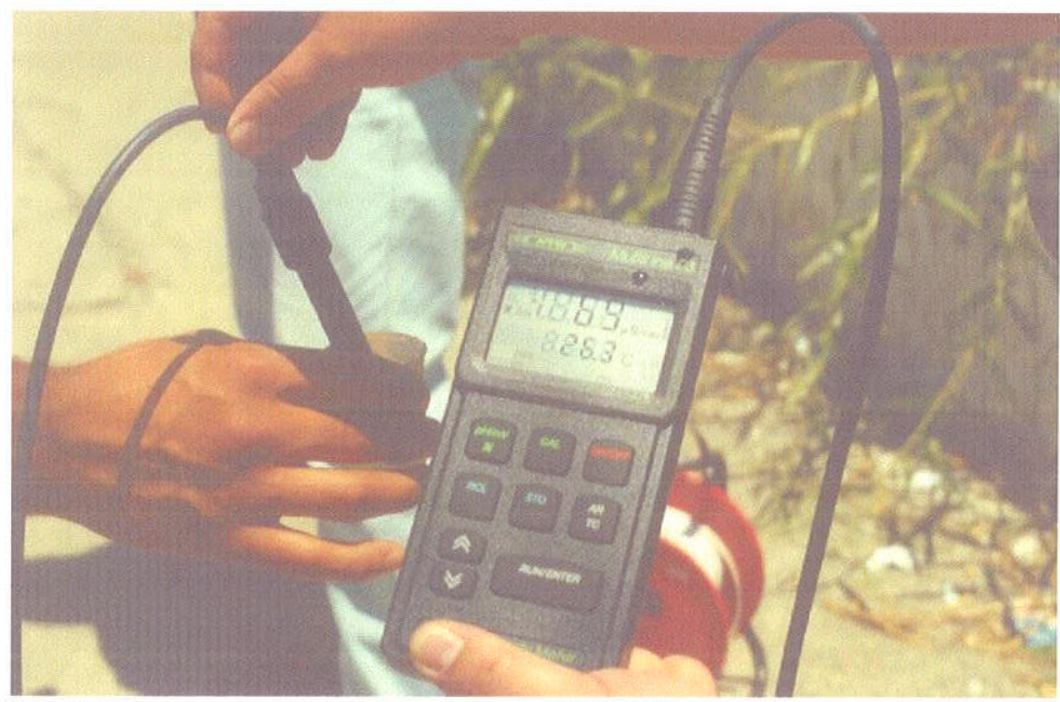

Foto 13 - Medida de condutividade elétrica em amostra de água do PMAdc-1 
Portanto, o critério pelo qual fol desenhada a pluma de contaminação nos mapas das Figuras D.11 e D.12 é eficiente e objetivo, apresentando uma relação direta com a contaminação em subsuperfície.

O Anexo XI apresenta dois mapas de solinas representativos dos valores de $R A$ e $A_{s p}$ (Figura A-XI.1 e A-XI.2, respectivamente) correspondentes à análise espectral feita sobre os dados brutos. Como pode-se observar nestes mapas a forma da pluma é similar à forma dos mapas anteriores, no entanto os valores são praticamente inversos, o que demonstra que a aplicação do AGC ressaltou a "zona de sombra" no período selecionado, como foi constatado pelas sondagens a trado.

\section{Discussão}

A presença de hidrocarbonetos em subsuperfície possivelmente modifica o meio do ponto de vista físico. Conforme os hidrocarbonetos (fase vapor e líquida) ocupam os poros, parte da água vai sendo expulsa deste (Oliveira, 1997) e isto, com certeza, muda a situação natural em que o meio se encontrava antes da contaminação. A ocupação por hidrocarbonetos $(K=2)$ e a expulsão de parte da água $(K=80)$ contida neste meio, consequentemente diminui a constante dielétrica, o que causa diferenciação na seção de GPR em relação a um local não contaminado.

A anomalia relacionada à contaminação na área de estudo apresenta-se na forma de ausência de sinal nas seções processadas. Este tipo de anomalia é denominada por "zona de sombra" ou "apagão". A verificação mais importante sobre a interpretação foi feita através de sondagens a trado, as quais mostraram que a zona de sombra estava efetivamente relacionada à contaminação. A delineação da pluma de contaminação a partir dos resultados obtidos com os dados de radar mostrou que esta estava além do que vinha sendo indicada pelos dados adquiridos pontualmente a partir de poços de monitoramento e de remediação até então instalados.

A utilização de antenas blindadas em uma área com elevado nivel de urbanização como no caso estudado foi fundamental para detecção e delineação da pluma de contaminação em subsuperfície, apesar de que as antenas utilizadas para execução das sondagens CMP (não blindadas) também indicaram zonas de sombra, não apresentando refletores nos locais contaminados. $\mathrm{Na}$ área estudada a aplicação de "stacking" maior que 128 proporcionou uma zona de sombra mais abrangente mas não foi possivel esclarecer se isto se aproxima mais da 
situação real, o que no caso não mostrou ser vantajoso, pelo contrário, somente serviu para aumentar o tempo de levantamento de campo. No entanto, deve-se ter claro que em outra área de estudo um "stacking" maior poderia ser o ideal para uma aquisição de dados de qualidade.

Foi possivel verificar que a análise de resoluçãoXprofundidade pode ser decisiva para o sucesso dos objetivos do levantamento, pois comparando-se o resultado das antenas, observase que as zonas de sombra são quase imperceptiveis nas seções adquiridas com a antena de $100 \mathrm{MHz}$ mesmo com stacking maior por apresentar menor resolução. Na área estudada a antena de $250 \mathrm{MHz}$ apresentou bons resultados. Os parâmetros de aquisição foram definidos primeiramente de acordo com orientação do manual de operação do instrumento (RAMAC, 1998) e sugerido por Annan (1992), sendo modificados durante uma linha teste de levantamento e analisados para averiguar se ocorria melhoria na qualidade dos dados. Este procedimento seria a melhor maneira de tirar o máximo do método para que o levantamento de campo seja bem sucedido do ponto de vista dos objetivos em outras áreas de estudo.

Para o mesmo caso foi necessário utilizar passos e parâmetros de processamento diferentes nas seções adquiridas com antenas diferentes. O processamento aplicado foi simples, no entanto deve-se ter em mente que não se trata de uma receita única, sendo que cada caso deve ser analisado de forma diferente devido às suas especificidades.

A análise de velocidade reforça a idéia de que nos locais contaminados se trata de um meio com constante dielétrica menor (P-13 e P-14) do que os valores observados como "background" nos perfis P-7 e P-10 e na CMP-1. A velocidade de propagação do sinal nos perfis que apresentaram zona de sombra é maior, conseqüência da diminuição da constante dielétrica. Mesmo o valor calculado de $K$ a partir do perfil $P_{-7}$, executado em período de clima seco e, portanto, com menos água no melo, foi relativamente maior e mostra que o sinal de radar relacionado à presença de contaminante orgânico no meio difere de um sinal relacionado a um meio com menos água.

A análise espectral feita sobre os trechos contaminados (espacial e temporalmente) confirma que a zona de sombra neste caso é produto da falta de reflexão, pois o conteúdo energético praticamente mantém-se o mesmo no período seguinte (60 a 100ns) ao correspondente à zona de sombra (30 a 60ns), diferentemente da parte correspondente a não contaminada na seção onde a energia do sinal vai sendo atenuada conforme o sinal se propaga em profundidade (=avanço de tempo). 
A manifestação da contaminação através da zona de sombra provavelmente é uma resultante da presença de fase adsorvida e residual no solo, fase vapor contida nos poros, fase livre e dissolvida, pois durante levantamento de dados a partir das sondagens executadas para averiguação da interpretação e de poços de monitoramento e de remediação, foram observados: odor no solo amostrado (fase adsorvida, vapor e residual), nos poços de monitoramento e de remediação (fase vapor); condutividade elétrica nula em água amostrada de alguns poços e sondagem (fase dissolvida) e lâmina e película do produto (fase livre).

Os PM Adc-2, PM Adc-3 e F-4, e secundariamente o PM Adc-1 apresentaram o valor de condutividade elétrica nulo, ou muito baixo, provavelmente devido à presença de fase dissolvida na água. Estes poços também apresentaram fase livre, sendo que nos perfis de GPR próximos a estes pontos (P-13, P-14, P-5, P-6 e P-10) não foi possível diferenciar visualmente nas seções dos perfis a presença desta fase livre em relação às outras fases, mas observa-se que a velocidade de propagação do sinal nas seções dos perfis P-13 e P-14 foi maior do que o valor calculado em outras seções que apresentaram zona de sombra. Provavelmente isto ocorra devido ao fato do grau de contaminação nestes locais ser maior do que ao longo das outras linhas, o que pareça consistente já que estes perfis são os que se situam mais próximos dos tanques de armazenamento. $\mathrm{O}$ fato do $\mathrm{F}-4$ apresentar gasolina em fase livre no inicio do furo pode ser explicado por um vazamento de linha do posto. Também é interessante notar que o furo F-6 apresentou cheiro de gasolina em quase toda sua extensão, com exceção de um pequeno trecho entre $60-80 \mathrm{~cm}$. Este trecho faz parte do aterro o qual é caracterizado pelo alto grau de heterogeneidade e provavelmente neste trecho a argila depositada o tenha impermeabilizado. Em contrapartida, a análise de velocidade com base em dados relacionados com a seção do perfil P-10 e poços ao longo do mesmo, indicou um valor de $\mathrm{K}$ relativamente alto o qual seria estabelecido como valor de background, no entanto os mapas de $R A$ e $A_{s p}$ indicaram um trecho anômalo neste perfil, confirmado por amostragem $\mathrm{e}$ medida de condutividade elétrica da água no local. Neste caso o refletor sugerido como topo da camada saturada em $47 \mathrm{~ns}$ pode não estar relacionado à mesma. Adotando $41 \mathrm{~ns}$, relacionado a outro refletor o qual poderia ser do topo da camada saturada, obtém-se a velocidade de $0,105 \mathrm{~m} / \mathrm{ns}$ e $\mathrm{K}=8,2$, o deve ser considerado como valor correspondente à contaminação.

Os dados adquiridos da sondagem F-1 mostram que, apesar da existência de contaminação por esgoto e litologia argilosa, dois fatores que causam atenuação de sinal do 
GPR, a contaminação por gasolina apresentou-se de maneira diferenciada e possibilitou a delineação da pluma.

O critério estabelecido para quantificar a pluma de contaminação tanto em extensão e, secundariamente, em concentração a partir dos valores de $R A$ e $A_{s p}$, proporcionou resultados confiáveis e desprovidos de subjetividade. Na realidade, a definição da extensão da pluma foi o principal resultado positivo, pois os mapas produzidos tanto com referência na interpretação visual como os referenciados em critérios numéricos resultaram similares. Por outro lado, afirmar que a concentração de contaminação está diretamente relacionada com o valor de $A_{s p}$ seria um tanto precipitado, pois para se confirmar esse tipo de afirmação seria necessário realizar amostragens e análises químicas adequadas de água, solo e vapor em alguns pontos com valores de $A_{s p}$ diferentes. De qualquer maneira, o objetivo principal foi atingido, ao proporcionar um meio pelo qual fosse possivel delinear a pluma na forma mais próxima da situação existente no local.

\section{Conclusões e recomendações}

Atualmente a detecção de contaminantes hidrocarbonetos em subsuperfície por métodos geofísicos deixou de ser um mito como pode ser observado no levantamento bibliográfico apresentado na Parte $\mathrm{C}$. Na última década, principalmente, muitos pesquisadores têm dirigido seus esforços para o desenvolvimento de novas técnicas geofísicas como também compreender melhor o que ocorre no meio contaminado por hidrocarbonetos. Das metodologias que vêm sendo aplicadas, a do GPR é a que vem dando melhores resultados pois, além das mudanças ocorridas no meio devido à contaminação modificar as propriedades eletromagnéticas e, conseqüentemente, causar contrastes nas medidas, também é um método de alta resolução, econômico e rápido.

Apesar desses avanços, a indicação da contaminação como também a compreensão do efeito da interação do contaminante com o meio são muito subjetivos e contraditórios na literatura. Por outro lado a utilização do método geralmente é feita em condições ideais ou somente como experimentos. A tendência das pesquisas no que diz respeito ao GPR é procurar definir qual o comportamento do contaminante em subsuperfície do ponto de vista eletromagnético, para então tornar o trabalho de detecção e mapeamento da pluma mais objetivo. 
Na pesquisa desenvolvida aqui, pode-se afirmar que a presença de hidrocarbonetos em subsuperfície causou anomalia na seção do GPR na forma de ausência do sinal, denominada por "zona de sombra" ou "apagão" apesar das condições desfavoráveis para aplicação do método. As sondagens executadas em locais interpretados como contaminados (F-4, F-6 e F7) e não contaminado ( $F-1)$ confirmaram as suspeitas.

A constituição litológica de predominância argilosa, não afetou a possibilidade de deteç̧ão do contaminante em subsuperficie. Por um lado a presença do contaminante de característica resistiva proporciona contraste em relação à argila e água como também menor atenuação, por outro lado a possibilidade do contaminante expulsar parte da água dos poros causa a homogeneização do meio do ponto de vista eletromagnético, o que explicaria a ausência de reflexão na parte contaminada.

No caso estudado a ocorrência de fase livre nos poços e sondagens é praticamente nula, no entanto o odor de contaminante é forte em poços e sondagens (fase vapor) como nas amostras das sondagens (fase adsorvida, vapor e residual), o que nos leva a concluir que provavelmente a contaminação no local, na época do levantamento, apresentava-se na forma de fase vapor, adsorvida, residual e dissolvida. A suposição de existência de fase dissolvida é baseada na medida de condutividade elétrica em amostras de águas proveniente dos PM Adc2, PM Adc-3 e F -4 , as quais apresentaram valor $0 \mu \mathrm{S} / \mathrm{m}$ (zero) em contraste com valores entre 400 e $800 \mu \mathrm{S} / \mathrm{m}$ aproximadamente, dos outros pontos medidos. Enfim, a complexa distribuição do contaminante em subsuperficie se manifesta nas seções do GPR.

Quanto ao fato da área de estudo ser constituída de vários elementos que contribuem para produzir um alto nível de ruído externo, não impediu a utilização do método, já que foram utilizadas antenas blindadas. Com a utilização de antenas não blindadas para execução de sondagem CMP também foi possivel observar "zona de sombra" sendo que somente a CMP-1 executada em área isenta de contaminação proporcionou a formação de um refletor.

A possibilidade de deteç̧ão da gasolina em subsuperfície foi produto de uma conjunção entre a escolha de antenas blindadas, a definição dos parâmetros de aquisição e o processamento aplicado aos dados.

A antena que proporcionou melhores resultados foi a de $250 \mathrm{MHz}$ provavelmente devido ao fato desta apresentar melhor resolução do que a de $100 \mathrm{MHz}$. Neste caso o compromisso 
resoluçãoXprofundidade foi resolvido com a antena de $250 \mathrm{MHz}$. As seções produzidas pela antena de $100 \mathrm{MHz}$ apresentam zona de sombra de forma sutil.

A definição dos parâmetros de aquisição adotou como base teórica a orientação dada no manual (Ramac, 1998) e as diretrizes sugeridas por Annan (1992), sendo que a partir daí executou-se uma linha teste para verificação da resposta do sinal para aquele meio. Além disso, na área de estudo experimentou-se "stacking" de 128 e posteriormente de 256 para observar se ocorria intensificação do sinal. Neste caso, o "stacking" maior foi desvantajoso pois não houve ganho qualitativo, duplicando o tempo de levantamento. Isto não significa que em outras áreas a utilização de "stacking" maior não proporcionaria um ganho de qualidade. A escolha dos parâmetros de aquisição é especifica para cada caso estudado, sendo definida através de uma linha teste, procedimento padrão para este tipo de levantamento.

O processamento aplicado aos dados foi simples o qual adotou como base eliminar os ruídos, compensar a perda de energia do sinal e corrigir o tempo zero nas seções. A seção final é resultante de vários testes de processamento para cada passo. Portanto, não existe uma receita única sendo necessário para cada situação um processamento diferente.

O estabelecimento de um critério numérico para delineação da pluma de contaminação foi bem sucedido e contribui para, praticamente, eliminar a subjetividade da interpretação, proporcionando esboços similares ao feito de acordo com a interpretação visual. $O$ critério $R A$ foi o que melhor resultou no aspecto de abrangência da pluma. O critério $A_{s p}$ proporcionou valores que sugerem relação com a concentração da contaminação em subsuperfície, o que somente poderia ser afirmado caso fosse executado amostragens de água e solo de maneira adequada para análises químicas.

Finalmente, conclui-se que o método é aplicável e eficiente para estudos de contaminação em subsuperfície proveniente de vazamentos de tanques de armazenamento em postos de serviço pois, na pior condição do ponto de vista teórico, foi possivel detectar a contaminação e delinear a pluma além da extensão indicada por métodos diretos.

Um passo interessante que comprovaria ou não as hipóteses seria a produção de modelos sintéticos que simulassem as hipóteses sugeridas e assim poderiam ser comparados com as seções levantadas como também contribuiriam na compreensão da interação física do contaminante com o meio. 


\section{Referências bibliográficas}

ALONSO, M. \& FINN, E.J. (1972) Física - Um curso universitário. Campos e Ondas. Ed. Edgard Blücher. v 2.600p

ANNAN, A.P. (1992) Use and techniques of GPR in near surface geophysics. Society of Exploration Geophysicists. Workshop Notes, Sensor \& Software Inc.110p

ANNAN, A.P.; BAUMAN, P; GREENHOUSE, J.P.; REDMAN, J.D. (1991) Geophysics and DNAPLs. Ground Water Management $n^{\circ} 5$. Proceedings of the Fifth National Outdoor Action Conference on Aquifer Restoration, Ground Water Monitoring and Geophysical Methods. Las Vegas, Nevada. p 963-977.

ANNAN, A.P.; BREWSTER, M.L.; GREENHOUSE, J.P.; REDMAN, J.D.; SCHNEIDER;;G.W.; OLHOEFT, G.R.; SANDER, K.A. (1992) Geophysical monitoring of DNAPL migration in a snady aquifer. Expanded Abstracts SEG 62nd Annual Meeting. New Orleans. P 344-347

AQUINO, W.F.; DEHAINI, J.; MENDES, J.M.B. (1998) Geo-Radar para detecção de contaminação por hidrocarboneto. Anais do II Workshop de Geofísica Aplicada. Rio Claro, SP. (CD-ROM)

BEDIENT, P.B.; RIFAI, H.S.; NEWELL, C.J. (1994) Ground Water Contamination: transport and remediation. Prentice-Hall International, Inc., Englewood Cliffs, N.J. 542p

BENSON, A.K. (1995) Applications of ground penetrating radar in assessing some geological hazards: examples of groundwater contamination, faults, cavities. Journal of Applied Geophysics. Elsevier Science B.V., Amsterdam. v 33. p 177-193.

BENSON, A.K.; PAYNE, K.L.; STUBBEN, M.A. (1997) Mapping groundwater contamination using dc resistivity and VLF geophysical methods - A case study. Geophysics, v 62, n 1, p 80-86.

BERMEJO, J. L.; SAUCK, W. A.; ATEKWANA, E. A. (1997) Geophysical discovery of a new LNAPL plume at the Former Wurtsmith AFB, Oscoda, Michigan. Ground-Water Monitoring Review. Fall, p 131-137. 
BÖRNER, F.; GRUHNE M.; SCHÖN, J. (1993) Contamination Indications Derived from Electrical Properties in the Low Frequency Range. Geophysical Prospecting. v. 41, p 8398.

BREWSTER, M.L. \& ANNAN, A.P. (1994) Ground-penetrating radar monitoring of a controlled DNAPL release: $200 \mathrm{MHz}$ radar. Geophysics, $\vee 59, \mathrm{n} 8, \mathrm{p}$ 1211-1221

BREWSTER, M.L.; REDMAN, J.D.; ANNAN, A.P. (1992a) Monitoring a controlled injection of perchloroethylene in a sandy aquifer with ground penetrating radar and time domain reflectometry. Proceedings of the Symposium on the Application of Geophysics to Engineering and Environmental Problems (SAGEEP). Chicago, Illinois, p 611

BREWSTER, M.L.; ANNAN, A.P.; REDMAN, J.D. (1992b) GPR Monitoring of DNAPL Migration in a Sandy Aquifer. Proceedings of Fourth International Conference on Ground Penetrating Radar. Rovaniemi, Finland. Geological Survey of Finland, Special Paper (in press).

BREWSTER, M.L.; ANNAN, A.P.; GREENHOUSE, J.P.; SCHNEIDER, G.W.; REDMAN, J.D. (1992c) Geophysical detection of DNAPLs: field experiments. Paper presented the IAH Conference "Modern trends in Hydrogeology". Hamilton, Ontario, Canada.

BREWSTER,M.L.; ANNAN, A.P.; GREENHOUSE, J.P.; KUEPER, B.H.; OLHOEFT, G.R.; REDMAN, J.D.; SANDER, K.A. (1995) Observed migration of a controlled DNAPL release by geophysical methods. Ground Water. v. 33, n. 6, p. 977-987

CARTWRIGHT, K. \& McCOMAS, M.R. (1968) Geophysical surveys in the vicinity of sanitary landfills in northcastern Illinois. Ground Water. Ohio-USA. v. 6, n 5, p 23-30.

CHERRY, J.A. (1987) Groundwater contamination by petroleum products. Paper presented at the Twelfth World Petroleum Congress. Houston, Texas. p 115-123.

CHERRY, J.A.; FEENSTRA, S; KUEPER, B.H.; McWHORTER, D.W. (1990) Status of in situ technologies for cleanup of aquifer contaminated by DNAPLs below the water table. Paper prepared for: International Specialty Conference on How Clean is Clean? Cleanup 
Criteria for Contaminated Soil and Groundwater Air and Waste Management Association. 17p

CRUZ-SANJULIÁN, J.; OLÍAS, M.; VALLE, M.; RUBIO, J.C. (1992) Hidrogeological investigation of ground water in Albolote (Granada, Spain). Ground Water Monitoring Review. Summer, p188-194

DANIELS, J.J.; ROBERTS, R.; VENDL, M. (1995) Ground penetrating radar for the detection of liquid contaminants. Journal of Applied Geophysics. Elsevier Science B.V., Amsterdam. v 33. p 195-207.

DANIELS, J.J.; GRUMMAN, D.L.; VENDL, M.A. (1997) Coincident antenna three-dimensional GPR. Journal of Environmental and Engineering Geophysics. v 2, n 1, p. 1-9.

DAILY, W; RAMIREZ, A.; JOHNSON, R. (1998) Electrical impedance tomography of a perchloroethelyne release. Journal of Environmental \& Engineering Geophysics, $\vee 2, n$ 3, p 189-201.

DAVIS, J.L. \& ANNAN, A.P. (1989) Ground-penetrating radar for high resolution mapping of soil and rock stratigraphy. Geophysical Prospecting, v 37, p. 531-551.

DOMENICO, P.A. \& SCHWARTZ, F.W. (1990) Physical and chemical hydrogeology. John Wiley \& Sons, Inc. Singarpore. $824 p$.

DUARTE, O.O. (1997) Dicionário enciclopédico inglês-português de Geofisica e Geologia. Sociedade Brasileira de Geofísica. Edição preliminar. 304p

FETTER,C.W. (1993) Contaminant hidrogeology. MacMillan Publishing Company. EUA. 400p

FISHER, E; McMECHAN, G.A.; ANNAN, A.P. (1992) Acquisition and processing of wideaperture ground-penetrating radar data. Geophysics. v. 57, n. 3, p 495-504

FISHER, S.C.; STEWART, R.R.; JOL H.M. (1994) Processing ground penetrating radar data. Proceedings of the Fifth International Conference on Ground Penetrating Radar. $p$ 661-675 
FISHER, S.C.; STEWART, R.R.; JOL H.M. (1996) Ground penetrating radar (GPR) data enhancement using seismic techniques. Journal of environmental and engineering geophysics. v. 1, n. 2, p 89-96

FREEZE, R.A. \& CHERRY, J.A. (1979) Groundwater. Prentice-Hall International, Inc., Englewood Cliffs, N.J. 604p

FROLHIC, R.K.; URISH, D.W.; FULLER, J.; O'REILLY, M. (1994) Use of geoelectrical methods in groundwater polluiton surveys in a coastal environment. Journal of Applied Geophysics. Elsevier Science Publishers B.V., Amsterdam. n 32, p 139-154.

GREENHOUSE, J.P. BREWSTER, M.; SCHNEIDER, G.; REDMAN, D.; ANNAN, P; OLHOEFT, G; LUCIUS, J.; SANDER, K.; MAZELLA, A. (1993) Geophysics and solvents: The Borden Experiment. The Leading Edge. p 261-267

GREENHOUSE, J.P. \& HARRIS, R.D. (1983) Migration of contaminants in groundwater at a landfill: a case study. 7. DC, VLF, and inductive resistivity surveys. In: J.A. Cherry (GuestEditor), Migration of Contaminants of Groundwater at a Landifill: A Case Study. J. Hydrol., n 63, p. 177-197.

GUIASP (2001) http://mapas.nacidade.com.br/SCRIPTS/hsrun.exe/Single/mapas/web/ MapasSP/Stateld/BsyUieuV0eeiwFjvDhpo9uZ- LJ/HAHTpage/HS_CanalMapa? zoom $=6$ (acessado 01/02/2001)

HIDROPLAN - Hidrogeologia e Planejamento Ambiental S/C Ltda (1997) Laudo técnico de avaliação sobre a situação de contaminação em área próxima ao Auto Posto na Freguesia do Ó, São Paulo, SP. (Cliente confidencial).

HUBBARD, S.S; PETERSON, Jr, J.E.; MAJER, E.L.; ZAWISLANSKI, P.T.; WILLIANS, K.H.; ROBERTS, J.; WOBBER, F. (1997) Estimation of permeable pathways and water content using tomographic radar data. The Leading Edge, p. 1623-1628

INSTITUTO BRASILEIRO DE GEOGRAFIA E ESTATISTICA - IBGE (1999) Malha Municipal Digital do Brasil: situação em 1997. RJ (CD-ROM) 
KELLER, G.V. (1988) Rock and mineral properties. In: Misac N. Nabighian. Eletromagnetic Methods in Applied Geophysics. Tulsa, Oklahoma, SEG. v. 1, cap. 2, p. 13-51.

KELLER, G.V. \& FRISCHKNECHT, F.C. (1966) Electrical methods in geophysical prospecting. Pergamon press Inc. N.Y. 519p.

KELLY, W.E. (1976) Geoeletric Sounding for Delineating Ground-Water Contamination. Ground Water. v. $14, n \cdot 1$, p. $6-10$

KING, T.V.V. \& OLHOEFT, G.R. (1989) Mapping organic contamination by detection of clayorganic processes. Proc. AGWSE/NWWA/API Conf. on petroleum hydrocarbons and organic chemicals in ground water - Prevetion, detection, and restoration, pg. 627640.

KUEPER, B.H.; HAASE, C.S.; KING, H.L. (1991) Consideration of DNAPL in the operation and monitoring of waste disposal ponds constructed in fractured rock and clay. For publication in Proceedings, First Canadian Conference on Environmental Geotechnics. Canadian Geotechnical Society. Montreal, Canada.

KUEPER, B.H.; REDMAN, D. STARR, R.C.; REITSMA, S.; MAH, M. (1993) A field experiment to study the behavior of tetrachloroethylene below the water table: spatial distribution of residual and pooled DNAPL. Ground Water. v. 31, n. 5, p 756-766

LEE, S; McMECHAN, G.A.; AIKEN, C.L.V. (1987) Phase-field imaging: The electromagnetic equivalent of seismic migration. Geophysics, v 52, n 5, p 678-693.

LIEN, B.K. \& ENFIELD, C.G. (1998) Delineation of subsurface hydrocarbon contaminant distribuition using a direct push resistivity method. Journal of Environmental \& Engineering Geophysics, v 2, n 3, p 173-179

LIG (1999) http://geolig.igc.usp.br/images/mnt.tif (acessado dia 05/01/2001) 
LIU, L. \& QUAN, Y. (1997) GPR Attenuation tomography for detecting DNAPL's. Proceedings of the Symposium on the Application of Geophysics to Engineering and Environmental Problems (SAGEEP).v I, p.241-251

LUCIUS, J.E. \& POWERS, M.H. (1997) Multi-frequency GPR surveys. Proceedings of the Symposium on the Application of Geophysics to Engineering and Environmental Problems (SAGEEP).v I, p.355-364

MACKAY, D.M.; ROBERTS, P.V.; CHERRY, J.A. (1985) Transport of organics contaminants in groundwater. Environmental Science Technology. v 19, n5, p 384-392.

MATIAS, M.S.; SILVA, M.M.; FERREIRA, P.; RAMALHO, E. (1994) A geophysical and hydrogeological sudy of aquifers contamination by a landfill. Journal of Applied Geophysics. Elsevier Science B.V.n 32 p. 155-162

MAZÁC, O.; BENES, L.; LANDA, 1.; MASKOVA, A. (1990) Determination of the extent of oil contamination in groundwater by geoelectrical methods. In: Stanley $\mathrm{H}$. Ward (Editor), Geotechnical and Environmental Geophysics, SEG. v. 2, p. 107-112.

NASH, M.S.; ATEKWANA, E.; SAUCK, W.A. (1997) Geophysical investigation of anomalous conductivity at a hydrocarbon contaminated site. Proceedings of the Symposium on the Application of Geophysics to Engineering and Environmental Problems (SAGEEP). $v$ 2, p 675-683.

NEWMARK, R.L. \& DAILY, W.D. (1998) ) Monitoring DNAPL pumping using integrated geophysical techniques. Journal of Environmental \& Engineering Geophysics, v $3, n$, p 7-13

NGUYEN,V.T.; QUICK,M.J.; ERIKSEN,A.S.; BOOTH,S.; ROEST,D.; WAGEBERT,A.; AlNUAMY,W.; NAKHKASH,M.; ZHANG,D.;HUANG, Y. (1997) An evaluation of geophysical techniques to measure sub-surface hydrocarbon contamination at a disused fuel distribution depot. Proceedings of the Symposium on the Application of Geophysics to Engineering and Environmental Problems (SAGEEP), v I, p. 251-259. 
NOBES, D.C. (1996) Troubled waters: environmental applications of electrical and electromagnetic methods. Surveys in Geophysics. v 17, p $393-454$.

OLHOEFT, G.R. (1985) Low-frequency electrical properties. Geophysics. v 50, n 12, p 24922503.

OLIVEIRA, E. (1997) Ethanol flushing of gasoline residuals - microscale and field scale experiments. Tese de Doutorado em Ciências da Terra, Universidade de Waterloo, Canadá. p 297

ORELLANA, E. (1974) Prospeccion geoelectrica por campo variables. Madrid, Editora Paraninfo. 571p

ORELLANA, E. (1982) Prospeccion geoelectrica en corriente continua. Madrid, Editora Paraninfo. 578p.

PARASNIS, D.S. (1997) Principles of Applied Geophysics. New York, Chapman and Hall. $5^{\text {a }}$ Edição. $402 p$

RADPRO (1996) Manual do software de processamento de dados do GPR RAMAC na versão 2.25. Malä-Geoscience. $52 p$

RAMAC/GPR (1997) Manual do instrumento na versão 2.28. Malä-Geoscience. $65 p$

RAMAC/GPR (1998) Software versão 2.49/BETA. Malä-Geoscience.

REDMAN, J.D. \& ANNAN, A.P. (1992) Dieletric Permitivity monitoring in a sandy aquifer following the controlled release of a DNAPL. Proceedings of Fourth International Conference on Ground Penetrating Radar, Rovaniemi, Finland. Geological Survey of Finland, Special Paper.

SÃO PAULO (Estado). Companhia de Tecnologia de Saneamento Ambiental (1997) Processo 29-00237-97. CETESB 
SAUCK, W.A., ATEKWANA, E.A., NASH, M.S. (1998) High conductivities associated with na LNAPL plume imaged by integrated geophysical techniques. Journal of Environmental and Engineering Geophysics. $\vee 2, n$ 3, p 203-212.

SCHNEIDER, G.W. \& GREENHOUSE, J.P. (1992). Geophysical detection of perchloroethylene in a sandy aquifer using resistivity and nuclear logging techniques. Proceedings of the Symposium on the Application of Geophysics to Engineering and Environmental Problems (SAGEEP). Chicago, Illinois. p 619

SZARANIEC, E. (1979) Towards unification of geophysical problems for horizontally stratified media. Geophysical prospecting, $\vee 27, n 3$, p 576-583

TELFORD, W.M.; GELDART, L.P.; SHERRIF, R.E. (1990) Applied geophysics. Cambridge, Cambridge University Press. 770p

TOPP,G.C.; DAVIS,J.L.; ANNAN, A.P. (1980) Eletromagnetic determination of soil water content: measurements in coaxial transmission lines. Water Resources Research. $\vee 16, n$ 3, p 574-582

URISH, D.W. (1983) The Practical Application of Surface Electrical Resistivy to Detection of Ground-water Polluition. Ground Water. v. 21, n 2, p 144-152.

URSIN, B. (1983) Review of elastic and electromagnetic wave propagation in horizontally layered media. Geophysics, v 48, n 8, p 1063-1081.

VANHALA, H. (1997) Mapping oil-contaminated sand and till with the spectral induced polarization (SIP) method. Geophysical Prospecting. v. 45, p 303-326

VANHALA, H.; SOININEN, H.; KUKKONEN, I. (1992) Detecting organic chemical contaminants by spectral-induced polarization method in glacial till environment. Geophysics. $v 57, n 8, p$ 1014-1017.

VICKERY, A.C. \& HOBBS, B.A. (1998) Contributions of surface geophysics to environmental site investigation of former oil distribuition terminals. Journal of Environmental \& Engineering Geophysics, v 3, n 3, p 101-109 
von HIPPEL, A.R. (1954) Dieletric materials and applications. Britsh library, 438p.

WARD S.H. (1990) Geotechnical and environmental geophysics. Tulsa, Oklahoma. SEG. v.2, $343 p$

WERKEMA, Jr., D.D.; ATEKWANA, E.; SAUCK, E; ROSSBACH, S.; DURIS, J. (2000) Vertical distribuition of microbial abundances and apparent resistivity at an LNAPL spill site. Proceedings of the Symposium on the Application of Geophysics to Engineering and Environmental Problems (SAGEEP), p 669-678

WHITELEY, B. (1997) Delineation of voided and hydrocarbon contaminated regions with RDEM and STI. Proceedings of the Symposium on the Application of Geophysics to Engineering and Environmental Problems (SAGEEP), v II, p. 597-608.

YILMAZ, O. (1987) Seismic data processing. Society of Exploration Geophysicits, v 2, Tulsa, OK, EUA., 526p

ZHDANOV, M.S. \& KELLER, G.V. (1994) The geoelectrical methods in geophysical exploration. Elsevier Science B.V.. The Netherlands. 873p. 
A N EX O I 
Quadro A-I.1 Propriedades elétricas dos materiais terrestres e contaminantes líquidos hidrocarbonetos (Whiteley, 1997)

\begin{tabular}{|c|c|c|}
\hline MATERIAL & $\begin{array}{c}\text { CONSTANTE } \\
\text { DIELÉTRICA }\end{array}$ & $\begin{array}{c}\text { RESISTIVIDADE } \\
\text { (ohm.m) }\end{array}$ \\
\hline Ar & 1 & Infinito \\
\hline Água fresca & 81 & $50 \mathrm{a} 300$ \\
\hline Agua salgada & 81 & 0.25 \\
\hline Areia & $5 \mathrm{a} 30$ & $100 \mathrm{a}>10000$ \\
\hline Argila/silte & $10 \mathrm{a} 100$ & $0.1 \mathrm{a} 10$ \\
\hline Solo & $10 \mathrm{a} 50$ & $20 \mathrm{a} 1000$ \\
\hline Calcário/arenito & $5 \mathrm{a} 15$ & $100 \mathrm{a}>10000$ \\
\hline Benzeno/ Tolueno* & 2 & $>1000000$ \\
\hline TCE/PCE** & $2 \mathrm{a} 3$ & $>1000000$ \\
\hline
\end{tabular}

* o autor relaciona à denominação LNAPL

** o autor relaciona à denominação DNAPL

Quadro A-I.2 (Hubbard et. al., 1997)

\begin{tabular}{|c|c|}
\hline MATERIAL & CONSTANTE DIELETRICA \\
\hline Areia (seca) & $3-6$ \\
\hline Areia (saturada) & $20-30$ \\
\hline Siltes & $5-30$ \\
\hline Xistos & $5-15$ \\
\hline Argilas & $5-40$ \\
\hline Solo úmido & 30 \\
\hline Solo cultivado & 15 \\
\hline Solo rochoso (rocha alterada?) & 7 \\
\hline Solo arenoso (seco) & 3 \\
\hline Solo arenoso (saturado) & 19 \\
\hline Solo argiloso (seco) & 2 \\
\hline Solo argiloso (saturado) & 15 \\
\hline Arenito (saturado) & 6 \\
\hline Calcário (seco) & 7 \\
\hline Calcário (saturado) & $4-8$ \\
\hline Basalto (saturado) & 8 \\
\hline Granito (seco) & 5 \\
\hline Granito (saturado) & 7 \\
\hline
\end{tabular}




Quadro A-I.3 (Börner et al., 1993)
\begin{tabular}{|c|c|c|c|c|c|}
\hline $\begin{array}{c}\text { Substância } \\
\text { química }\end{array}$ & $\begin{array}{c}\text { Condutividade } \\
\text { elétrica } \\
(\mathrm{mS} / \mathrm{m})\end{array}$ & $\begin{array}{c}\text { Constante } \\
\text { dielétrica }\end{array}$ & $\begin{array}{c}\text { Momento dipolo } \\
(\mathrm{C} . \mathrm{m})\end{array}$ & $\begin{array}{c}\text { Tensão superficial } \\
(\mathrm{N} / \mathrm{m})\end{array}$ & $\begin{array}{c}\text { Viscosidade } \\
(\mathrm{Pa} . \mathrm{s})\end{array}$ \\
\hline Agua destilada & 0.19 & 80.37 & $6.14 \times 10^{-30}$ & $7.258 \times 10^{-2}$ & $1.00 \times 10^{-3}$ \\
\hline Hexano & 0.50 & 1.88 & 0 & $1.840 \times 10^{-2}$ & $3.20 \times 10^{-4}$ \\
\hline Diclorometano & 1.1 & 8.30 & $5.24 \times 10^{-30}$ & $2.800 \times 10^{-2}$ & $4.37 \times 10^{-6}$ \\
\hline Benzeno & 0.11 & 2.24 & 0 & $2.888 \times 10^{-2}$ & $6.42 \times 10^{-4}$ \\
\hline Metanol & 0.38 & 33.70 & $5.64 \times 10^{-30}$ & $2.261 \times 10^{-2}$ & $5.84 \times 10^{-4}$ \\
\hline $\begin{array}{c}\text { Mistura de óleo e } \\
\text { outras } \\
\text { substâncias } \\
\text { orgânicas }\end{array}$ & 0.50 & 2.00 & $?$ & $?$ & $1.00 \times 10^{0}$ \\
\hline
\end{tabular}

Quadro A-I.4 Propriedades do solo em função da saturação de PCE. (o coeficiente de reflexão é calculado para uma camada com $0 \%$ de PCE sobre uma camada com a saturação de PCE dada. A porosidade do solo foi assumida como 0.4. Outros DNAPL's têm propriedades similares ao PCE) (Brewster et al., 1992)

\begin{tabular}{|c|c|c|c|c|c|}
\hline $\begin{array}{c}\text { Saturação de } \\
\text { DNAPL } \\
(\% \text { volume de } \\
\text { poro) }\end{array}$ & $\begin{array}{c}\text { Densidade } \\
\left(\mathrm{g} / \mathrm{cm}^{3}\right)\end{array}$ & $\begin{array}{c}\text { Resistividade } \\
\text { elétrica } \\
(\mathrm{ohm}, \mathrm{m})\end{array}$ & $\begin{array}{c}\text { Permissividade } \\
\text { dielétrica } \\
\text { relativa }\end{array}$ & $\begin{array}{c}\text { Coeficiente de } \\
\text { reflexão de } \\
\text { ondas EM }\end{array}$ & $\begin{array}{c}\text { Perfil de } \\
\text { neutron térmico } \\
\left(\mathrm{cm}^{-1} \times 10^{-3}\right)\end{array}$ \\
\hline 0 & 2.03 & $69(14.5)$ & 29.7 & 0.0 & 11 \\
\hline 15 & 2.06 & $95(10.5$ & 24.3 & 0.05 & 57 \\
\hline 30 & 2.10 & $140(7.1)$ & 19.4 & 0.11 & 102 \\
\hline 45 & 2.14 & $230(4.4)$ & 14.9 & 0.17 & 148 \\
\hline 60 & 2.18 & $440(2.3)$ & 11.0 & 0.24 & 194 \\
\hline 75 & 2.22 & $1100(0.9)$ & 7.6 & 0.33 & 239 \\
\hline 100 & 2.28 & $\infty(0)$ & 3.4 & 0.49 & 315 \\
\hline & & & & & \\
\hline Compostos & & & & & 781 \\
\hline DNAPL & 1.62 & $\infty(0.0)$ & 2.3 & & 22.1 \\
\hline Água & 1.00 & $50.0(50.0)$ & 83.6 & & 4.3 \\
\hline Matriz & 1.71 & $\infty(0.0)$ & 4.5 & & \\
\hline
\end{tabular}


Quadro A-I.5 Propriedades físicas do tetracloroetileno (PCE), água e ar (Brewster \& Annan, 1994)

\begin{tabular}{|l|l|l|l|}
\hline & Densidade $\left(\mathrm{g} / \mathrm{cm}^{3}\right)$ & $\begin{array}{l}\text { Permissividade dielétrica } \\
\text { relativa }\end{array}$ & $\begin{array}{l}\text { Condutividade } \\
(\mathrm{mS} / \mathrm{m})\end{array}$ \\
\hline PCE & 1.62 & 2.3 & $5.6 \times 10^{-9}$ \\
\hline Água* & 1.00 & 83 & 76 \\
\hline $\mathrm{Ar}$ & 0 & 1.0 & $2.5 \times 10^{-14}$ \\
\hline
\end{tabular}

- 0.01 molar de solução de $\mathrm{NaCl}$ a $10^{\circ} \mathrm{C}$

Quadro A-I.6 Valores de permissividade relativa e velocidade segundo manual do GPR (RAMAC/MALÄ-Geoscience, 1997)

\begin{tabular}{|l|c|c|}
\hline \multicolumn{1}{|c|}{ Meio } & Permissividade relativa & Velocidade $(\mathrm{m} / \mathrm{\mu s})$ \\
\hline Ar & 1 & 300 \\
\hline Água fresca & 81 & 33 \\
\hline Calcário & $7-16^{*}$ & $75-113^{*}$ \\
\hline Granito & $5-7^{*}$ & $113-134^{*}$ \\
\hline Xisto & $5-15^{*}$ & $77-134^{*}$ \\
\hline Concreto & $4-10^{*}$ & $95-150^{*}$ \\
\hline Argila & $4-16^{*}$ & $74-150^{*}$ \\
\hline Silte & $9-23^{*}$ & $63-100^{*}$ \\
\hline Areia & $4-30^{*}$ & $55-150^{*}$ \\
\hline Moraina & $9-25^{*}$ & $60-100^{*}$ \\
\hline Gelo & $3-4^{*}$ & $150-173^{*}$ \\
\hline Permafrost & $4-8^{*}$ & $106-150^{*}$ \\
\hline
\end{tabular}

* Os valores são para meio insaturado 
A N E X O II 
Tabela A-II.1 - Descrição litológica dos furos de sondagem a trado

\begin{tabular}{|c|c|c|}
\hline $\begin{array}{l}\text { Furo } \\
\left(n^{\circ}\right)\end{array}$ & $\begin{array}{l}\text { Profundidade } \\
\qquad(\mathrm{cm})\end{array}$ & Descrição litológica \\
\hline \multirow[t]{4}{*}{$F-1$} & $0-20$ & Areia média grossa cinza com fragmentos de concreto \\
\hline & $20-127$ & $\begin{array}{l}\text { Material heterogêneo variando de silte-arenoso a silte } \\
\text { argiloso com cores de marrom-avermelhado para marrom } \\
\text { amarelado com pedregulhos }\end{array}$ \\
\hline & $127-152$ & $\begin{array}{l}\text { Argila plástica com pouca areia com cores variando de } \\
\text { marrom claro a tons de cinza }\end{array}$ \\
\hline & $152-352$ & $\begin{array}{l}\text { Argila plástica com cores variando de marrom-claro a tons de } \\
\text { cinza }\end{array}$ \\
\hline \multirow[t]{4}{*}{$\mathrm{F}-4$} & $0-63$ & $\begin{array}{l}\text { Material arenoso cinza-preto com fragmentos de rejeito } \\
\text { industrial }\end{array}$ \\
\hline & $63-136$ & $\begin{array}{l}\text { Material argilo-arenoso vermelho cinza com fragmentos de } \\
\text { rejeito industrial }\end{array}$ \\
\hline & $136-236$ & Argila plástica cinza beje \\
\hline & $236-311$ & Argila plástica preta com muita matéria orgânica \\
\hline \multirow[t]{3}{*}{$F-6$} & $0-95$ & $\begin{array}{l}\text { Material heterogêneo variando de silte arenoso a silte } \\
\text { argiloso com cores cinza avermelhado para marrom } \\
\text { avermelhado }\end{array}$ \\
\hline & $95-150$ & Argila plástica cinza beje \\
\hline & $150-170$ & Argila plástica preta com muita matéria orgânica \\
\hline \multirow[t]{3}{*}{$F-7$} & $0-80$ & $\begin{array}{l}\text { Material heterogêneo variando de areno-argiloso para silte- } \\
\text { argiloso com fragmentos de rocha com cores variando de } \\
\text { marrom avermelhado para marrom escuro }\end{array}$ \\
\hline & $80-135$ & Argila siltosa de cor marrom \\
\hline & $135-193$ & $m$ cores variando de $n$ \\
\hline
\end{tabular}


Tabela A-II.2 - Descrição da presença de gasolina durante a execução dos furos de sondagem a trado

\begin{tabular}{c|c|l}
$\begin{array}{c}\text { Furo } \\
\left(\mathrm{n}^{\circ}\right)\end{array}$ & $\begin{array}{c}\text { Profundidade } \\
(\mathrm{cm})\end{array}$ & \multicolumn{1}{|c}{ Presença do contaminante } \\
\hline $\mathrm{F}-1$ & $127-352$ & Cheiro de esgoto \\
\hline $\mathrm{F}-4$ & $0-40$ & Encharcado de gasolina \\
\cline { 2 - 3 } & $40-161$ & Cheiro de gasolina \\
\cline { 2 - 3 } & $161-236$ & Cheiro e presença de gasolina \\
\cline { 2 - 3 } & $236-311$ & Cheiro de gasolina \\
\hline F-6 & $0-60$ & Cheiro forte de gasolina \\
\cline { 2 - 3 } & $60-80$ & Sem cheiro de gasolina \\
\cline { 2 - 3 } & $80-111$ & Cheiro de gasolina \\
\hline F-7 & $54-193$ & Cheiro de gasolina
\end{tabular}


A N E X O III 

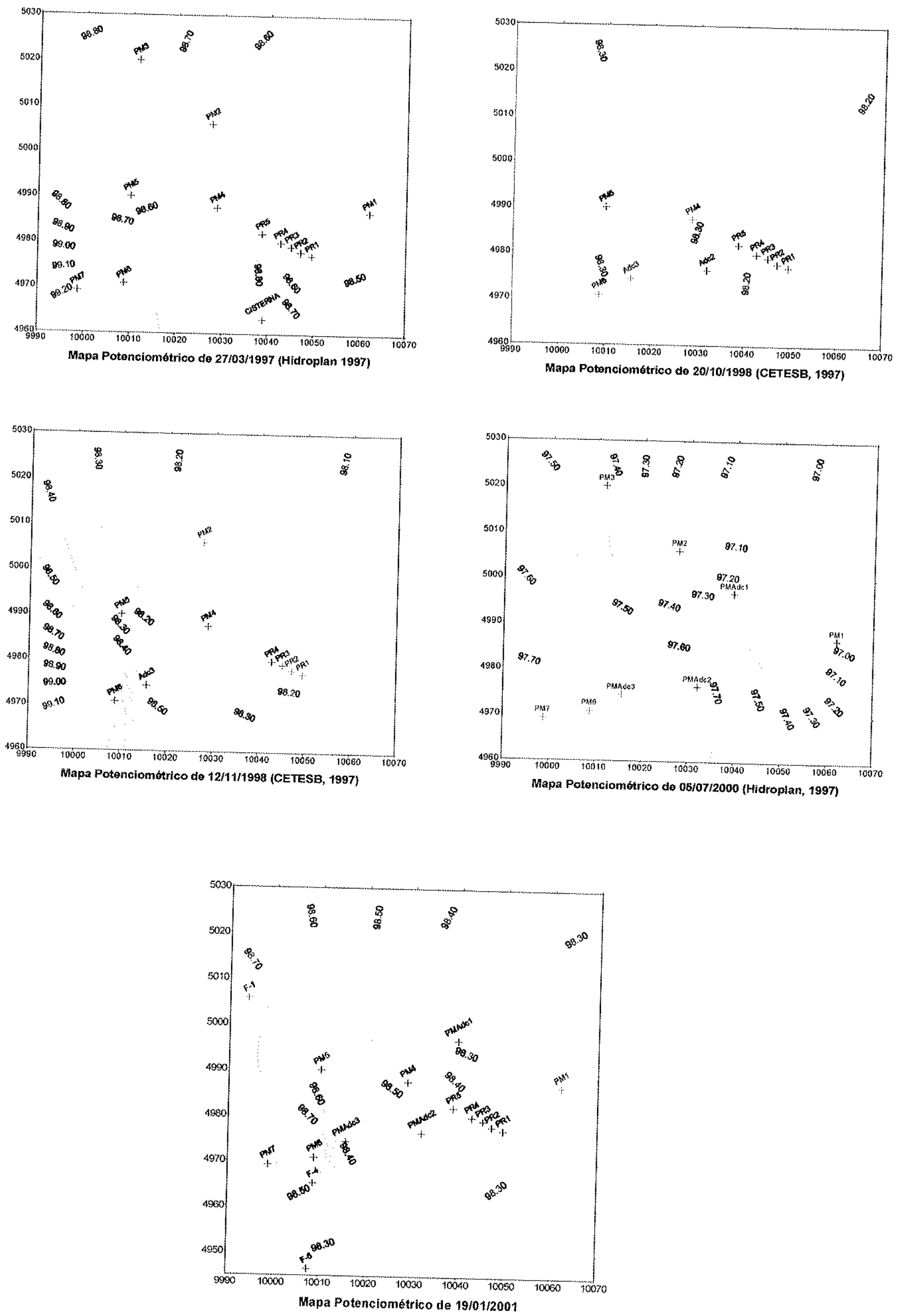

Figura A-III. 1 - Mapas potenciométricos da área de estudo referenciados em medidas de nivel d'água feitas
em épocas diferentes 
A N E X O IV 


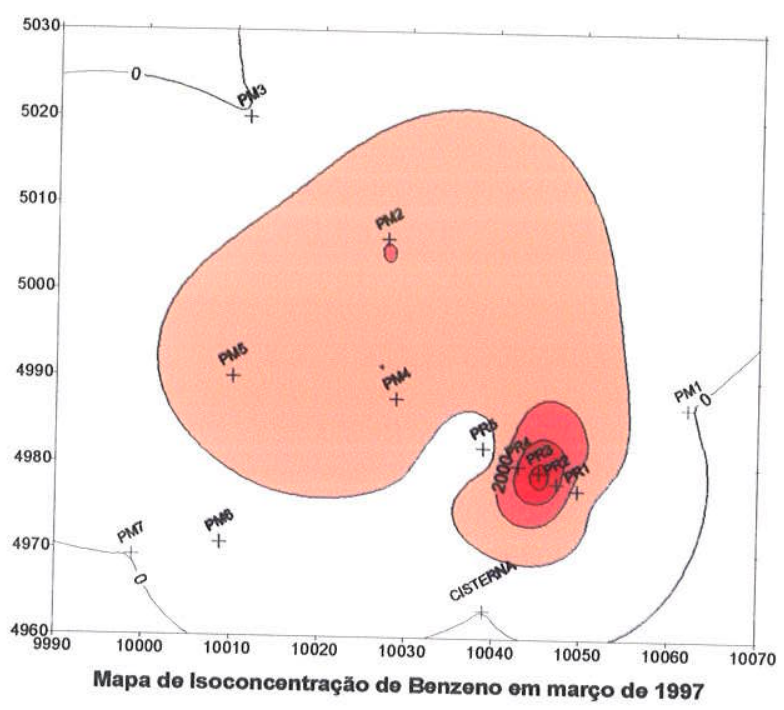

Concentração de Benzeno (ppb)

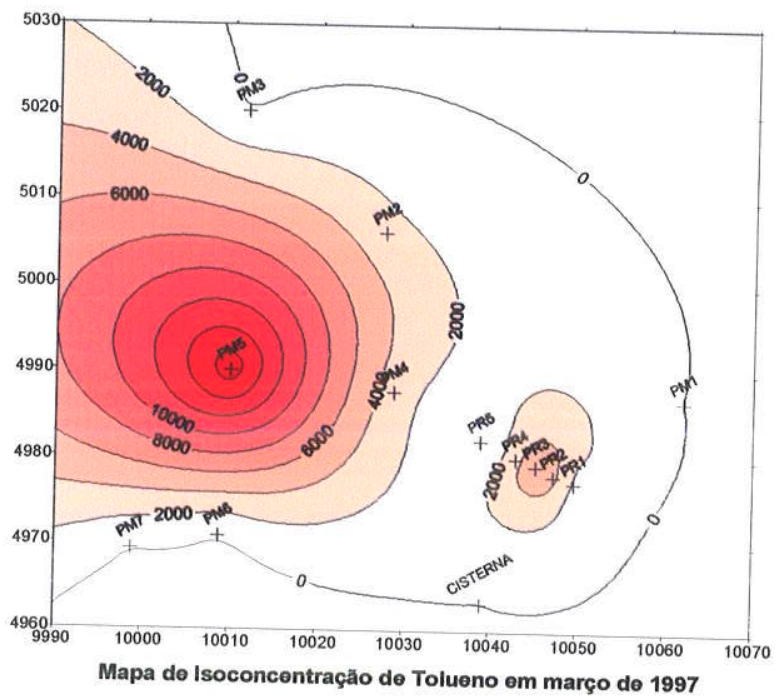

Concentração de Tolueno (ppb)

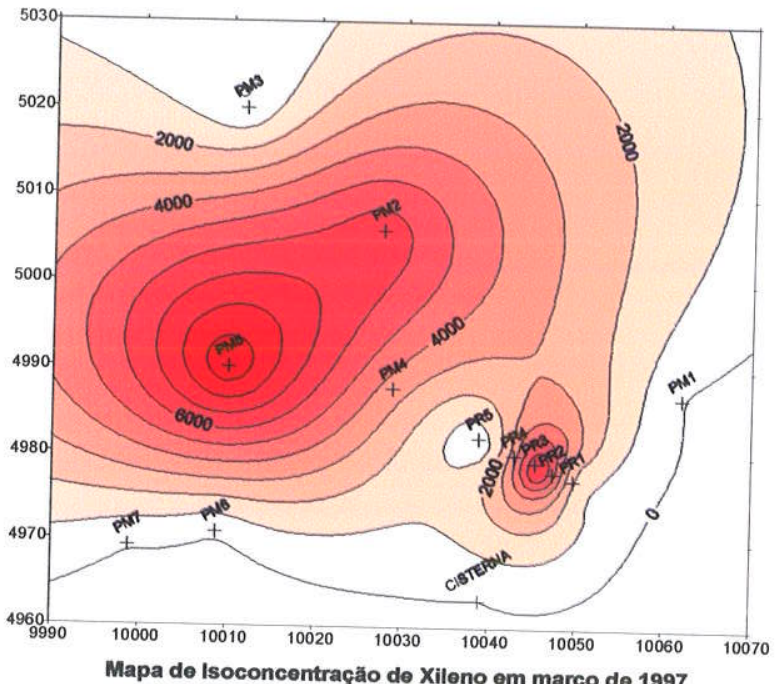

Concentração de Xileno (ppb)

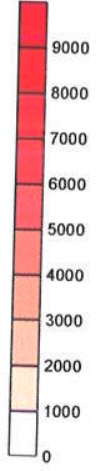


A N EX O V 

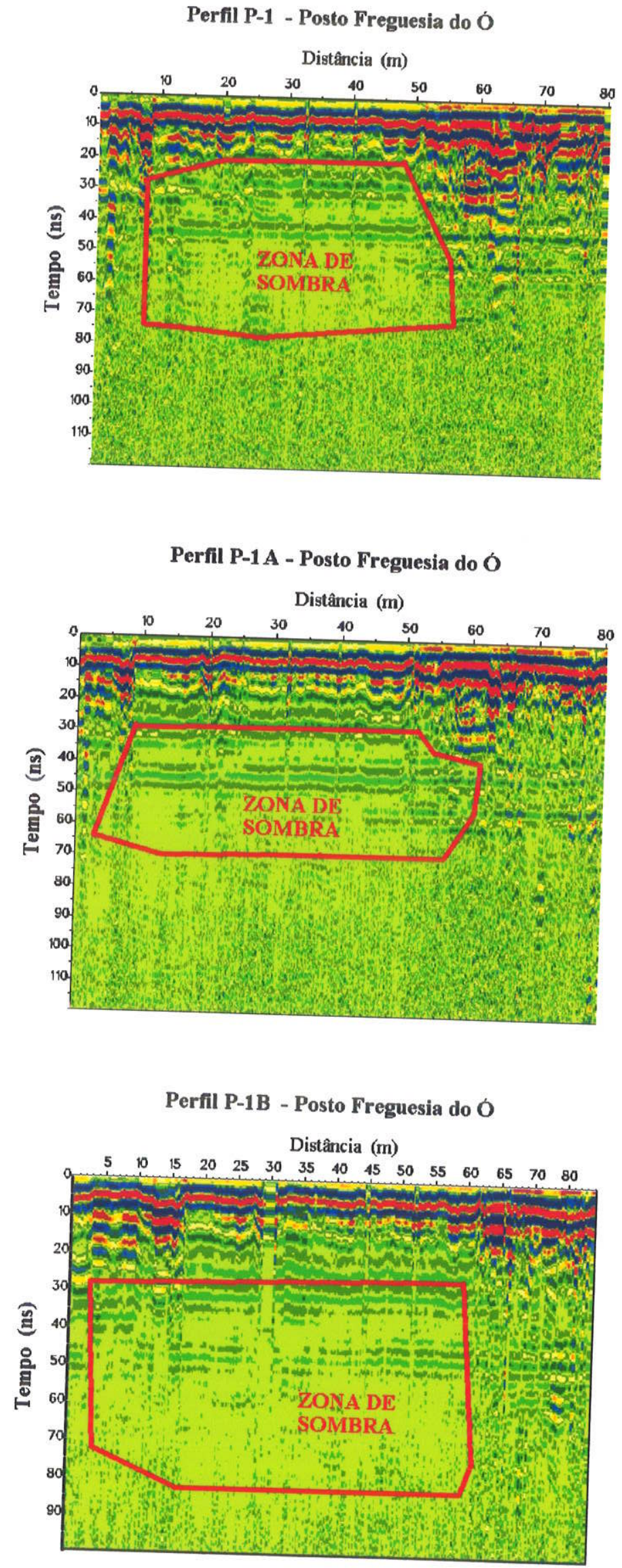


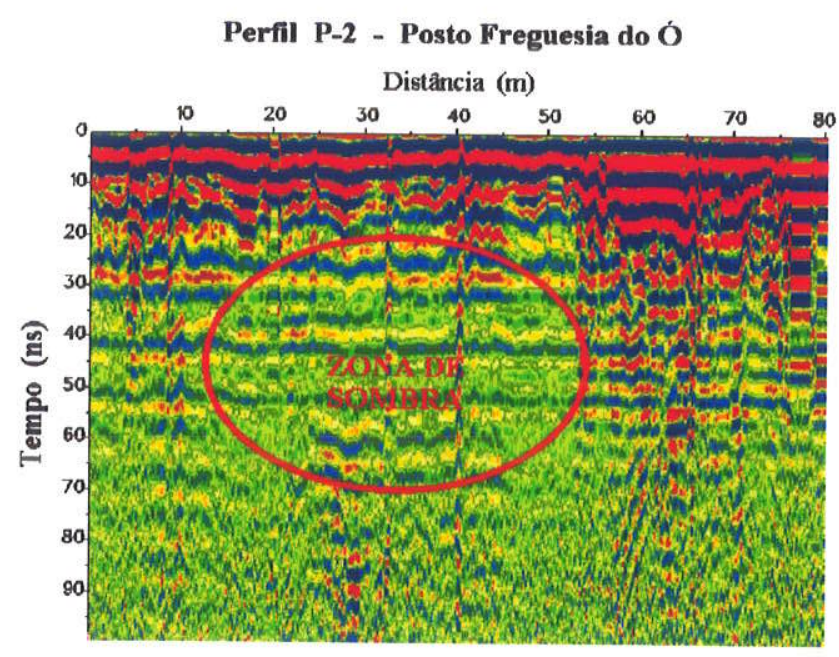

Perfil P-3 - Posto Freguesia do Ó

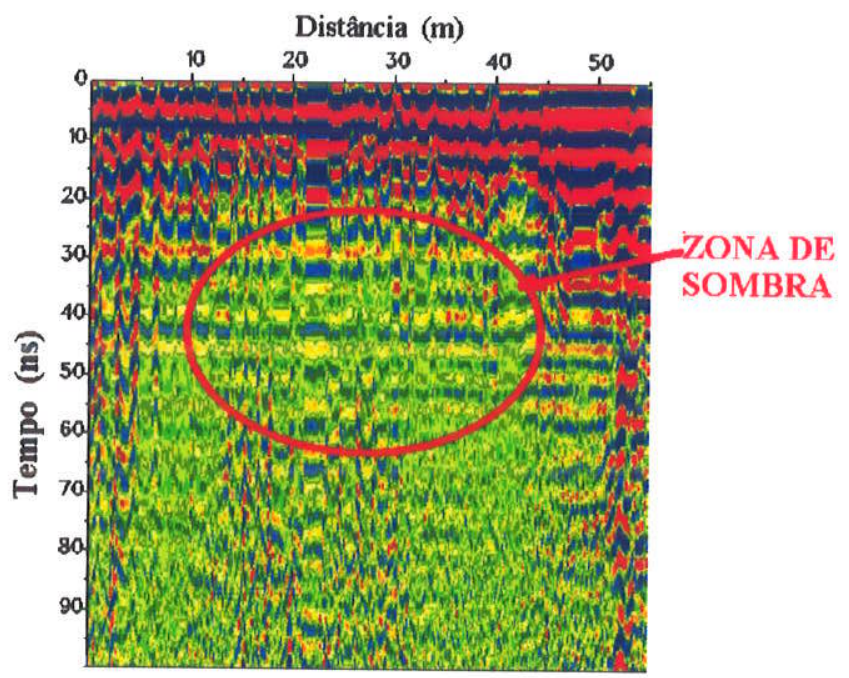

Perfil P-4 - Posto Freguesia do Ó

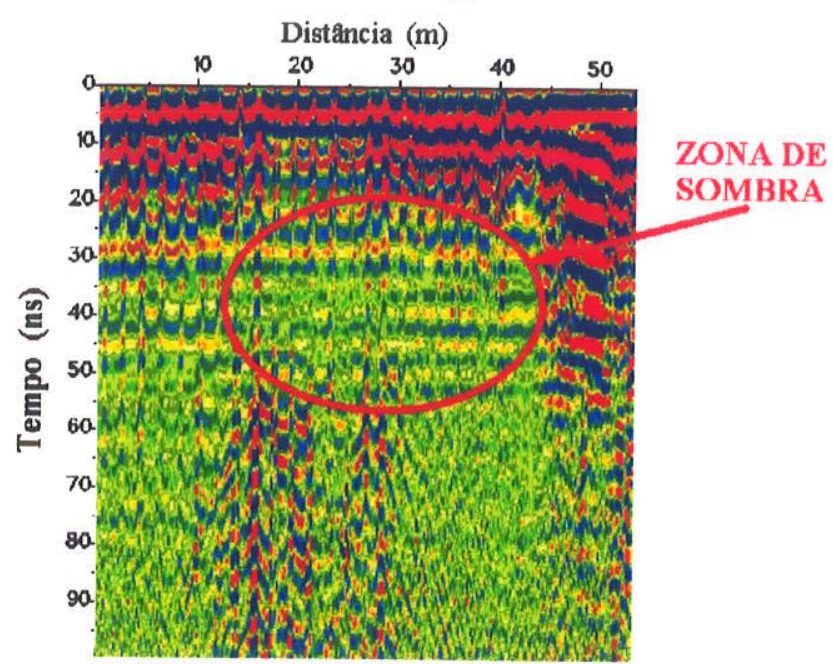


Perfil P-5 - Posto Freguesia do O

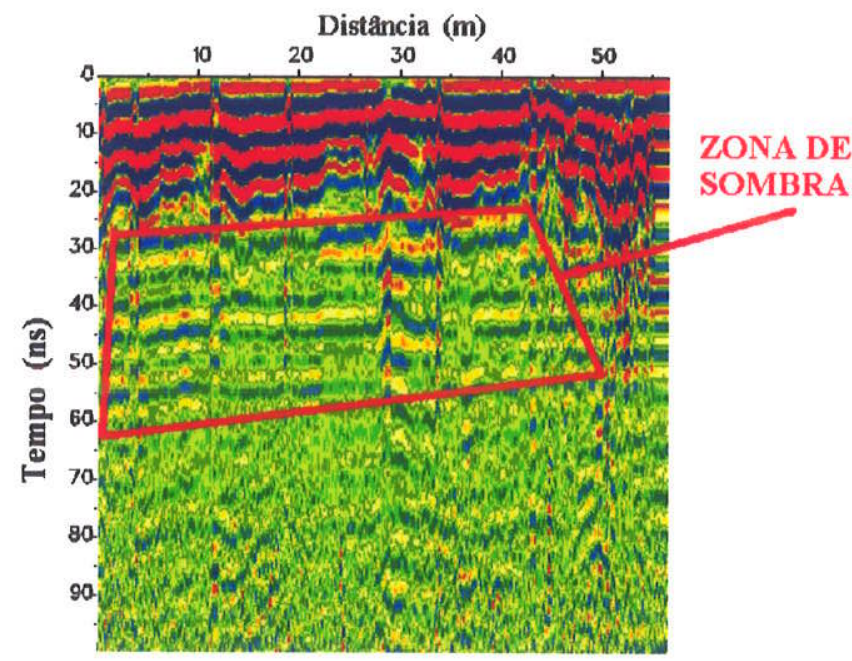

\section{Perfil P-6 - Posto Freguesia do Ó}

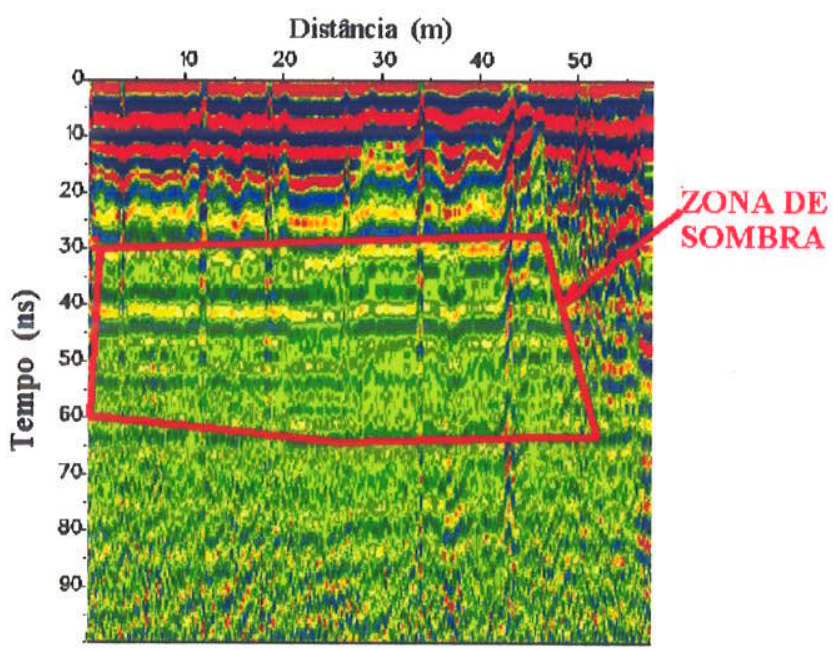

\section{Perfil P-6A - Posto Freguesia do Ó}

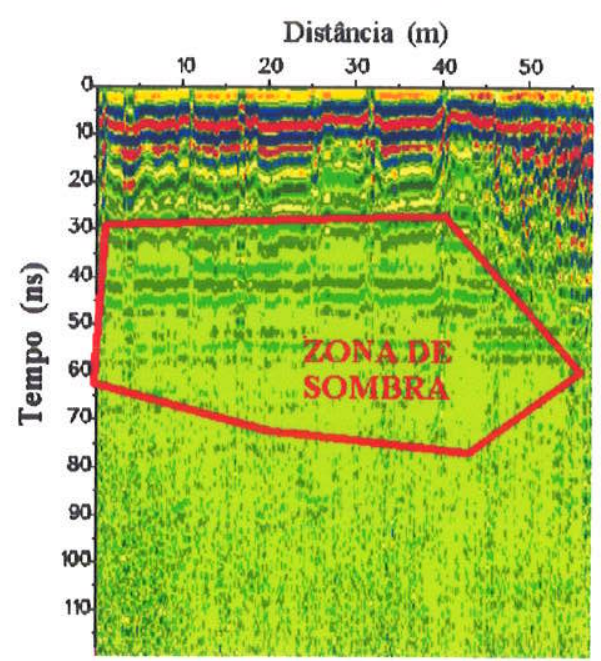




\section{Perfill P-7 - Posto Freguesia do Ó}
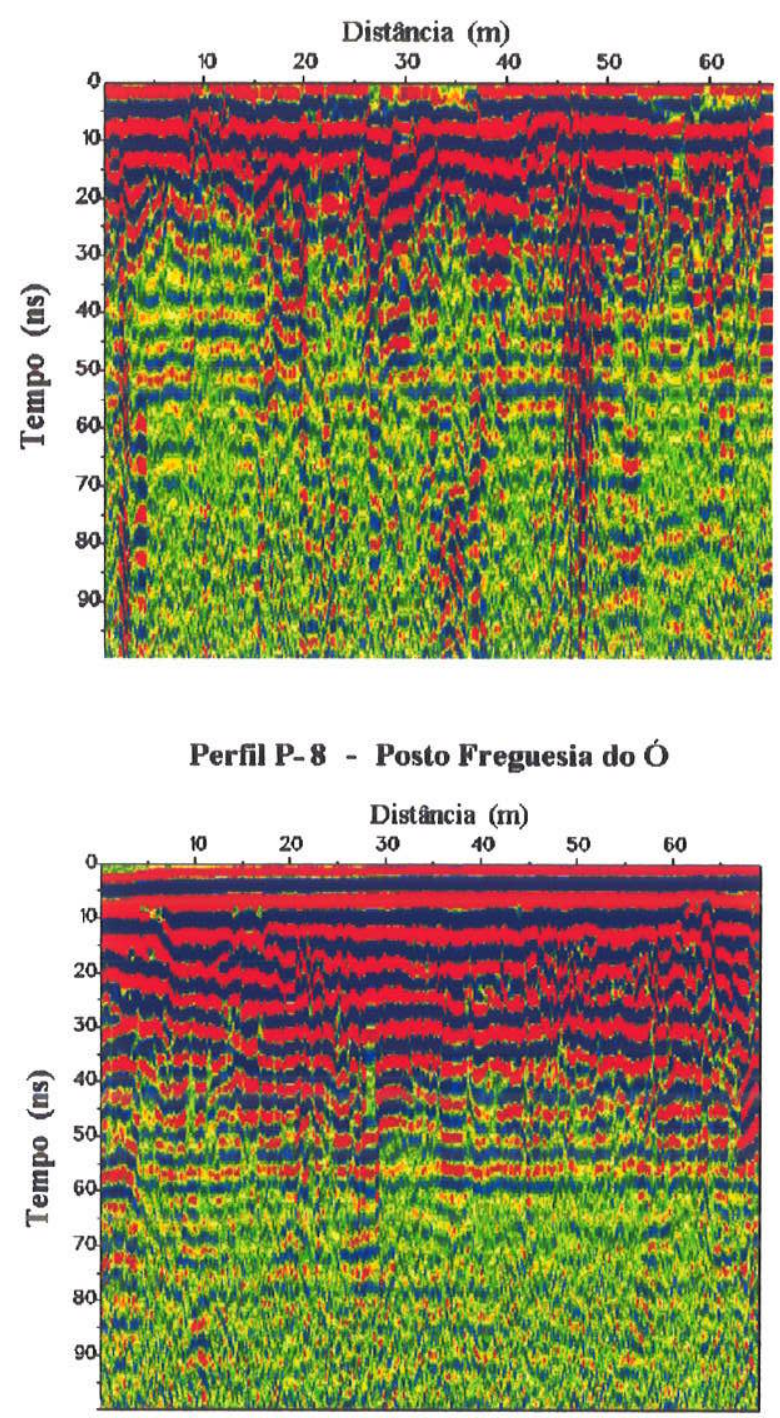

Perfil P-9 - Posto Freguesia do Ó

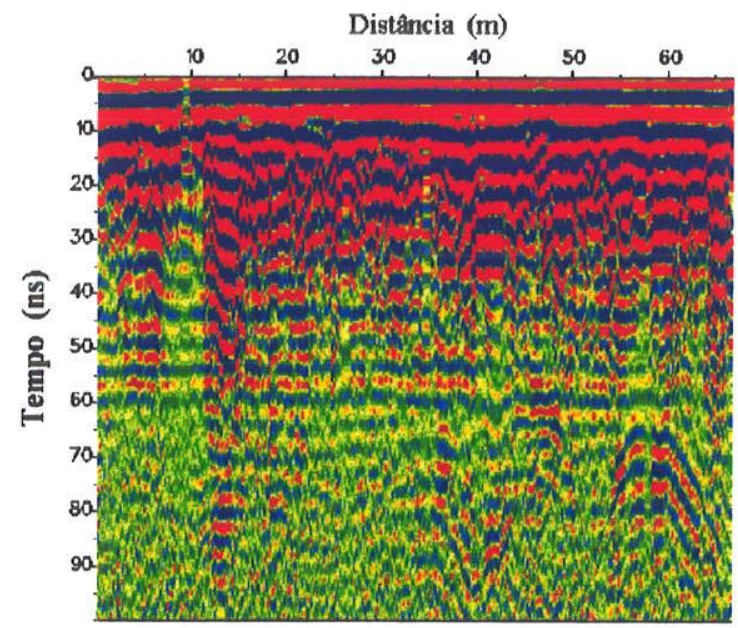




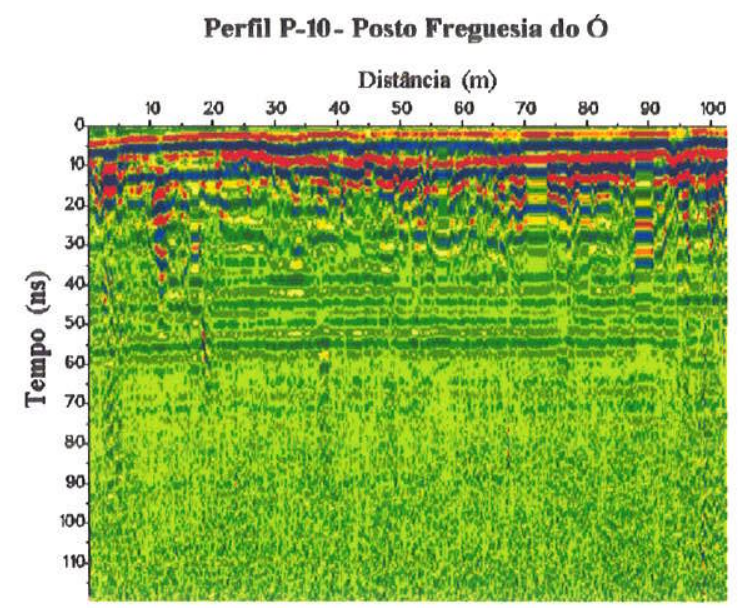

Perfil P-11 - Posto Freguesia do Ó

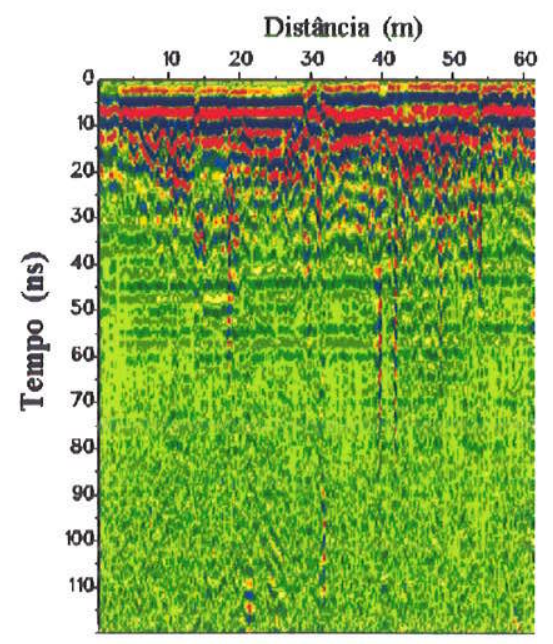

Perfil P-12 - Posto Freguesia do Ó

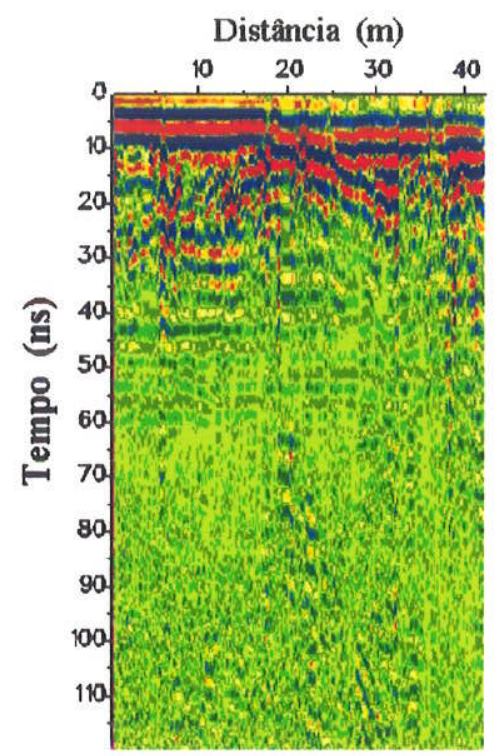




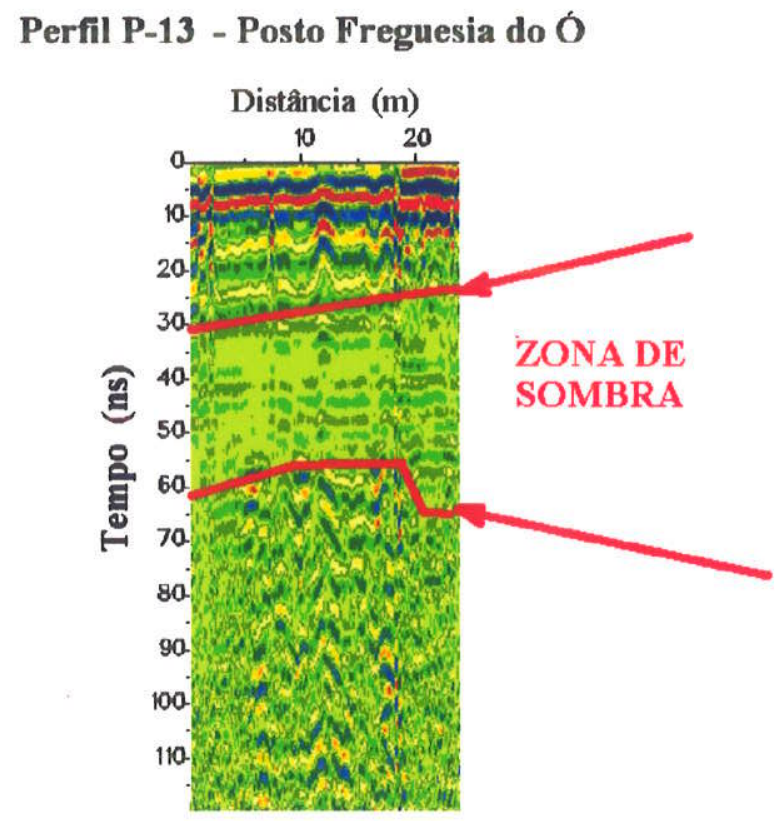

Perfil P-14 - Posto Freguesia do Ó

Distância (m)

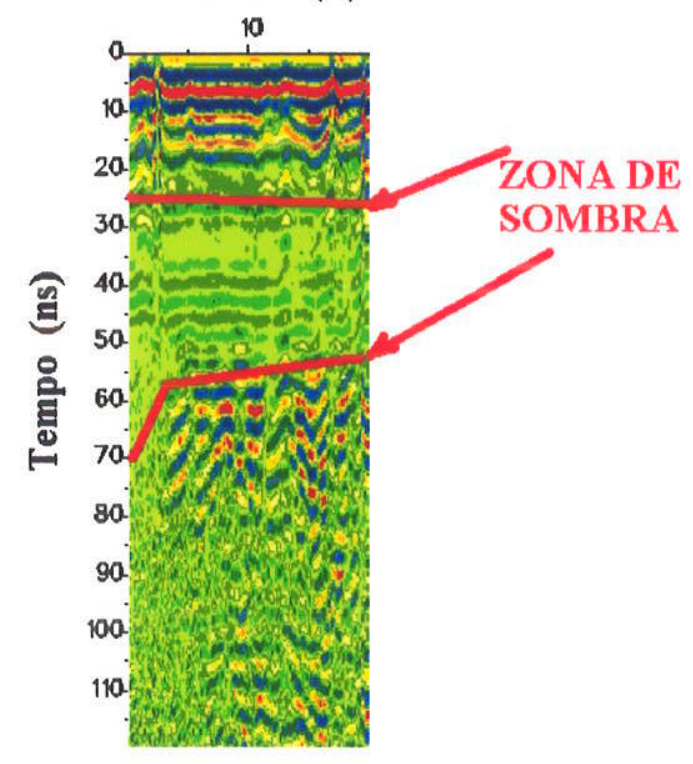


A N E X O VI 
Perfil P-1C - Posto Freguesia do Ó

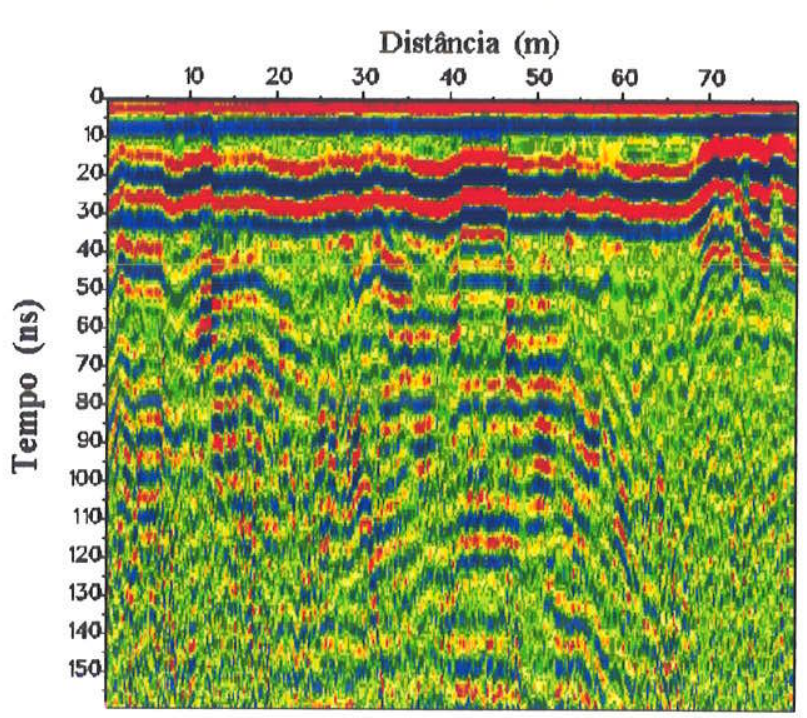

Perfil P-1D - Posto Freguesia do Ó
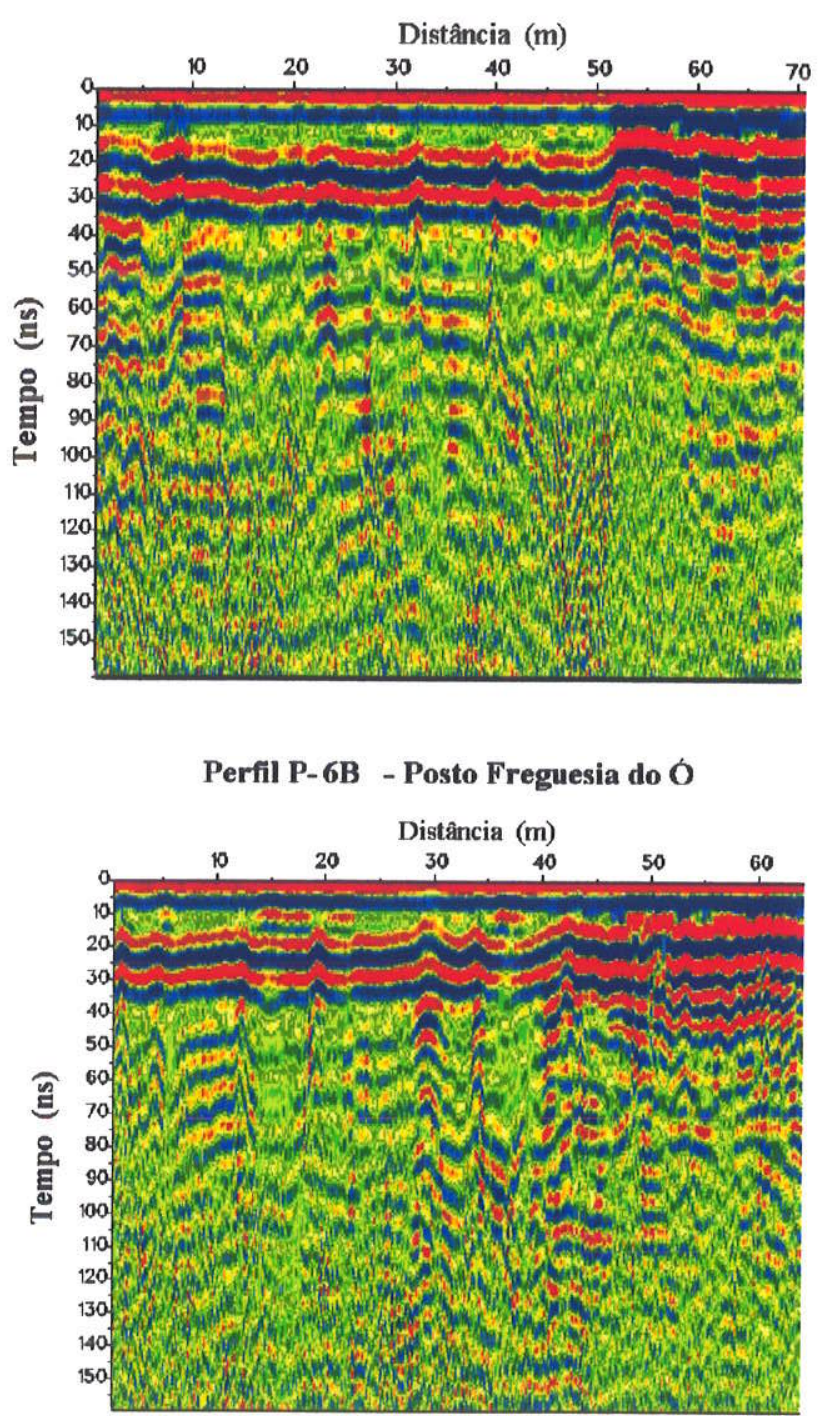
Perfil P-10A- Posto Freguesia do Ó

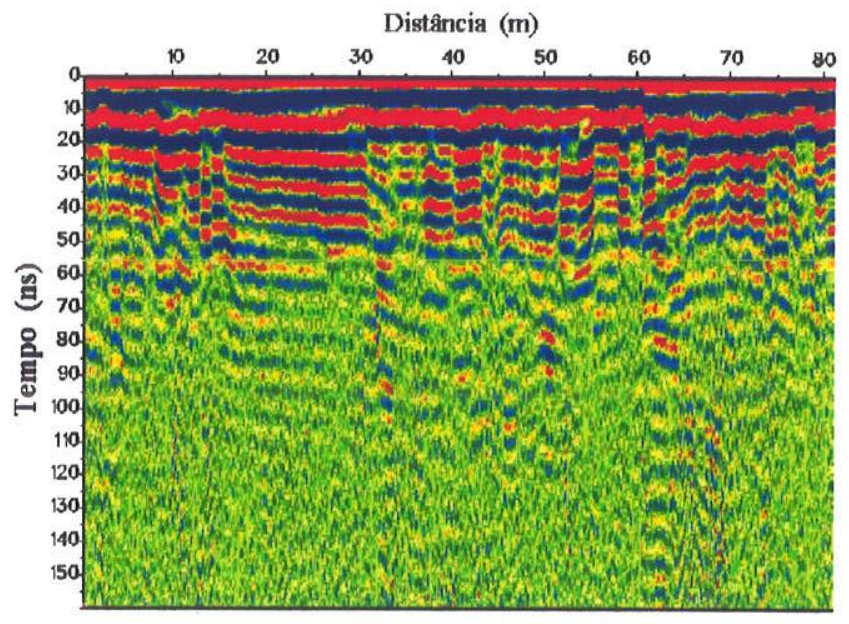

Perfil P-11A - Posto Freguesia do Ó

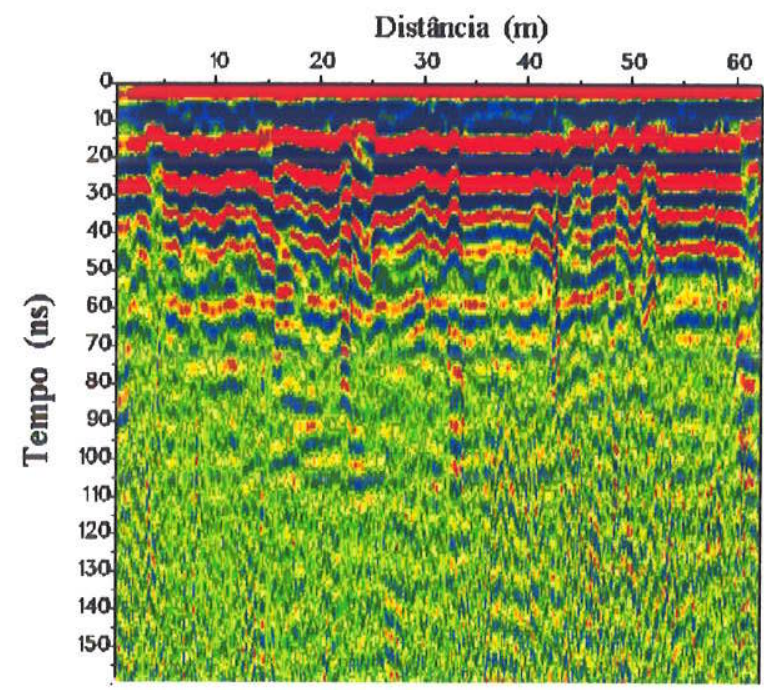

\section{Pernil P-12A - Posto Freguesia do Ó}

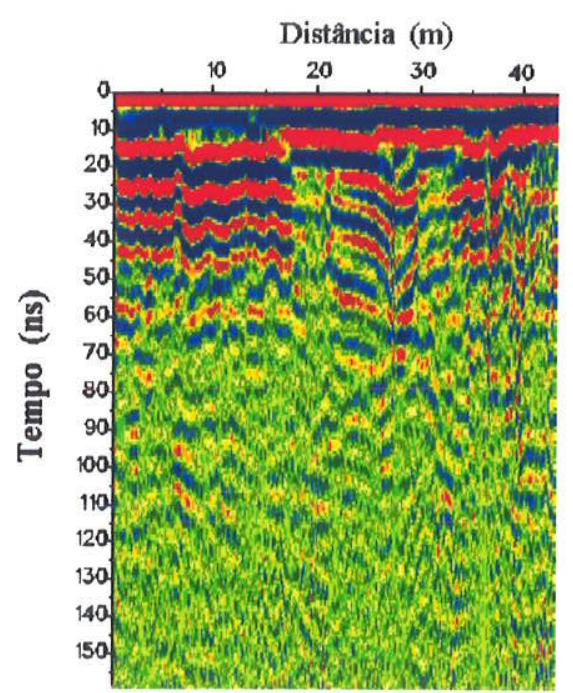




\section{Perfil P-13A - Posto Freguesia do Ó}

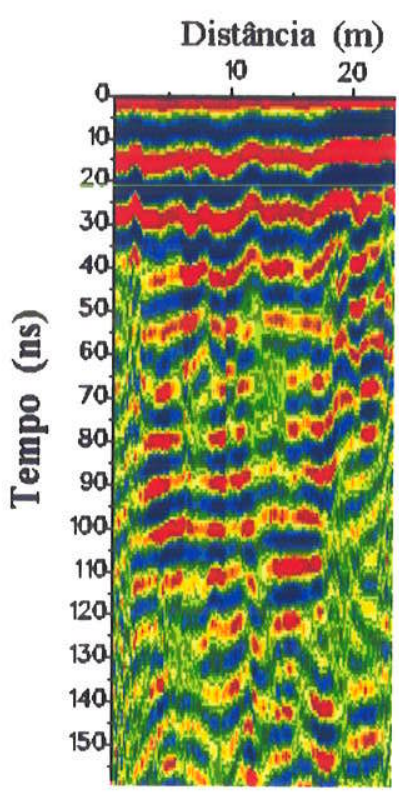

\section{Perfil P-14A - Posto Freguesia do Ó}

Distância (m)

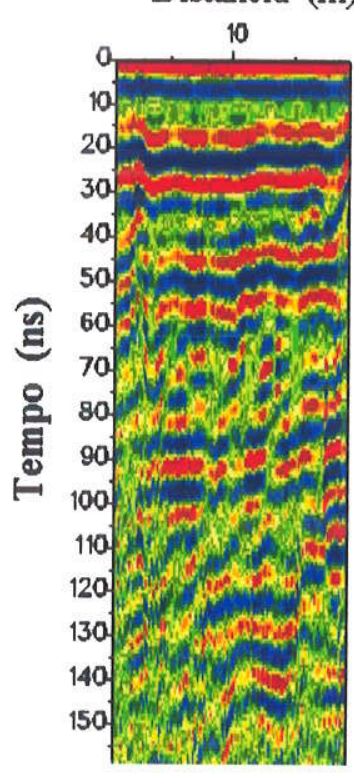


A N E X O VII 


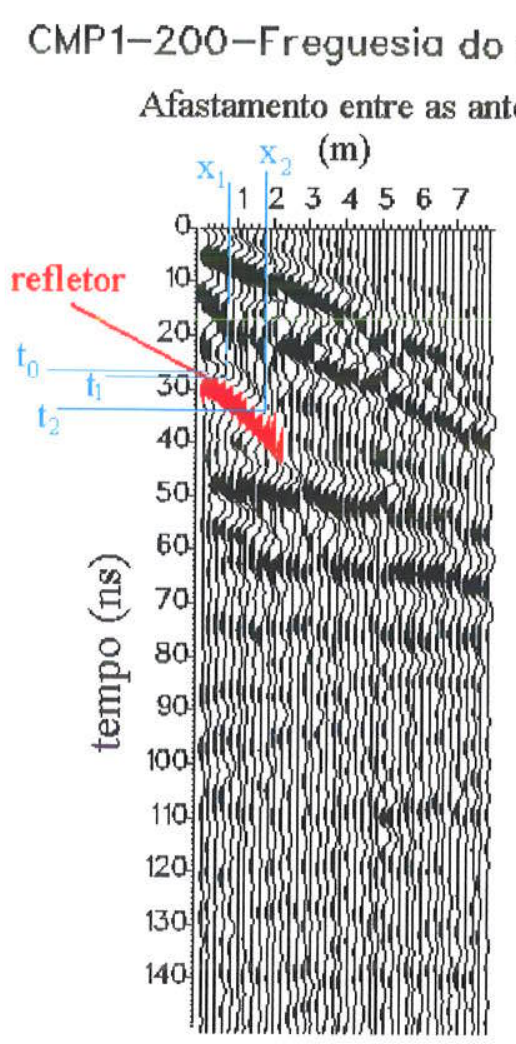

CMP2-200-Freguesia do ó Afastamento entre as antenas (m)

1234567

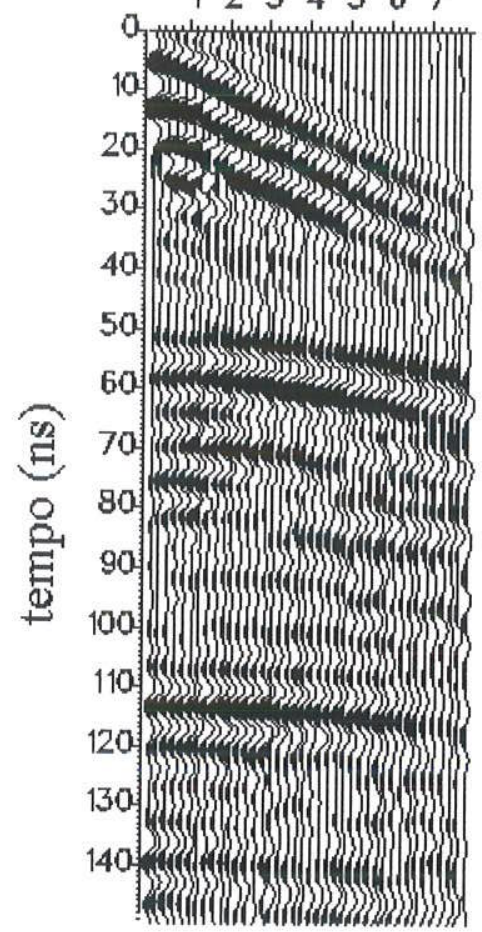

CMP1-100-Freguesia do ó

Afastamento entre as antenas

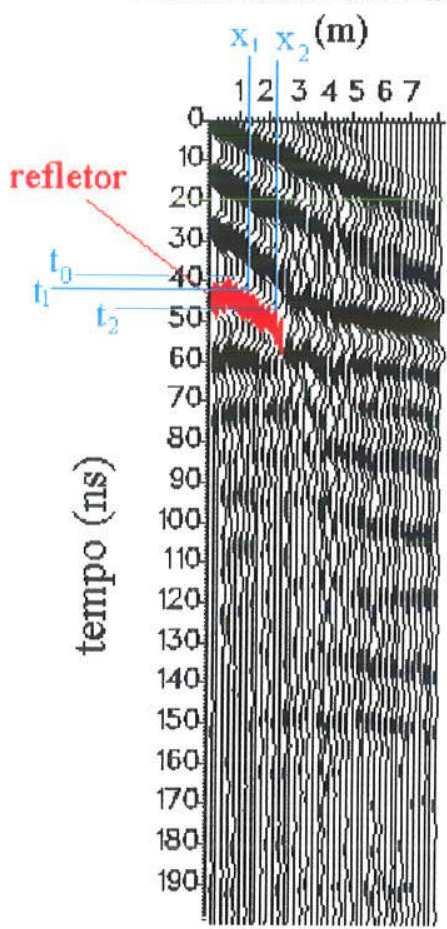

CMP2-100-Freguesia do ó Afastamento entre as antenas (m)

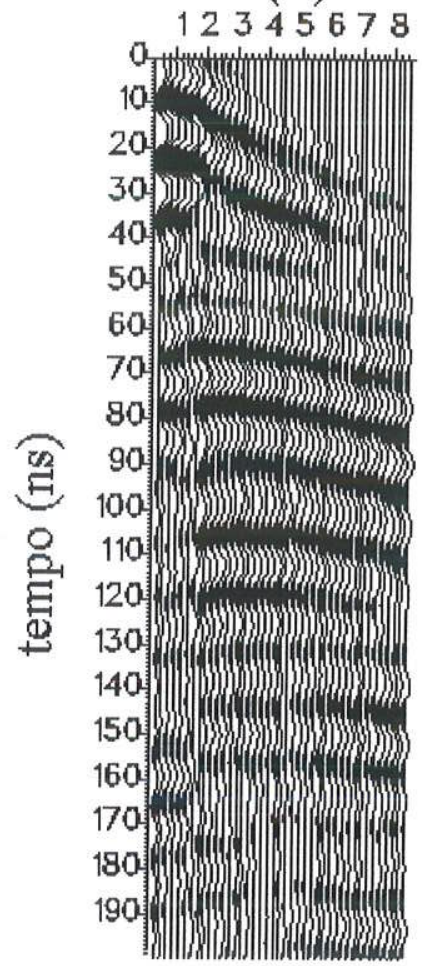


CMP3-Freguesia do Ó

Afastamento entre as antenas

(m)

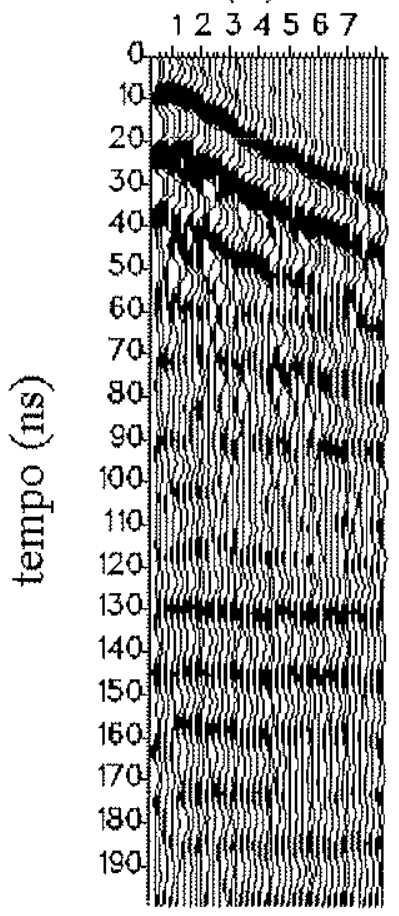

CMP-5-Freguesia do 0 Afastamento entre as antenas (m)

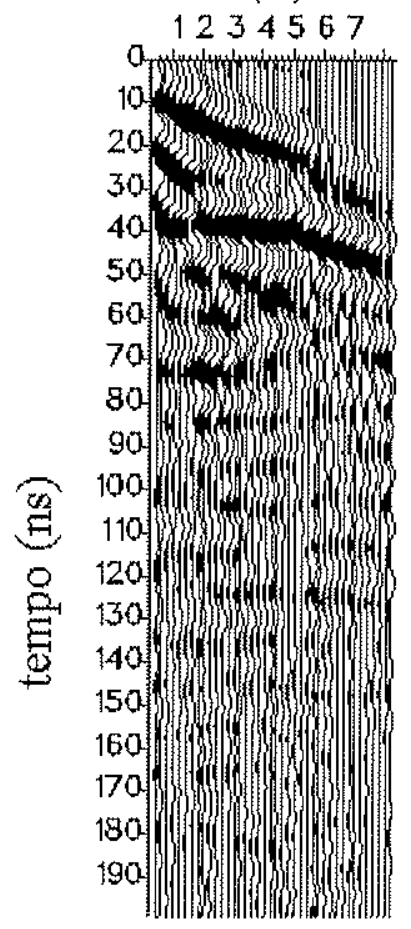

CMP-4 - Freguesia do Ó

Afastamento entre as antenas

(m)

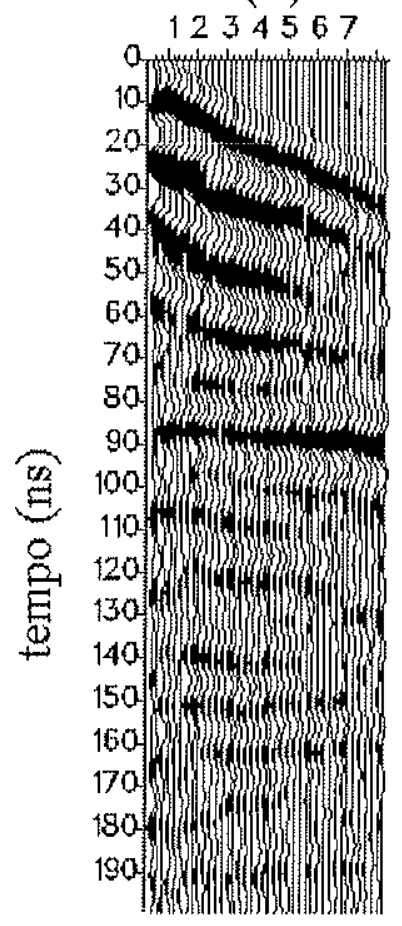

WARR-Freguesia do $́$

Afastamento entre as antenas

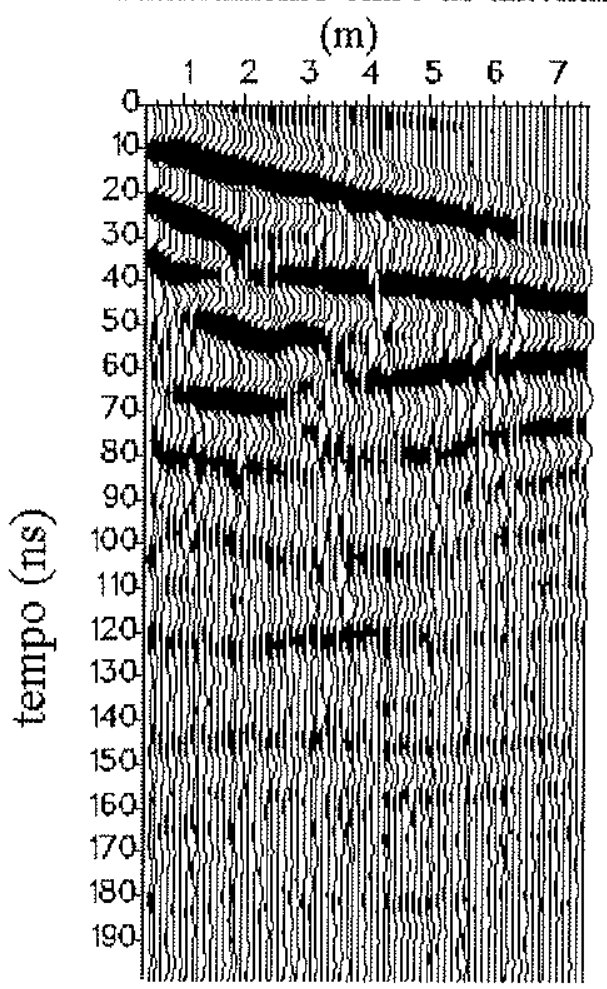


A N E X O VIII 


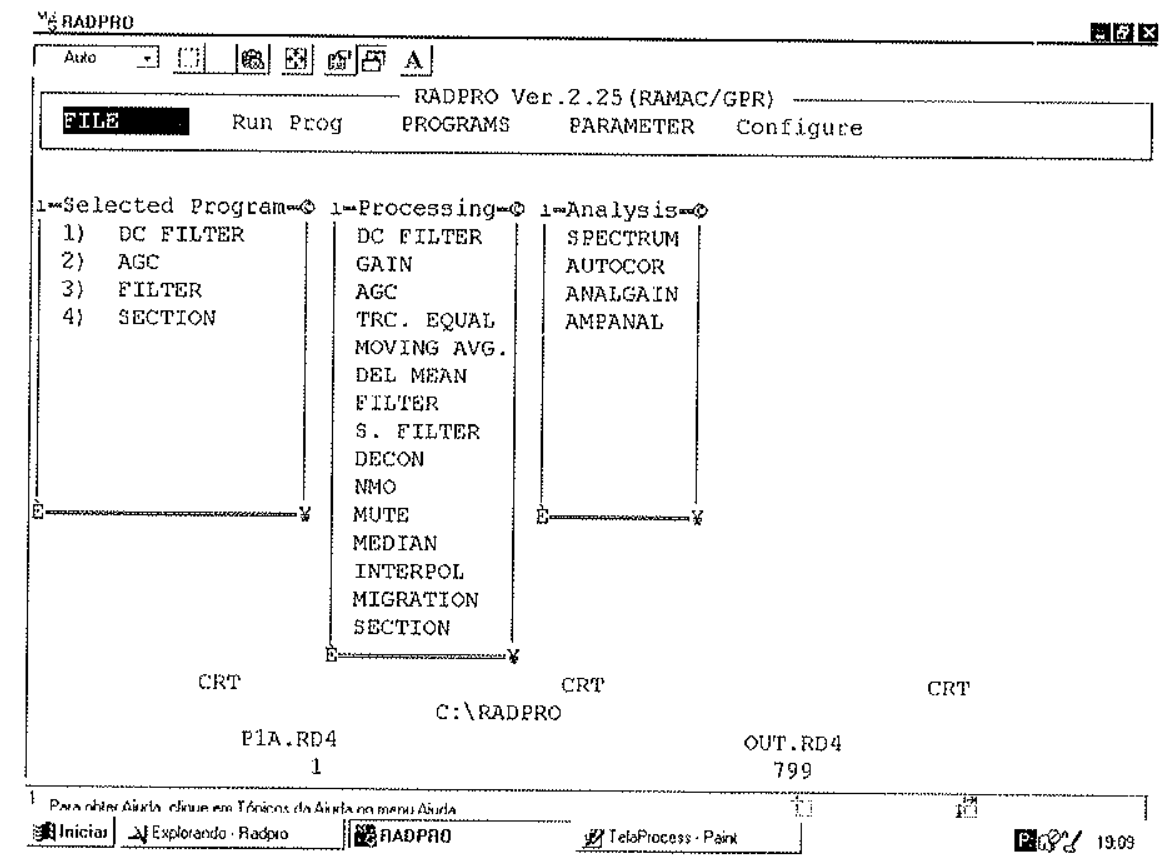

Figura A-VIII.1 - Sequência de passos do processamento em "Select Program" aplicado nas seções dos perfis levantados com a antena de $250 \mathrm{MHz}$

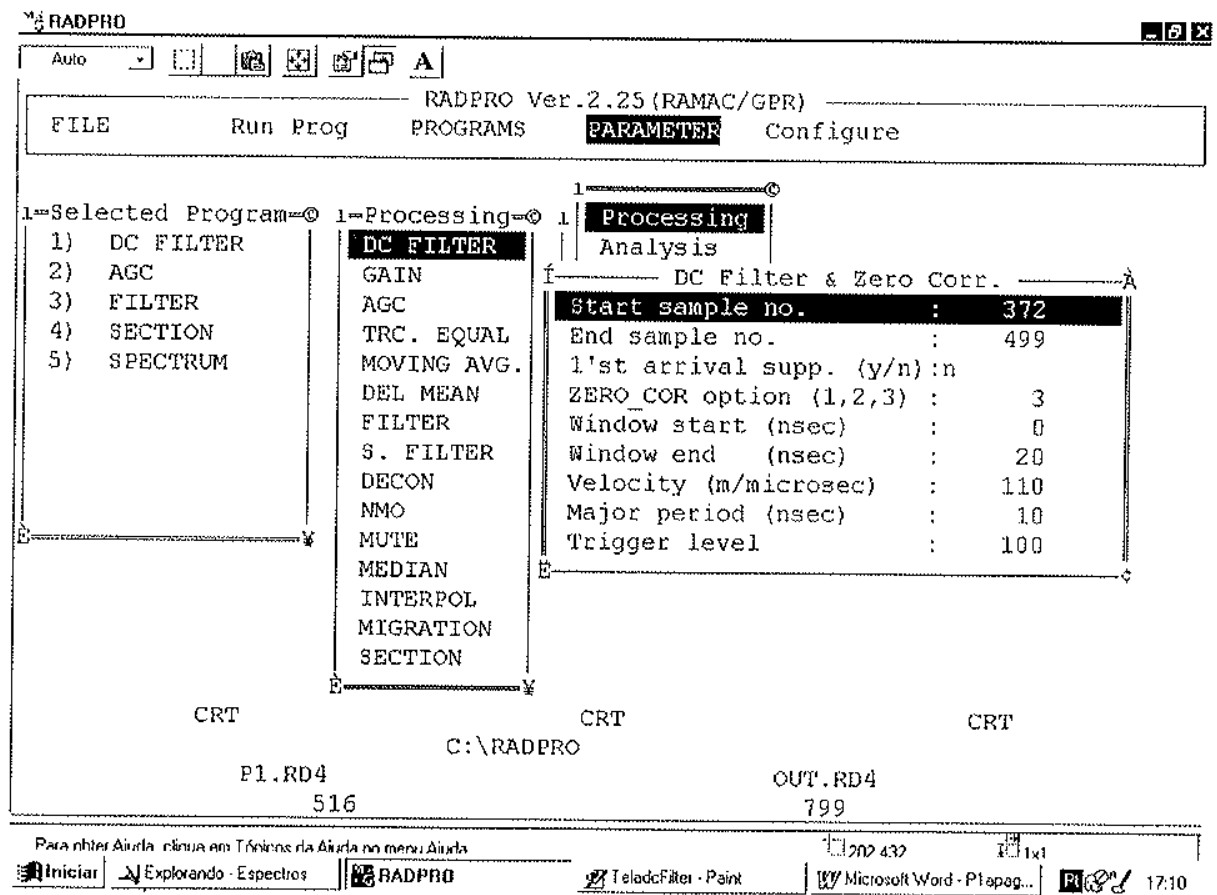

Figura A-VIII.2 - Parâmetros definidos no programa "DC-FILTER" aplicado nas seções dos perfis levantados com a antena de $250 \mathrm{MHz}$ 


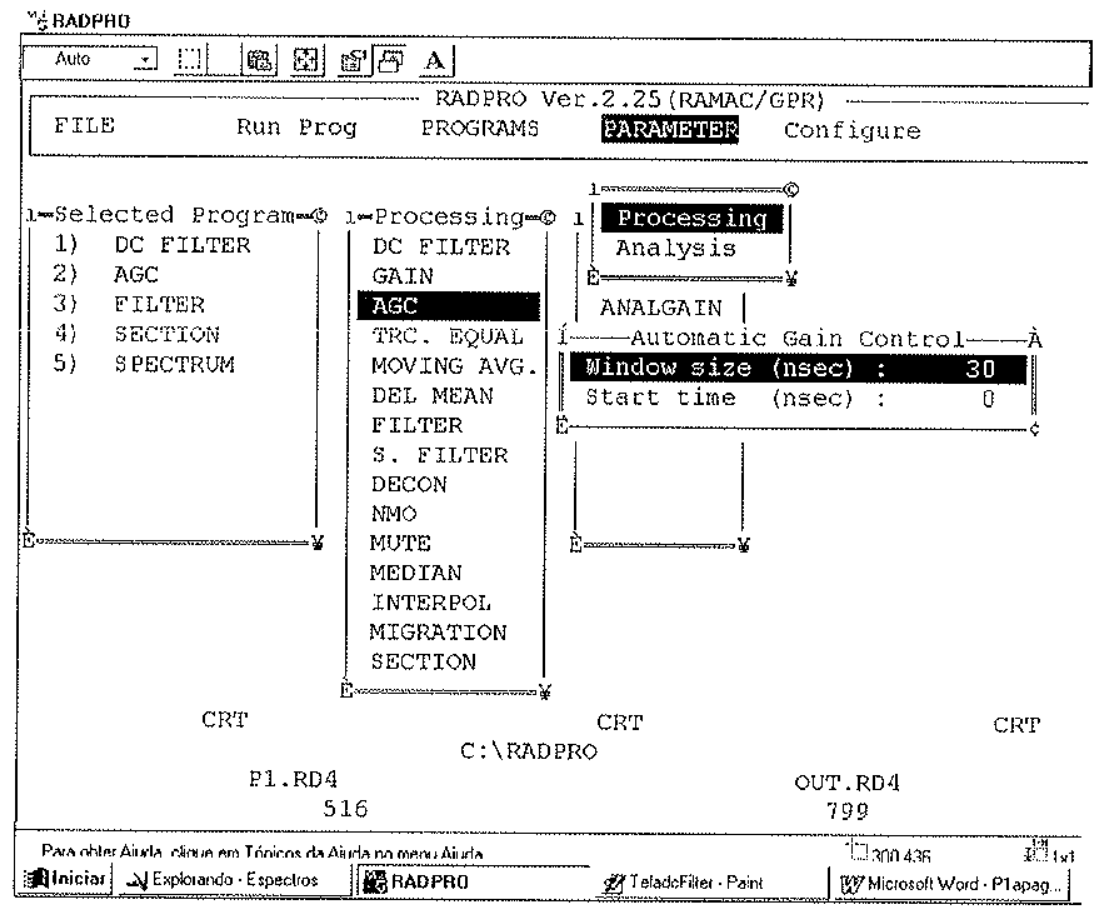

Figura A-VIII.3 - Parâmetros definidos no programa "AGC " aplicado nas seções dos perfis levantados com a antena de $250 \mathrm{MHz}$

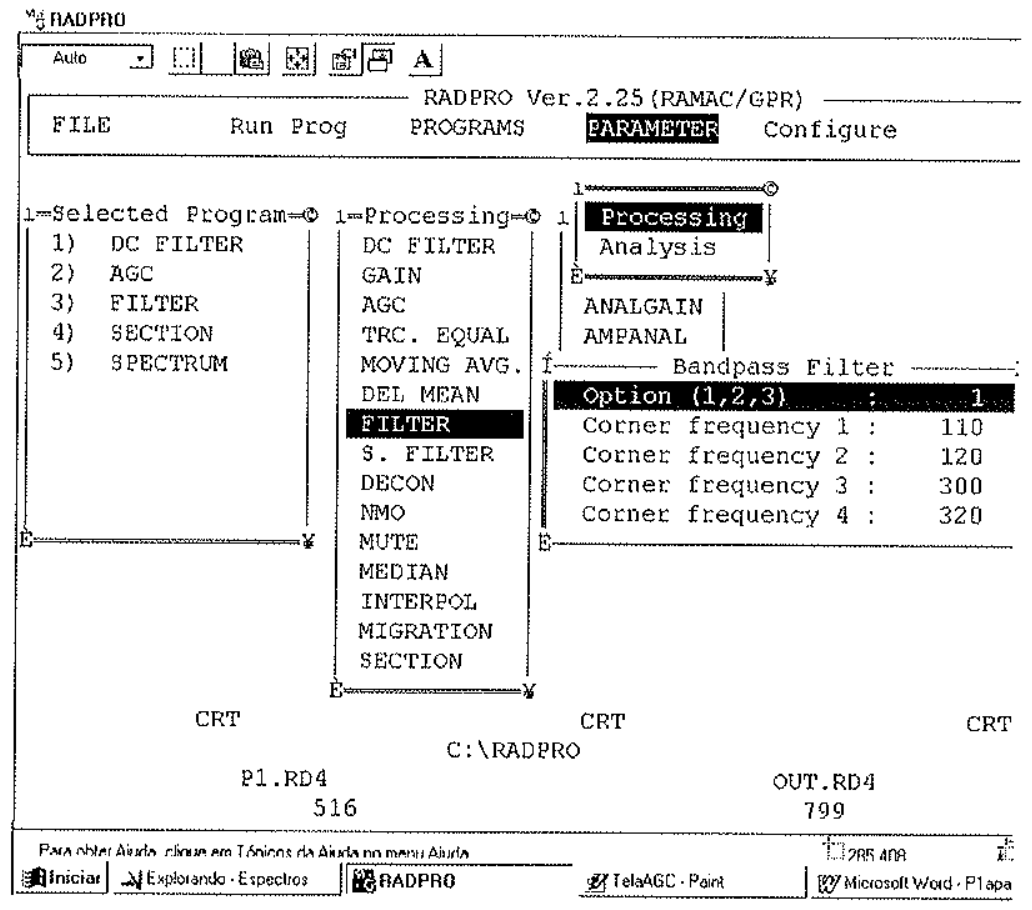

Figura A-VIII.4 - Parâmetros definidos no programa "FILTER" aplicado nas seções dos perfis levantados com a antena de $250 \mathrm{MHz}$ 


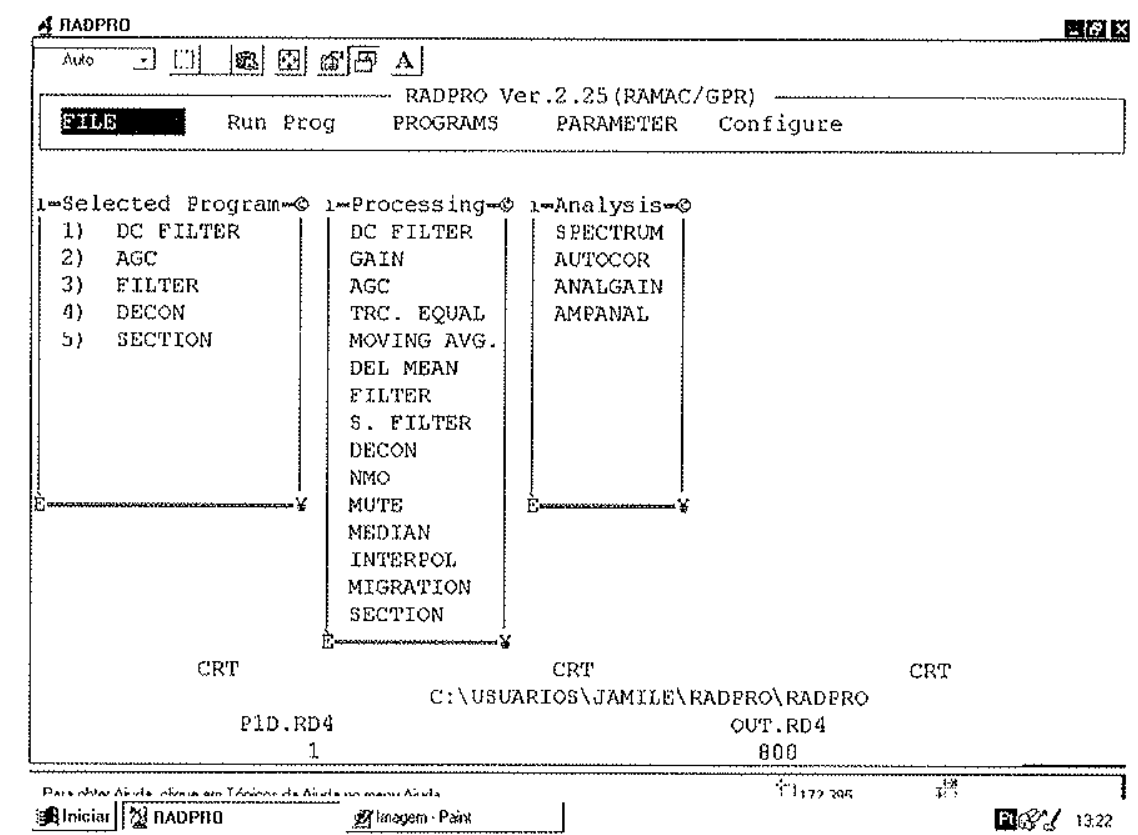

Figura A-VIII.5 - Sequência de passos do processamento em "Select Program" aplicado nas seções dos perfis levantados com a antena de $100 \mathrm{MHz}$

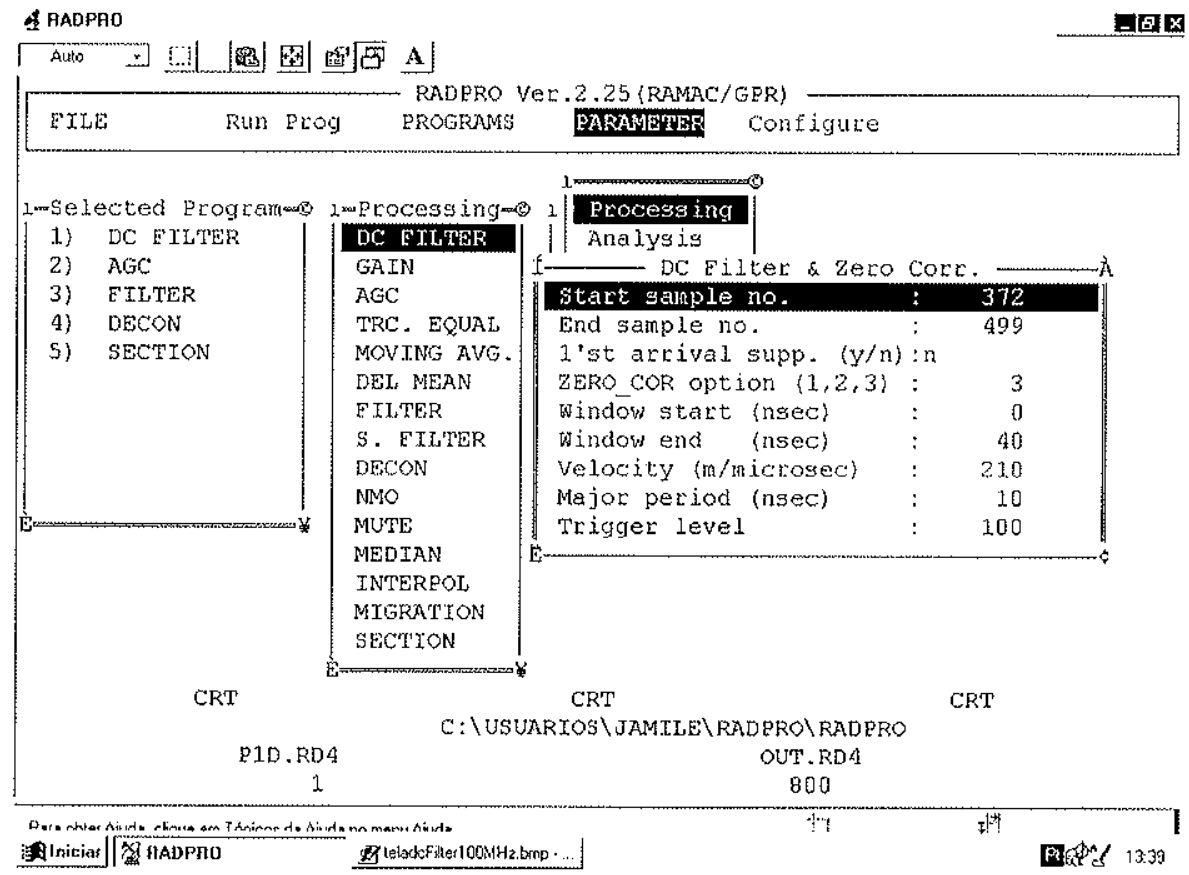

Figura A-VIII.6 - Parâmetros definidos no programa "DC-FILTER" aplicado nas seções dos perfis levantados com a antena de $100 \mathrm{MHz}$ 
A RABPHO

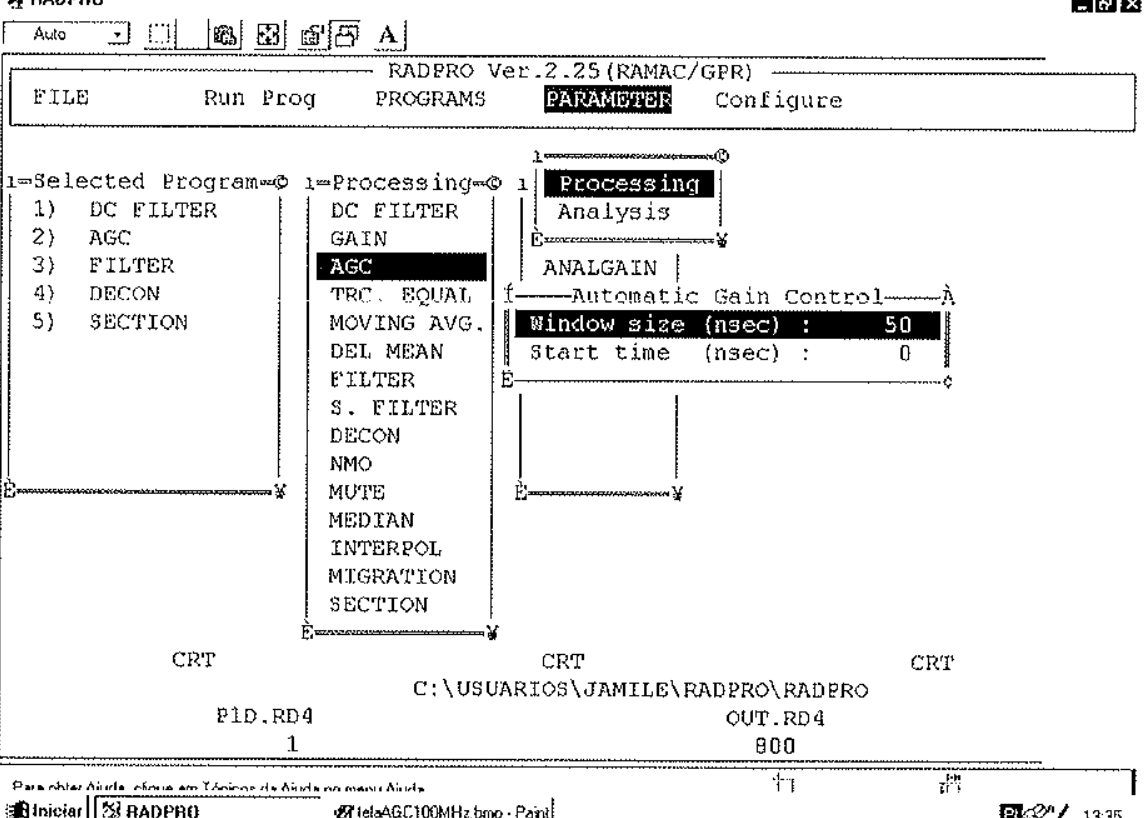

Aniciar

PI68: 13:35

Figura A-VIII.7 - Parâmetros definidos no programa "AGC " aplicado nas seções dos perfis levantados com a antena de $100 \mathrm{MHz}$

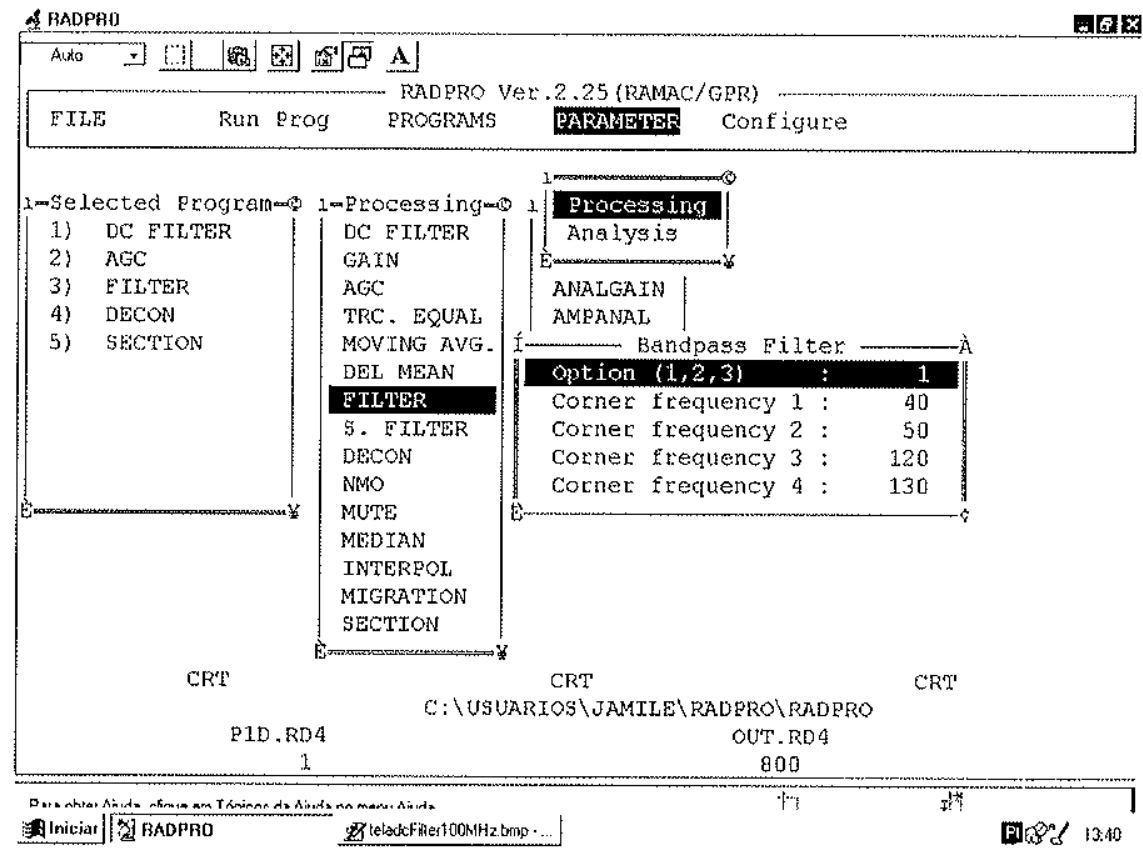

Figura A-VIII.8 - Parâmetros definidos no programa "FILTER" aplicado nas seções dos perfis levantados com a antena de $100 \mathrm{MHz}$ 


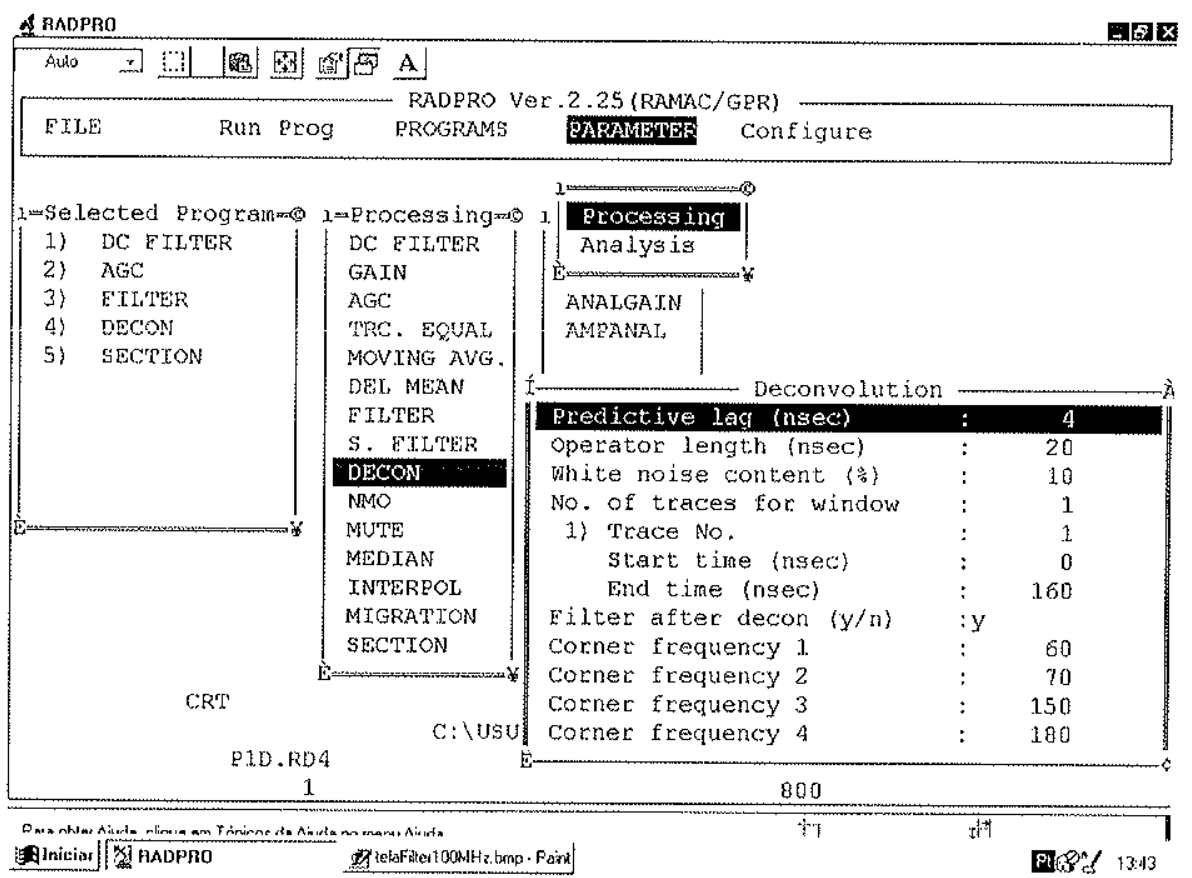

Figura A-VIII.9 - Parâmetros definidos no programa "DECON" aplicado nas seções dos perfis levantados com a antena de $100 \mathrm{MHz}$ 
A N E X O IX 


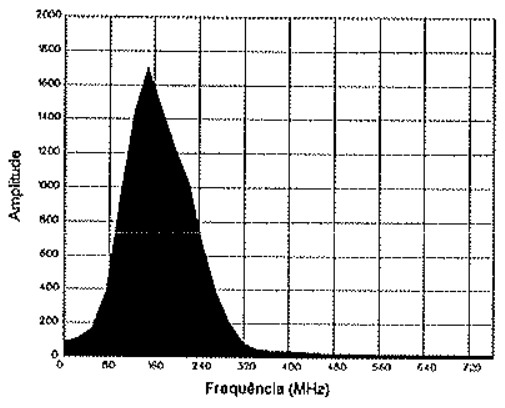

(a)

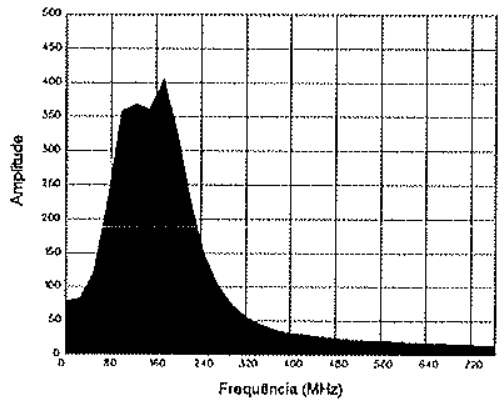

(b)

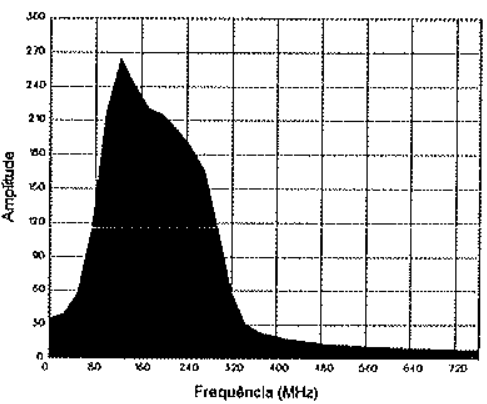

(c)

Figura A-IX.1 - Gráficos resultantes da análise espectral feita sobre os dados processados do perfil $P-1$ inteiro nos seguintes periodos: (a) 0-30ns; (b) 30-60ns e (c) 60-100ns

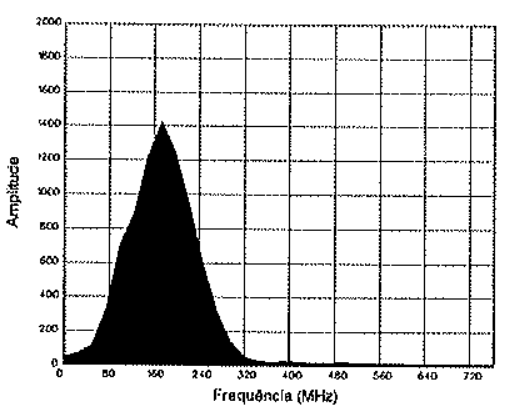

(a)

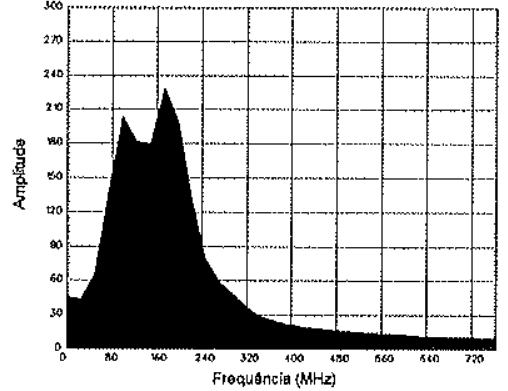

(b)

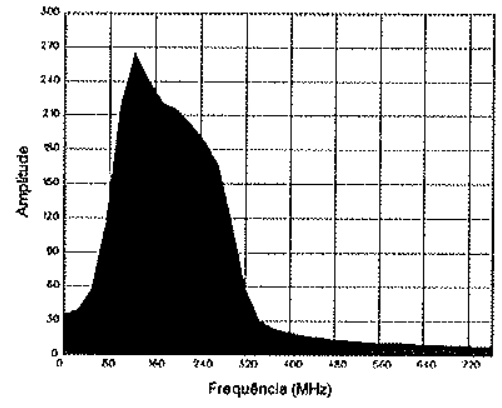

(c)

Figura A-IX.2 - Gráficos resultantes da análise espectral feita sobre os dados processados no trecho correspondente à "zona de sombra" do perfil P-1 nos seguintes periodos: (a) 0-30ns; (b) 30-60ns e (c) $60-100 \mathrm{~ns}$

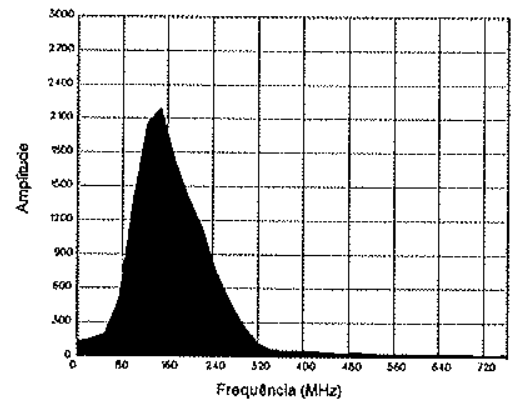

(a)

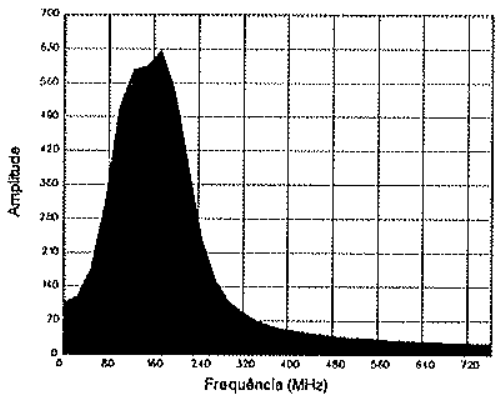

(b)

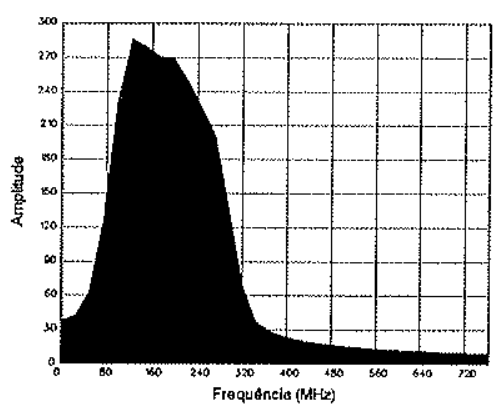

(c)

Figura A-IX.3 - Gráficos resultantes da análise espectral feita sobre os dados processados do periil P-1 no trecho sem "zona de sombra", nos seguintes periodos: (a) 0-30ns; (b) 30-60ns e (c) 60-100ns 


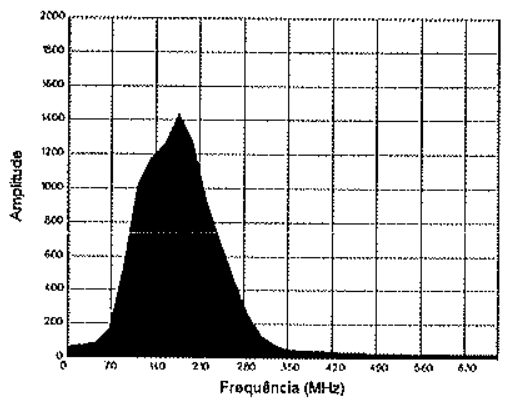

(a)

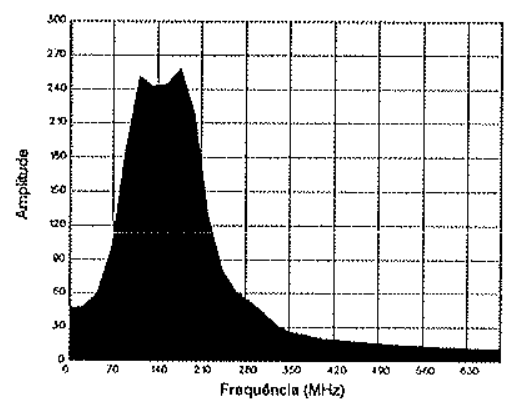

(b)

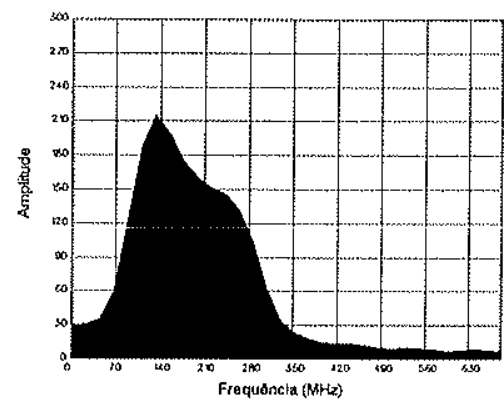

(c)

Figura A-IX.4 - Gráficos resultantes da análise espectral feita sobre os dados processados do perfil P-1A inteiro nos seguintes periodos: (a) 0-30ns; (b) 30-60ns e (c) 60-100ns

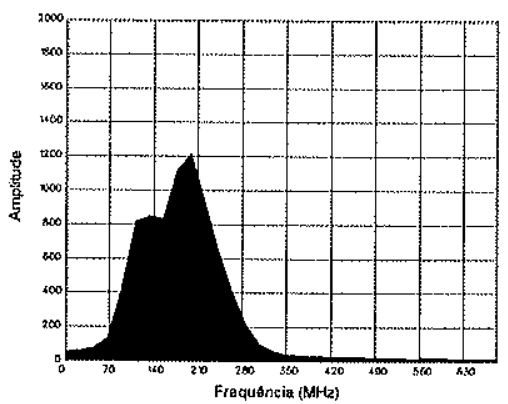

(a)

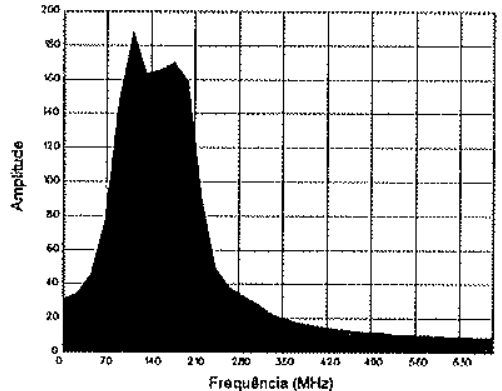

(b)

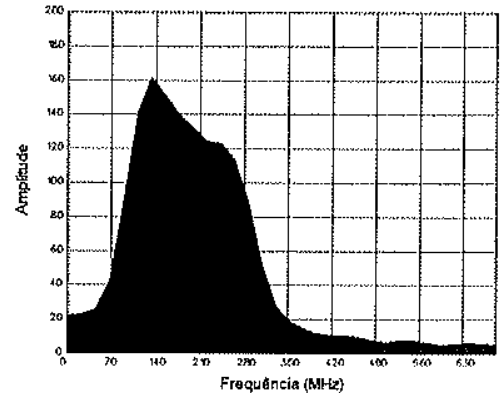

(c)

Figura A-IX.5 - Gráficos resultantes da análise espectral feita sobre os dados processados no trecho correspondente à "zona de sombra" do perfil P-1A nos seguintes períodos: (a) 0-30ns; (b) 30-60ns e (c) $60-100 \mathrm{~ns}$

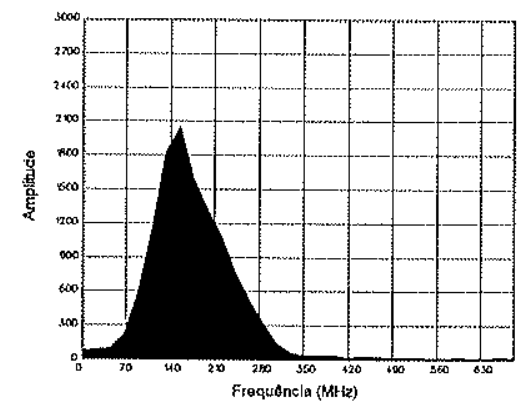

(a)

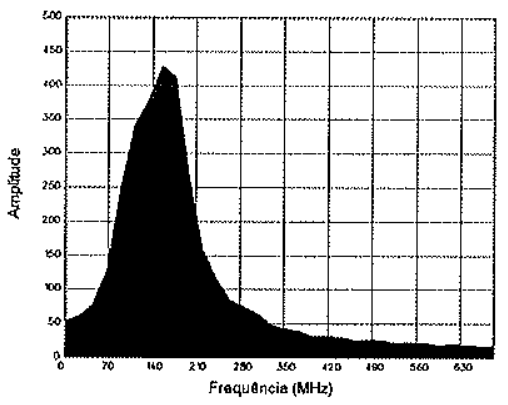

(b)

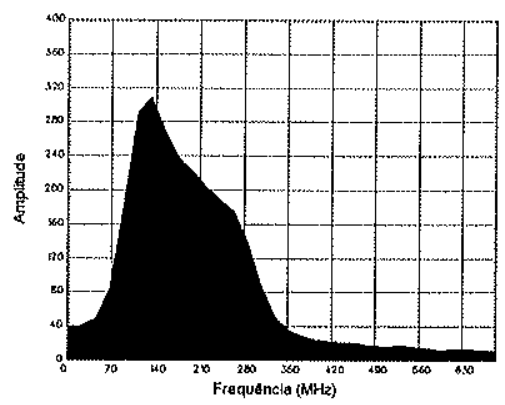

(c)

Figura A-IX.6 - Gráficos resultantes da análise espectral feita sobre os dados processados do perfil P-1A no trecho sem "zona de sombra", nos seguintes periodos: (a) 0-30ns; (b) 30-60ns e (c) 60$100 \mathrm{~ns}$ 


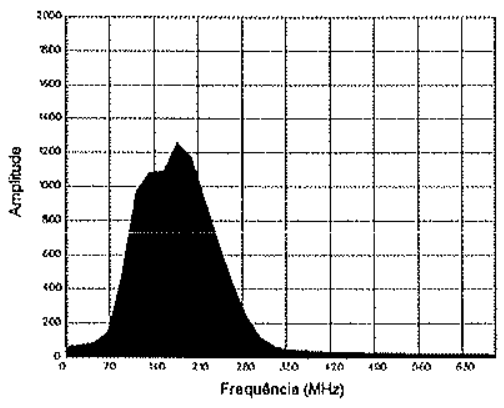

(a)

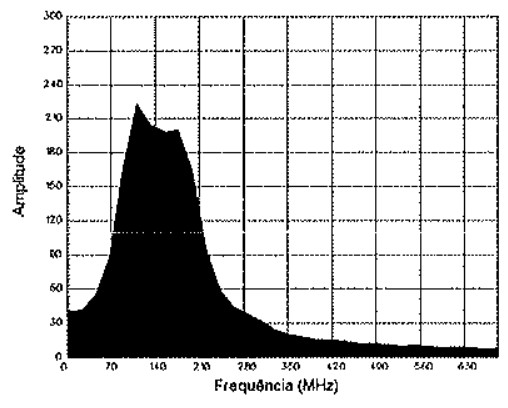

(b)

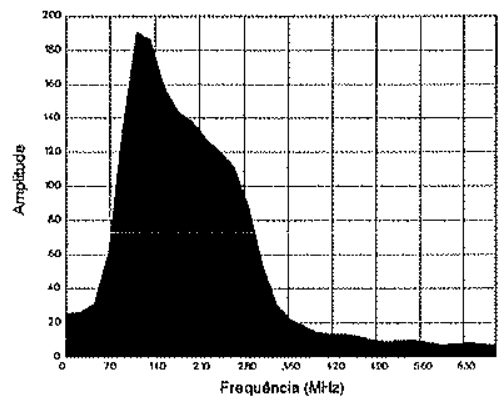

(c)

Figura A-IX.7 - Gráficos resultantes da análise espectral feita sobre os dados processados do perfil P-1B inteiro nos seguintes periodos: (a) 0-30ns; (b) 30-60ns e (c) 60-100ns

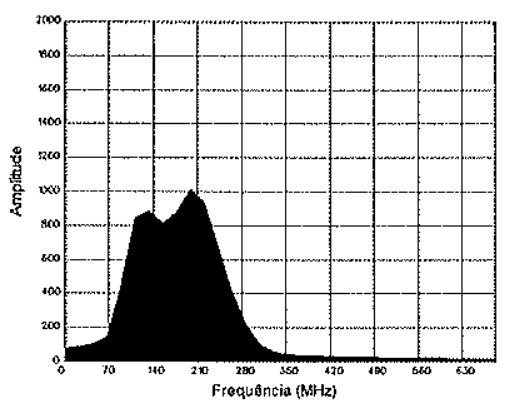

(a)

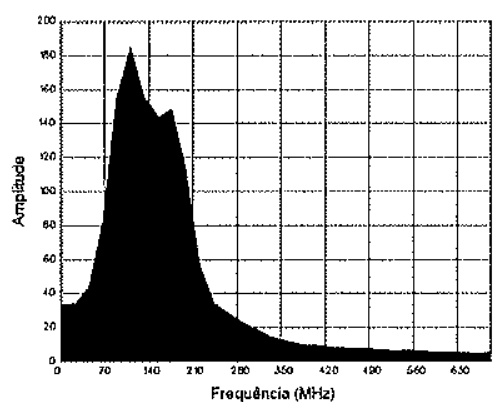

(b)

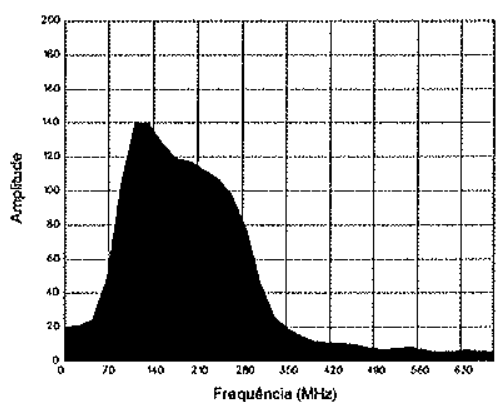

(c)

Figura A-IX.8 - Gráficos resultantes da análise espectral feita sobre os dados processados no trecho correspondente à "zona de sombra" do perfil P-1B nos seguintes períodos: (a) 0-30ns; (b) 30-60ns e (c) $60-100 \mathrm{~ns}$

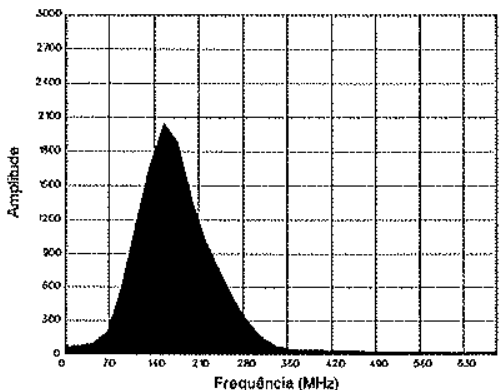

(a)

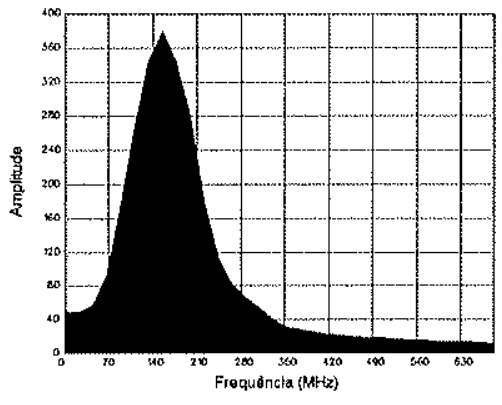

(b)

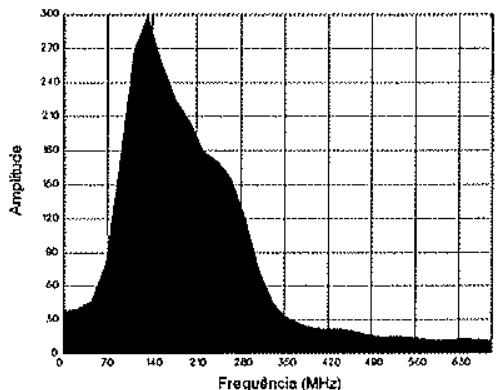

(c)

Figura A-IX.9 - Gráficos resultantes da análise espectral feita sobre os dados processados do perfil P-1B no trecho sem "zona de sombra", nos seguintes períodos: (a) 0-30ns; (b) 30-60ns e (c) 60$100 \mathrm{~ns}$ 


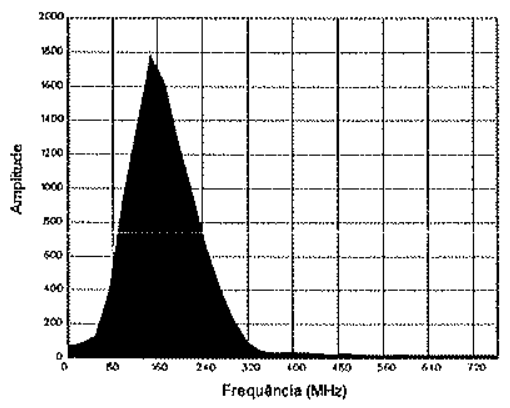

(a)

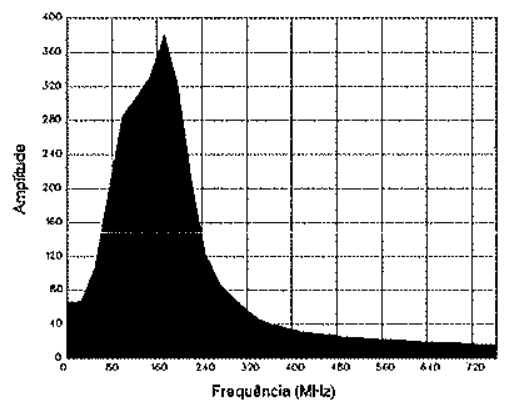

(b)

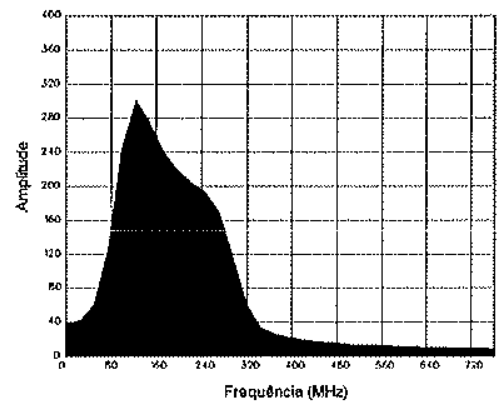

(c)

Figura A-IX.10 - Gráficos resultantes da análise espectral feita sobre os dados processados do pertil P-2 inteiro nos seguintes periodos: (a) 0-30ns; (b) 30-60ns e (c) 60-100ns

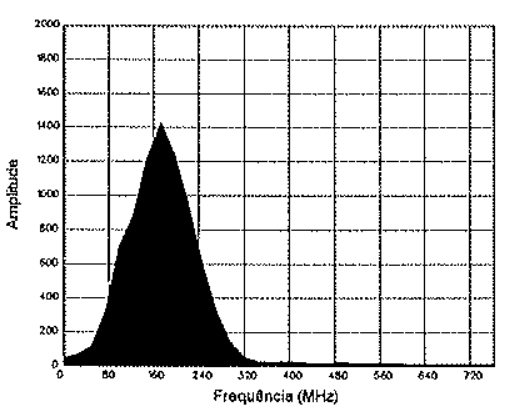

(a)

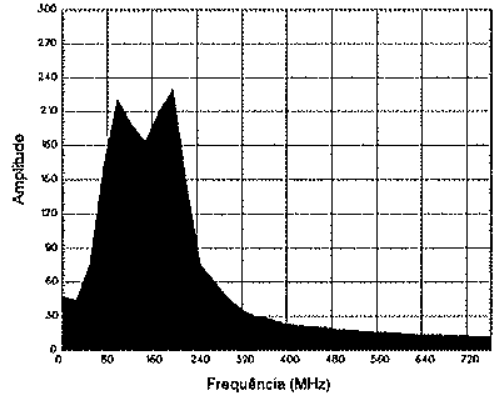

(b)

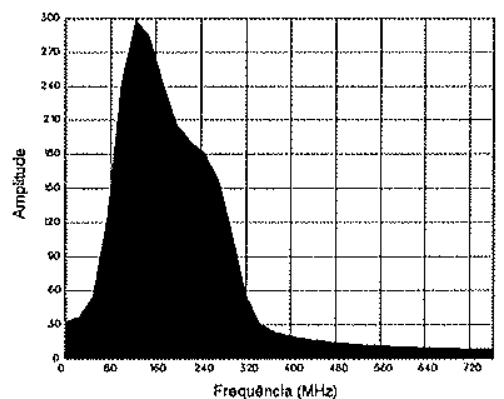

(c)

Figura A-IX.11 - Gráficos resultantes da análise espectral feita sobre os dados processados no trecho correspondente à "zona de sombra" do perfil P-2 nos seguintes períodos: (a) 0-30ns; (b) 30$60 \mathrm{~ns}$ e (c) 60-100ns

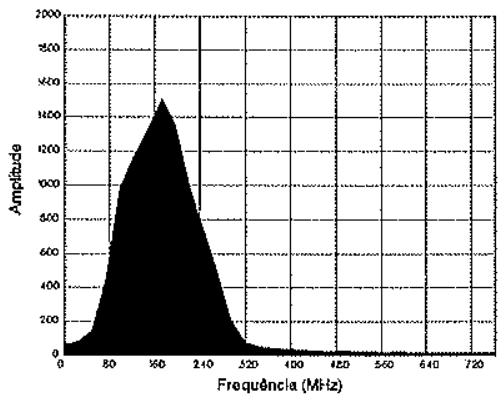

(a)

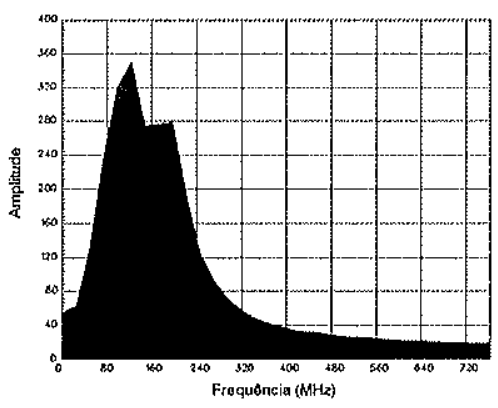

(b)

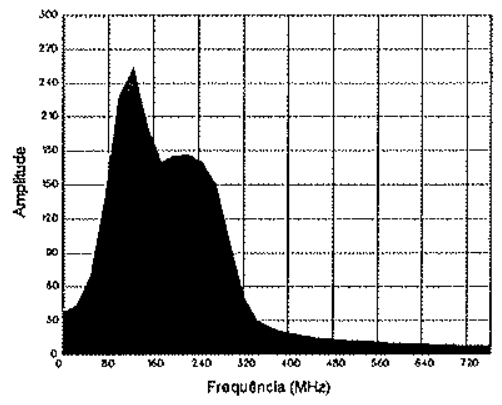

(c)

Figura A-IX.12 - Gráficos resultantes da análise espectral feita sobre os dados processados do perfil P-2 no trecho sem "zona de sombra", nos seguintes períodos: (a) 0-30ns; (b) 30-60ns e (c) 60-100ns 


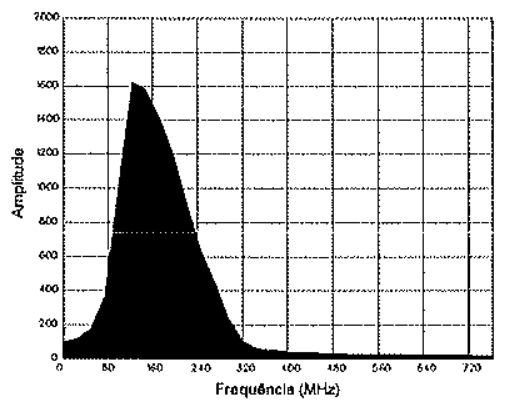

(a)

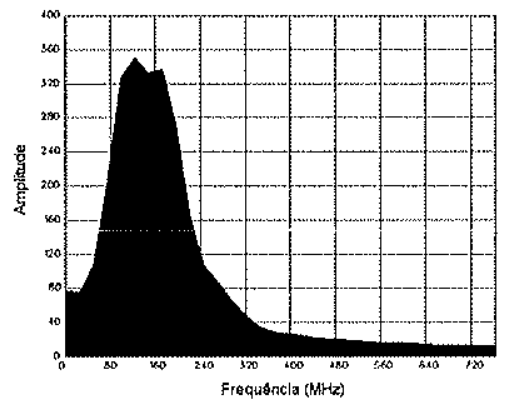

(b)

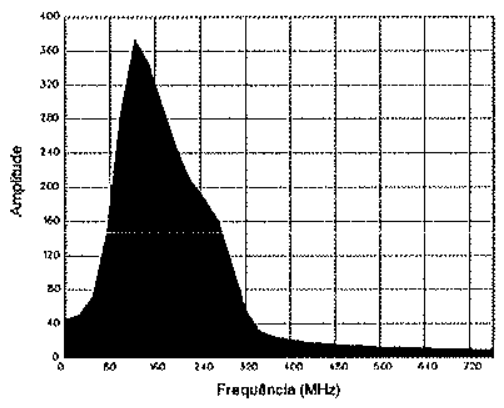

(c)

Figura A-IX.13 - Gráficos resultantes da análise espectral feita sobre os dados processados do perfil P.-3 inteiro nos seguintes períodos: (a) 0-30ns; (b) 30-60ns e (c) 60-100ns

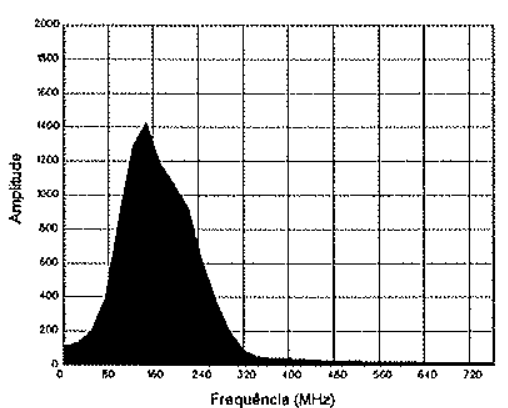

(a)

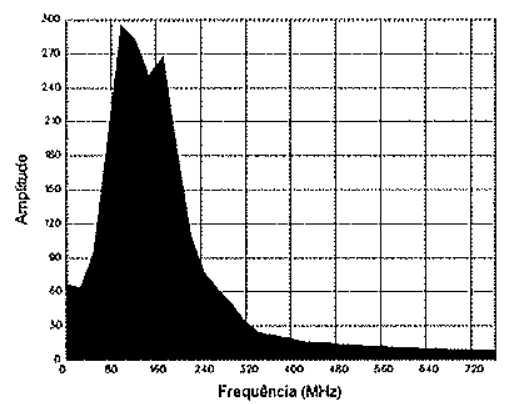

(b)

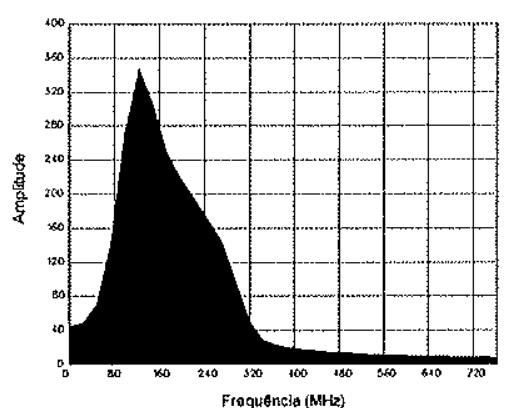

(c)

Figura A-IX.14 - Gráficos resultantes da análise espectral feita sobre os dados processados no trecho correspondente à "zona de sombra" do perfil P-3 nos seguintes períodos: (a) 0-30ns; (b) 3060 ns e (c) 60-100ns

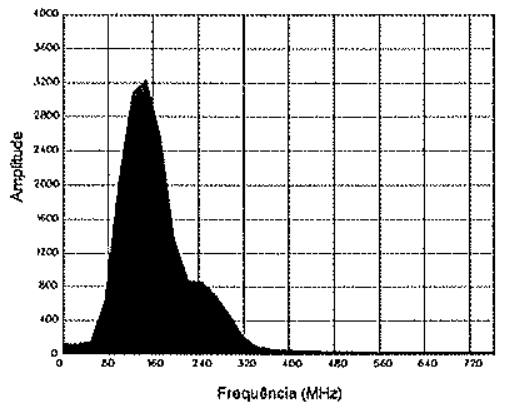

(a)

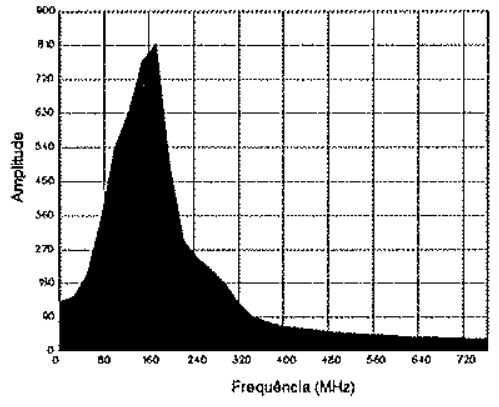

(b)

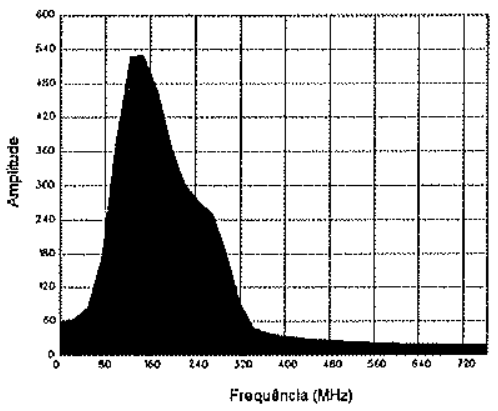

(c)

Figura A-IX.15 - Gráficos resultantes da análise espectral feita sobre os dados processados do perfil P-3 no trecho sem "zona de sombra", nos seguintes periodos: (a) 0-30ns; (b) 30-60ns e (c) 60-100ns 


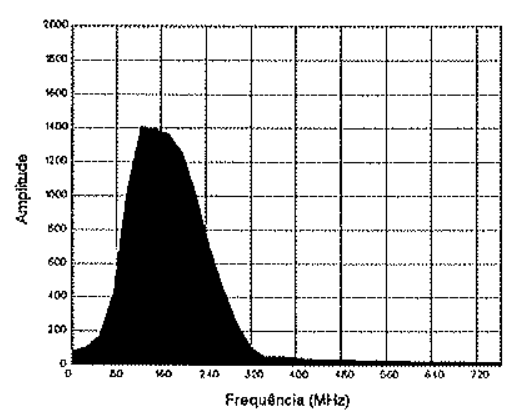

(a)

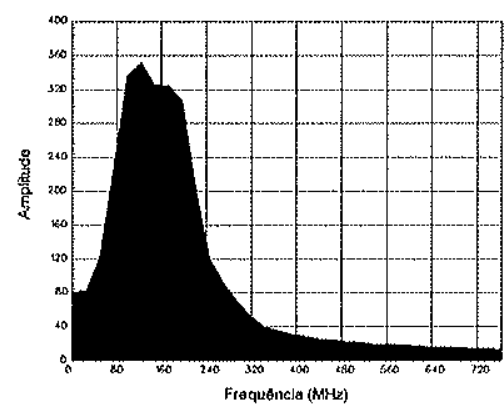

(b)

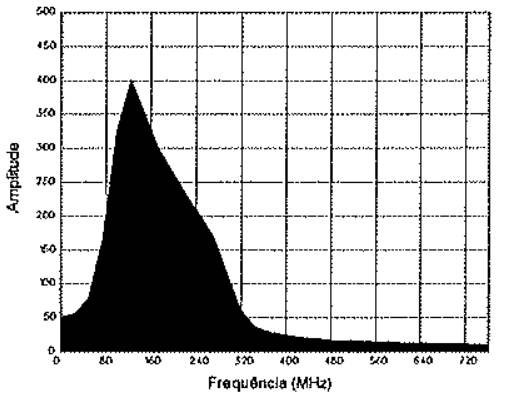

(c)

Figura A-IX.16 - Gráficos resultantes da análise espectral feita sobre os dados processados do perfil P-4 inteiro nos seguintes períodos: (a) 0-30ns; (b) 30-60ns e (c) 60-100ns

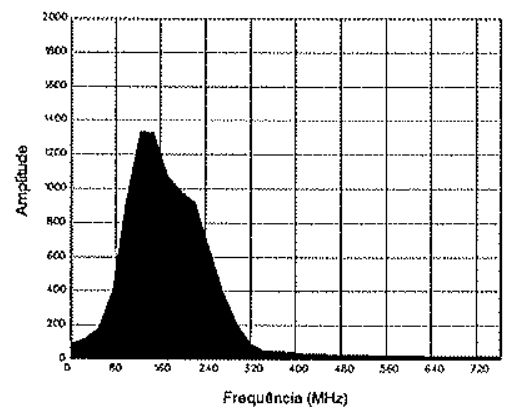

(a)

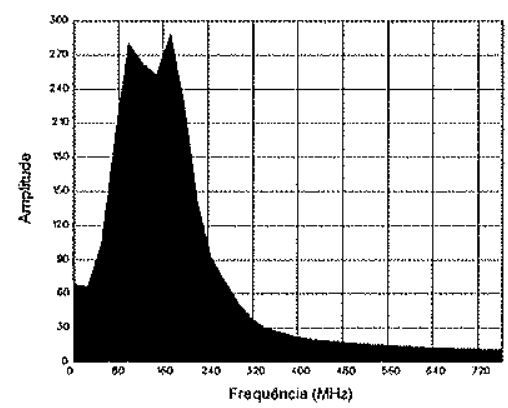

(b)

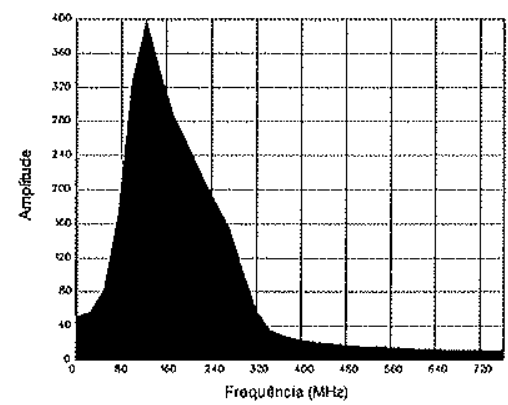

(c)

Figura A-IX.17 - Gráficos resultantes da análise espectral feita sobre os dados processados no trecho correspondente à "zona de sombra" do perfil P-4 nos seguintes períodos: (a) 0-30ns; (b) 3060ns e (c) 60-100ns

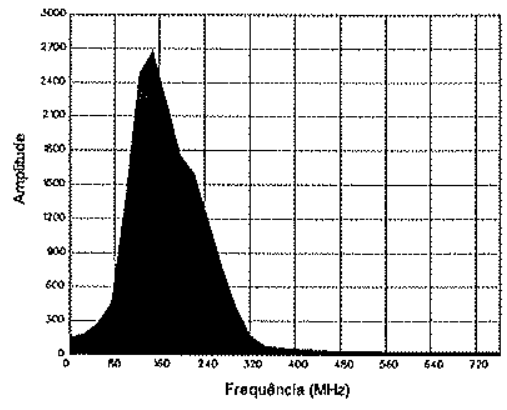

(a)

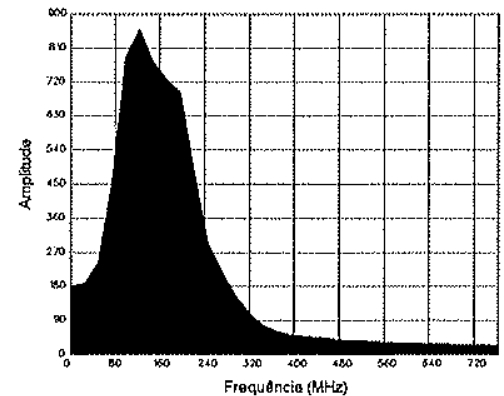

(b)

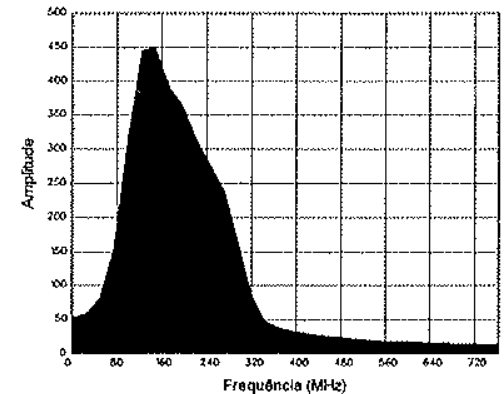

(c)

Figura A-IX.18 - Gráficos resultantes da análise espectral feita sobre os dados processados do perfil P-4 no trecho sem "zona de sombra", nos seguintes períodos: (a) 0-30ns; (b) 30-60ns e (c) 60-100ns 


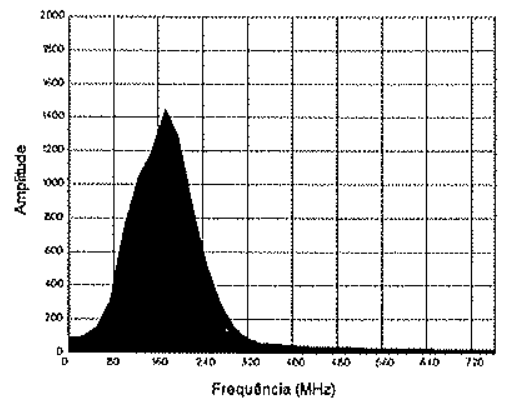

(a)

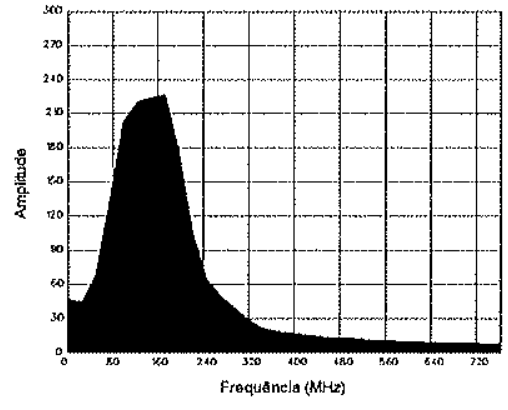

(b)

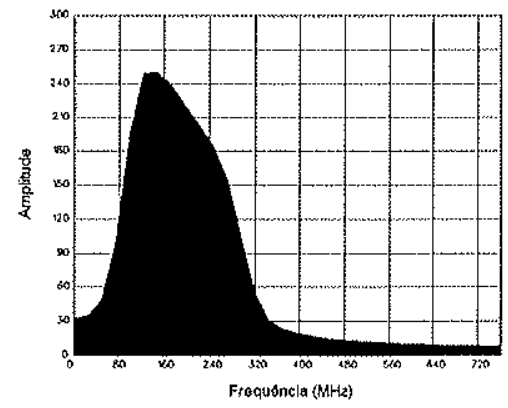

(c)

Figura A-IX.19 - Gráficos resultantes da análise espectral feita sobre os dados processados do perfil P-6 inteiro nos seguintes periodos: (a) 0-30ns; (b) 30-60ns e (c) 60-100ns

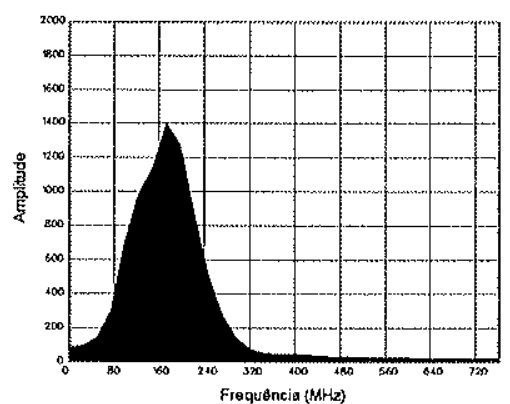

(a)

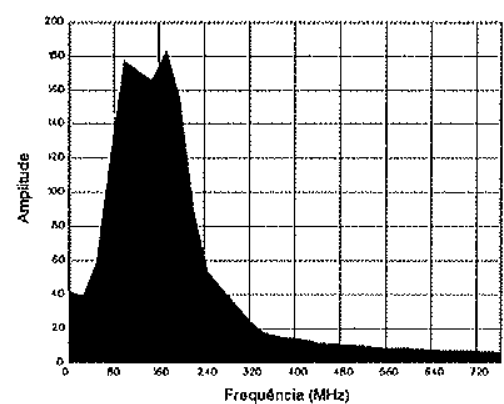

(b)

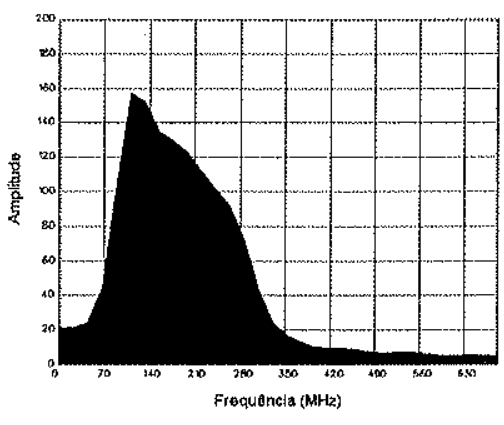

(c)

Figura A-IX.20 - Gráficos resultantes da análise espectral feita sobre os dados processados no trecho correspondente à "zona de sombra" do perfil P-6 nos seguintes períodos: (a) 0-30ns; (b) 3060 ns e (c) 60-100ns

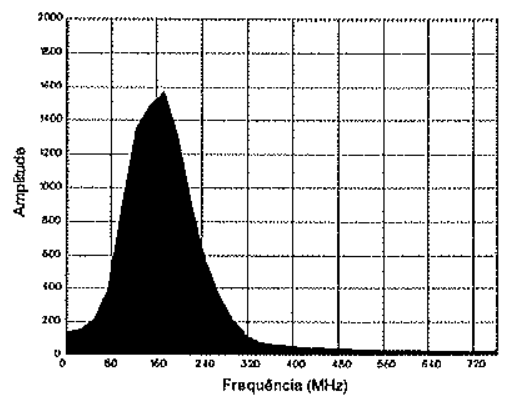

(a)

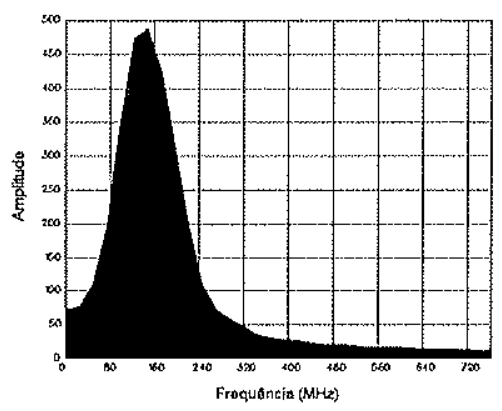

(b)

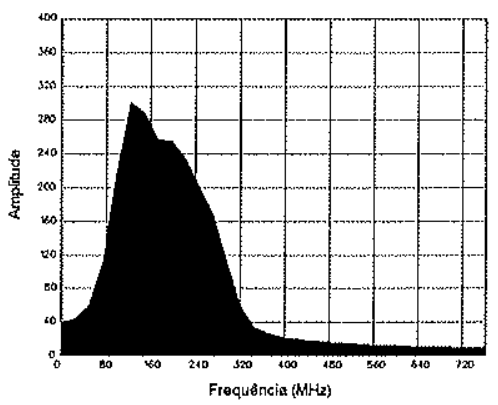

(c)

Figura A-IX.21 - Gráficos resultantes da análise espectral feita sobre os dados processados do perfil P-6 no trecho sem "zona de sombra", nos seguintes periodos: (a) 0-30ns; (b) 30-60ns e (c) 60-100ns 


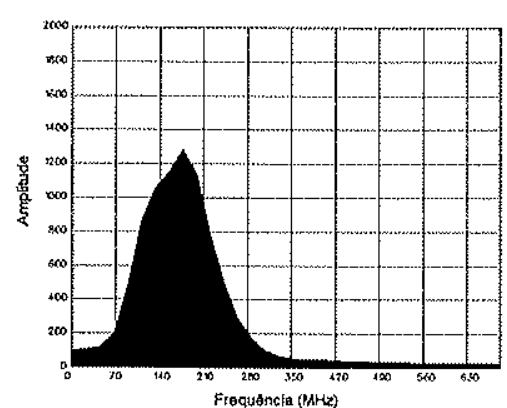

(a)

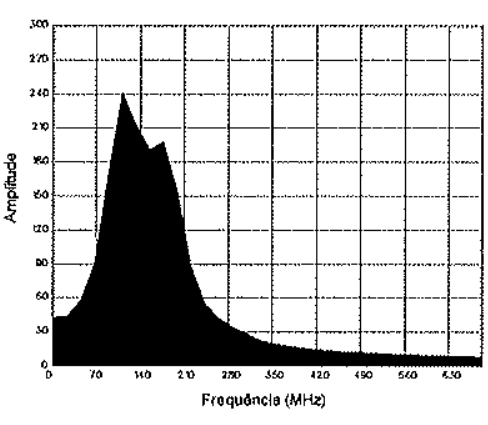

(b)

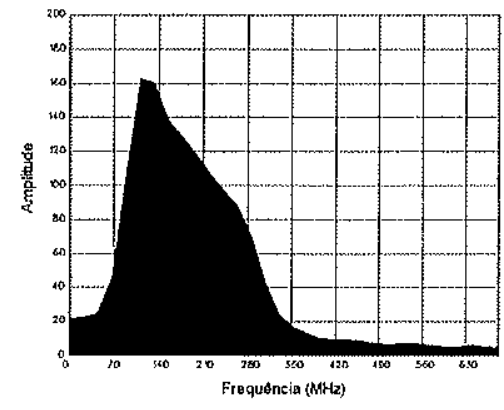

(c)

Figura A-IX.22 - Gráficos resultantes da análise espectral feita sobre os dados processados do perfil P-6A inteiro nos seguintes períodos: (a) 0-30ns; (b) 30-60ns e (c) 60-100ns

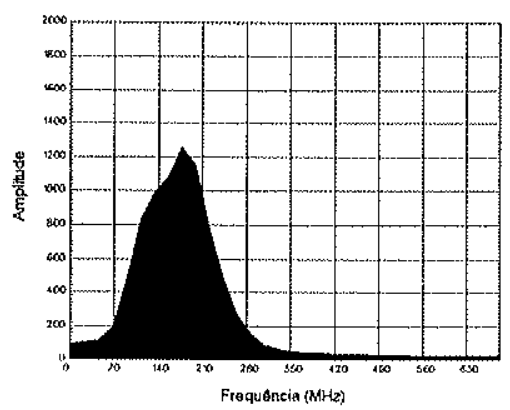

(a)

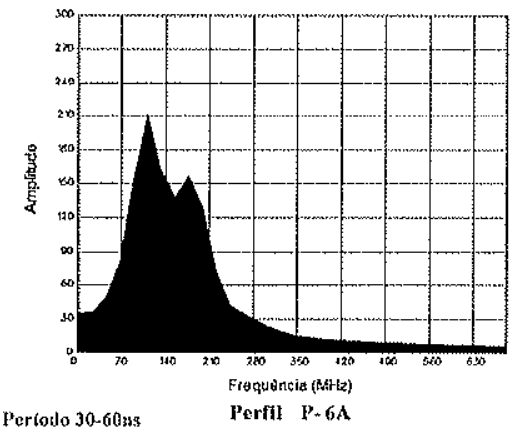

(b)

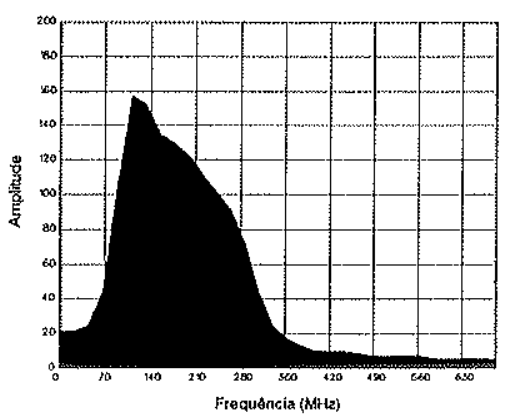

(c)

Figura A-IX.23 - Gráficos resultantes da análise espectral feita sobre os dados processados no trecho correspondente à "zona de sombra" do perfil P-6A nos seguintes períodos: (a) 0-30ns; (b) 30 60 ns e (c) 60-100ns

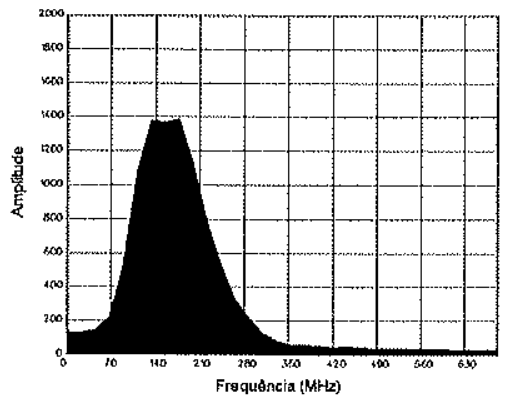

(a)

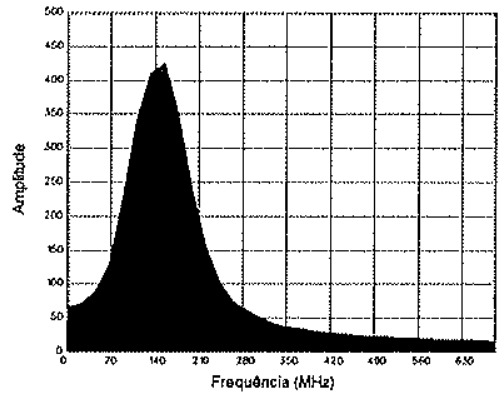

(b)

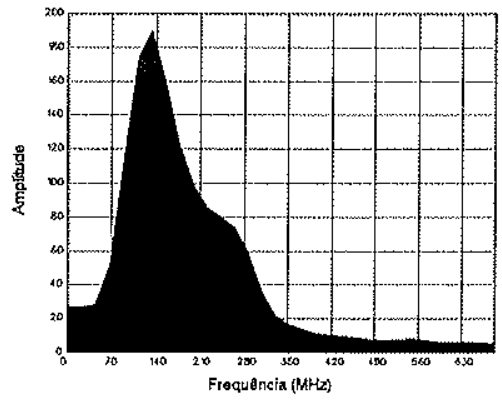

(c)

Figura A-IX.24 - Gráficos resultantes da análise espectral feita sobre os dados processados do perfil P-6A no trecho sem "zona de sombra", nos seguintes periodos: (a) 0-30ns; (b) 30-60ns e (c)60-100ns 


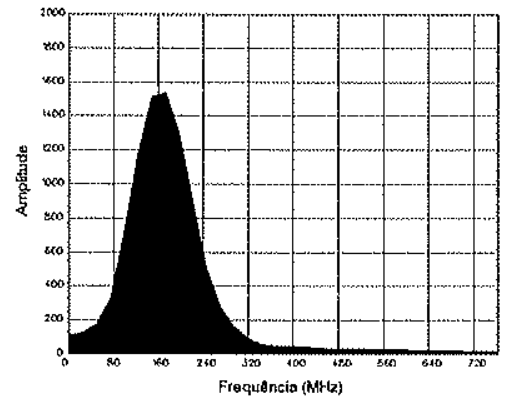

(a)

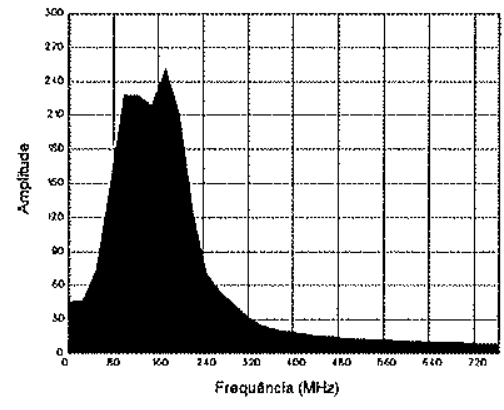

(b)

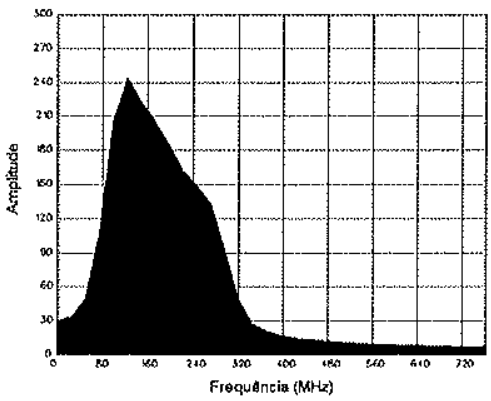

(c)

Figura A-IX.25 - Gráficos resultantes da análise espectral feita sobre os dados processados do perfil P-5 inteiro nos seguintes periodos: (a) 0-30ns; (b) 30-60ns e (c) 60-100ns

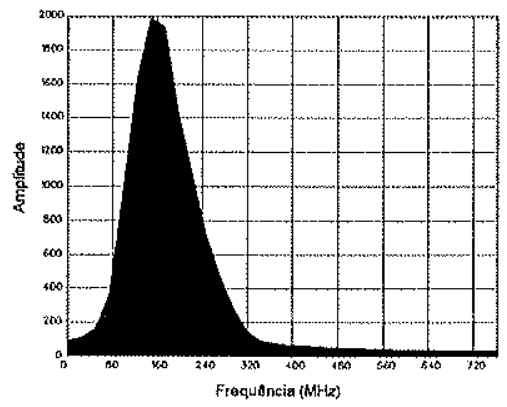

(a)

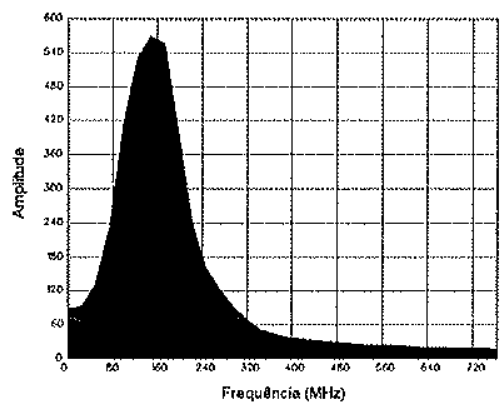

(b)

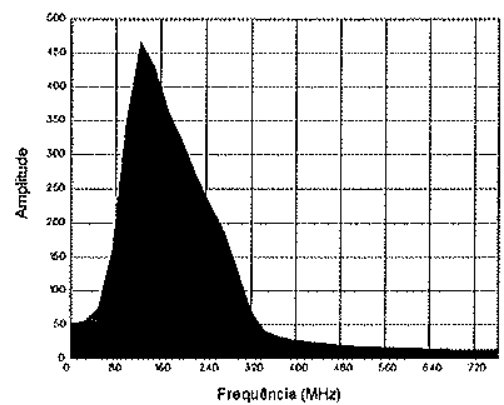

(c)

Figura A-IX.26 - Gráficos resultantes da análise espectral feita sobre os dados processados do perfil P-7 inteiro nos seguintes períodos: (a) 0-30ns; (b) 30-60ns e (c) 60-100ns

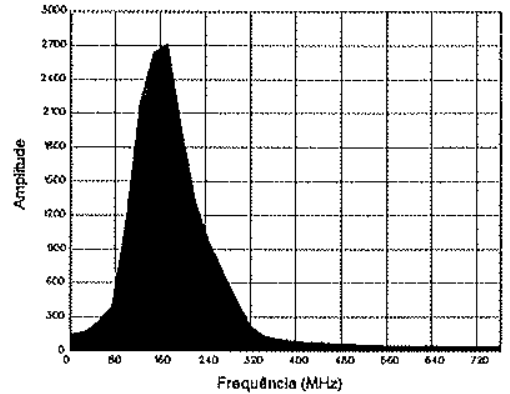

(a)

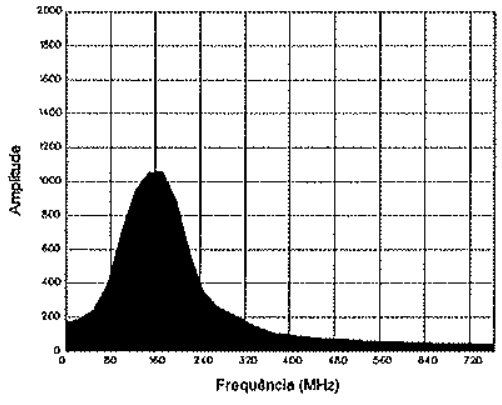

(b)

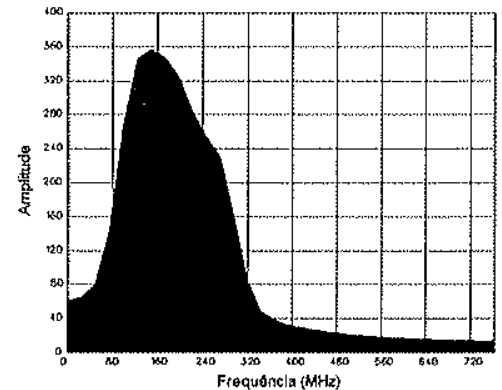

(c)

Figura A-IX.27 - Gráficos resultantes da análise espectral feita sobre os dados processados do perfil P-8 inteiro nos seguintes períodos: (a) 0-30ns; (b) 30-60ns e (c) 60-100ns 


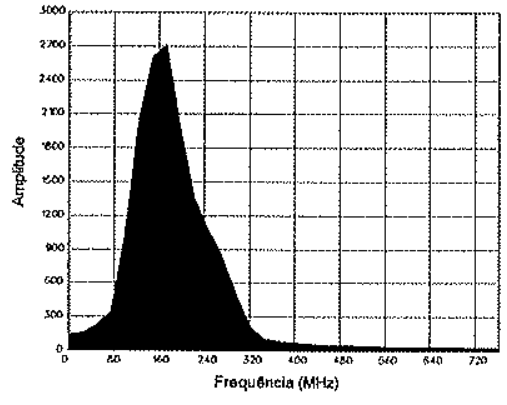

(a)

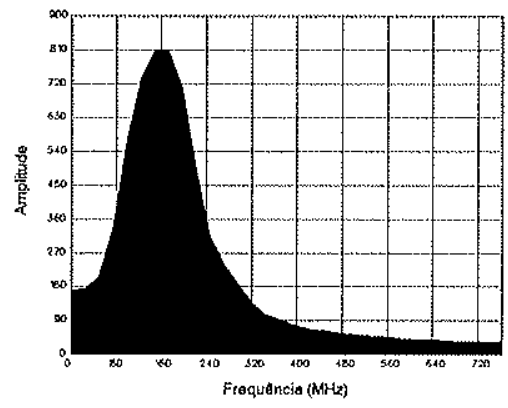

(b)

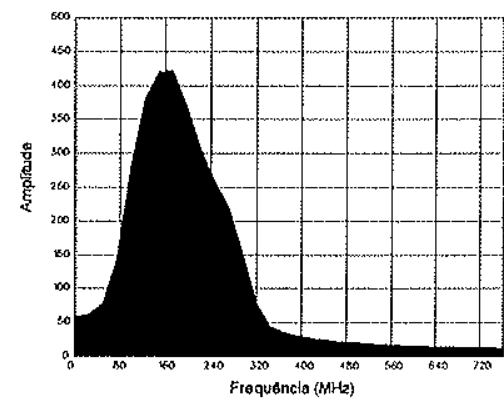

(c)

Figura A-IX.28 - Gráficos resultantes da análise espectral feita sobre os dados processados do perfil P-9 inteiro nos seguintes períodos: (a) 0-30ns; (b) 30-60ns e (c) 60-100ns

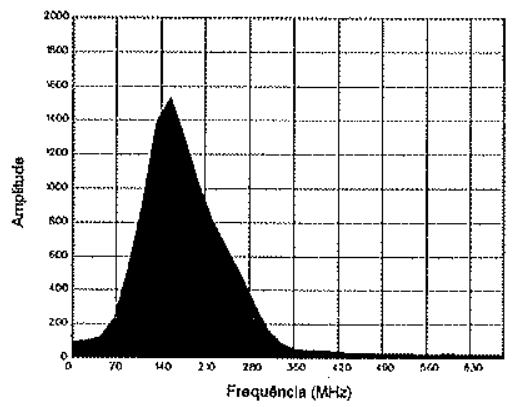

(a)

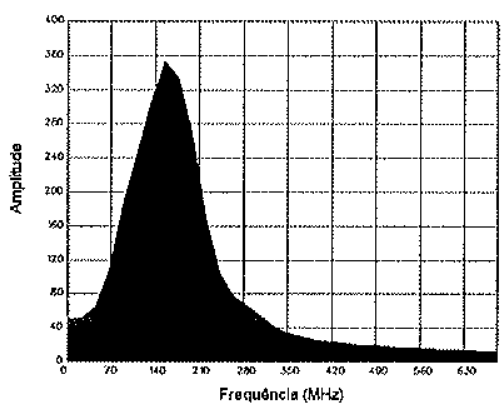

(b)

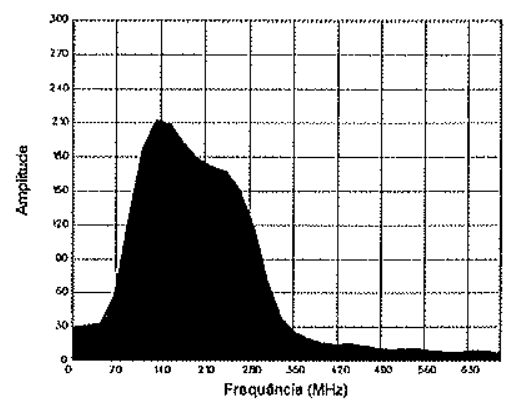

(c)

Figura A-IX.29 - Gráficos resultantes da análise espectral feita sobre os dados processados do perfil P-10 inteiro nos seguintes períodos: (a) 0-30ns; (b) 30-60ns e (c) 60-100ns

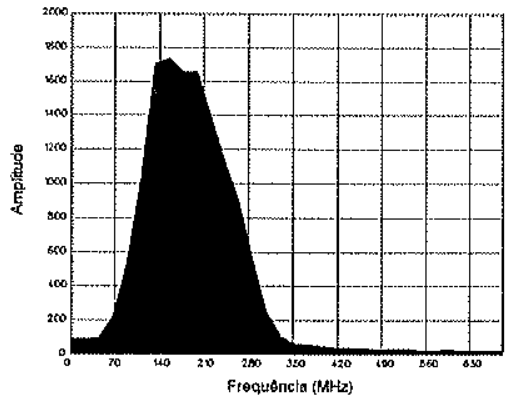

(a)

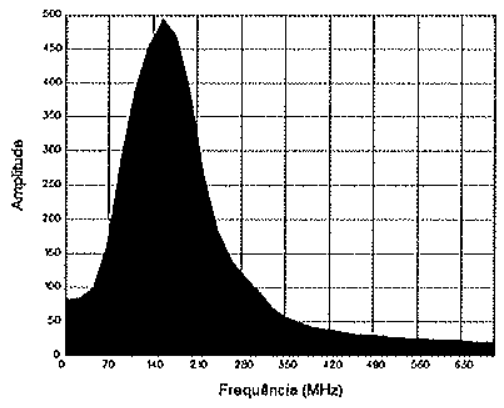

(b)

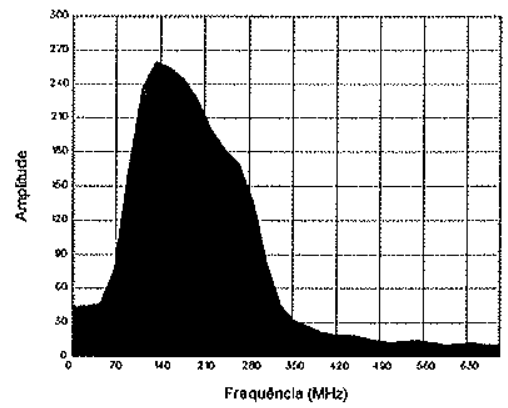

(c)

Figura A-IX.30 - Gráficos resultantes da análise espectral feita sobre os dados processados do perfil P-11 inteiro nos seguintes periodos: (a) 0-30ns; (b) 30-60ns e (c) 60-100ns 


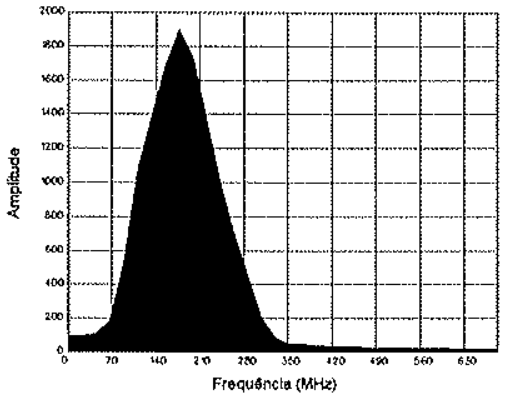

(a)

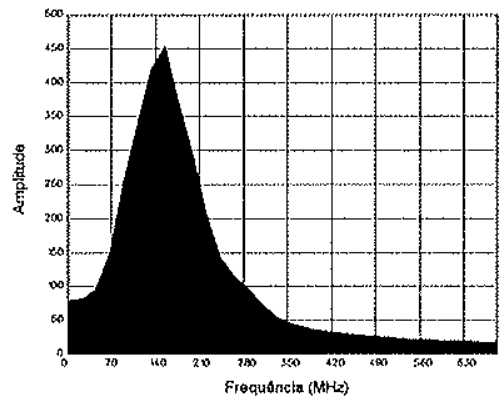

(b)

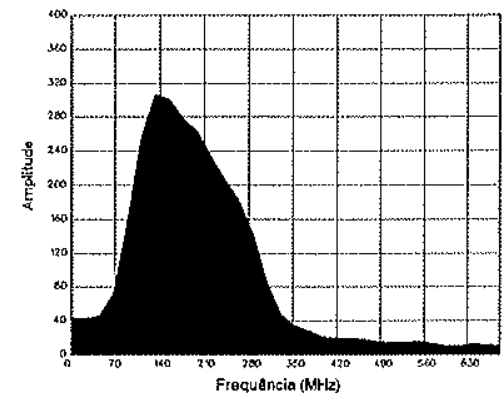

(c)

Figura A-IX.31 - Gráficos resultantes da análise espectral feita sobre os dados processados do perfil P-12 inteiro nos seguintes períodos: (a) 0-30ns; (b) 30-60ns e (c) 60-100ns

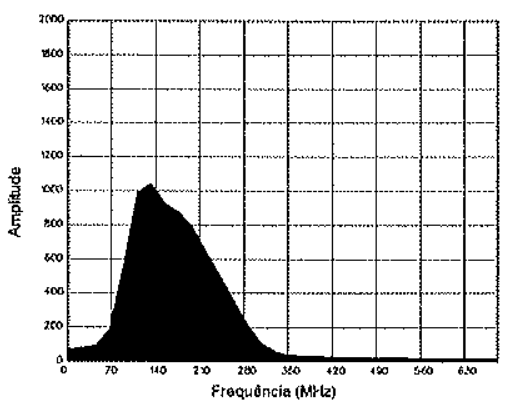

(a)

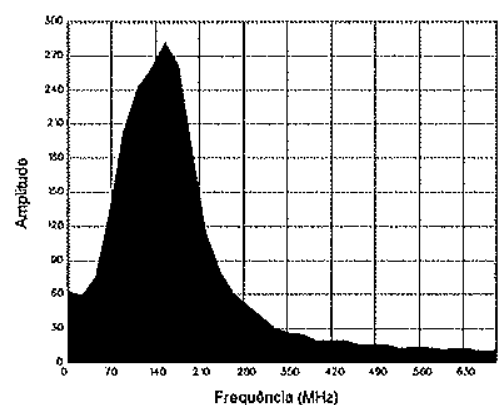

(b)

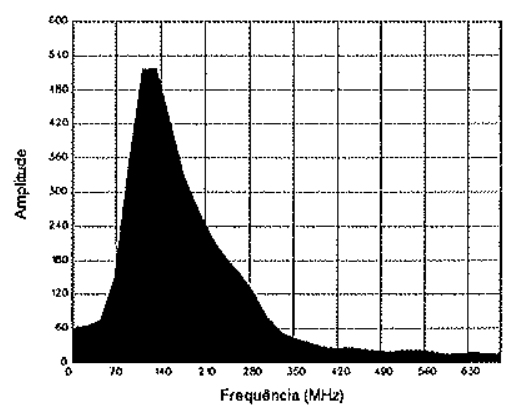

(c)

Figura A-IX.32 - Gráficos resultantes da análise espectral feita sobre os dados processados do perfil P-13 inteiro nos seguintes períodos: (a) 0-30ns; (b) 30-60ns e (c) 60-100ns

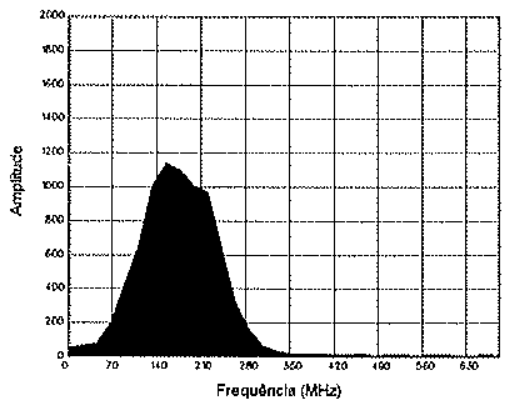

(a)

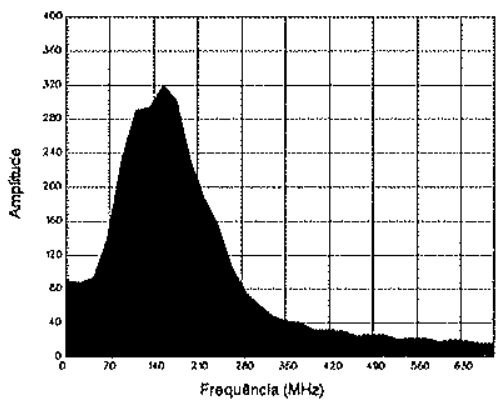

(b)

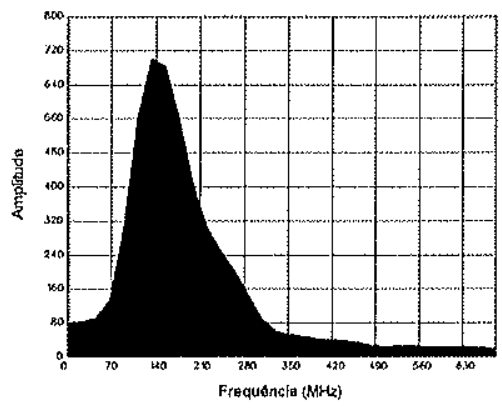

(c)

Figura A-IX.33 - Gráficos resultantes da análise espectral feita sobre os dados processados do perfil P-14 inteiro nos seguintes períodos: (a) 0-30ns; (b) 30-60ns e (c) 60-100ns 
A N E X O X 


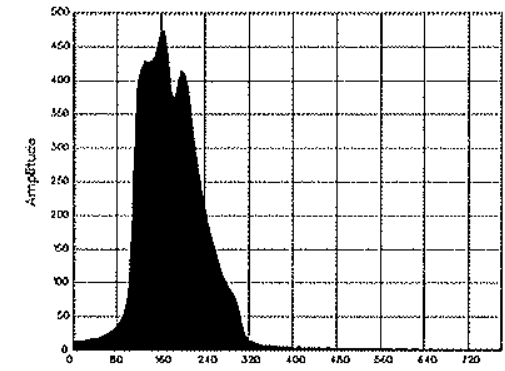

p.1

(1)0.100ns)
inason $1-799$

(a)

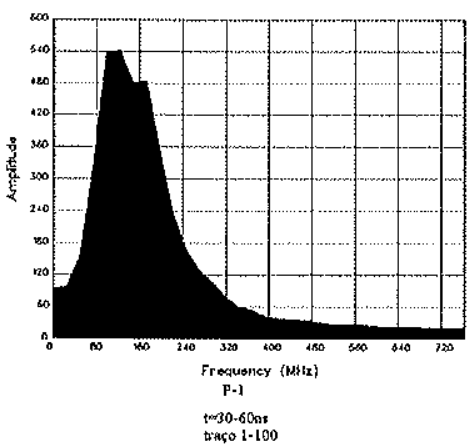

(b)

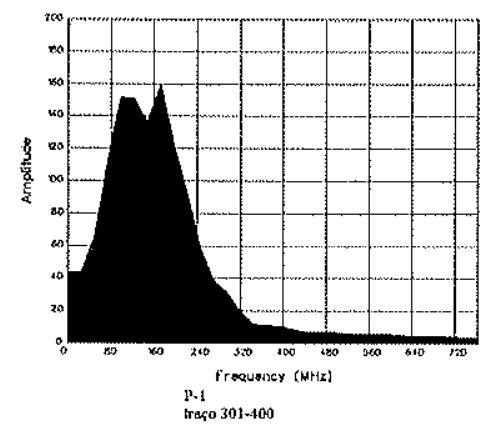

(e)

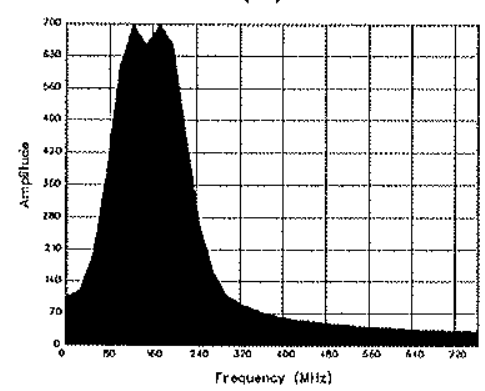

(h)

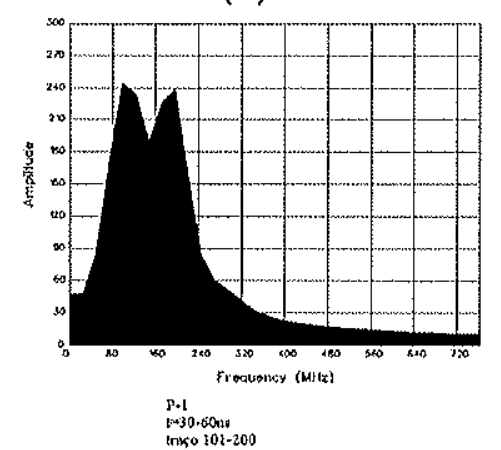

(c)

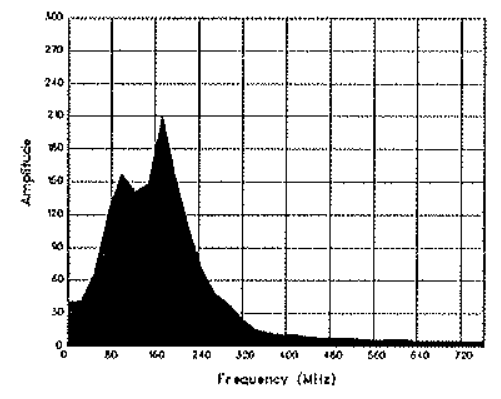

(f)

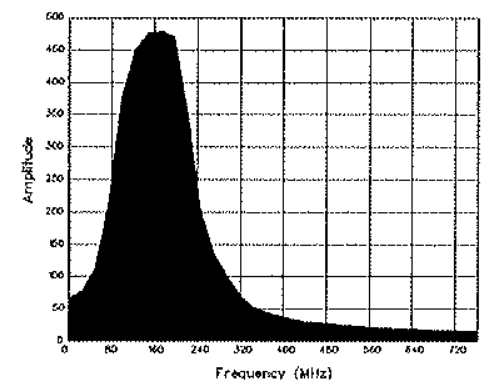

(i)

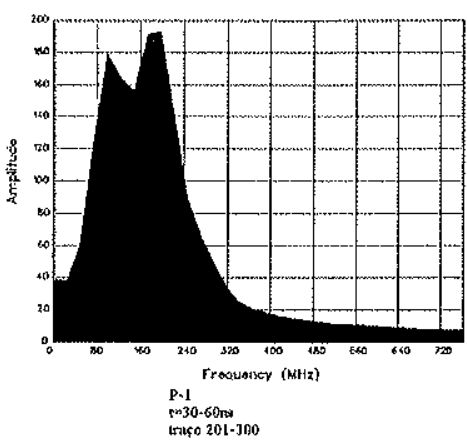

(d)

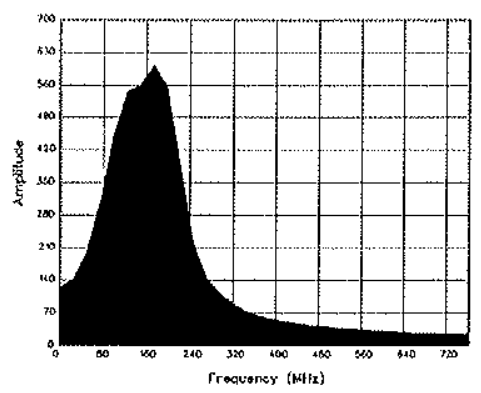

(g)

Figura A-X.1 - Gráficos resultantes da análise espectral executada sobre a seção processada do perfil P-1 para: (a) seção total $\left(A_{s t}\right)$; e para o período 30 a 60 ns $\left(A_{s p}\right)$ nos trechos de traços: (b)1100; (c) 101-200; (d) 201-300; (e) 301-400; (f) 401-500; (g) 501-600; (h) 601-700 e(i) 701-799 


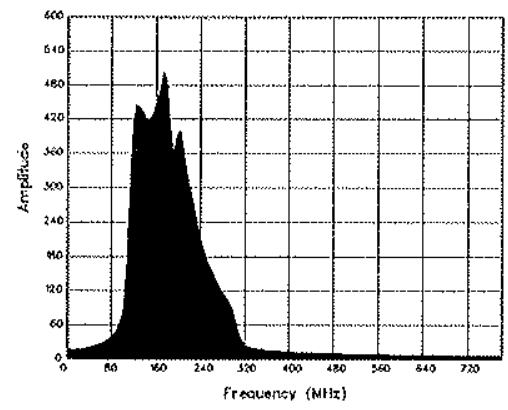

(a)

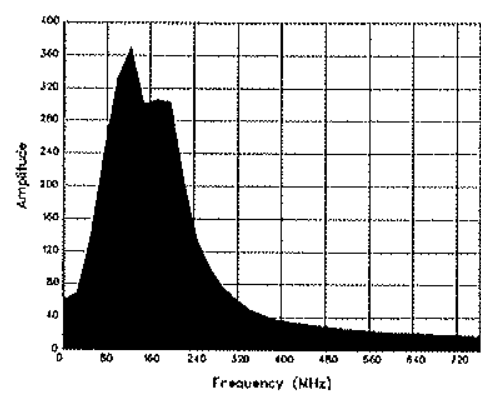

(b)

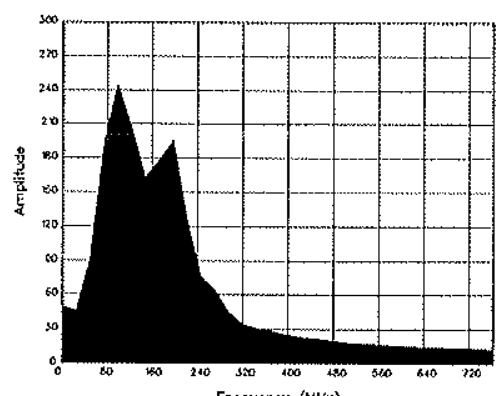

(e)

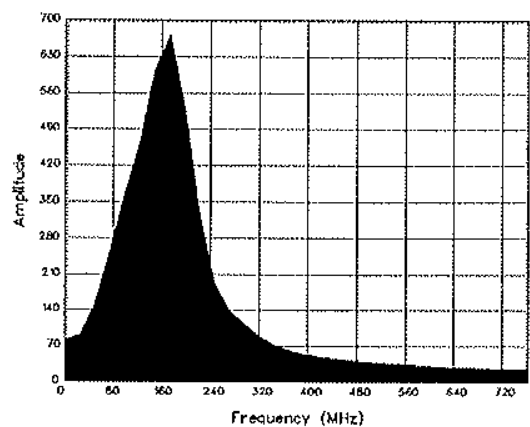

(h)

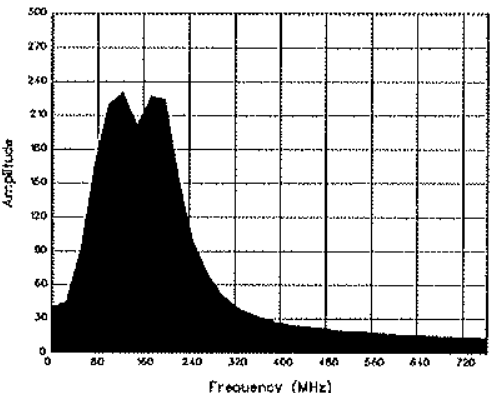

(c)

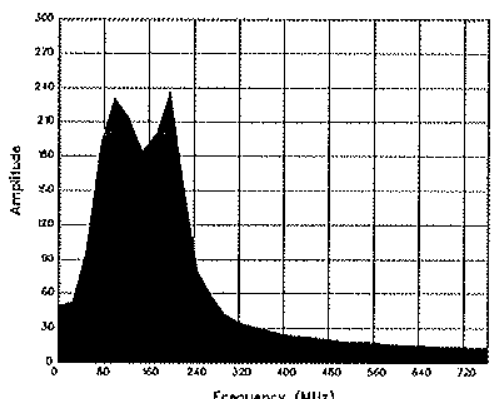

(f)

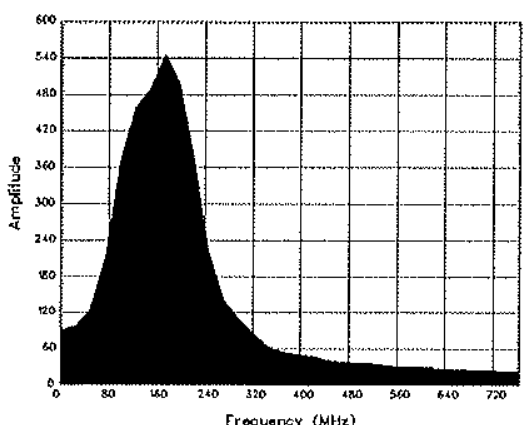

(i)

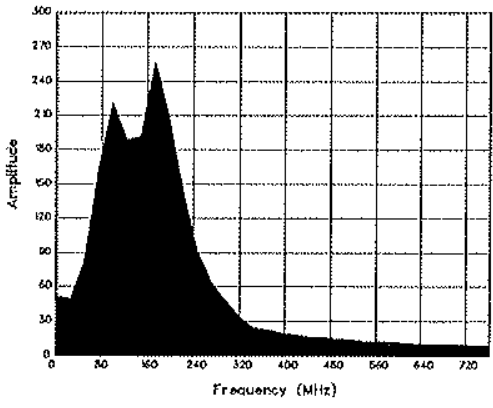

(d)

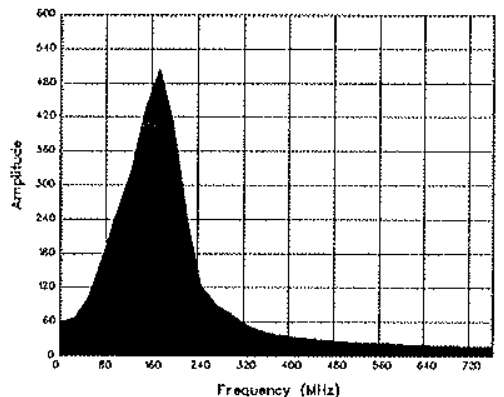

(g)

Figura A-X.2 - Gráficos resultantes da análise espectral executada sobre a seção processada do perfil P-2 para: (a) seção total $\left(A_{s t}\right)$; e para o período 30 a 60 ns $\left(A_{s p}\right)$ nos trechos de traços: (b) 1 100 ; (c) 101-200; (d) 201-300; (e) 301-400; (f) 401-500; (g) 501-600; (h) 601-700 e(i) 701-799 


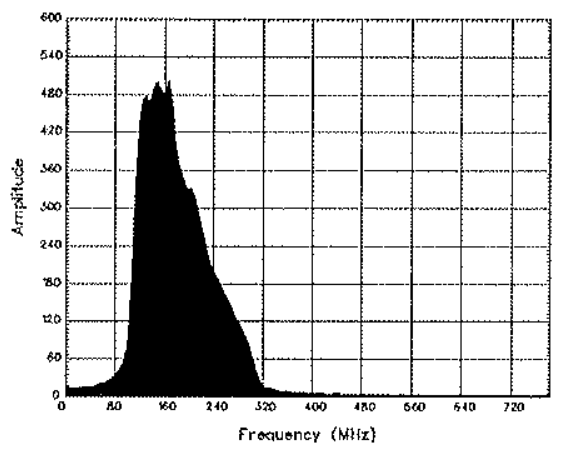

(a)

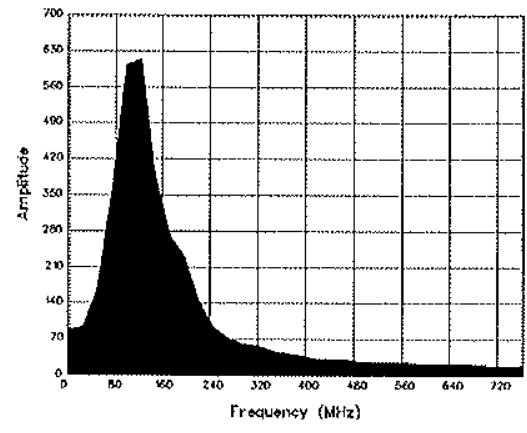

(b)

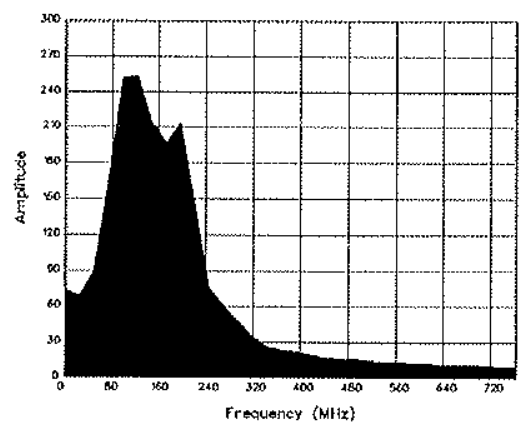

(e)

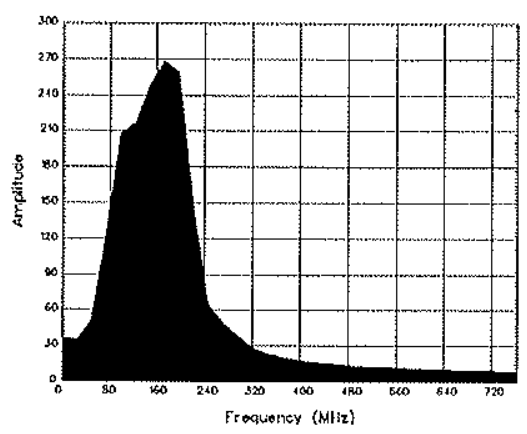

(h)

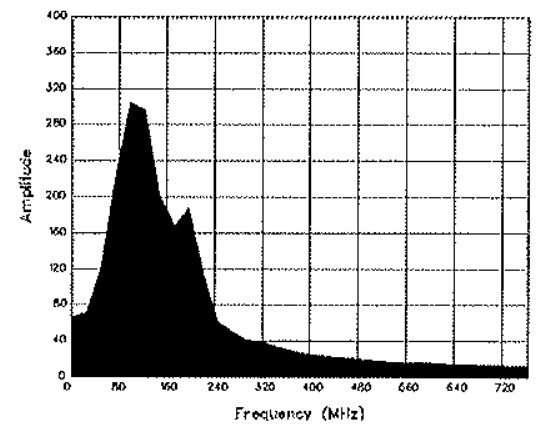

(c)

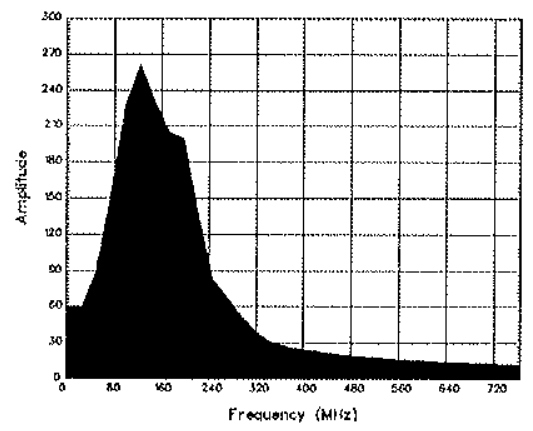

(f)

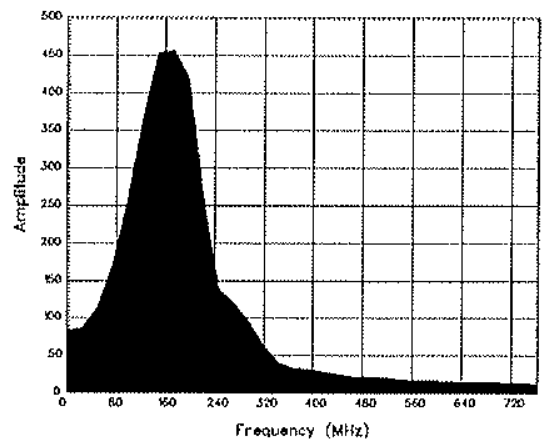

(i)

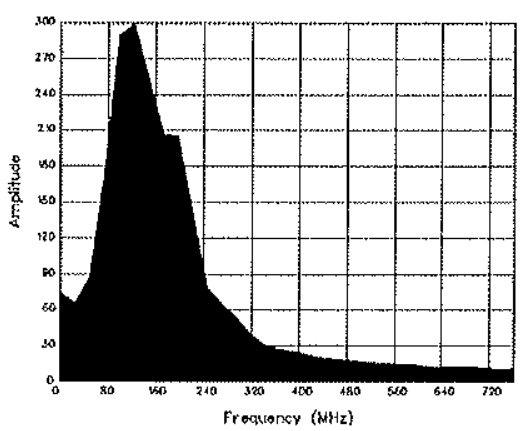

(d)

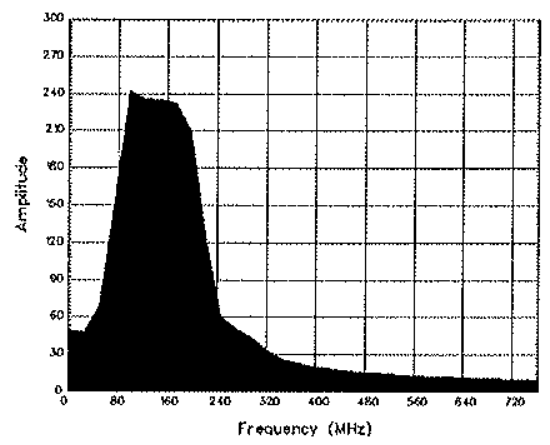

(g)

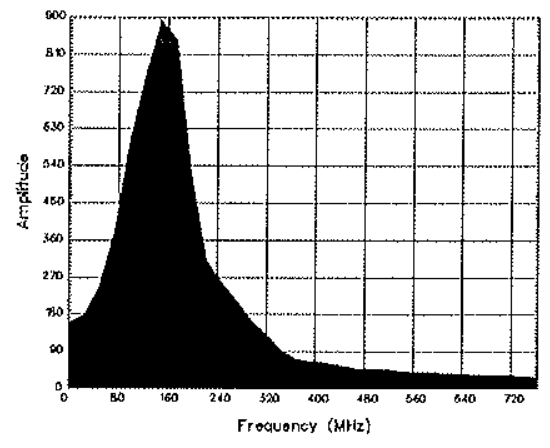

(j)

Figura A-X.3 - Gráficos resultantes da análise espectral executada sobre a seção processada do perfil P-3 para: (a) seção total $\left(A_{s t}\right)$; e para o periodo 30 a 60 ns $\left(A_{s p}\right)$ nos trechos de traços: (b) 1-60; (c) 61 120 ; (d) 121-180; (e) 181-240; (f) 241-300; (g) 301-360; (h) 361-420; (i) 421-480 e (j) 481-549 


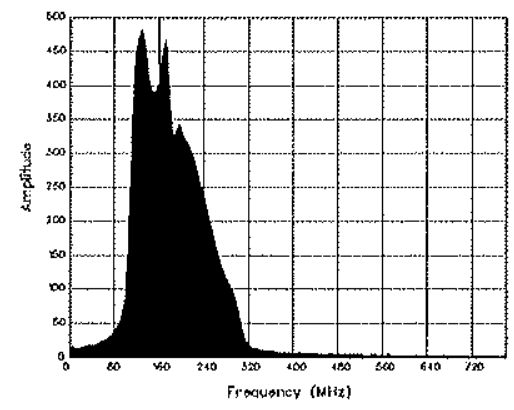

(a)

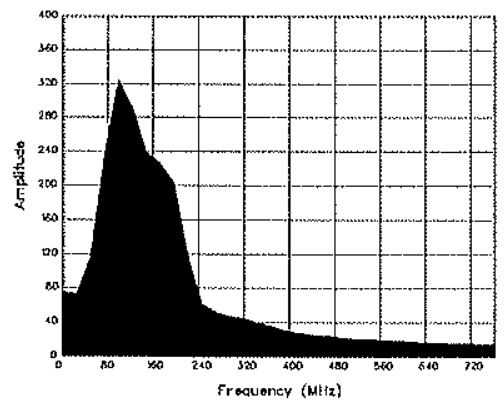

(b)

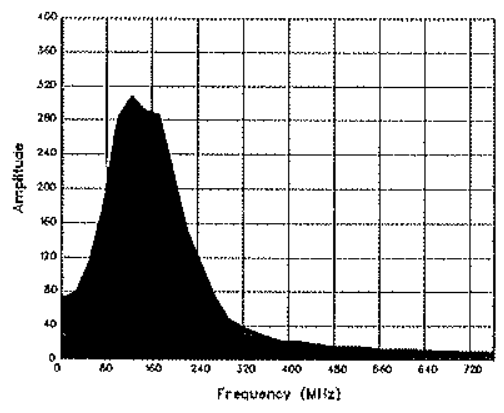

(e)

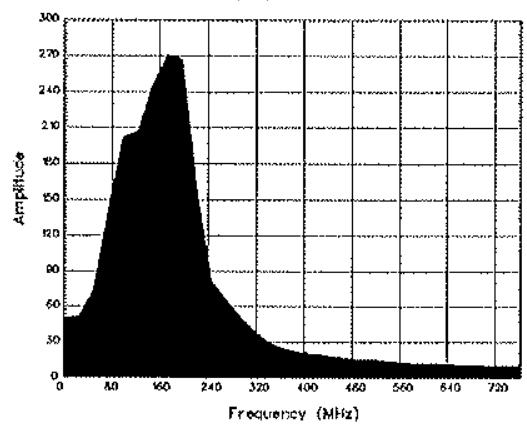

(h)

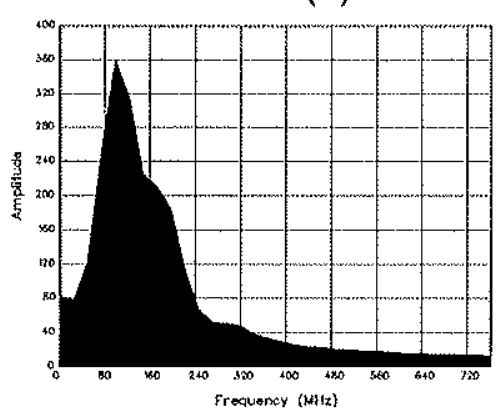

(c)

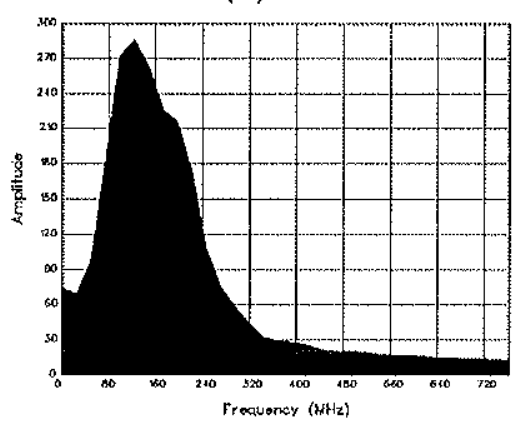

(f)

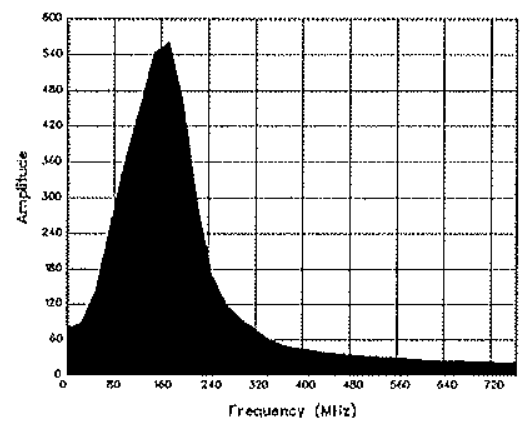

(i)

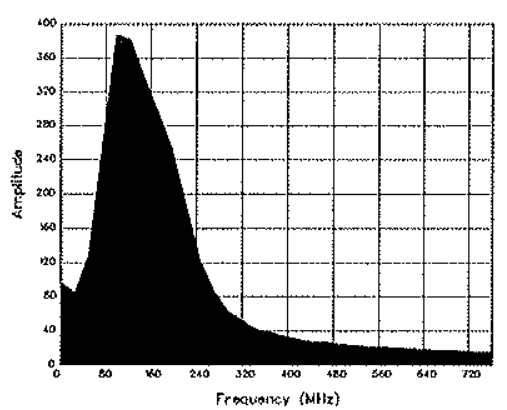

(d)

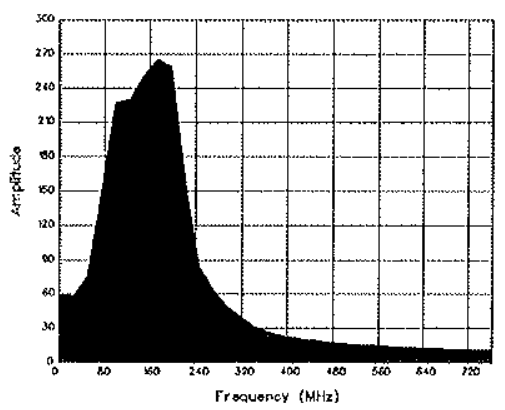

(g)

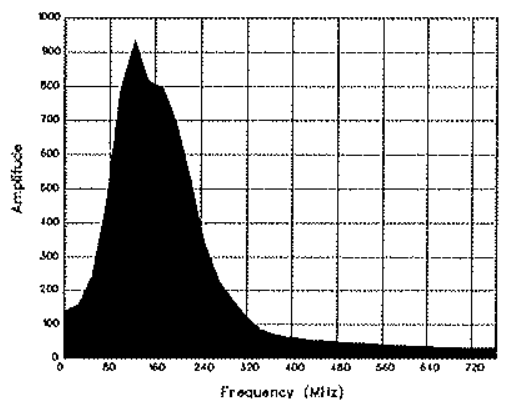

(j)

Figura A-X.4 - Gráficos resultantes da análise espectral executada sobre a seção processada do perfil P-4 para: (a) seção total $\left(A_{s t}\right)$; e para o período 30 a 60 ns $\left(A_{s p}\right)$ nos trechos de traços: (b)160 ; (c) $61-120$; (d) 121-180; (e) 181-240; (f) 241-300; (g) 301-360; (h) 361-420; (i) 421-480 e (j) 481-532 


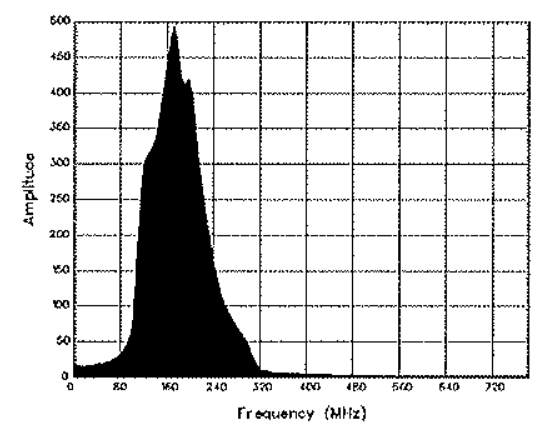

(a)

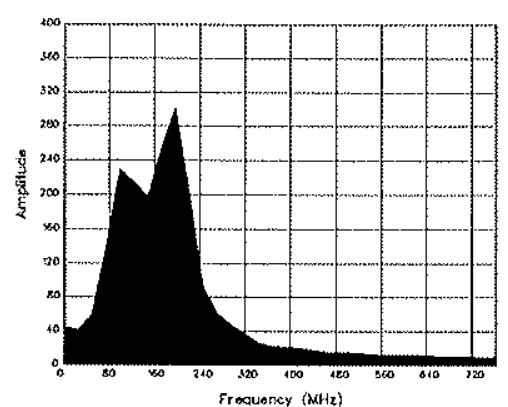

(b)

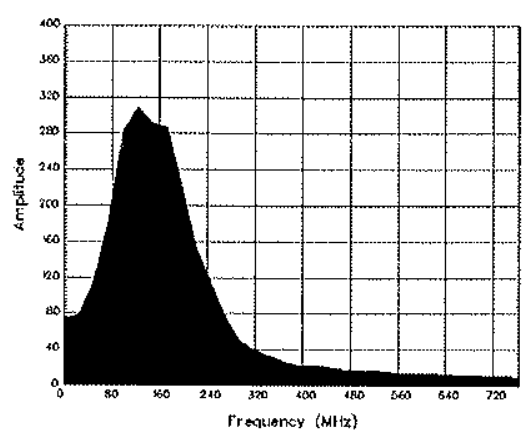

(e)

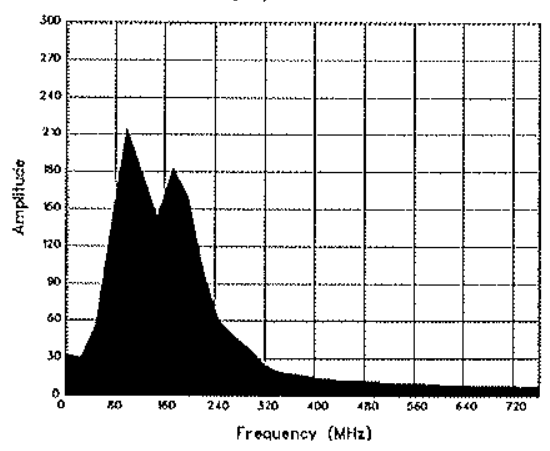

(h)

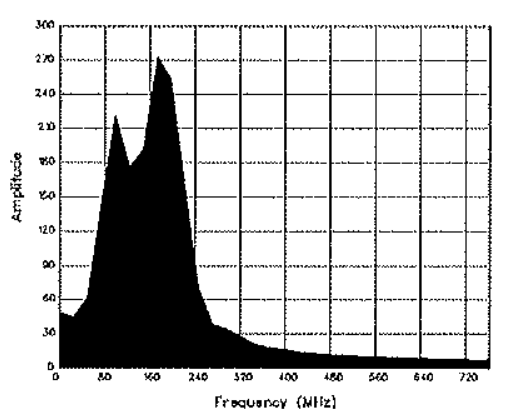

(c)

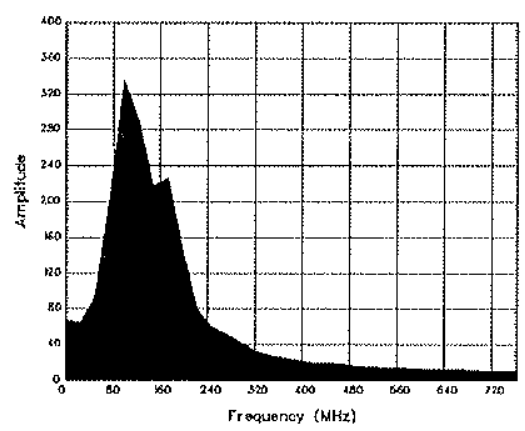

(f)

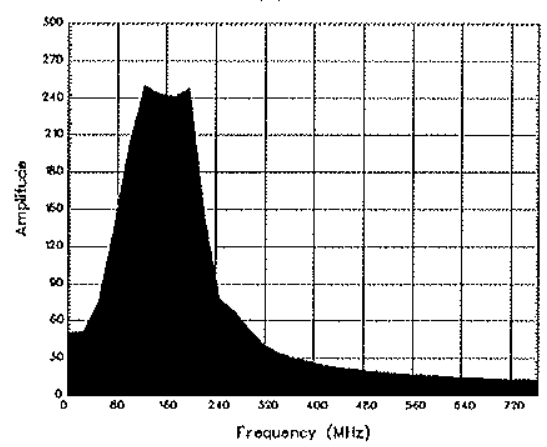

(i)

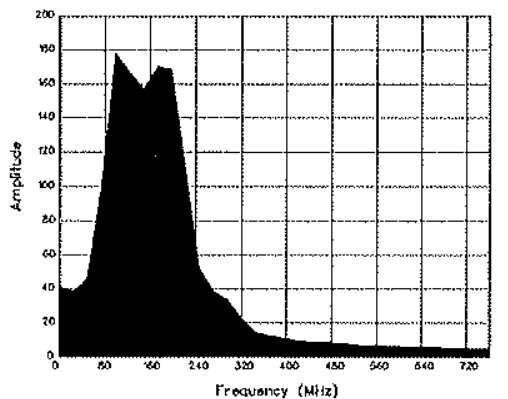

(d)

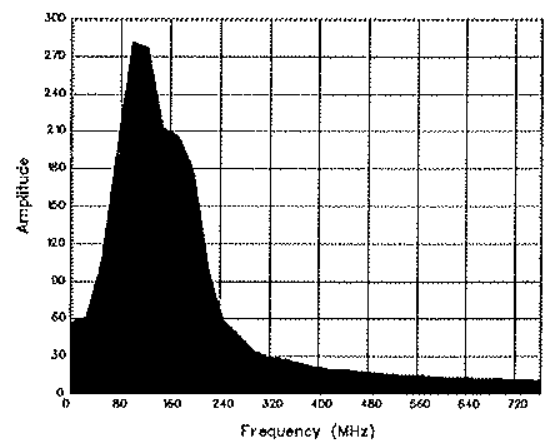

(g)

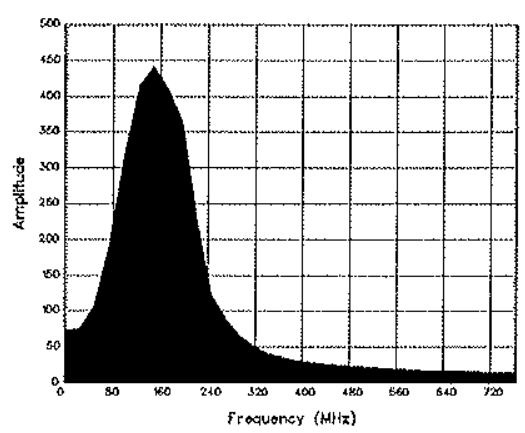

(j)

Figura A-X.5 - Gráficos resultantes da análise espectral executada sobre a seção processada do perfil P-5 para: (a) seção total $\left(A_{s t}\right)$; e para o periodo 30 a $60 \mathrm{~ns}\left(A_{s p}\right)$ nos trechos de traços: (b)1-60; (c) 61120 ; (d) 121-180; (e) 181-240; (f) 241-300; (g) 301-360; (h) 361-420; (i) 421-480 e (j) 481-564 


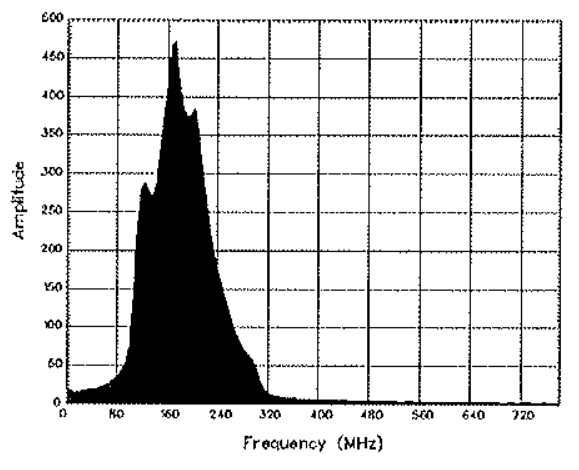

(a)

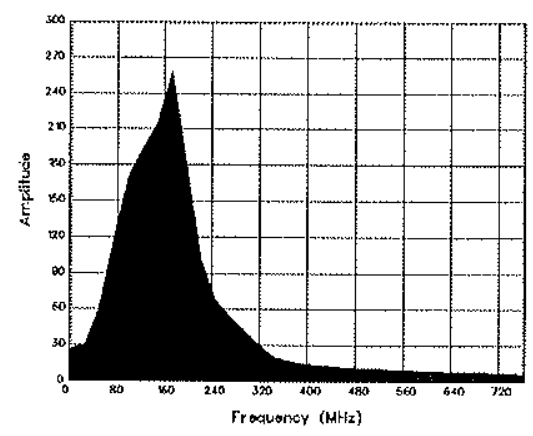

(b)

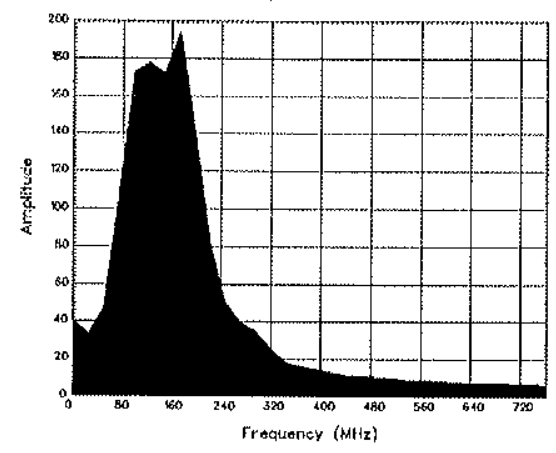

(e)

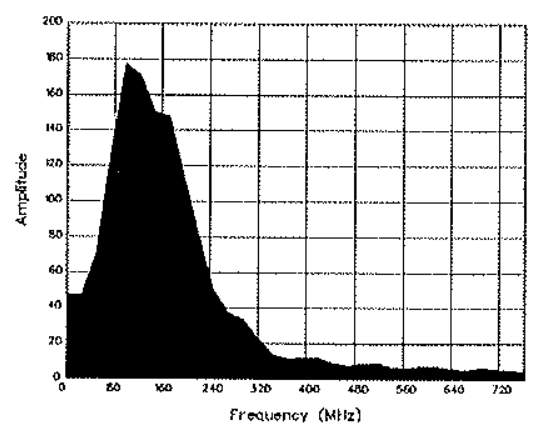

(h)

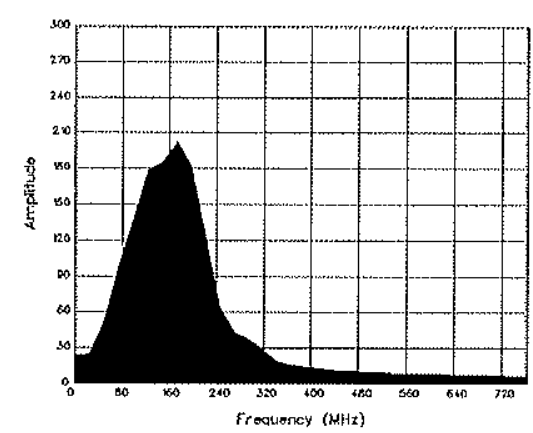

(c)

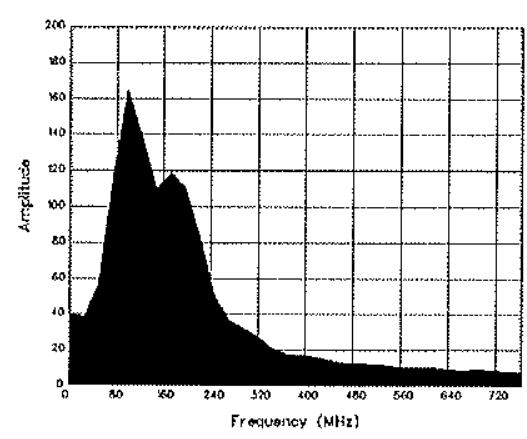

(f)

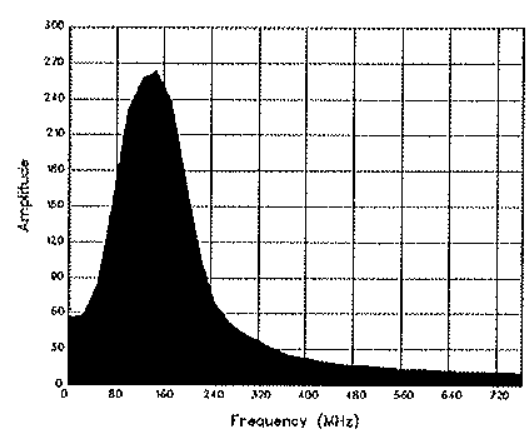

(i)

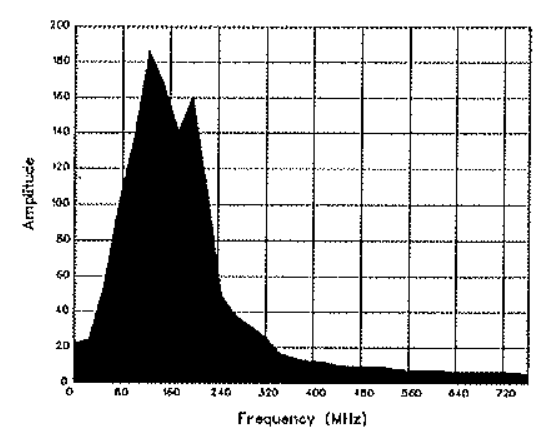

(d)

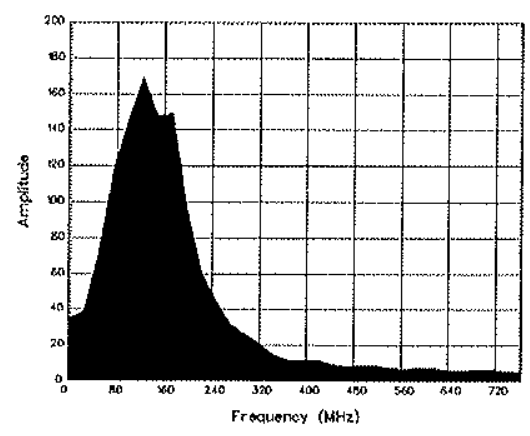

(g)

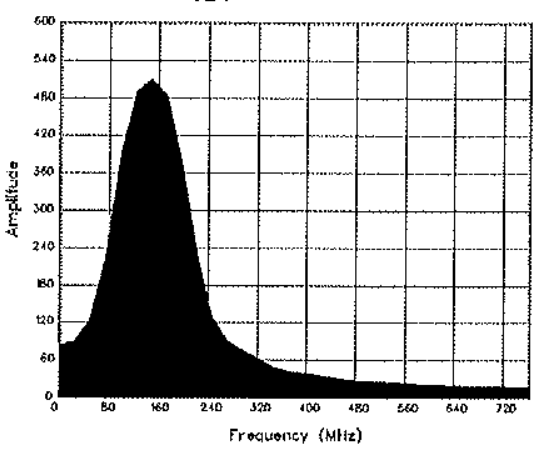

(j)

Figura A-X.6 - Gráficos resultantes da análise espectral executada sobre a seção processada do perfil P-6 para: (a) seção total $\left(A_{s t}\right)$; e para o período 30 a 60 ns $\left(A_{s p}\right)$ nos trechos de traços: (b) 1-60; (c) 61120; (d) 121-180; (e) 181-240; (f) 241-300; (g) 301-360; (h) 361-420; (i) 421-480 e (j) 481-576 


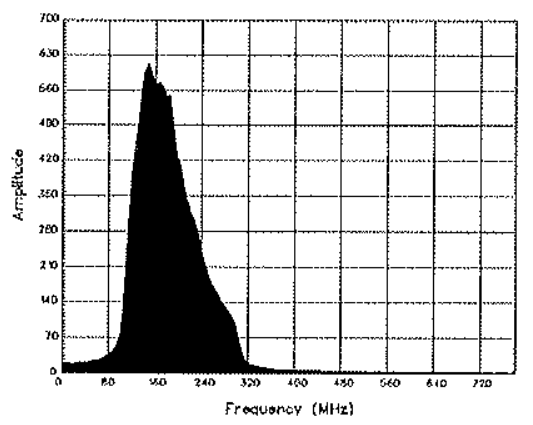

(a)

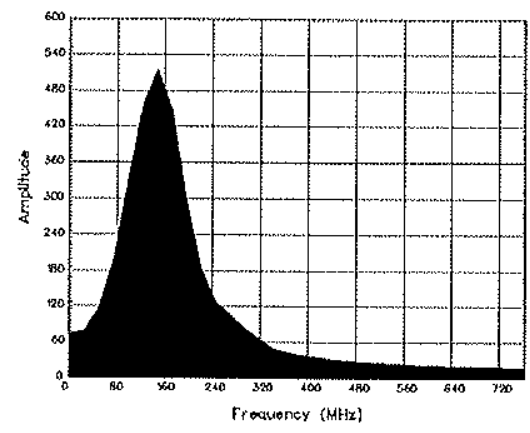

(b)

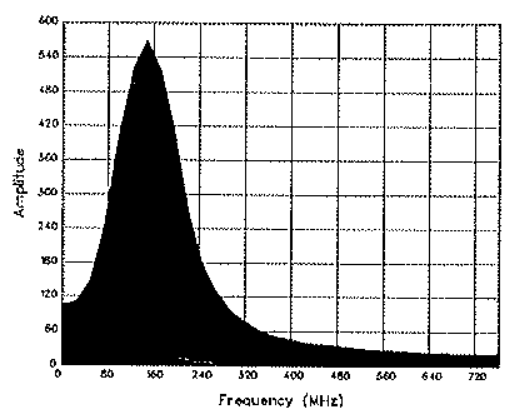

(e)

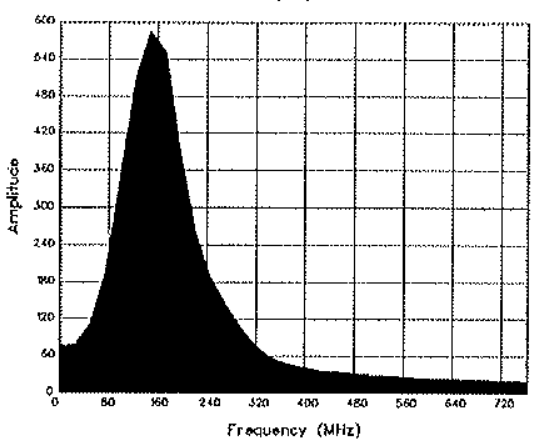

(c)

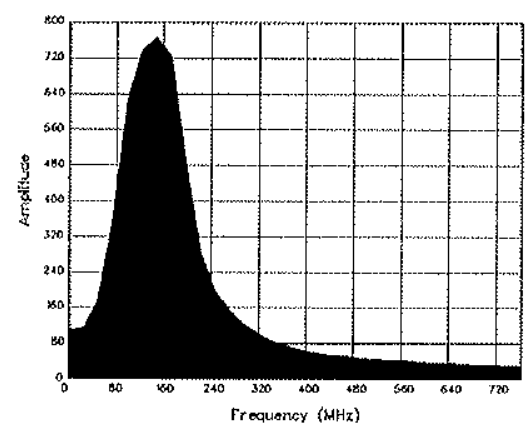

(f)

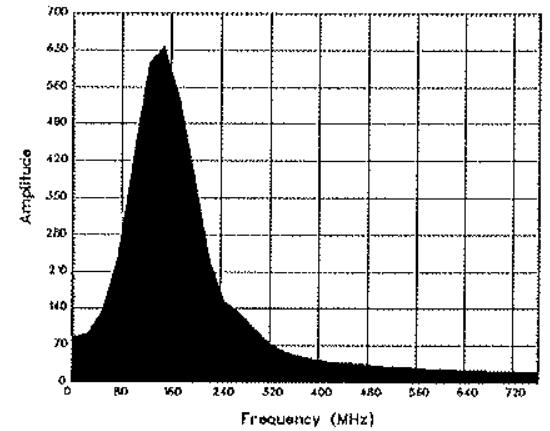

(d)

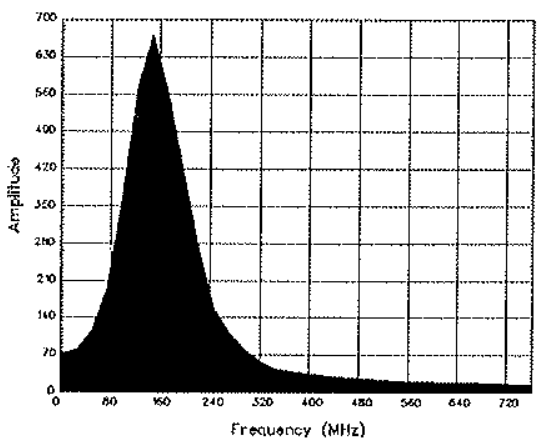

(g)

Figura A-X.7 - Gráficos resultantes da análise espectral executada sobre a seção processada do perfil P-7 para: (a) seção total $\left(A_{s t}\right)$; e para o período 30 a 60 ns $\left(A_{s p}\right)$ nos trechos de traços: (b) $1-110 ;(\mathrm{c})$ 111-220; (d) 221-330; (e) 331-440; (f) 441-550 e (g) 551-660 


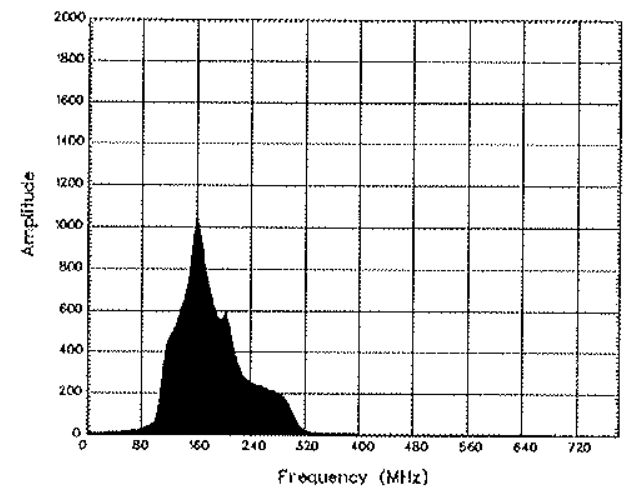

(a)

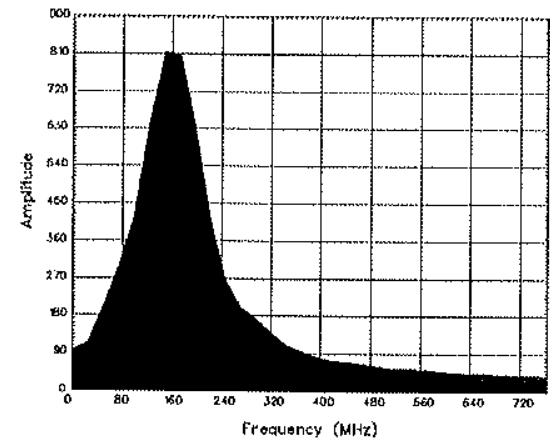

(b)

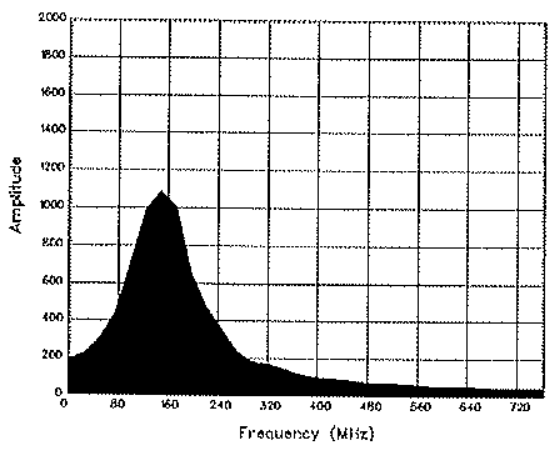

(e)

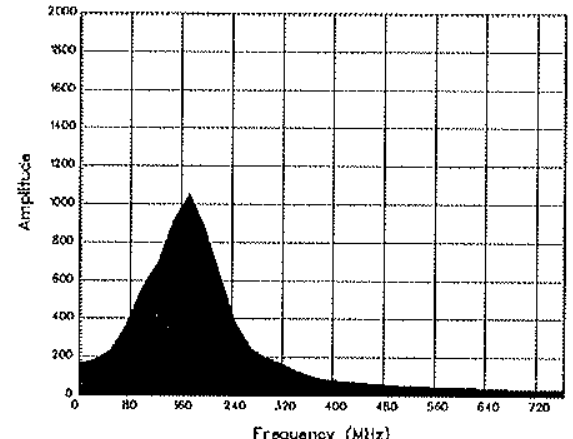

(c)

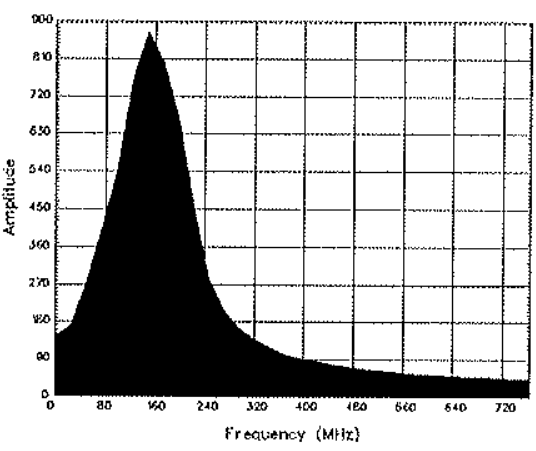

(f)

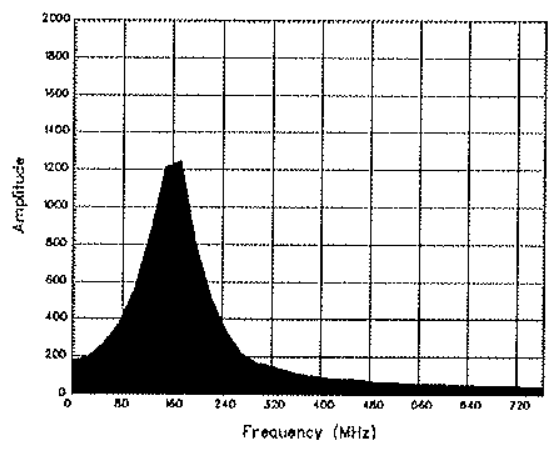

(d)

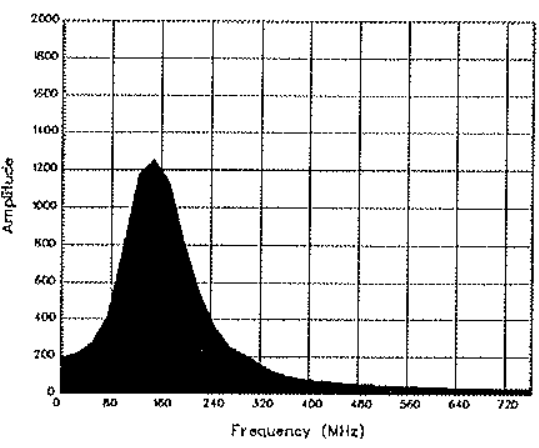

(g)

Figura A-X.8 - Gráficos resultantes da análise espectral executada sobre a seção processada do perfil P8 para: (a) seção total $\left(A_{s t}\right)$; e para o período 30 a 60 ns $\left(A_{s p}\right)$ nos trechos de traços: (b)1-110; (c) 111-220; (d) 221-330; (e) 331-440; (f) 441-550 e (g) 551-687 


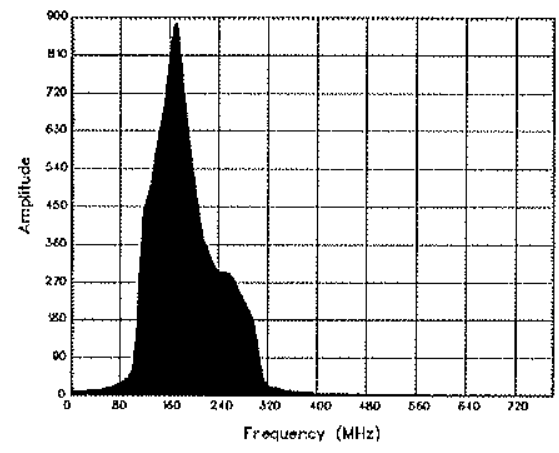

(a)

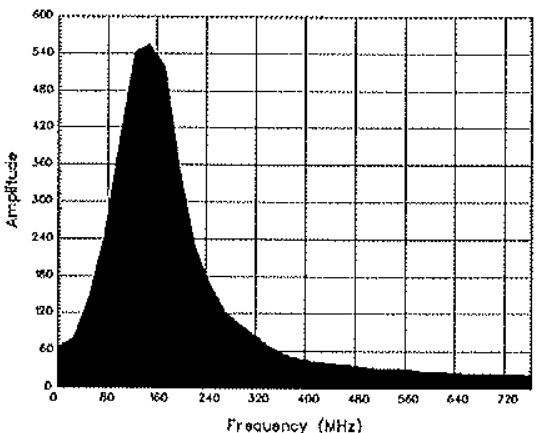

(b)

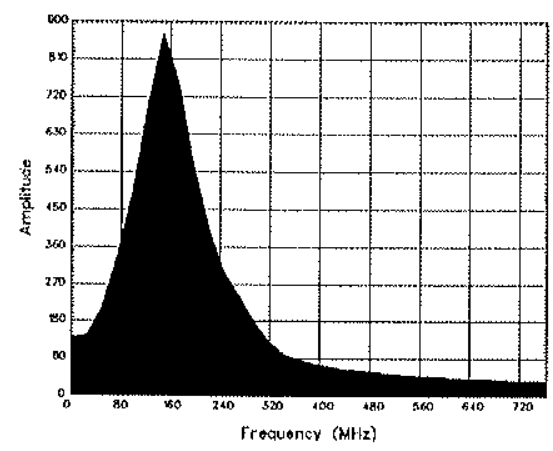

(e)

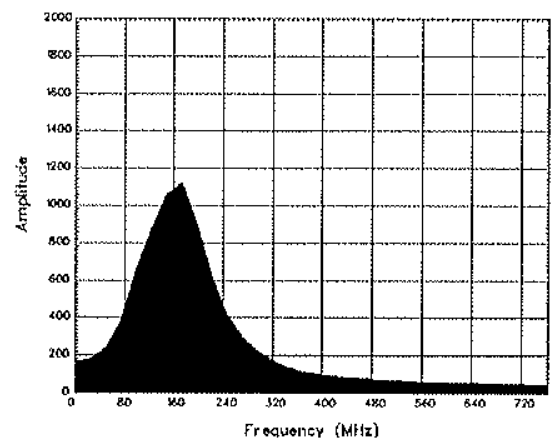

(c)

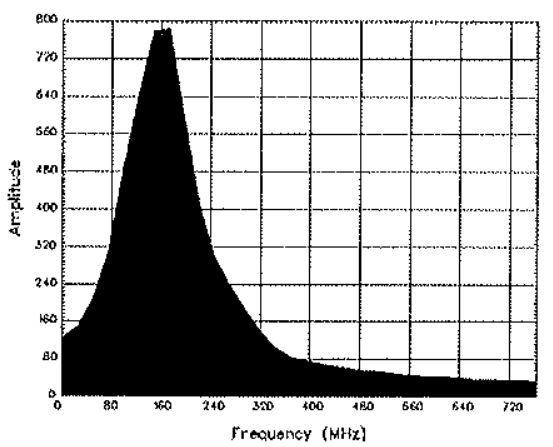

(f)

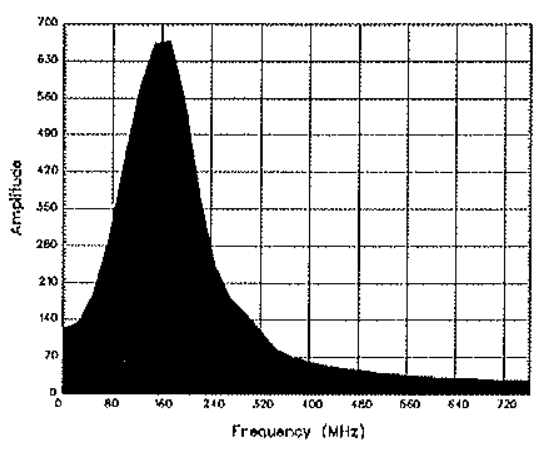

(d)

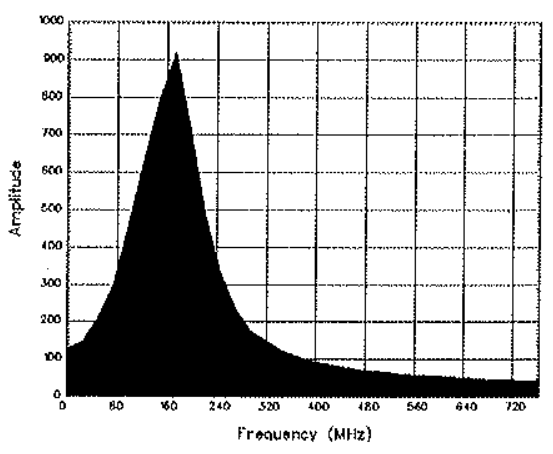

(g)

Figura A-X.9 - Gráficos resultantes da análise espectral executada sobre a seção processada do perfil P. 9 para: (a) seção total $\left(A_{s t}\right)$; e para o periodo 30 a $60 \mathrm{~ns}\left(A_{s p}\right)$ nos trechos de traços: (b)1-110; (c) 111-220; (d) 221-330; (e) 331-440; (f) 441-550 e (g) 551-665 


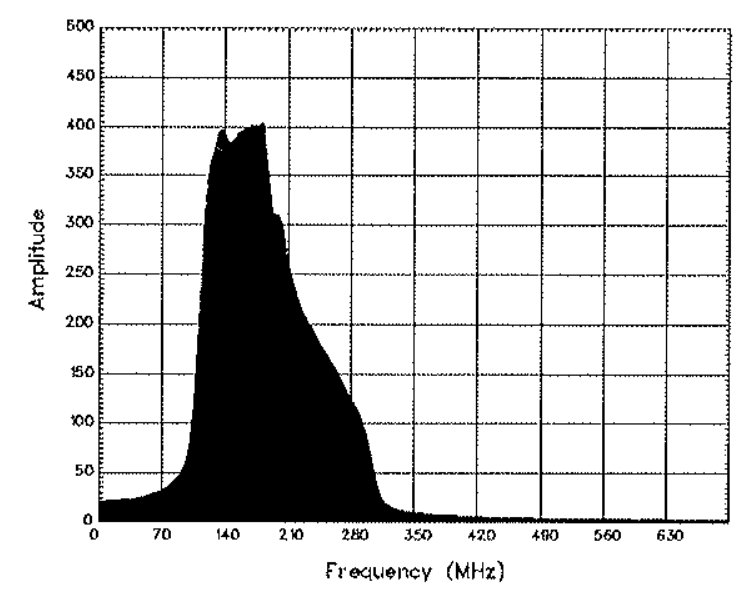

(a)

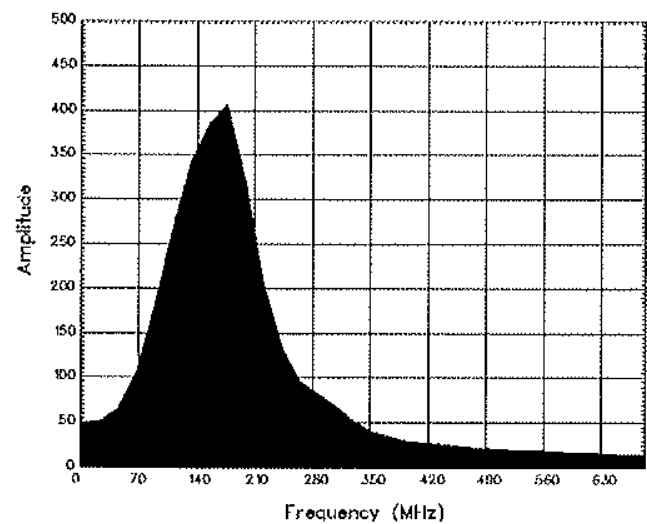

(b)

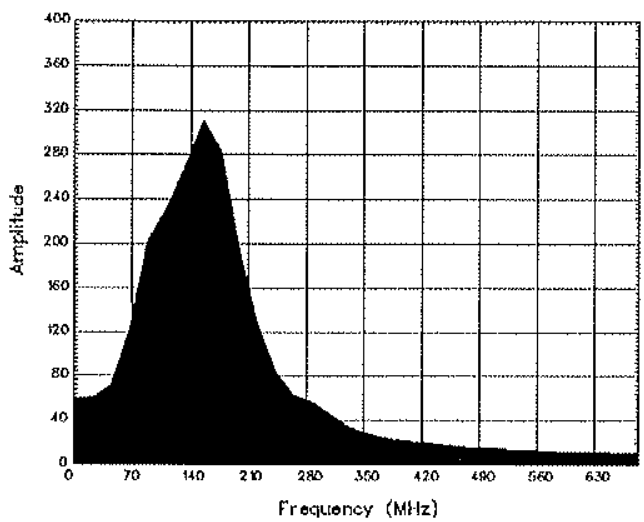

(d)

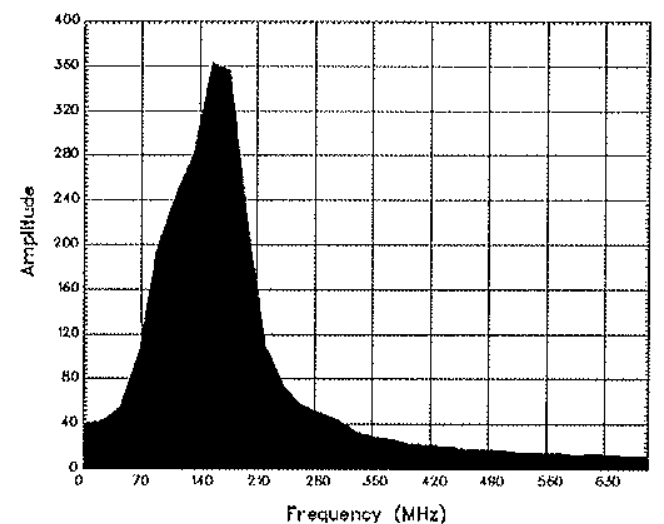

(c)

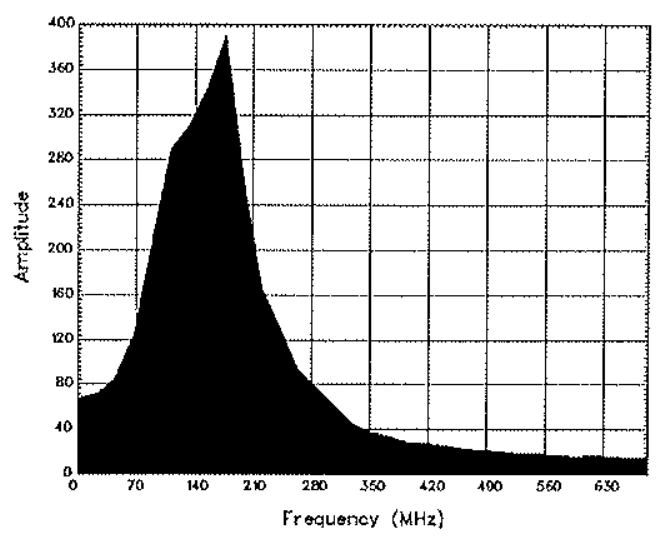

(e)

Figura A-X.10 - Gráficos resultantes da análise espectral executada sobre a seção processada do perfil P-10 para: (a) seção total $\left(A_{s t}\right)$; e para o período 30 a $60 \mathrm{~ns}\left(A_{s p}\right)$ nos trechos de traços: (b)1-200; (c) 221-400; (d) 401-600 e (e) 601-800 


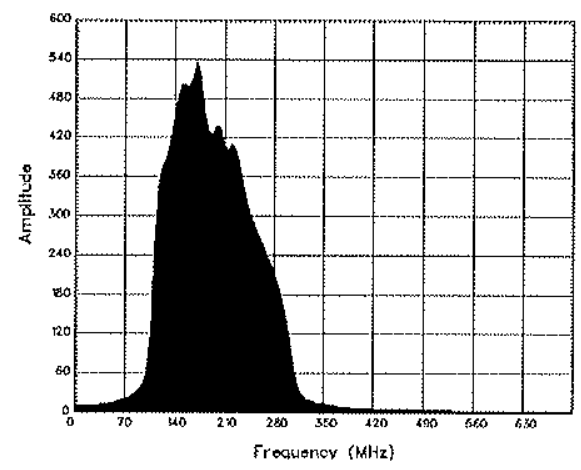

(a)

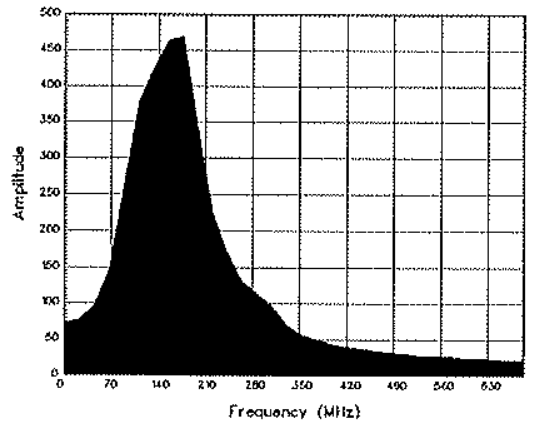

(b)

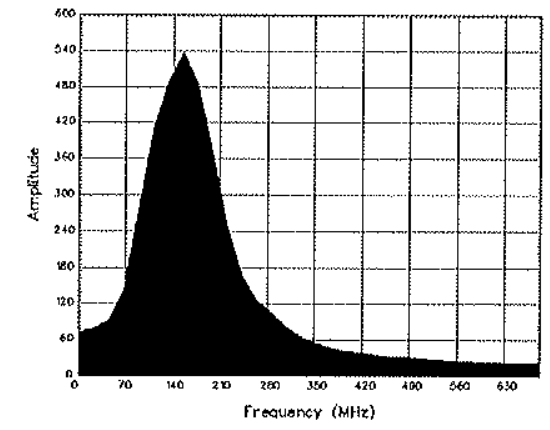

(c)

Figura A-X.11 - Gráficos resultantes da análise espectral executada sobre a seção processada do perfil P-11 para: (a) seção total $\left(A_{s t}\right)$; e para o período 30 a $60 \mathrm{~ns}\left(A_{s p}\right)$ nos trechos de traços: (b) 1 350 ; (c) $351-700$

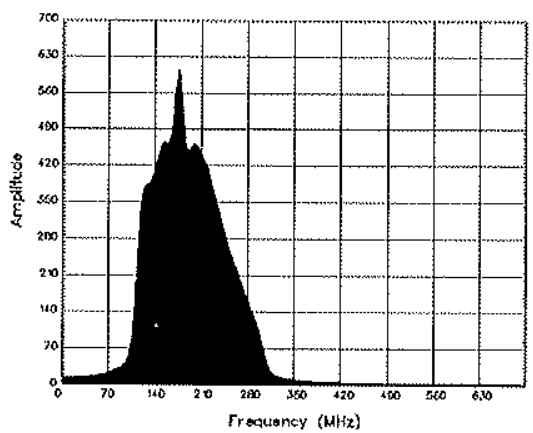

(a)

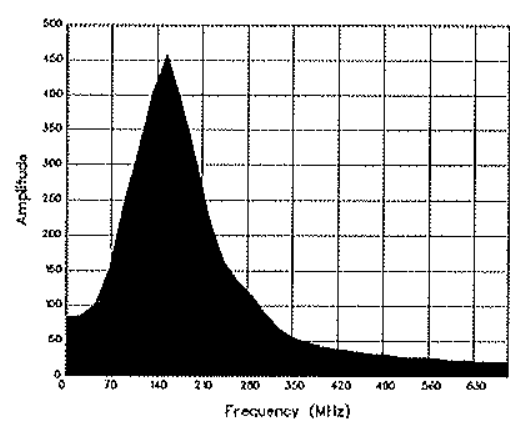

(b)

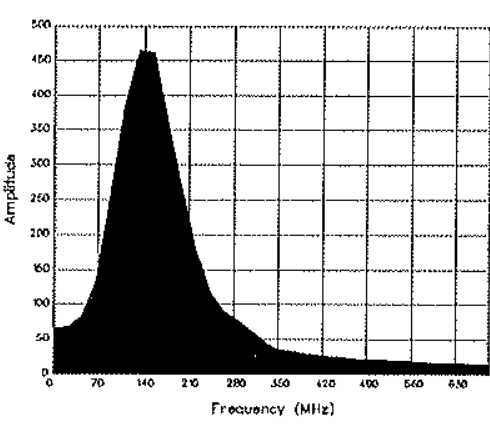

(c)

Figura A-X.12 - Gráficos resultantes da análise espectral executada sobre a seção processada do perfil P-12 para: (a) seção total $\left(A_{s t}\right)$; e para o período 30 a 60 ns $\left(A_{s p}\right)$ nos trechos de traços: (b)1200; (c) $201-400$ 


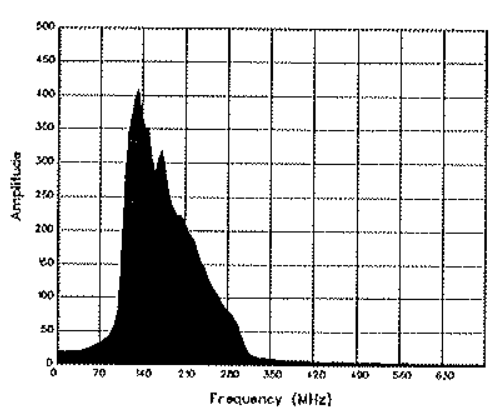

(a)

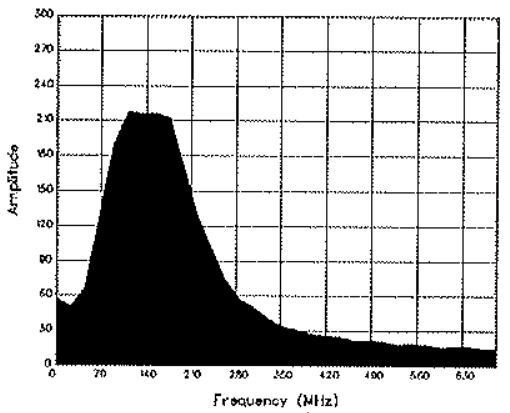

(b)

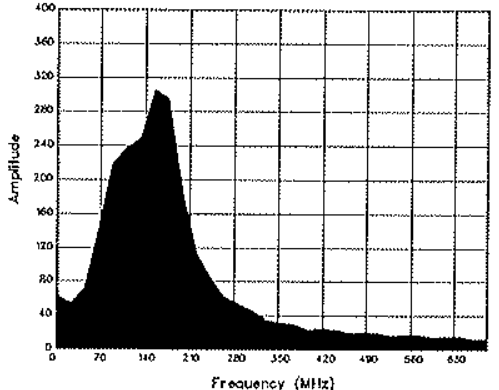

(c)

Figura A-X.13 - Gráficos resultantes da análise espectral executada sobre a seção processada do perfil P-13 para: (a) seção total $\left(A_{s t}\right)$; e para o período 30 a 60 ns $\left(A_{s p}\right)$ nos trechos de traços: (b) 1 115 ; (c) 116-238

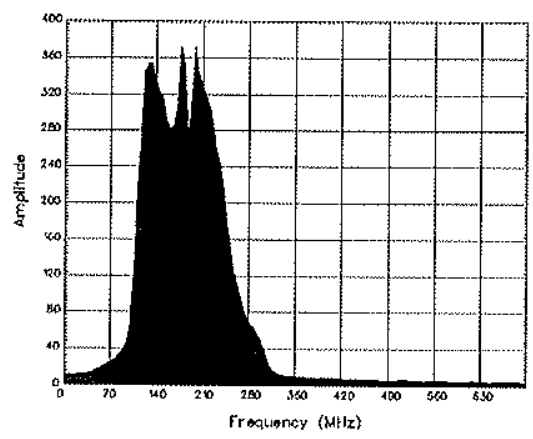

(a)

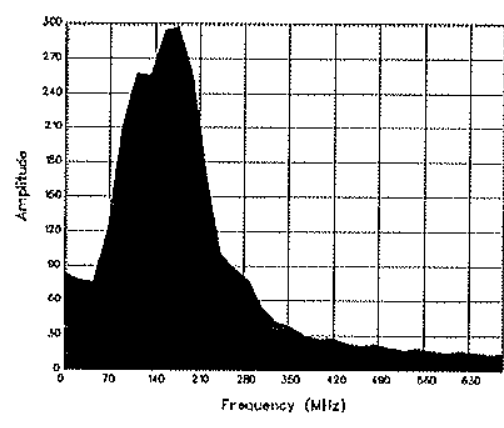

(b)

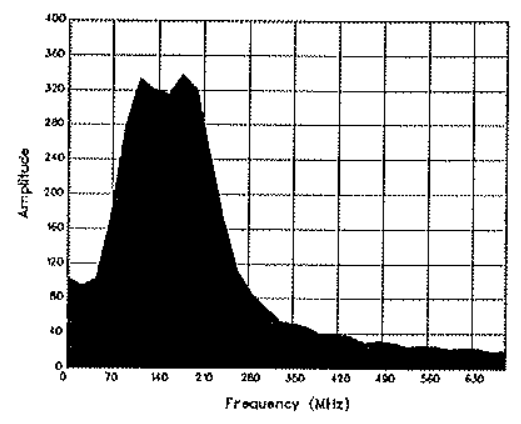

(c)

Figura A-X.14 - Gráficos resultantes da análise espectral executada sobre a seção processada do perfil P-14 para: (a) seção total $\left(A_{s t}\right)$; e para o periodo 30 a $60 \mathrm{~ns}\left(A_{s p}\right)$ nos trechos de traços: (b) 1 $100 ;$ (c) $101-197$ 
A N E X O XI 


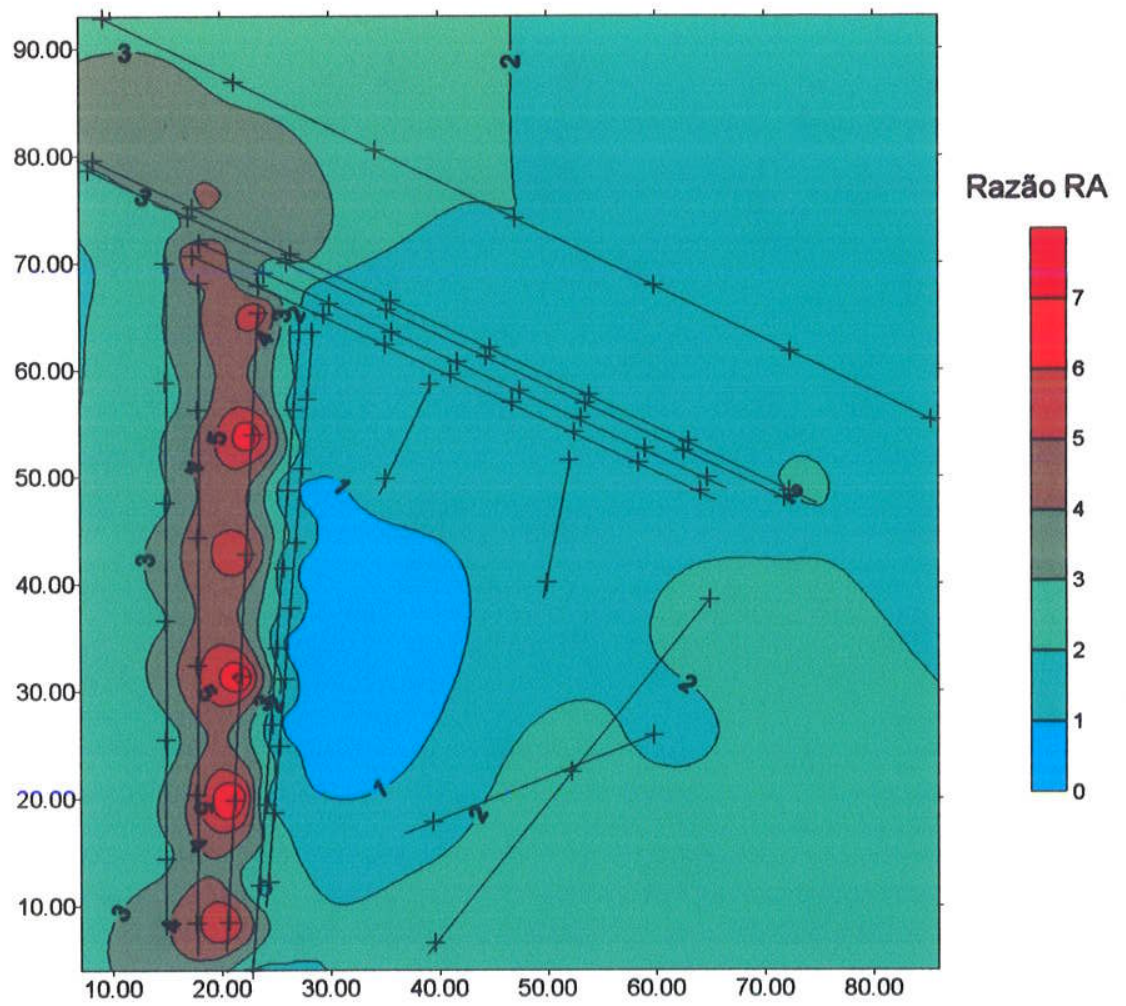

Figura A-XI.1. - Mapa de isolinhas para representar a distribuição dos valores de Asp antes da aplicação do processamento

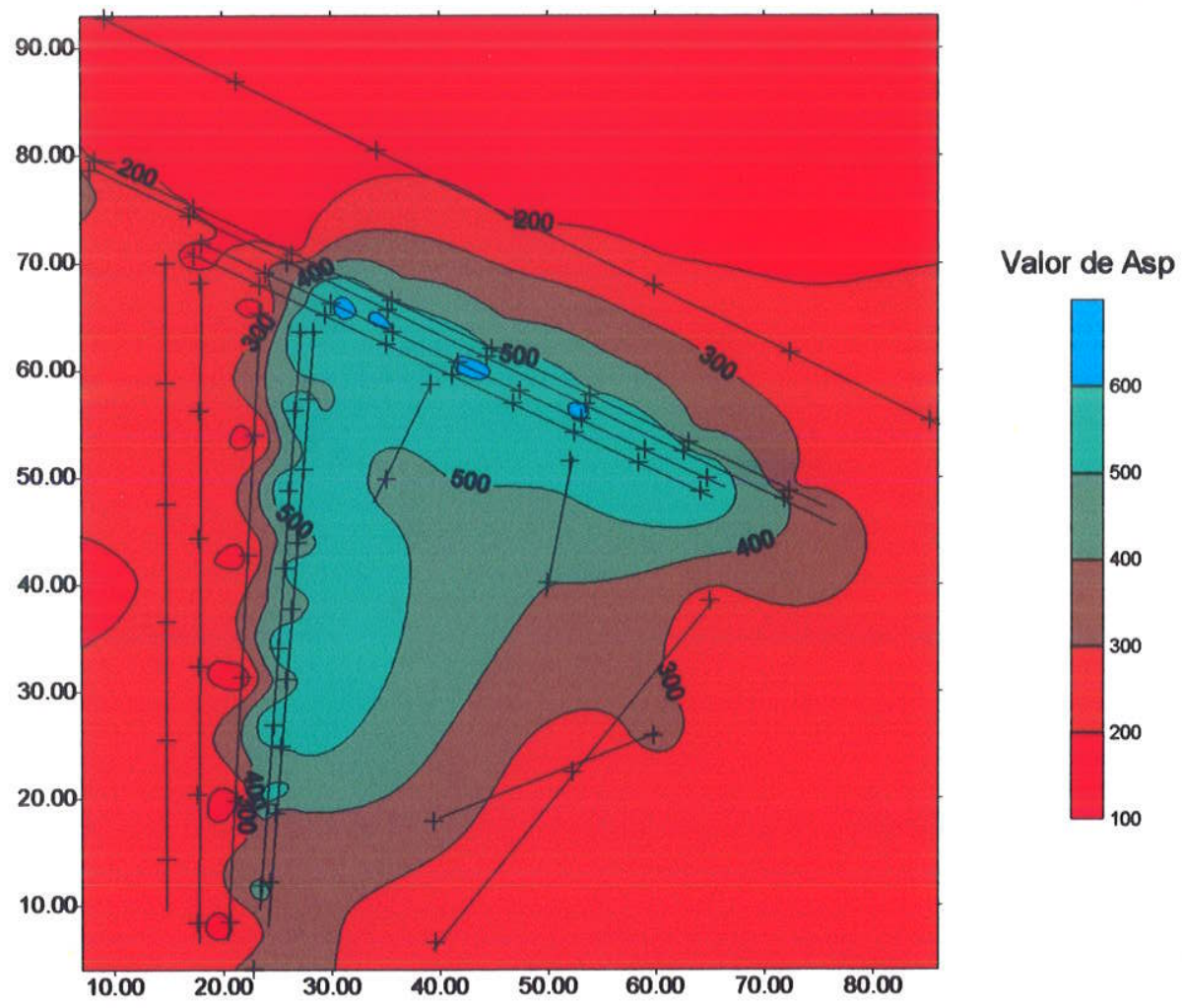

Figura A-XI.2 - Mapa de isolinhas para representar a distribuição dos valores de Asp antes da aplicação do processamento 